Slavistische Beiträge $\cdot$ Band 53

(eBook - Digi20-Retro)

\title{
Wolfgang Eschker
}

\section{Untersuchungen \\ zur Improvisation}

und Tradierung der Sevdalinka

an Hand der sprachliche Figuren

Verlag Otto Sagner München · Berlin · Washington D.C.

Digitalisiert im Rahmen der Kooperation mit dem DFG-Projekt „Digi20“

der Bayerischen Staatsbibliothek, München. OCR-Bearbeitung und Erstellung des eBooks durch den Verlag Otto Sagner:

http://verlag.kubon-sagner.de

( $)$ bei Verlag Otto Sagner. Eine Verwertung oder Weitergabe der Texte und Abbildungen, insbesondere durch Vervielfältigung, ist ohne vorherige schriftliche Genehmigung des Verlages unzulässig.

«Verlag Otto Sagner» ist ein Imprint der Kubon \& Sagner GmbH. 


\section{SLAVISTISCHE BEITRÄGE}

BEGRÜNDET VON ALOIS SCHMAUS

HERAUSGEGEBEN VON JOHANNES HOLTHUSEN

REDAKTION: PETER REHDER

Band 53 
WOLFGANG ESCHKER

\section{UNTERSUCHUNGEN ZUR IMPROVISATION UND TRADIERUNG DER SEVDALINKA AN HAND DER SPRACHLICHEN FIGUREN}

VERLAG OTTO SAGNER · MÜNCHEN 1971 


\section{VOR WOKT}

Die vorliegende Arbeit wurde 1969 von der Philosophischen Pakultät der Georg-August-Universität Göttingen als D1ssertation angenommen und am 5. Dezember 1970 mit einem preis der Süd os teuropa-Gesellschaft München ausgezeichnet.

An dieser Stelle möchte ich besonders meinen verehrten Lehrern, Herrn Professor Dr. Maximilian Braun und herrn Frofessor Dr. Karl-Heinz Pollok, die mich beim Zustandekommen dieser Arbeit mit wertvollen Anregungen und Ratschlägen unterstützt haben, aufrichtig danken.

Ebenso sage ich Herrn Professor Dr. Reinhard Lauer meinen Dank für seine freundlichen und sachkundigen Hinweise.

Hein Dank gilt weiterhin Herrn Dr. Muhamed Hadzijahic. Sarajevo, fur seine inregungen und Anteilnahme an meiner Arbeit.

Ein groBer Teil der Arbeit entstand während eines einjährigen Aufenthaltes in Sarajevo, der mir durch ein DAAD-Stipendium ermöglicht wurde. Auch diese Hilfe möchte ich hier dankend erwähnen.

$$
\text { W.E. }
$$


Elaleitung

Teil I

Vorbemerkungen

$\begin{array}{ll}\text { A. Figurae per adiectionem } & 18\end{array}$

I. Piguren der Wiederholung 18

1. Geminatio 18

a. Iteratio 18

b. Repetitio 27

2. Reduplicatio 33

3. Epiploke 38

4. Redditio 42

5. Anapher 44

a. Ganzversanapher 44

b. Halbversanapher 50

c. Verschräkung von Ganzvers-
anapher und Halbversanapher

6. Epipher 54

7. Complexio 57

8. Annominatio 58

a. Annominatio per adiectionem
vel detractionem

b. Annominatio per immutationem 62

9. Polyptoton 68

10. Pigura etymologica 74

11. Synonymie 80

a. Exkurs: Homonymie 85

II. Piguren der Häufung $\quad 87$

12. Koordinierende Häufung 87 
13. Polysyndeton und Asyndeton 94

a. Polysyndeton 94

b. Asyndeton 96

c. Verbindung von Polysyndeton
und Asyndet on

14. Epitheton 100

B. Figurae per ordinem 113

15. Isocolon 113

$\begin{array}{lll}\text { Te1l II } & 128\end{array}$

Vorbemerkungen 128

1. Ajde, draga, da asikujemo 130

2. Svi dilberi, samo moga newa 134

3. Ne rudim se mraku ni oblaku $\quad 138$

4. Sto se ono Tramik zamaglio 145

5. Djevojka vi ${ }^{2}$ s brda visoka 149

6. Poštala ljepotica Fata 154

7. U hostaru కecer mejtef kažu 159

8. Hostanice, vodo plementita 165

9. Dockan pō̄oh iz novoga hana 171

10. Sto Morava mutno teče 178

11. Telal viče od jutra do mraka 182

12. Djevojka je malo djevovala 1338

13. Semerkungen zu einigen der uhrigen unter-
suchten Lieder und itren Variarten

a. Karanfile, crijete moje 191

b. Od sevdaha goreg jada nema 193

c. Vjetar puङ̌, alkatmerom niše 194

d. Kakva ti je u Alage ljuba 194

e. Kujundžija, tako ti zanata 195

f. Dva su crjeta u bostanu rasla 195

8. Dva se draga na livadi l jube 196

14. Die Sevdalinka und das kunstlied 197

15. Schlub 208 
1. Hajde, dušo, da ą̆ikujemo 216

2. Albaberu, cr'jete moje 216

3. Svi dilberi, moga, majko, nejma 218

4. Jesam li ti govorila, dragi

5. Vjetar puse, alkatmeron niłe 220

6. Ne Cudim se mraku ni oblaku 221

7. Dr'je plantne vrh Tramika grada 222

8. Djevojka vile s visoka brda 223

9. Lepa ti je u Al-age ljuba 224

10. Pőetala Najla Džafer-bega 225

11. U Mostaru ఈeter mejtef kažu 226

12. Platno b'jele sarajke devojke 226

13. Mortanice, vodo plementia 227

14. Molila se Ana materina 228

15. Procrjetala ruža 1 sevlija 229

16. Zną 1i, dǔ̧, kad si moja bila 229

17. Sve ptičice pripjevaß̌, jedna ne pjeva 230

18. Kiła 1de, trava raste. 231

19. Bulovi se razdulali, ja 1 ' ne berem 233

20. Konj zelenko rosnu trava pase 233

21. Izvir voda izvirala 234

22. Raslo drvce bademovo 236

23. Sadim almu nasred Atmejdana 238

24. Zafali se Žuti limun na moru 239

25. Vijala se vinoloza vinova 240

26. Dva ou crjeta u bostanu rasla 242

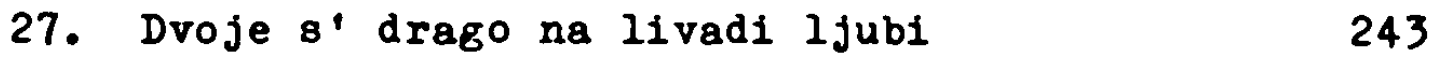

28. Snijeg pade drumi zapadołe 244

29. Nit ja sparam, nit ja drimam 245

30. Asan-aga na gradu sjedjałe 246

31. Alibeg se ljubom zavadio 247

32. Majka s Mehom večer večrałe 249 
33. Sinot podoh iz Niorita rana 250

34. Sto 8' Morava zamutila 251

35. Raela tunja na sred dŽehenema 252

36. Telal vile po Hercegovind 253

37. Bevojka je malo đevovala 255

Literaturverzeichnis 256

Abkürzungsverzelchnis der benutzten Texte 270 
Während die epischen Lieder bereits seit längerer Zeit Gegenstand intensiver wissenschaftlicher Forschung sind, fanden die lyrischen lieder erst in letzter Zeit in stärkerem MaBe Beachtung. Grundlegende Arbeiten wie die Polloks ${ }^{1}$ ) untersuchten jeweils die Foetik des gesamten Liebesliedmaterials des balkanslavischen Raumes, das auch die bosnisch-hercegovinische Volkslied-Liebeslyrik mit einschliebt.

Eine besondere Form. dieser letzteren Volkslied-Liebeslyrik stellt die Sevdalinka dar, deren Hauptmotive Liebessehnsucht, -trennung und -enttäuschung, seltener Liebeserfüllung sind. Der Terminus "sevdah" selbst ist aus dem Arabischen: "مودا" durch Vermittlung des Turkischen "sevda" in die serbokroatische Sprache: "sevdah" gelangt, wo er "Liebe, Liebessehnsucht" usw. bedeutet. 2) "Sevdalinka" ist die Bezeichnung für das stadtische Liebesvolkslied, das in seiner Entstehung und Anwendung ursprïnglich auf das Gebiet Bosniens und der Hercegovina beschränkt war. Die liehrzahl der Sevdalinke ist im jekavischen Dialekt wiedergegeven. Jedoch ist dieses lied auch in Gebieten, die sich des Ikavischen bedienen (etwa liostar, Travnik), anzutrefien.

lier das Wort "Sevdalinka" in vezug auf diesen iiedtypus zuerst verwanate, ist unbekarnt; man nimnt ar, daB es professionelle Sänger waren, die es einführten. 3 )

Neben musikalischen Teraini wie "ravna" oder "poravna

1) Pollok, K.-H., Studien zur Foetik und Kompositior des balkanslawischen lyrischen Volksliedes, Opera Slavica V, Göttingen 1964, im folgenden stets nur als $\mathrm{P}$ o $1 \mathrm{l}$ o k zitiert.

2) Skaljit, A., Turcizmi u srpskohrvatskom jeziku, Sarajevo 1965, S. 561 f.

3) Milołevit, V., Bosanske narodne pjesme, Knj. 1, Eanja Lika 1954, S. 8. Vgl. dazu auch. Muradbegovit, d., Sevdalinka, pesma feudalne gospode, Folitika, 5.12.134C, Br. 11677 , S. 14: "Ko je taj naziv (sevdalinka, ii.E.) dao ovoj vrsti nase rarodne pesme, o tore se ne bi dalo niłta stvarno reti, ali je vrlo vercuatno da je on potekao od Cigana." 
pjesma" trifft man auch häufig auf die Bezeichnung "varoska pjesma" (= Stadtlied), ein Ausdruck, der die Provenienz dieses Iiedes eben als Stadtlied betont, und dessen sich u.a. Kuhat und Kuba bedienten.

Man hat es hfer mit einem für die Volksdichtung ansonsten seltenen glücklichen Umstand zu tun: das lied läbt sich in seiner Entwicklung von den ersten Anfängen an verfolgen, ein Phänomen, dem man auf dem Gebiet der Volksdichtung ähnlich nur noch bei der russischen "Častuřka" begegnet.

Es ist festrustellen, daB dieses Ifed fähig ist, sich im Laufe der zeit zu verändern und viele Neuerungen in sich aufzunehmen. Es kann in seiner Entwicklung verschiedene Richtungen einschlagen und ist dann schlieBlich nicht mehr reines liebeslied wie in seinen Anfängen. So hat es z.B. manche Züge von Trinkliedern verarbeitet, die seinem innersten liesen völlig fremd sind ( $v g l$. dazu $I, 14$ ), es kann - in jüngerer zeit sogar zur "politischen Sevdalinka" werden (vgl. dazu besonders II, 13 a), und es ist mit anderen Volksliedern des balkanslavischen Raumes eine durchaus fruchtbare Symbiose eingegangen, wobei es manchmal schwer ist zu entscheiden, ob es sich noch um eine Sevdalinka handelt oder nicht. Die Begriffsbestimmung wurde im Laufe der Zeit immer schwieriger. Erschwerend kommt bei der Beantwortung dieser Prage noch hinzu, dab in den meisten Pällen die Melodien nicht mit verzeichnet worden sind, denn nicht zuletzt die Melodie ist in diesem Punkt von entscheidender Tichtigkeit.

Das alles ist aber letztlich eine Frage der Gattung und des Gattungsbewubtseins, eine Prage, die in der Volksdichtung ohnehin schwer $2 u$ beantworten ist, ganz abgesehen davon, ob es uberhaupt möglich ist, feste Grenzen in den einzelnen Volksliedgattungen zu umreiBen. Aus diesem Grunde wurden hier zunächst nur solche Sevdalinke herangezogen und behandelt, die man zum Kern, zum Grundstock dieser Gattung rechnen kann, bei denen es sich also um eigentliche Liebeslieder handelt. ${ }^{1)}$

1) Dabei wurden hauptsächlich die Kriterien von V. Milosevic fúr die Auswahl der Lieder zugrunde gelegt. Vgl. dazu ldilosevik, V., Sevdalinka, Banja Luka 1964, S. 4 ff. 
Dariber hinaus muß das städtische Liebesvolkslied grundsätzlich vom dörflichen unterschieden werden, da diese beiden Typen in Entstehung ${ }^{1)}$, Verbreitung und Tradierung merklich differieren. Stellt das dörfliche lied, das meist textlich einfacher, archaischer ist, mehr eine kollektive schöpfung dar ${ }^{2)}$, so hat man im Stadtied, das textlich und melodisch vielfach komplizierter gestaltet ist (häufige Taktwechsel, freie Melismen), eine individuelle lieddichtung vor sich. In vielen Fällen ist sogar der Autor bekannt. 3)

Hinzu kommt noch, daB das Stadtlied, rein soziologisch bedingt, stärker fremden Einflüssen ausgesetzt ist und sich diesen gegenüber auch aufnahmebereiter zeigt, wohingegen das Dorflied strenger der Tradition verhaftet bleibt. So wurde die Sevdalinka jahrhundertelang vorwiegend von türkischen, in jüngerer Zeit aber auch von österreichisch-ungarischen Einflüssen geprägt. ${ }^{4)}$

Der aus der türkischen Liebeslyrik hereinwirkende orientalische Geist manifestiert sich vor allem in der für die Sevdalinka charakteristischen kunstvollen Darstellung sinnlicher und sentimentaler Erlebnisse sowie in der unbefangenen Behandlung und Schilderung der Erotik.

An der sprachlichen Gestaltune der Sevdalinke sind Turzismen in hervorragendem Maße beteiligt. 5 )

Darüber hinaus bedient sich die Sevdalinka - wie die gesamte südslavische Volksdichtung - zur Erleichterung von Improvisation und Tradierung durchweg sprachlich-rhetorischer Figuren, wobei sich einige für diesen Liedtypus besonders charakteristische

1) Vgl. dazu besonders II, 1 und II,8.

2) Damit sei der Grundfeststellung, daR "jedes Lied ... auf einen schöpferischen Einfall einer künstlerisch mehr oder weniger begabten Persönlichkeit zurück (-geht, W.E.) n, nicht widersprochen. Vgl. dazu Braun, M., Das Volkslied als philologisches Problem, ïelt der Slaven, Jg. 3, Tiesbaden 1958, S. 4.

3) Vgl. dazu z.B. II,8.

4 ) Vgl. zum österreichisch-ungarischen EinfluB II, 14.

5) Darauf wird im folgenden jeweils besonders hingewiesen werden. 
und vorzüglich verwendete herauskristallisieren.

Es versteht sich, daB Arbeiten, die das Iiedmaterial eines gröBeren Raumes untersuchen, die Unterscheidung 2 wischen Stadtund Landlied nicht getroffen haben. Ho das Dorflied gesondert fur sich untersucht wurde, geschah dies oft in der Auffassung, daB dieser Typ als der archaischere wissenschaftlich interessanter sei. 1) Das mag mit dazu beigetragen haben, daß über die Sevdalinka als Stadtlied bisher noch keine gröBere Untersuchung vorliegt. Dabei könnte sich gerade eine solche Untersuchung im Rahmen einer bestinmten Gattung und innerhalb eines genau lokalisierbaren Territoriums halten. Das ist ein Umstand, der sich in diesem Maße auf balkanslavischem Raum nicht wiederholt, da die territorialen Ubergänge und - wie bereits erwähnt - auch die gattungsmäßigen fließend sind. Die kiusikwissenschaft hat sich diesen Umstand bel weitem mehr zunutze gemacht als die Philologie.2)

Von literaturwissenschaftiicher seite liegt bis heute noch keine grundlegende Untersuchung uber die Sevdalinka vor. Es existiert jedoch eine Vielzanl von Aufsätzen, Vorworten zu verschiedenen Sammlungen und Kommentaren, die sich teils wissenschaftlich, teils pseudowissenschaftlich - wenn man an die zahlreichen Zeitungs- und in neuerer Zeit auch Runkfunk- und Fernsehkommentare denkt - mit diesem liedtypus beschaftigen. Ihre rauptsächlichen Themen sind Frafen nach Motiven sowie nach Ursprung und Trägern des Liedes. Aussagen über die türkischen Elemente in der Sevdalinka vervollständigen den Bestand dieser Publikationen.

Die Sevdalinka, die

1. fremder, besonders nachhaltif aber türkischen Einflüssen gegenüber offen war

2. in stärkerem Maße als das Dorflied eine individuelle Schöpfung mit vielfach bekanntem Autor ist

1) Vgl. etwa Jensen, J., Untersuchungen zur Hetrik und Shythmik des serbokroatischen Volksliedes (Phil. Diss., Göttin̨en 1953, maschinenschriftiich), S. 6.

2) killosevic, V., Bosanske narodne pjesme, Knj. 1.2.3.4., Basja Luka 1954-1964. Nilołevic, V., Sevdalinka, Banja Luka 1964 u.a. 
3. auf ein bestimmtes Gebiet - Bosnien und Hercegovina beschränkt ist und

4. ein urbanes Lied ist,

hat melodisch wie textlich ihren eigenen Stil herausgearbeitet, der sie grundsätzlich von den dörflichen Hebesliedern Bosniens und der Hercegovina und von den Dorfliebesliedern allgemein unterscheidet.

Die vorliegende Arbeit befaßt sich mit den sprachlichen Figuren in der Sevdalinka. Das sind die Figuren, die in erster Iinie der Improvisation und Tradierung der Lieder dienen. Ihr Schmuckcharakter soll dabei auBer Betracht bleiben, wenngleich auch gelegentlich auf ihn zu verweisen sein wird.

Umfassendere Werke, die sich mit der Poetik, also mit Tropen und Piguren der Lieder befassen, liegen zwei vor:

1. Zima, Luka, "Pigure u nasem narodnom pjesnittva s njihovom teorijom"1). In dieser verhältnismäßig frühen Untersuchung beschränkt sich der Verfasser auf eine bloße Aufzählung der P1guren, belegt an einem ilaterial aus allen Gebieten der serbokroatischen Volksdichtung.

2. Pollok, Karl-Heinz, "Studien zur Yoetik und Komposition des balkanslawischen lyrischen Volksliedes" 2 ). In dieser Arbeit behandelt der Autor ebenfalls alle Figuren, aber in bezug auf ihre Crnatusfunktion, und untersuckt ferner die Komposition der Liebeslieder des gesamten balkanslavischen Raumes.

On eine möglichst breite Naterialgrundlage zu bekommen, habe ich für meine Arbeit alle erreichbaren Sevdalinke aus einem Zeitraum von drei Jahrhunderten herangezogen, ausgenend von den Sevdalinke der Erlanger Handschrift bis zu den jüngsten Aufzeicinungen.

lieben reinen Sevdalinkasammlungen (Dizdar u.a.) wurden auch in Anthologien (Vuk, Prodanovic u.a.) und Zeitschriften (Bosanska vila, Behar u.a.) enthaltene Lieder, die sich als Sev-

1) Zima, L., Pigure u nałem narodrom pjesnittva s njihovon
teorijom, Zagreb 1880 .

2) Follot, K. -H., a.a.0. 
dalinke erwiesen, berücksichtigt. Bei speziell bosnisch-hercegovinischen Liedersammlungen mußte eine Unterscheidung einerseits zwischen Stadt- und Dorflied (Simit, Rihtman, die überwiegend Dorflieder aufzeichneten, u.a.) und andererseits $z w i-$ sehen Sevdalinka, Ballade und Romanze (Davidovit, Kurt u.a.) getroffen werden.

Trotz der an und für sich richtigen Feststellung, daB "Hort una Feise eine unlösbare Einheit bilden" ${ }^{1)}$, soll in dieser Arbeit hauptsächlich die textliche Seite des bosnischen lyrischen Volksliedes untersucht werden, wenn auch gelegentliche Verweise und Berücksichtigungen der kielodie nicht zu vermeiden sind. Als Rechtfertigung für dieses Vorgehen seien nur zwei $2 i-$ tate angefuhrt: "Diese Formel ( $d a B$ Wort und Weise eine unlösbare Einheit bilden, T.E.) ist insofern unrichtig, als man allerorts dieselben lelodien zu verschiedenen Texten gesellt." ${ }^{2}$ ), was auch für die Sevdalinka in vieler. Fällen zutrifft. Und: "Weil gerade ein Lied nicht die Sume von Text und Melodie ist, sagt auch die Textbetrachtung auch schon etwas uber die musikalische Seite aus." 3 )

Eine Berijcksichtigung der Melodien wäre erforderlich bei einer Untersuchung von Metrik und Rhythmik der Lieder; diese sollen hier jedoch nicht behandelt werder.

1) Fischer, H., Volkslied, Schlager, Evergreen, in: Volksleben, 3d. 7, Tübingen 1965, S. 10.

2) Seemann, E. und "iora, W., Volkslied, in: Deutsche Fhilologie im AufriB, hg. v. Stammler, $7 .$, Sd. 2, 1954, S. 1-24, Spalte 25 .

3) Fiscier, ت̈., a.a.0., S. 10. 
TEIL I

\section{Vorbemerkungen}

Dieser Teil behandelt im AnschluB an Lausberg ${ }^{1)}$ die snrachlichen Piguren, die für die Improvisation und Tradierung und gegebenenfalls für die Komposition der Sevdalinke von Bedeutung sind. Einige fiir die Sevdalinka weniger wichtige sprachliche Figuren konnten dabei auBer Betracht bleiben. Es handelt sich hier im wesentlichen um Hyperbaton und Anastrophe, die wegen der verhältnismäßig freien Fortstellung des Serbokroatischen nicht eindeutig $z u$ bestimmen sind, des weiteren um die figurae per detractionem (Zeugma, Ellipse), die in der Sevdalinka relativ selten und dann mit geringerer Improvisationsfunktion aufreten. ${ }^{2)}$ Eine Ausnahme bildet hierbei das Asyndeton, das häufiger anzutreffen ist und das $i c h$, wegen seiner Verwandtschaft mit dem Polysyndeton, zusammen mit diesem behandelt habe.

Die Belege zu den untersuchten Piguren wurden, um einen I möglichst großen Uberblick zu bieten, den verschiedensten Sammlungen entnommen.

1) Lausberg, H., Handbuch der literarischen Rhetorik, Bd. 1.2., iiuinchen 1960, \$\$ 599-749, im folgenden stets nur als $L$ a $u$ s b e $r g$ zitiert.

.2) Diese Figuren sind nicht nur für die Sevdalinka, sondern für die lyrische Volksdichtung des gesamten balkanslavischen Raumes von geringerer Bedeutung. $\mathrm{Vgl}$. dazu Follok, s. 126 (figurae per detractionem), S. 127 (Ellipse), S. 130 (Zeugma), S. 133 (iyperbaton und Anastrophe). 
Bei einer Nichtberücksichtigung der figurae per detractionem ${ }^{1)}$ lassen sich die sprachlichen Figuren in zwei Hauptgruppen einteilen, In die figurae per adiectionem und die figurae per ordinem.

\section{A. Pigurae per adiectionem}

Hier lassen sich wiederum zwei Hauptgruppen unterscheiden: einmal die Wiederholung, zum anderen die Häufung jeweils von Worten, Wortgruppen, Satzteilen und Sätzen.

\section{Piguren der Niederholung}

\section{Geminatio}

"Die $g$ e m i n a $t$ i (...) besteht in der Wiederholung des gleichen Wortes oder der gleichen Wortgruppe an einer Stelle im Satz, meist am Satzanfang: ... Terminologisch wird die Wiederholung des Einzelwortes (... i $t$ e $r$ a $i o$ ) von der Wiederholung einer iortgruppe (... r e p e $i t i o)$ oft unterschieden. ${ }^{2}$ )

Die Fulle und Verschiedenheit des Liedmaterials legt auch hier eine Trennung zwischen iteratio und repetitio nahe.

\section{a. Iteratio}

Tird die iteratio verwendet - und sie ist eine in der Sevdalinka recht häufig anzutreffende Pigur - so ist sie oft am Liedanfang zu finden, und zwar in der Form des Appellativs, was mehrere Beweggründe hat: einmal kommt der appellativen Wiederholung gerade in einem Liebeslied eine affektive, emphatische Wirkung zu. Zum anderen hat diese Wiederholungsfigur besonders am Anfang dadurch eine gröBere Bedeutung, daB der Sänger ${ }^{3}$ ) durch die doppelte (oder ggf. mehrfache) Setzung eines

1) Zur Begründung eines solchen Vorgehens vgl. S. 17.

2) Lausberg $\$ 616$.

3) Ich behalte auch im folgenden den Terminus "Sänger" bei, obwohl wir es im lyrischen Lied in cer Mehrzah.l der Fälle mit einer "Sängerin" zu tun haben. Vgl. dazu auch den Terminus "Zenske pjesme", den etwa Vuk im Gegensatz zu den "junacise pjesme", die meist von liänern gesungen wercien, gebraucht. 
Wortes die Aufmerksamkeit für seine Aussage wecken kann. Dies ist zwar bei den lyrischen Liedern nicht in dem MaBe der Pall wie bei den epischen, wo der Sänger für eine Hörerschaft singt ${ }^{1)}$, sollte dennock aber nicht auBer acht gelassen werden: mag die oder der Angeredete in Wirklichkeit nicht anwesend sein, im BewuBtsein des Süngers ist sie (er) es dennoch, auch wenn die appellative iteratio zumeist einen Wonolog des Sängers einleitet, der nichtsdestoweniger im weiteren Verlauf des Liedes aufgegeben oder zu einem Dialog erweitert werden kann. So ist es nicht verwunderlich, daB die appellative iteratio am Liedanfang in der Sevdalinka fast einen formelhaften Charakter annimmt. Um aber gänzlich zur Formel zu werden, wird sie in diesen verfeinerten Liedern doch $z u$ sehr varifert.

Der Liedanfane und auch der versanfang, mit dem es sich ähnlich verhält, stellt für den Schöpfer improvisierter Dichtung stets eine größere Schwierigkeit dar als dessen Fortsetzung. So wird nicht zuletzt der improvisatorische Hert dieser Figur zu ihrer häufigen Verwendung besonders am Liedanfang in der Sevdalinka geführt haben:

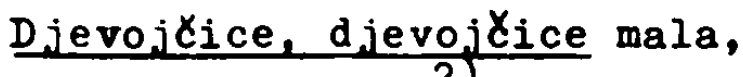
Ti si moje srdce ${ }^{2}$ otrovala! ...

$$
\text { Dizdar I, Nr. } 41
$$

oder, die für die Sevdalinka typische Setzung von türkisch "ala" statt serbokroatisch "bog" $(=\text { Gott })^{3)}$ :

1) Vgl. etwa Karadzit, V. St., Srpske narodne pjesme, Knj. 1-4, Beograd 1953-54, Knj. 1, Beograd 1933, S. XVI: "Zersske pjesme pjeva $i$ jedno ili dvoje samo radi svoga razgovora, a junałke se pjesme najviše pjevaju da drugi slusaju;...".

2) Die 2 itate werden originalgetreu wiedergegeben, auch wenn sich der Aufzeichner, wie z.B. H. Dizdar, der etymologischen Schreibweise (etwa: srdce u.ä.) bedient. Jedoch werden die Zeilenanfänge grundsätzlich mit großen Buchstaben viedergeceben.

3) Vgl. dazu Skaljit, A., a.a.0., S. 82: "... àla-åla! interj. (ar.) bože, boze! ...". 
"Ala, ala, ja velika straha, Strah je mene biti u Cardaku, ...

Bugarinovit, S. $62 \mathrm{f}$.

Ein Imperativ am Lied- oder Versanfang hat dieselbe Funktion und zieht dieselbe improvisatorische Erleichterung nach sich; er ist hier als variante zu der appellativen iteratio anzusehen:

Truni, truni, jaglute vezeni, Truni, truni, srce u menika, ...

Rubit XXIV, Nr. 23

Nicht selten ist der Fall der iteratio, bei dem ein wort oder oft nur eine semantisch weniger bedeutende Interjektion zwischen die wiederholten Glieder gesetzt wird. Diese Lockerung ${ }^{1}$ ) tut der iteratio keinerlei Abbruch; Funktion und "irkung bleiben àieselben:

"Dodji, dilber, dodji;

Do vecer, pod pendzer!" ...

Kuhat I, Rr. 354

oder:

"Ustaj Cevojko, ustaj lepoto,

Ustaj lepoto, saba zora je!" ...

$$
\text { Vasiljevit, Nr. } 133
$$

In der beiden letzten Beispielen wurde jeweils ein Vokativ eingescnoben, der die "'irkurif der iteratio nur noch intensiviert.

Charakteristisch fir die Sevdalinka urd nur hier anzutreffen ist die iterative Wiederholune der Interjektion "aman":

Aman, aman, kad ke petak doti, Kad ce dragi ispred dvora proci, ...2)

$$
\text { llilarovic I, lir. } 54
$$

1) Vël. dazu Lausberg $\$ 618$.

2) Auch der Freitag (petak) in der Fortsetzung dieses Verses verweist auf eine Sevdalinka, da dieser Tag der muslimische Feiertae ist. 
Als besonders typisch für die Sevdalinka muB auch folgende Form angesehen werden:

A na glavi fesak, fino-fesak,

A na fesu kita od nizama, ...

Ristic, Nr. 42

In diesem Beispiel handelt es sich nicht um einen Anruf oder Imperativ, vielmehr wird das Substantiv mit epithetisch erläuterndem bzw. vereindringlichendem Vorschlag wiederholt. Während ansonsten das Epitheton $z u$ "fes" oder "fesak" meist "crven" u.ä. ist, ist das Iterationsepitheton zu "fes, fesak" uberwiegend "fino".

Ebenso häufig findet sich in der Sevdalinka folgende iteratio:

Tut prolazi hodza Omer-hodza,

Govorio hodza Omer-hodza: ....

Bos. vila 1892 , S. 396

oder:

"Oj Boga mi beže Jovan-bež,

"Tebe dvorim tri godine dana, ...1)

Bos. vila 1905, S. 139

Hier wird zunächst der Titel allein genannt und dann noch einmal in Verbindung mit dem Namen seines Trägers wiederholt. In einem Liebeslied verwand, dürte die iterative setzung des Titels in der Absicht geschehen sein, das Ansehen des Burschen, der ja seinen Wert herausstreichen will, bei der angesprochenen Person zu vergrößern. Die Tatsache, daß die Titel eigens hervorgehoben werden, mag im vorliegenden Falle auf türkischen Einflus zurückzuführen sein, da die türkische Herrschaft auf

1) Die Verwendung des slavischen Eigennamens Jovo in diesem Lied ändert nichts daran, daB es sich um eine Sevdalinka handelt. Die Sevdalinka mag gewandert und zuruickgekommen sein und dabei den serbokroatischen Namen aufgenommen haben. Auch können falsche Aufzeichnungen ein Grund für diesen Viderspruch sein. (Vgl. dazu auch Dizdar, H., Sevdalinke, Sarajevo 1944,S.16 f.). Jeder Grundlage dagegen durfte der Angrift Kurts entbehren, der in der Einleitung zu seiner Iiedersammlung dem "großen Vuk" vorwarf, die muslimischen Namen vorsätzlich verändert $z u$ haben, um so die muslimischen Lieder zu verserbisieren (Vgl. dazu Kurt, M.-Dz., Hrvatske narodne Zenske pjesme (Huslimanske), Sv.1, Mostar 1902,S.6ff.: 
jugoslavischem Gebiet eine reine Beamtenherrschaft war, die dementsprechend Titel, Rang und Orden würdigte. Wenn diese iteratio wie die oben erwähnte appellative ebenfalls als emphatische gewertet werden muB, da mit Rang und Titel geprahlt werden soll, so darf jedoch ihr Improvisationswert keineswegs unterschätzt werden; auch diese "Titel- bzw. Rangiteratio" erreicht in der Sevdalinka fast den Charakter einer Formel:

Nennung des Ranges zieht in den meisten Fällen automatisch den Namen des Trägers und nochmalige Setzung des Ranges nach sich. Für den Formelcharakter dieser Figur spricht auch ihr zahlreiches Vorkommen in der Sevdalinka, womit sich dieses lied deutlich von den übrigen jugoslavischen Liebesliedern absetzt.

Die letzten drei Beispiele sind gleichzeitig ein Beleg dafür, daB die iteratio nicht ausschlieblich als Appellativ oder Imperativ am Lied-bzw. Versanfang gesetzt wird, sondern auch - wenngleich seltener - im Liedinnern auftritt.

Eine Variante zu dem zuletzt behandelten Typ bildet die Form der iteratio, bei der eine angefürte Tätigkeit, Gegenstand, Eigenschaft usw. zur Namensbildung führt, etwa in dem Beispiel:

Biser nize Biser-begovica, Pomaze joj Bulsa sirotica, ...

$$
\text { B08. vila 1894, S. } 267
$$

War es in dem letzten Beispiel ein Gegenstand, der zur Namensbildung fünte, so ist es im folgenden eine Tätigkeit:

Seter-Salko, ne ̧eteri mi se!

Jer ako se pocmeł setereriti, ...

$$
\text { HH VII, Nr. } 85^{1)}
$$

1) Auffallend ist, daB sich diese iterationes meist in der ersten Zeile eines Liedes finden. Vgl. etwa auch:

Zafali se Fala materina, Da je ljepse na svijetu nema: …153

hahnliche Beispiele ließsen sich anführen, in denen eine einmal genannte Eigenschaft zur Namensbildung führt. Vgl. hierzu auch I, 10, zur figura etymologica. 
Weniger haufig als die doppelte erscheint in den liedern (die dreifache Setzung des gleichen Wortes:

Neka ga, neka, nek' gazi

Samo nek' Ceste dolazi, ...

$$
\text { Dizdar I, Nr. } 246
$$

oder in reiner, d.h. nicht erweiterter Form:

Neka, neka, nek' se Zeni,

Sretno mu bilo! ...

MH VII, Nr. 126

Als Spezialfall der iteratio muB die mit "ah" oder "aj" einigeleitete gewertet werden. Ein Vergleich mit den Liebesvolks- liedern anderer Gegenden Jugoslaviens ergab, daB diese inter.jektiven Vorschläge dort zwar nicht fehlen, daB sie aber bedeutend seltener vorkommen als in der Sevalinka. Hier begegnet " vielfach sogar der Fall, daB jeder Vers in einem Iied mit "ah" coder "aj" bzw. dessen Variante "haj" eingeleitet wird:

Haj kolika je Jahorina planina, Haj siv je soko preletiti ne moze. Haj a kamo li dobar junak na konju. Haj djevojka je preletila bez konja! Haj svi Bosanci dobre konje sedlaju, Haj a Bosanke ruse kose Cełljaju. ${ }^{1)}$

$$
\text { Dizdar I, Nr. } 124
$$

Diese die Verse einleitenden Interjektionen haben 2 wei vers schiedene Vorteile und Wirkungen: einmal dienen sie in syllal bischer Dichtung - und mit einer solchen haben wir es in dies sen Iiedern zu tun - dazu, den Anfang des neuen (und somit rnachtraglich das Ende des vorhergehenaen) Verses zu markieren, l und zum zweiten erleichtern sie am Liedanfang die Einstimmung ifür Sänger und Hörer, die in den Heldenliedern etwa mit dem

11) Dieses Beiepiel führt auch Skaljit an (Vgl. dazu

Skaljit, A., a.a.0., S. 76). Sin weiteres Lied dieser Gruppe, vgl. Dizdar I, Nr. 259. 
Guslevorspiel erreicht wird.

" $A j "$, ein Ausruf melancholischer verzückung, kommt aus dem Türkischen "ây", wo er ein Ausruf der Vermunderung, Uberraschung, des Schmerzes und der Trauer ist." 1 )

2u "ah" sagt Skaljit: "Das ist eine Interjektion vieler Sprachen. Im Türkischen, Persischen und Arabischen ist " $\bar{a}$ " ein Ausruf des Schmerzes, der Hoffnung, des Bereuens, der Verzückung. Im Türkischen kommt er auch als Substantiv vor, und wahrscheinlich kam er auch zu uns (d.h. in die serbokroatische Sprache, W.E.) als Substantiv aus dem Türkischen." ${ }^{2)}$

Auch heute noch wird "ah" als Substantiv gebraucht und bedeutet "Wunsch", "Sehnsucht", "Seufzen", etwa: "puno aha $i$ sevdahan. 3)

Nachdem somit Herkunft und Bedeutung dieser Interjektionen dargelegt worden sind, erscheint es nicht mehr verwunderlich, da $B$ beide in der Sevdalinka so zahlreich verwendet werden, auch wenn diese Interjektionen ihre ursprüngliche intensive Bedeutung verloren haben dürften:

Ah moj doro, dobri doro,

Sta je tebi dodijalo, ...

und etwas weiter in demselben lied:

Ah moj beže, dobri beze,

Nije meni dodijalo...

$$
\text { Dizdar I, Nr. } 4
$$

oder

Ai nevene, moj nevene,

Blago onom, ko te bere....4)

Blagajit, Nr. 14

1) Skaljit, A., a.a.0., s. 76.

2) Skaljit, A., a.a.0., S. 74 .

3) Skaljit, A., a.a.0., S. 74.

4) Das "nevene" (Ringelblume oder nach Vuk (Vgl. dazu

Karadzit, V. St., Srpski rjecnik, 4 izd., Beograd 1935,

S. 427): Totenblume) ist ebenfalis Appeliativ. In der häufigen Gleichsetzung von Blume (Pflanze, Tier usw.)

und geliebter Person in Form der Metapher macht die Sevdalinka keine Ausnahme (Vgl. zu den Metaphern Pollok,S.22 ff.). 
Beide Beispiele zeigen übrigens die iteratio in erweiterter Form.

Die mit "aj" ("haj") oder "ah" eingeleiteten iterationes (und dasselbe gilt für die repetitio ${ }^{1)}$ ) unterstreichen noch die emphatische Wirkung dieser Pigur. Im orientalisch beeinfluBten städischen Liebeslied sind derartige Wiederholungen im Gegensatz zu den anderen Wortwiederholungsfiguren wie etwa dem Polyptoton oder der annominatio häufiger als in den einfacheren Dorfliedern orthodoxer Gebiete, nicht zuletzt deswegen, weil sie dem Wunsch nach Ausdruck der Sehnsucht in stärkerem Maße Rechnung tragen. 2)

1) Vgl. dazu I, $1 \mathrm{~b}$.

2) Den orthodoxen Nädchen war es möglich, bereits vor ihrer Heirat bel verschiedensten Anlässen mit Burschen zusammenzukommen. Die muslimischen Mädchen dagegen mußten bis zu ihrer Verheiratung ihr Leben abgeschlossen von der Umwelt in der Frauenabteilung der muslimischen Häuser (Harem) verbringen. Vgl. dazu auch Hangi, A., Die Hoslims in BosnienHercegovina, Sarajevo 1907, S. 169: "Hat ein Mädchen das vierzehnte oder füfzehnte Jahr erreicht, gilt es für erwachsen, darf das Haus nicht mehr ohne Begleitung verlassen und muß auf der Straße gleich einer verheirateten Frau den verhuillenden Schleier (Peredza) tragen."

Diese andere Art des "Abgeschlossen-Seins" findet auch in der Sevdalinka selbst des öfteren ihren Ausdruck, wenn der Bursche z.B. verlangt, das Madchen solle seinen das Gesicht verhüllenden Schleier abnehmen:

\section{"Skini duvak, da ti vidim lice!"}

$$
\text { Milanovic III, S. } 54 \text { ff. }
$$

Hangi sagt auf S. 170 f. weiter: "Die erwachsenen liadchen bei den Moslims führen ein recht einsames Leben. bit unerwachsenen Iädchen $z u$ verkehren verbietet das SelbstbewuBtsein. Wit verheirateten Prauen ist der intime Verkenr schon wegen der durch die Verheiratung verschieden gewordenen Fflichtensphären sehr erschwert... Deshalb schließen sich gleichalterige Hidchen bei den Moslims besonders enge aneinander, klagen sich gegenseitig ihr Leid, tauschen ihre ilünsche, Hoffnungen und Gefühle aus, .... Deshalb kommen die Madchen häufig zusammen, ... tanzen und singen und vergnügen sich in xindlich unschuldiger iieise."

Diese Iieder, in aenen die muslimischen Maidchen ihrer Sehnsucht Ausdruck geben, sind die Sevdalinke. Die in ihnen so zahlreich erscheirenaen emphatischen viederholungen lassen sich nach oben Gesabtem schon rein psychisch erkiären. 
Hatten alle bisher untersuchten Pälle der iteratio schon einen nicht zu unterschätzenden improvisatorischen Wert im Rahmen e $1 \mathrm{n}$ e $r$ Verszeile, so kommt der iteratio, die eine zweite nach sich zieht, eine in aieser Beziehung noch gröBere Bedeutung zu:

Duni mi, duni hladane, Dodi mi, dodi, dragane....

Dizdar I, Nr. 61

Hier werden zwei iterationes, parallel verstärkt durch die Pigur des Isocolons, steigernd nacheinander gebraucht.

Dieses Beispiel leitet über zu dem folgenden, wo die iteratio kompositorische Funktion erhält, indem sie das Lied gliedert. Diese Pälle sind jedoch auBerst selten:

Of javore, javore! Ti si drvo najbolje!

Pod tobom sam kose plela, svog dragana klela.

Of javore, javore, ti si drvo najbolje!

Pod tobom je zimi zima, ljeti hladovina!

Ja sam cura, pa cura, pa sam nesto nacula:

Koji momak sokak m'jenja, taj djevojke nema!

of javore, javore, ti si drvo najbolje!

Pod tobom sam vino pio, djevojke ljubio.

$$
\text { Dizdar I, Nr. IyI }
$$

Jeder ungerade Vers (auBer dem funften) beginnt mit der Appellativ-Iteratio "oj javore, javore" und deutet damit Strophenbildung an. Dies mag den Aufzeichner (Hamid Dizdar) veranlaBt haben, das Iied tatsächlich strophenartig abzudrukken (Es dürfte kein Zufall sein, daB er bei dem fünften Vers, der keine iteratio aufweist, auf eine Strophenmarkierung verzichtete.). Der Aufzeichner nutzte also, indem er den Text dieser Sevalinka in Strophen anordnete, die sprachliche Porm zu ästhetischen Zwecken aus. ${ }^{1)}$

1) Dizdar, H., Sevdalinke, Sarajevo 1944, S. 6: "Ja sam takoder nekim pjesmama dao tehnicki izgled, formu, razstavivi im tekst na kitice.... Tako, po mome misijenju, ljepre izgledaju 1 lakse in je Citati." 


\section{b. Repetitio}

Bei der repetitio handelt es sich um die Wiederholung von mehreren Worten bzw. einer Wortgruppe. 1)

In noch starkerem Haße als die iteratio, bei der nur ein Wort wiederholt wird, erleichtert die repetitio durch die mehrmalige Setzung derselben Wortgruppe die Improvisation des Iiedes. Die mehrfache Wiederaufnabme gleicher Worte kann fü den Sänger dadurch produktiv werden, daB er sich indessen den weiteren Verlauf des Liedtextes vordenken und konstruieren kann. Jede einzelne Wiederholungsfigur wird diesbezüglich einen verschiedenen Wert haben.

Wegen der engen Verwandtschaft von repetitio und iteratio lassen sich beide Figuren nach annäherna denselben Gesichtspunkten unterteilen. Auffallend ist jedoch, daß die repetitio im Gegensatz zur iteratio äuBerst selten in der Form des (hier erweiterten) Appellativs anzutreffen ist; bei einem Anruf zieht die Sevdalinka die kuirzere iteratio vor: Ein erweiterter Appellativ würde seine vereindringlichende Wirkung selbst schwächen. Der improvisatorische Wert jedoch erhöht sich beträchtlich, da ein erweiterter Appellativ in der Form der repetitio meist den Umfang einer ganzen Verszeile einnimmt:

Nila moja, mila moja,

Đe si sinot bila? ...

$$
\text { Dizdar I, Nr. } 155
$$

oder:

Mila mati, mila mati,

Nuto mene jada....

Kuba 1907, S. 109, Nr. 154

Weitaus häufiger stöbt man dagegen auf die reine repetitio, die nicht als Appellativ gedacht ist:

Vet od suze, vet od suze,

Zvornickijeh cura...

Dizdar I, Nr. 56

1) Vgl. dazu Lausberg $\$ 616$. 
Was Funktion und Wirkung aieser drei Beispiele betrifft, so gilt hier das für die Parallelfälle der iteratio Konstatierte. ${ }^{1)}$

Als Sonderform der reinen repetitio ist nier noch der Fall anzufuhren, bei dem ein ganzer Vers wiederholt wird. Diese Ganzverswiederholung findet man in der Sevdalinka nicht selten; der Improvisationswert erhöht sich aurch den gröBeren Umfang der doppelt gesetzten Glieder. $D a$ es sich um aie viederholung eines ganzen Verses handelt, der eine semantische Einheit bildet, wird die Aussage gleichzeitig beträchtlich vereindringlicht :

Kad moj dragi legne spati,

Karamfil te mirisati;

Karamfil te mirisati

a moj dragi uzdisati.

Anarit II, Nir. 3

Ein weiteres Beispiel für die Ganzversrepetitio in der Sevalinka ist folgendes:
An moj Aljo, crne oci,
Ti ne hodaj sam po noti.
Ti ne hodaf sam po noti,
Ja tu tebi sama doti.

$$
\text { Dizdar I, Nr. } 2
$$

Die repetitio in gelockerter Form, bei der sich zwischen die wiederholten Glieder ein anderes Wort einschiebt, kommt - wie das Pendant in der iteratio - ziemlich häufig vor. Es können wiederum entweder bedeutungstragende Worte sein - meist Eigennamen, gebraucht in der Form des Appellativs - oder auch nur Interjektionen, die dann überwiegend nur Pullfunktion haben. Die Beispiele zeigen, daB diese Lockerung aie Wirkung der repetitio keinesfalls beeinträchtigt, sondern sie im Gegenteil rur noch unterstreicht:

1) VGl. dazu S. 18 ff. 
"Ne plac", haro, ne plac", zlato,

Ko ljubio, taj kazati.

Rubit XXV, N.r. 4

oder:

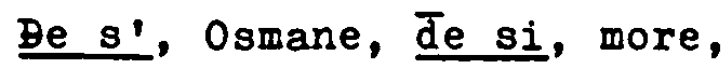

Za tobom me flava bole?

Vasiljevit, Nr. 285

So wie die iteratio zumeist a:n Iied-bzw. Versanfang anzutreffen ist, findet sich auch die repetitio in der uberwiegenden Zahl der Fälle an dieser exponierten Stelle. Nur ist es hier weniger die Forn des zwei- oder mehrmals gesetzten Appellativs, die bei der iteratio am Anfang bevorzugt wird, als die auch dort häufige Variante dazu: die imperative Wiederholung. Eine solche zeigt das erste der beiden letztgenannten Beispiele. Im zweiten Beispiel erscheint die emphatische Wiederholung einer Frage, die die schmerzliche Sehnsucht verdeutlichen soll. Im Liedinnern tritt die repetitio seltener auf; in solchen Fällen handelt es sich überwiegend um die Viederholung eines ganzen verses.

Hurde in den beiden zuletzt zitierten Beispielen jeweils ein Elgenname im Vokativ zwischen die Glieder der repetitio gestellt, so schiebt sich im folgenden Beispiel eine füllesde Interjektion zwischen sie:

San zaspala, aj san zaspala,

Dilber Ajła u bał̌i....

Dizdar I, Nr. 234

Dieses Ґeispiel leitet zu der nächsten Gruppe über, nämlich der mit "aj" oder "ah" eingeleiteten repetitio, welche Einleiturg sich schon bei der iteratio als typisch für die sevdalinka erwiesen hatte:

Ajnit' od kiß̌e, nit od ki ̌e, lit' od b'jela sn'jeca...

Dizdar I, Nr. 56 
Diesen interjektiven Vorschlag findet man ebenfalls in repetitiones, die einen ganzen Vers wieaerholen:

Ej, ja zagrizoh Sareniku jabuiku,

Aj, i poljubih Bsmer duzel djevojku,

Al, 1 poljubih Esmer đuzel djevojku...

Vasiljevit, Nr. 280

Das lied Dizdar I, Nr. 56, aus dem bereits das vorletzte Beispiel zitiert murde, ist auch ein Beleg dafür, daB die repetitio kompositorische Punktion annehmen karn: diese Pigur markiert hier Gliederungsabschnitte, die klare Tendenz zur Strophenbildung zeigen. Aus diesem Grunde hat wohl auch der Herausgeber das Lied in Strophenfcrm aufgezeichnet. ") Zur Illustration mögen hier nur die ersten beiden der füf gleichgebauten Strophen des Liedes dienen:

Dosla Drina, aj dosla Drina

od br'jega do br'jega.

oj, diko moja,

Od br'jega do br'jega!

Ajnit' od kige, nit' od kise, Nit' od b'jela sn'jega.

dj, ciko meja,

Nit' od b'jela sn'jega!

$$
\text { Dizdar I, Nr. } 56
$$

Nichtstrophenbildende, aber ebenfalls kompositorische Bedeutung komrt den repetitiones in Liedern wie Dizdar I, Mr. 238 oder Kurt, Nr. 40 zu:

1) Vyl. dazu S. 26, Anm. 1 . 
Sarajka djevojka majci plakala:

"Ne daj me, ne daj me, majko daleko!

Osta mi, osta mi, cv'jece nejako!

Ko te ga, ko te ga, majko, zaljevat:

Izjutra, izjutra hladnom vodicom,

U vecer, u vecer rosnim suzama!"

Dizdar I, Nr. 238

oder:

Dva cvijeta, dva cvijeta

U bostanu rasla:

Mavi sumbul, mavi sumbul

I Zuta zerina.

Ode sumbul, ode sumbul

Dolje niz Doljane,

Osta sama, osta sama

O bostanu Fata....

$$
\text { Kurt, Nr. } 40^{1)}
$$

Hier gewinnt die repetitio liedgestaltende Funktion durch ihre konsequente Durchfürung von Liedanfang bis Iiedende. Dizdar I, Nr. 238 gebraucht lediglich einen auslösenden Einleitungsvers ohne repetitio, dem sich dann der Monolog ${ }^{2)}$ des Mädchens durchgehend in Form der repetitio anschlieBt. Es ist nicht zuletzt diese Wiederholungsfigur, die, in den letzten beiden Versen antithetisch verwand und durch ein Isocolon verstärkt, die Schönheit dieses Iiedes ausmacht.

Der Vollständigkeit halber sei noch bemerkt, daB sich im Gegensatz zu der iteratio die dreimalige setzung der repetitio in reinen Textsammlungen äuBerst selten findet. Zieht man jedoch das Notenbild zum Vergleich heran, so ist festzustellen,

1) Während das Iied aus Dizdar vollstänäig zitiert murde, sind aus dem zweiten nur die ersten acht zeilen angefibrt, denen im Originaltext noch 20 gleichgebaute verse folgen.

2) Vgl. zu dem monologischen Aufbau von Iiedern Pollok, besonders $S .161$ ff. 
daB die Melodie häufig elne dreifache repetitio verlangt. Man muB daher - da die lieder ja gesungen und nicht rezitiert werden - mit drei - und mehrfachen repetitiones in weit gröBerem Umfang rechnen, als aus reinen Textsammlungen hervorgeht. Fillworte wie "aman", "džanum" oder die zuvor behandelten Interjektionen "aj" und "ah", aber auch selbständige, bedeutungstragende Worte wie etwa "djevojka" werden manchmal so oft wiederholt, daB sich Refrains herausbilden. Oft verlangt die Melodie auch die Wiederaufnahme halber oder ganzer Verse. All diese Wiederholungen treten in reinen Textsanmlungen meist nicht in Erscheinung. Folgende Gegenüberstellung von Text- und Notenbeispiel mag das veranschaulichen:

Text: Dizdar I, Nr. 46:

Djevojka je pošla za goru na vodu, Vodu da zafati, kuci da se vrati.

Melodie: Miloševit IV, S. 90:

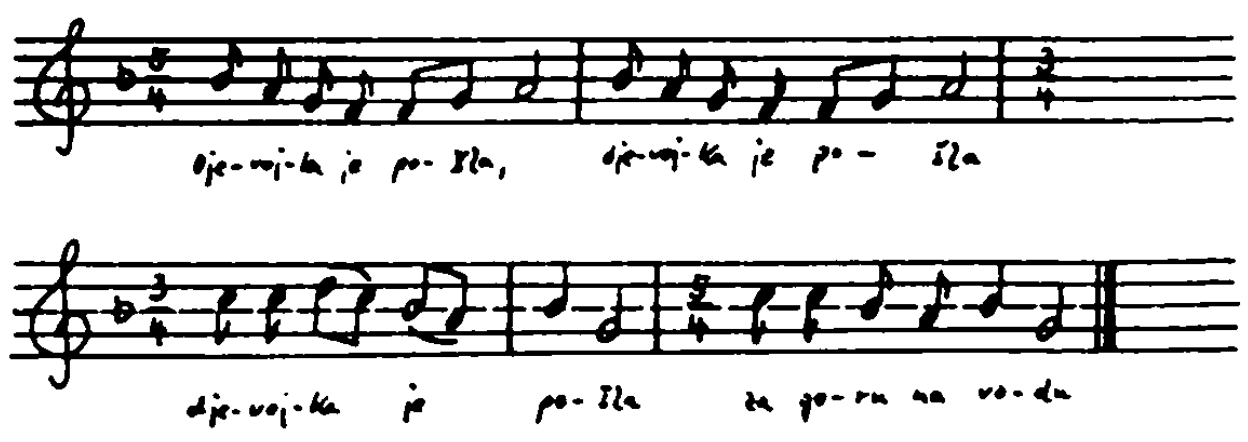

Hier erfordert also die Melodie die dreimalige Wiederholung des Halbverses "djevojka je pošla", was aus der - in diesem Sinne unvollständigen - Textaufzeichnung nicht ersichtlich wird. 


\section{Reduplicatio}

"Eine besondere Art der $g$ e $m i n$ a $i \circ$ ist die >Anadiplose $=r$ e $d$ p $l i c$ a $t i o:$ sie besteht in der Wiederholung des letzten Gliedes einer syntaktischen oder verstechnischen Gruppe $z$ u Beginn der nachstfolgenden symtaktischen oder verstechnischen Gruppe...."1).

Bei der Untersuchung der Sevdalinka kommt vor allem die reduplicatio an der Versgrenze in Betracht.

Der Grund für die häufige Verwendung dieser Figur ist darin zu suchen, das der Versanfang - wie überhaupt jeder Einsatz dem Sänger gewöhnlich mehr Schwierigkeiten bereitet als dessen Fortsetzung. 2) Insofern bei der reduplicatio Versende und Versanfang identisch sind, erleichtert sie dem improvisierenden Sänger den ubergang zum folgenden Vers. Nebenbei bemerkt kann gerade die reduplicatio noch andere Piguren (Chiasmus, Antithese, pseudoetymologisches Wortspiel) auf sich ziehen. 3 )

Rein sprachlich können bei der Realisierung dieser Figur folgende verschiedene Möglichkeiten unterschieden werden:

Die wiederholte Aussage in Form der reduplicatio kann sprachlich wie inhaltlich ohne stärkere Klimax ${ }^{4}$ weitergefürt, sozusagen schwach erweitert werden:

Ja ga nisam srcem sevdisala,

Sevdisala, ni begenisala...

$$
\text { Rubit 4, S. } 290
$$

1) Lausberg $\oint 619$.

2) Man denke nur an das Guslevorspiel in den epischen Iiedern oder die vielen formelhaften Einleitungsverse und -worte, die dieser Tatsache Rechnung tragen. Vgl. dazu auch S. 23.

3) Vgl. dazu Pollok, S. 84 f.

4) Bei einer genauen Betrachtung der untersuchten Lieder lieB sich feststellen, daß die reduplicatio in den meisten Fällen - teils stärker, teils schwächer - zusammen mit der Fjgur der Klimax auftritt. Diese nicht zu berücksichtigen, hisBe das Wesen der reduplicatio nicht ganz erfassen. 
Das Verb "Gefallen finden" (begenisat1) im AnschluB an die reduplicatio der Worte "lieben" (sevdisati) bedeutet hier keine Steigerung, sondern weist eher in die Richtung einer synonymischen Wiederholung.

Oder:

3

Drugog nă̌la, Sarajliju,

Sarajliju, kujundziju...

Vasiljevit, Nr. 226

Auch dieses zweite Beisplel enthält noch keine Klimax, sondern vielmehr eine Präzisierung durch die Berufsbezeichnung.

Beide 21 tate stehen gleichzeltig fur die reduplicatio, in der lediglich ein Wort wiederholt wird.

Die folgende Gruppe gibt Belopiele, in denen mehrere Worte in gleicher Form am Versende und -anfang gesetzt werden; zudem wird hier die reduplicatio durch eine stärkere Klimax fortgefuihrt:

Prekosutra hotu za drugoga,

za drugoga, za jarana troga.

$$
\text { Kurt, Nr. } 34
$$

Hier handelt es sich ebenfalls um eine Präzisierung, die als Zuspitzung eine nicht geinge Steigerung einschlieBt, da der "andere" (drugoga) ausgerechnet der "Preund" (jarana) des verlassenen Burschen 1st.

Oder:

I lipła sam 1 svom braci draža,

Draka braci neg' bracina ljuba"...

Milosevit IV, Nr. 3

Diese reduplicatio (in chiastischer Porm) erhält ihre steigernde Portfuhrung durch einen Vergleich.

Alle vier Beispiele sollen darlegen, dab die reduplicatio nicht nur als solche den Ubergang von Vers zu Vers erleichtert, sondern dab ihr improvisatorischer Wert daruber hinaus 
oft auch die Portsetzung des folgenden Verses betrifft: die reduplicatio evoziert eine Erweiterung (in mehr oder weniger gesteigerter Porm).

Handelt es sich in den bisher gegebenen $2 i$ taten um reine, d.h. nicht abgewandelte reduplicationes, so sollen die folgenden zwei Beispiele für diese Figur in leicht veränderter Form geben. Heist geschteht diese Veränderung dadurch, dab die einzelnen Glieder der reduplicatio in verschiedenen Kasus ${ }^{1)}$ wiederholt werden:

Ona doziva sultan Selima:

Sultan Selime, car gospodine! ...

$$
\text { Dizdar I, Nr. } 52
$$

Eine weitere der möglichen Abwandlungen besteht etwa in der Weglassung des Epithetons in der zweiten Setzung:

Izgorješ dva nova ducana,

Dva ducana $i$ nova mehana, ...

Cubelit, S. 114

Das in der reduplicatio fortgefallene Adjektiv ist aber noch so stark im Bewußtsein des Sängers, daß es sich ihm bei der Portsetzung aer reduplicatio, die hier in der Form einer Aufzählung vorkommt, sofort von neuem anbietet.

Beide Beispiele für die veränderte reduplicatio lassen erkennen, dab ihre Grundfunktion erhalten ${ }^{-}$bleibt.

Wird die reduplicatio zum kennzeichnenden Stilmittel des ganzen Liedes, so stellt sie nicht nur eine Erleichterung für die Improvisation und Tradierung dar, sondern hat auch deutlich kompositorische Funktion. In solchen Beispielen nähert sich die reduplicatio der gradatio. 2$)$ Einen derartigen Pall illustriert das folgende Beispiel, wenr auch die reduplicatio hier nicht konsequent das ganze lied hindurch verwand wird:

1) Vgl. dazu I, 9, zum Polyptoton.

2) Vgl. dazu I, 3, zur gradatio bzw. Epiploke. 
Kad ja pod̄oh na Bendbasu,

$\mathrm{Na}$ Bendbasu na vodu,

I povedob b'jelo jagnje,

B'jelo jagnje sa sobom!

Sve od jada 1 Zalosti,

Ne bil' dragu vidio!

Sve djevojke na vratima,

Na vratima stajahu,

Samo moja dilber draga

Na demirli pendzeru.

Sve djevojke u bijelu,

U bijelu temberu,

Moja draga u crvenom,

U crvenom džamfezu!

U ruci joj od biljura,

Od biljura mastrafa,

Iz naştrafe tri cvijeta,

Tri cvijeta zaljeva:

B'jel albaber, i karamfil, 1)

I rumenu ruzicu!

Ja joj nazvah: "Selam alejk,

Selam alejk, djevojce!"

Ona meni: "Dod' doveze,

Dod', dovece dilberte!"

Ja ne odoh prva vecer,

vec ja odoh drugu not.

Druge noti moja draga

Za drugog se udala!

$$
\text { Dizdar I, Nr. 1112)3) }
$$

1) Diese contradictio in adiecto (b'jel = wei $B$, albaber $=$ $r \circ t$ e Nelke) ist ein Beleg dafür, das die türkischen Worte nicht immer in ihrer ursprunglichen Bedeutung verstanden und verwertet werden. Damit soll jedoch nicht die biöglichkeit ausgeschlossen werden, daB solche contradictiones gelegentlich Ausdruck expressionistischer Techniken im Volksiled sein können.

sinm. 2 und 3 siehe S. 37 
Dieses lied, das sich im übrigen heute noch groBer Beliebtheit exfreut 1), gehört zu den sog. "mahalske pjesme" (Straßen-, Gassenlied $\left.{ }^{2}\right)$, die die Burschen bei ihrem abendichen Gang durch die Gassen sangen. In Sarajevo hatte dieser Brauch noch eine Erweiterung erfahren: hier fuhrten sie ein Lämmchen mit einer Glocke um den Hals hinter sich her, was die Madchen ihrerseits unter dem Vorwand des BlumengieBens an die Fenster lockte. ${ }^{3)}$

Fortsetzung von S. 36:

2) Eine Sevdalinka, in der die reduplicatio regelmäBig von Anfang bis Ende gebraucht wird, fuihrt Pollok an ( $V_{g l}$. dazu Pollok, S. 84). Es handelt sich um das Lied iUH VII, Nr. 9.

3) Oft ist es so, daß ein lied auf eine Figur - hier die reduplicatio - spezialisiert ist. liat der Sänger erst einmal den iert einer Figur für die Improvisation erkannt, verwendet er sie gern noch häufiger, manchmal so oft, daB die Figur liedgestaltende Funktion annimmt. $V_{g l}$. dazu auch einige Beispiele zur Epiploke $(I, 3)$.

1) Es sei nur daran erinnert, daß es diese Sevdalinka war, die dem aus Bosnien stammenden jugoslavischen Schriftsteller Ivo Andric anläBlich der Verleihung des Nobelpreises 1961 in Schweden auf einem Empfang vorgespielt wurde, um inm eine Aufmerksamkeit zu erweisen.

2) Der Terminus "Gassenlied" darf hier jedoch nicht wie bei uns abwertend verstanden werden.

3) Vgl. dazu Miloševit, V., Bosanske narodne pjesme, Knj. 1.2.3.4., Banja Luka 1954-1964, Knj. 2, Banja Luka 1956, S. 14. 


\section{Epiploke}

"Die $g r$ a d a $i \circ$ ist eine fortschreitende Anadiplose...n

Da der lateinische Terminus "gradatio" in jüngerer zeit vielfach die Bedeutung von reiner klimax angenommen hat ${ }^{2}$, soll der Eindeutigkeit halber im folgenden für diese Figur der griechische Terminus (Epiploke) verwendet werden. Dabei wird jedoch nicht übersehen, daß die Epiploke in den meisten Fällen eine Steigerung herbeiführt.

Die enge Verwandtschaft der Pigur der ipiploke mit der dēr reduplicatio führt $z u$ einem annähernd gleichen Einteilungsschema.

Da aber die Epiploke eine fortgeführte reduplicatio darstellt, versteht es sich von selbst, daB ihr Wert für die Improvisation der Lieder entsprechend höher ist.

Als erste sei die Epiploke erwähnt, deren Durchfürung für den Text nur eine schwächere klimax ergibt:

Ne bi l' bio de sam naumio,

Naumio gore, u Zagorje,

U_zagorje, u zeleno borje...

Milosevit III, Nr. 5

oder:

O Ilija, vilajlija!

Što ti ljuba tiho odi,

Tiho odi, suze roni,

Suze roni, ne govori?

Kuhat II, Nr. 550

Im ersten Beispiel handelt es sich mehr oder weniger um eine bloBe lokale Erweiterung bzw. genauere Definierung des Ortes.

1) Lausberg $\$ 623$.

2) Vgl. dazu Wilpert, G. v., Sachwörterbuch der Literatur, Berlin 1963 zu "gradatio" und "Klimax". 
Im zweiten Beispiel wird die zunächst angedeutete Klimax "tibo odi, suze roni" durch die folgende Antiklimax "suze roni, ne govori" wieder zurükgenommen.

Stärkere Klimax wird durch den Gebrauch der Bpiploke in folgenden Beispielen hervorgerufen:

A moj dragi, moje milovanje.

iiilovanje, Cesto spominjanje,

Spominjanje, Ces to uzdisanje,

Kad uzdahnem hotu da izdahnem.

$$
\text { Dizdar I, Nr. } 71
$$

Hier erfährt die Kimaxreihe milovanje - spominjanje uzdisanje, deren Mortmaterial als im übrigen für die Sevdalinka typisch gelten darf, eben durch ihre Einkleidung in eine Epiploke schon im Formalen besondere Betonung.

In einer ähnlichen Epiploke wird das erste Glied (am Zeilenende) in Verbalform durch das zweite Glied (am Zeilenanfang) in Substantivform (bzw. einmal als Gerundium) wieder aufgenommen:

Ona te te cesto mirisati,

U mirisu na me pomisliti.

U migljenju $2 a$ mom uzdahnuti,

Uzdisuti tebe poljubiti!

$$
\text { Dizdar I, Nr. } 116
$$

Im folgenden Beispiel wird die Epiploke in anderer Weise realisiert:

Al' ja nadoh zelenu livadu,

Na livadi mog dragog dolama,

Na dolami svilena marama.

Na marami sedefll tambura,

Kod tambure crvena jabuka.

$$
\text { Dizdar I, Nr. } 263
$$

Es handelt sich nicht wie in den vorigen Beispielen um deutliche Steigerung eines Begriffes, sondern um die Aneinanderreihung verschiedener Gegenstände zum Zwecke der Hervorhe- 
bung eines bestimmten. Dabei verfährt der Sänger so, daB er, um eine gewisse Spannung hervorzurufen, vom weniger Wichtigen zum Wichtigen, dem Apfel ${ }^{1)}$, fortschreitet.

Diese kettenartig angeordnete Epiploke führt über zu dem letzten Beispiel, nämich der "Kettenepiploke" mit kompositorischer Punktion: Die Epiploke in dieser Form dominiert in dem Lied derart, daß sie für die formale Prägung desselben bestimmend wird:

Dva se draga na livadi ljube,

Oni misle da niko ne vidi,

Al' to vidi na livadi trava,

Trava kaze nad sobom ovcama,

Ovce kazu kraj sebe cobanu,

Coban kaž na vodi vodaru,

Vodar kaže u selu imamu,

Imam kaže svome mujezinu,

A mujezin 1 ocu $i$ majki.

Ljuto kune gizdava divojka:

nO travice, zemlje ne probila,

Bile ovce, poklali vas vuci,

A Cobana obisili Turci,

A vodara voda odnijela, iluzejina ${ }^{2)}$ ufatila zima,

A imama pritisla munara

Bog ubio i oca 1 majku!"

Bajraktarevic, Nr. VIII 3 )

Die Epiploke, die im ersten Teil des Liedes konsequent angewendet wird, wirkt insofern auch für den 2 weiten Teil kompositorisch gestaltend, als ihre Glieder in diesem wieder auf-

1) tiber die Bedeutung des Apfels auch in der muslimischen Volksliebeslyrik, vgl. Hangi, A., Die Moslims in BosnienHercegovina, Sarajevo 1907, S. 179 f.

2) Wonl: mujezina.

3) Vgl, 2u diesem Lied II, 13h und III,27. 
genommen werden, wenn auch nicht in der Figur der Epiploke, so doch in der von dieser angegebenen Reihenfolge.

Da das oben für die reduplicatio Konstatierte auch für die Epiploke zutrifft, konnte auf weitere Beispiele zu dieser Figur verzichtet werden, zumal die Epiploke in leicht (meist polyptotisch) abgewandelter Form bereits in den beiden letzten Beispielen in Erscheinung tritt und die Epiploke, die mehr als ein Wort umfaBt, in dem aus Kuhad II, Nr. 550 zitierten Lied.

Die behandelten Figuren geminatio, reduplicatio, Epiploke finden durchweg häufige Verwendung wie in der Sevdalinka, so auch in der gesamten volkstümlichen liebesdichtung des balkanslavischen Raumes. 1) Der Grund dafür liegt nicht zuletzt in ihrem hohen improvisatorischen Wert.

1) Vgl. dazu Pollok, S. 86 . 
4. Redditio

"Die Wiederholung als (syntaktisch-semantische oder metrische) Klammer (...) wird durch die Pigur der $r$ e d d i $t i o$ dargestellt..."i)

Die Bedeutung dieser Pigur für die Sevdalinka ist nicht allzu groB, da sie in diesem Iied nur vereinzelt anzutreffen ist. Der Vollständigkelt halber aber soll auch auf diese Figur eingegangen werden.

Fiir die Komposition kommt der redditio kaum Bedeutung $2 u$, wohl aber fur die Improvisation. Dabei erscheint die redditio in kleinerem Rahmen, die nur ein oder zwei Worte doppelt setzt, seltener, als dieselbe Pigur in gröBerem Rahmen, bei der ein ganzer Vers durch 2 wel weitere gleichlautende eingeschlossen wird. Wird die redditio innerhalb eines Verses realisiert ("Einversredditio"), so bilden die umrahmenden porte in den meisten pällen Versanfang und Versende:

"Ne kuni me, moja majko, ne kuni!

Nisu mi in nadavale djevojke, ...

Kuhat III, Nr. 885

Ein Beispiel für die redditio, deren Glieder nicht diese exponierten Stellen einnehmen, ist folgendes:

Ali meni kara-uber dude,

Kara-aber, a u kara-doba:...2)

Kuhad I, Nr. 241

oder, verbunden mit einer Epipher:

Sad te dragi iz Car\$1je doti;

Kome doci, kome 1 ne doci, ...

Popovit-Rodoljub, Nr. 78

1) Lausberg $\$ 625$.

2) Auf dasselbe Beispiel stößt man des öfteren.

Vgl. auch Kuba 1907, S. 632, Nr. 319 oder, offensichtlich in zersungener oder falsch aufgezelchneter Form in Bos. vila 1886, S. 205:

Sinot ment kara-haber dojde,

Kara-haber, u kara-haberu: ... 
Die Zitate, die im übrigen auf Grund ihres Wortmaterials als typisch für die Sevdalinka gelten dürfen, sind gleichzeitig Belege fü die Wiederholung eines Wortes (Beispiel 2 und 3) und die Wiederholung zweier Worte (Beispiel 1) innerhalb dieser Pigur.

Produktiver für Improvisation wie Komposition ist der Fall der "Mehrversreddition, bei der zwei gleichlautende Verse einen dritten einschließen:

$$
\begin{aligned}
& \text { Ili } i \cdot \mathrm{y}^{1)} \text { il' ne is'o, } \\
& \text { Loj je sevdah kraj tebe, } \\
& \text { Il'me hotes, il'me netes, } \\
& \text { Moj je sevdah za tebe! }
\end{aligned}
$$

Vasiljevit, Nr. 119

Trotz der Bedeutungsnuancierung durch den Hechsel der Präpositionen innerhalb der wiederholten Verse (kraj gegenüber 2a), darf diese Pigur doch als redditio angesehen werden.

Die "Einversredditio" stellt bei der Improvisation gröBere Anforderungen an den Sänger als die "Mehrversredditio", da er in dem engen Rahmen eines Verses für die an betonter Stelle stehenden Glieder der redditio einen metrisch wie semantisch geeigneten Mittelbau finden muß.

1) Wohl: is.o. 


\section{Anapher}

Eine weitere Wortwiederholungsfigur, die in der Sevdalinka eine wichtige Rolle spielt, ist die Anapher.

"Die absatzmäßige Wiederholung des Anfangs eines Kolon oder eines Komma (...) heiBt Arapher..."1).

Bei der Untersuchung der Anapher in der Sevdalinka soll zunächst eine Unterteilung dieser Figur in die Anapher nur am Versanfang (Ganzversanapher) und in die Anapher an Versanfang und Versmitte, meist nach der Zäsur (Halbversanapher), vorgenommen werden. Im AnschluB daran wird auf die verschränkung dieser beiden Arten der Anapher eingegangen.

\section{a. Ganzversanapher}

$\mathrm{DaB}$ Wortwiederholungsiguren besonders am Iied-bzw. Versanfang beliebt sind, weil sie die Improvisation des Liedes erleichtern, wurde schon bei früher behandelten Figuren (iteratio, repetitio, reduplicatio u.a.) festgestellt. Der Improvisationserleichterung dient in besonderem KaBe auch die Ganzversanapher: Der Sänger beginnt zwei oder mehrere Verse mit demselben fort und führt so das lied, indem er nur die Fortsetzung eines jeden Verses variiert, seinem Ende entgegen. Nach dieser Einleitung wird der folgende Teil der Verse in verschiedener ïeise realisiert.

Posetala Fazli-begovica

Posetala drumom zirokijem...

$$
\text { Ristic, Nr. } 5
$$

oder

Ruç mladi Ivan beze

RuCa beže u seku pogleda:...

$$
\text { Davidovit, Nr. } 4
$$

Diese Art der Ganzversanapher stellt lediglich eine Wiederholung von Gliedern am Versanfang dar. DaB sie wesentlich der

1) Lausberg $\$ 629$. 
Improvisationserleichterung dient, läbt sich daran erkennen, daB im ersten Beispiel auch ohne die zweite Setzung von "posetala" die Aussage dieselbe bliebe (Posetala Fazli-begovica drumom Sirokijen); im zweiten konnte die Konjunktion "i" das $z$ weite Glied der Anapher ersetzen (Ruca mladi bež i u seku pogleda). Der Sänger verwendet am Versanfang jedoch eine Anapher, um der. zweiten Vers mühelos anzuschließen und sich dadurch gleichzeitig eine schöpferische Pause zu verschaffen, die ihm zeit gibt, die Fortsetzung der Verse zu konzipieren.

Dieser Fortsetzung sind aber innaltlich wie formal Grenzen gesetzt, da eine einmal gebrauchte Anapher nicht jede beliebige Feiterfürung gestattet.

Kolika je dubljina u moru, Kolika je širina u svjetu,...

Hak II, Nr. 4

oder:

Na njemu su tulbet gace, tur sunoves,

Na njemu je tanka koßa, hase ogroßa,... Milosevit IV, Nr. 415

In diesen Beispielen zieht die Anapher wie so oft eine Aufzählung nach sich. Dabei entsteht vielfach die Figur des Isocolons: die Verse werden parallel gebaut. Der Sänger erleichtert sich somit in einer Art Kettenreaktion durch den Gebrauch von Anapher, Aufzählung (koordinierende Häufung in asyndetischer 8gf. polysyndetischer Form) und Isocolon die Improvisation in dreifacher Heise.

I ubila tri riljad' ovaca,

I ubila tri mlada pastira....

Davidovic, Nr. 3

Auch diese Ganzversanapher ist mit der Figur des Isocolons verbunden; letzteres Beispiel enthalt noch Klimax und Antiklimax, und zwar Klimax im Hert und Antiklimax in der Anzahl der Erschlagenen. 
Steigerungen, durch die Pigur der Anapher eingeleitet, sind häuflg anzutreffen und dienen dann besonders als effektvoller IiedabschluB:

Bez rakije nema zivovanja,

Bez Pazile nema milovanja!

$$
\text { Dizdar I, Nr. } 1
$$

Die Ganzversanapher besteht hier lediglich in der wiederholten Präposition "bez".

Im Rahmen der slavischen Antithese ${ }^{1)}$ erscheint eie als Wiederholung von "ili" (bzw. "ali") und "niti". Wegen der Pormelhaftigkeit, die der slavischen Antithese eigen ist, nimmt sie hier eine Sonderstellung ein:

Sto se ono sjaji na pendzeru?

Ali srmu kuju kujundzije,

Ali zlatom vezu vezilice

Al' Je zlato niz kanat' salito?

Jok 1 konju nogu salomilo?"

nNiti srmu kuju kujundzije,

Niti zlatom vezu vezilice,

Nit je zlato niz kanat salito, Vet je...2)3)

Dvorovit, S. $43 \mathrm{ff}$.

Handelte es sich in den bisher gegebenen Beispielen - abgesehen von dem Spezialfall der slavischen Antithese - um Anaphern, die nur zwei Verse umfassen und der Improvisationserleichterung in kleinem Rahmen dienten, sollen die folgenden

1) Das balkanslavische Volkslied - und mit ihm die Sevdalinka - hat gegenüber dem ostslavischen Volkslied eine besondere Form der slavischen Antithese (negativer Vergleich) herausgebildet. Vgl. dazu Pollok, S. 56, Anm. 12.

2) Zur Beziehung von Anapher und Polysyndeton vgl. Lausberg, H., Elemente der literarischen Rhetorik, 2. Aufl., Binchen 1963, \$267.

3) Schauplatz (pendzer) und Personen (kujundzije) dieses Liedes weisen sofort auf eine Sevdalinka. 
Iledabschntte brw. ganzen Lleder zeigen, das diese Plgur auch die gesamte Komposition eines Iledes bestimmen kann.

In einer Kettenaufrählung erscheint diese Figur in der fur das Volkslied 80 typischen drelmaligen Setrung:

Jednom vidjeh: Bogu se moljałe, Jednom vidjeh: ložnicu steraße, Jednon Fidjeh: puce razpinjałe...

$$
\text { Dizdar I, Nr. } 11
$$

Verbunden mit der Pigur der koordinterenden Häufung:

Volim tebi, vec svemu ovijetu!

Volim tebi, vec ocu 1 majci,

Volim tebi, vel bratu 1 seki...

Bo8. Fla 1905, S. 381

Teilkompositorische Punkt1on, nämlich strophenbildende, zeigt die wapher in folgendem Ifed, das ganz zitiert wrd:

Gdje a1 dubo, gdje ol rano,

Gdje $B 1$ dante mio?

Gdje 81 sunce ogrijano,

Gdje 81 danas bio?

Ta sinot se tebi mlada

Bał zac'jelo nadah,

Sunce zade, pada tama,

A ja ostah Bama.

Dizdar I, Nr. 69

Die erote "Strophe" lot ganz auf der Anapher "gdje e1" (viermal) aufgebaut, um die dort gestellte Prage zu vereindringlichen, während die zweite (die sntwort) auf die cnapher ganz vereichtet.

Relativ häufig aind auch Lieder anzutreffen, die $81 \mathrm{ch}$ ron nnfang bis Ende derselben Ganzversanapher bedienen: 
Znał li dragi, Zalosna ti majka!

Kad se od nas proti nemogałe,

Od nasega nama $i$ jordama,

Od mog nama $i$ od trog jordama

A od moje burundzuk kosulje,

A od troje vezene gjecerme, ...

Hak I, Nr. 38

Nach vier anapherlosen Einleitungsversen wendet das lied in den zwanzig weiteren Versen durchgehend die Anapher an, verbunden mit der Form der Aufzählung ${ }^{1}$ (Leichte Abwandlungen wie in "od mojijeh" und "od trojijeh" gegenüber "a od moje" und "a od troje", die zweimal auftreten, fallen dabei nicht stark ins Gewicht). Die Anapher besteht hier in den stets wiederholten Forten "a od". Der Hechsel der Possessivpronomina "moje" und "troje" von Zeile zu Zeile leitet über zu der Sonderform der Anapher auf Abstand oder der "verschränkten Anapher"2). Diese Figur hat in den überwiegenden Fallen kompositorische Bedeutung, da sie sich oft durch das ganze lied zieht. Heist handelt es sich um ein Frage-Antwort-Spiel, das in einem fingierten oder direkten Dialog realisiert wird.

Fingierter Dialog:

Jesi l' Djido u Saraj'vo hodio?

A jesi li kara-kalem vidio?

Anake su obrvice $u$ mene. Jesi l' Djido u rozdiju hodio?

A jesi li jezi-cage vidio?

Anako je bielo liłce u mene. Jesi l' Djido uz to more hodio?

A jesi li trnjnicu vidio? Anake su crne oti $u$ mene.

Blagajic, vr. 26

1) Deutlich kommt in dieser Aufzählung von Schmuck- und Kleidungsstücken (wie anterija, dolama, biser, pojas, ogrlica, fes, terluk, kundur u.v.a.) die Vorliebe der Sevdalinka für solche Gegenstände zum Ausdruck. Diese Freude am Luxus scheint typisch orientalisch.

2) VGI. dazu Pollok, S. 88. 
Direkter Dialog:

Tko ti kupi kolanceto?

On ga kupi, ja ga nosim.

Tko t1 kup1 orma jelek?

On ga kupi, ja ga nosim....

Kuhad II, Nr. 771

Das erste lied wurde vollständig zitiert, von dem zweiten nur die ersten vier von vierzehn gleichgebauten Versen.

Weitere Beispiele zur verschränkten Anapher sind u.a. die Lieder Dizdar I, Nr. 187 oder MH VII, Nr. 46. An letzterem zeigt Follok, wie eine solche Pigur auch die Punktion einer formelhaften Hendung annehmen kann: "Jede der beiden Anaphern bildet das syntaktische Gerüst für jeweils einen Teil der drei aufeinanderfolgenden parallelisierten zweigliedrigen Aussagen. Nachdem der Sänger bel der ersten Anwendung die allgemeine Brauchbarkeit der beiden Wendungen erkannt hat, greift er bei den folgenden Aussagen auf diese syntaktischen Schemata zurück und gibt ihnen damit für den konkreten Pall den Charakter stehender Wendungen.

Abgesehen von der Erleichterung, die durch den Gebrauch solcher Formeln bel der Liedimprovisation bzw. bei der Iiedtradierung eintritt, erfahren die einzelnen Aussagen durch die damit verbundenen Parallelisierungen zugleich eine Ausdrucksintensivierung. Solche Formeln haben ihre Vorteile jedoch nicht nur für den Sänger selbst, auch die Zuhörer - als potentielle Mitoder Nachsänger - stehen diesen Ausdrucksklischees positiv gegenuber. Bei innen spielt - über die leichtere Rezipierbarkeit hinaus - auch das Moment der Vorausahnung eine gewisse Rolle."1)

1) Pollok, S. 88 f., Anm. 15. 
b. Halbversanapher

Die Halbversanapher trifft man in den Liedern häufig an, wenn auch etwas seltener als die Ganzversanapher. Sie hat ausschlieblich improvisatorischen Wert; kompositorische Bedeutung kommt inr nicht zu.

$U$ kadune Hasan-aginice:

Devet §teri, devet divojaka, ...

$$
\text { Kurt, Nr. } 15
$$

oder:

Porucuje liejrußa djevojka:

"Aman paðo, aman Alipa§o,...

Novi behar $1941 / 42$, S. 231

In belden fällen führt die verwendung der Halbversanapher inbaltlich nicht $2 u$ efner Erweiterung: "Töchter" schliebt "Mädchen" ein im ersten Beispiel; im zweiten wird nach der Halbversanapher lediglich noch der Name des pasa (Ali) hinzugesetzt.

Polgende zwei Zitate zeigen eine Weiterfuhrung des Inhalts innerhalb der von der Halbversanapher nachfolgend verlangten sprachlichen Form, und zwar wird diese erreicht im ersten Falle durch einen verkirzten Vergleich und im zweiten durch eine schon tei dar Ganzversanapher behardelte Aufzählung.

Verkuirzter Vergleich:

I to me je majka nacerala.

Dva obraza, dva gjula rumena, ...

Kuba 1907, S. $634, N r \cdot 330$

und :

Dva Pašica dva zlatna nozica, ...

$$
\text { Dizdar I, Nr. } 7
$$

Aufzählung:

Sama Zanje, sama snoplje veze,

Sama pjeva, sama pripijeva: ...

Bejtic (Bilten II), S. 387 
Eine Aufzählung, verbunden mit einer Halbversanapher, findet sich auch in der besonderen Porm der slavischen Antithese:

Il' si melet, 仼 dそenetska hurija,

nNit sam melet nit dZenetska hurija,

$$
\text { Zovko I, Nr. } 76^{1)}
$$

\section{c. Verschränkung von Ganzversanapher und Halbversanapher}

Bei der Behandlung von Ganzversanapher und Halbversanapher soll zum Schluß auch noch auf die Verschränkung beider hingewiesen werden. Grundsätzlich müssen zwei Durchführungsmöglichkeiten unterschieden werden: Ganzversanapher und Halbversanapher wiederholen dassel be Hort, und Ganzversanapher und Halbversanapher wiederholen verschiedene Horte.

Verschränkung von Ganzversanapher und halbversanapher mit demselben Wort:

A dva oka dva vrela studena, Dva obraza dva gjula rumena, A dva brka dva kargala zlata, ...

$$
\text { Hak II, Nr. } 20
$$

Das Asyndeton im zweiten Vers steht aus verstechnischen Grürden; trotzdem kann mar auch hier von einer Anapher sprechen.

Oder, in asyndetischer Aufzählung:

Ne pij vina, ne pusi duhana,

lie ałikuj, ne vezi sevdaha? ...

$$
\text { Blagajic, Nr. } 1
$$

1) Beachte in dieser Sevdalinka den EinfluB islamischer Religion (melet = Engel, dZenetska hurija = Paradieseshuri, Faradiesmiddchen). 
In letzten Beispiel beruhen Ganzvers- und Halbversanapher nur auf der mehrfachen Setzung der Verneinungapartikel "ne". Ahnlich werden auch bei der Anapher innerhalb der slavischen Antithese nur Konjunktionen wiederholt. Nachfolgend eine vollständige slavische Antithese, die hier das ganze lied ausmacht:

Sto se ono tamo sjaji,

Tamo sjaji u gori?

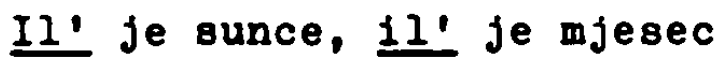

II' su sjajne zvjezdice.

Nit' je sunce, nit' je mjesec,

Nit. su sjajne zvjezdice,

Vet su ono bjeli dvori,

Nioga dragog u gori.

Dizdar I, Nr. 276

Verschränkung von Ganzversanapher und Halbversanapher mit verschiedenen Worten:

Koja gora zimi je zelena,

Koja roda zimi leda nema, ...

Dizdar I, Nr. 64

oder (mit Parallelismus in der verstärkten Pigur des Isocolons):

0 zlu hrastu - o mon b'ielam vratu,

0 zlu drvu - o mom b'jelom grlu! ...

Und etwas weiter in demselben lied (mit Binnenreim und Assonariz):

Sindir halke - moje b'jele sake,

sindir kuke - moje b'jele ruke!"

Novi behar $1939 / 40$, S. 348

Bel einmaliger Verwendung in einem lied haben Halbversanapher und Verschränkung von Ganzvers- und Halbversanapher ausschlieBlich improvisatorische Bedeutung. Treten diese Figuren jedoch mehrfach auf, so werden sie für Gestaltung und 
Aufbau des liedes bestimmend. Dies aber geschleht in reiner Form sehr selten; meist tragen andere Piguren wie die koordinierende Häufung in Porm einer Aufzäblung (Beispiel Hak II, Nr. $20^{1}$ ), das Isocolon oder auch das Polyptoton das Hauptgewicht. Die Figur der Anapher dient dann lediglich eirer Vereindringlichung.

Eine Anapher in polyptotisch abgewandelter Porm mag abschlleBend folgendes Beispiel demonstrieren:

Siver prosi od juga divojku,

Siver prosi, a jug se ponosi; ...

Rubic XXIV, S. 311, Nr. 15

1) Siehe dazu S. 51. 


\section{Epipher}

"Die absatzmäBige Wiederholung des Schlusses eines Kolon oder eines Komma (...) heibt Epipher......1)

Auch die Epipher ist in aen Liedern relativ häufig anzutreffen, wenngleich seltener als ihr Fendant, die Anapher. kist wiederholt sie nur die Worte unmittelbar am Versende; gelegentlick aber umfaBt die Wiederholung die halbe Zeile oder noch größere Versabschnitte.

Wozes li, liujo, prebolet?n

- Ne mogu, draga, prebolet', ...

Vasiljevic, Nr. 246

oder:

Ode za'va za goru na vodu.

Kad je doßla za goru na vodu, ... Bajraktarević, Nr. I

Beide Beispiele demonstrieren die Epipher im eigentlichen sinne, d.h. die, die in zwei unmittelbar aufeinanderfolgenden versen erscheint. Im ersten Falle schließt sie jeweils Frage und Antwort ab, wie die Anapher inrerseits beide einleitete ${ }^{2}$, und unterstreicht somit auch formal deren enge inhaltliche Verbindung. Im zweiten Palle wiederholt sie jeweils die adverbiale Bestimung jes Ortes $z$ cen Verb "iti", das der aspekt der Hardlung entsprechend als "otići" (Aorist) brw. "doti" (Perfext) begegnet.

Neben der Epipher in direkt aufeinanderfolgenden Versen, die in den liedern am häufigsten vorkommt, findet sich auch die Epipher auf Abstand, bei aer sich zwischen die beiaen die Epipher aufweisenden Verse ein dritter Vers schiebt:

1) Lausberg $\$ 631$

2) VGl. dazu S. 48 f. 
Štaku ti po cardaku

Kao paunica,

Pjevatu ti na cardaku

Kao slavaj ptica, ...

Vasiljevit, Nr. 124

oder, eingebettet in eine slavische Antithese:

oj Moravo, Bto si zamukena?

Ili pasic vojisku vodi.

II' carevit konja poji?

Niti pašit vojsku rodi.

Nit' carevic konja poj1,

Vec plivaju dvi Horavke, ...

Lillosevit IV, Nr. 429

Die Epipher in polyptotisch abgewandelter Porm mögen folgende zwei zitate demonstrieren, wobei im ersten ein typischer Schauplatz der Sevdalinka - Sarajevo - erscheint:

Sa tebe mi se vidi Sarajevo

I dva sela oko Sarajeva....

Sajnovit XX, S. 152, Nr. 2 und :

Irla bratu po djevojku.

Jel daleko ta djevojka? ...

Kuba 1906, S. 500, Nr. 74

Eine Eplpher, die sich uber mehrere Verse erstreckt, deren Hortmaterial als charakteristisch für die Sevdalinka gelten darf, bringt folgendes 2 itat, $Z$ wischenstück eines lüngeren Iiedes:

Kada dode na avlijska vrata,

Na avliji otvorena vrata.

Kada dode na cardaku na vrata,

Na Cardaku zatvorena vrata.

Nogom lupi u hrastova vrata, ...

Dizdar I, Nr. 82 
Es iet nicht zuletzt diese Epipher, die es aem improvisierenden Sänger erleichtert, das Iled stufenartig fortzuführen.

Sevdalinke, in denen sich der Sänger der Epipher so konsequent bedient, dab gie fü die Gestaltung des gesamten Liedes bestimmend werden, sind nicht zahlreich. Ein Beispiel dafür gibt folgendes Lied:

Bajram ide, bajramu se nadam.

Sta bih dragom bajramluka dala?

Kad bih dragom vezen jagluk dala

Dragi mi je, malo bih mu dala.

Kad bih dragom bołtaluka dala,

Sirota sam, mnogo bih mu dala.

Rad bih dragom b'jelo lice dala,

Hvalit ce se medu jaranima.

Kad bih dragom po dureka dala,

Azgin dragi, mirovati nete.

$$
\text { Dizdar I, Nr. 15 }{ }^{1) 2)}
$$

Findet sich in der Sevdalinka auch gelegentlich eine längere Epipher (wie in dem oben zitierten Beispiel Bajraktarevit, Nr. I), so überwiegen doch die Fälle, in denen diese Pigur nur ein oder zwei Worte wiederholt.

1) Es ist u.a. die Erwähnung des "bajram", des größten muslimischen Festes, was dieses Lied als eine Sevdalinka erkennen läBt.

2) Ein ähnliches Beispiel führt Ristic (ir. 33) an, wo sechs der ersten acht Verse die Epipher "u ruci" bzw. polyptotisch abgewandelt "iz ruke" und "s ruke" aufzeigen. 
7. Complexi으

"Die c o m p 1 e $x i \circ(\ldots)$, die haufig als e x qu $i$ $81 t i \circ(\ldots)$ auftritt, ist die Kombination der Anapher (...) mit der Epipher (...) ...". 1)

In der Sevdalinka findet sich die complexio äuBerst selten.

Da sich bei der Realisierung dieser Figur ein weitgehender Parallelismus auch des versinnern aufdrängt, hat sie für die Improvisation besondere Bedeutung. Die folgenden beiden zitate enthalten zugleich ein Antitheton, das der complexio des öfteren ein besonderes Gepräge gibt:

Koja ima ponosi se \& njime, Koja nema uzdiłe za njime

Kuhac I, Nr. 46

und:

Kada puhnes, nikom nisi draga,

$\left.\underline{\mathrm{Kad}}^{2}\right)$ ja puhnem, svakome sam draga!

Bajraktarevic, Nr. IX

Eine complexio in Verbindung mit einer parallelen Aufzählung, die eine schwache Klimax aufweist, zeigt folgender Iiedabschnitt:

Kad obucem telmi dibu, meni star ne da,

Kad opałem hazna kolan, meni star ne da,

Kad ja pojdem u rod majci, meni star ne da, ...; Nilobevit IV, Nr. $409^{3)}$

1) Lausberg $\$ 633$.

2) "Kad" als Kurzform 2u "kada" hat der Sänger wohl deshalb gewählt, um das folgende "ja" einfügen und so das Antitheton noch hervorheben zu können.

3) Dieses Iied, zu dem eine grobe Anzahl von Varianten existiert, wird von den Sammlern oft in der Art aufgezeichnet, daß die Epipher "meni star ne da" einen eigenen Vers bildet (etwa Dizdar I, Nr. 264 u.a.). Vgl. dazu auch III.17. Da jedoch Hilosevit, der bei seiner Aufzeichnung die Melodie mit berucksichtigt, das Lied in der 0.a. Form wiedergibt, scheint aie Bestimmung der iortgruppe "meni star ne da" als Epipher gerechtfertigt. 


\section{Annominatio}

Die annominatio zählt wie die folgenden drei Piguren (Polyptoton, figura etymologica und Synonymie) zu den Wortwiederholungsfiguren bel gelockerter Wortgleichheit, die stets mit einer mehr oder wenlger starken Lockerung der Wortbedeutung verbunden 18t. Diese Lockerung der Wortbedeutung kann dabel einmal nur einen Teil des Wortkörpers (annominatio, Polyptoton und figura etymologica), zum anderen den ganzen Wortkörper (Synonymie) betreffen.

"Die annominatio sparonomasier ist ein (pseudo-)etymologisches Spiel mit der Geringfügigkeit der lautlichen Änderung einerseits und der interessanten Bedeutungsnuance, die durch die lautliche Änderung hergestellt wird, andererseits. Hierbei kann die Bedeutungsapanne bis ins Paradoxe gesteigert werden. Die so hergestellte Etymologie (...) zwischen den beiden Wörtern wird dem Publikum als eigene Arbeitsleistung vom Autor zugemutet...n. 1)

Wegen ihres zahlreichen Vorkommens in der Sevdalinka erscheint eine Unterteilung der annominatio in eine annominatio per adiectionem vel detractionem und in eine annominatio per immutationem, die auch Pollok vornimmt ${ }^{2)}$ ), als angebracht.

1) Lausberg $\$ 637$.

2) Vgl. dazu Pollok, S. 92 ff. sowie Lausberg $\$ 638$.

3) Auf die annominatio per transmutationem, d.h. eine paronomastische Wiederholung in Porm eines Anagramm, kann hier verzdchtet werden, da sie in dem untersuchten Liedmaterial wegen inres außerst seltenen Vorkommens nur eine untergeordnete Rolle spielt. 


\section{a. Annominatio per adiectionem vel detractionem}

Pollok sagt dazu: "Der Unterschied zwischen den beiden Hortkörpern kann in der Erweiterung oder Kürzung des einen itortkörpers gegenüber dem anderen Wortkörper bestehen (...). Paronomasien dieses Typs sind in den slawischen Sprachen durch die mannigfaltigen Präfigierungs- und Suffigierungsmöglichkeiten in der Wortbildung verhaltrismäBig leicht zu gestalten,....1).

Es kann daher nicht überraschen, daß diese Figur auch im bosnisch-hercegovinischen Liebeslied häufige Verwendung findet. Die "marnigfaltigen Práfigierungs- und Suffigierungsmöglichkeiten" sind gleichzeitig auch eine Grundlage zur Erleichterung der Improvisation. So greift der Sänger improvisierter Dichtung, der sich in zeitlicher Aohängigkeit von der lielodie befindet, gern auf dasselbe Wort in präfigierter oder suffigierter Form zurück. Um eine völlige Bedeutungsgleichneit der wiederholten Forte handelt es sich dabei nie; der semantische Unterschied ist jeweils verschieden stark. Er kann

1. ganz geringfügig sein:

Iragi rece: "Doti tu ti, u akłam!"

Dragi rede, pa porede, uzaman!...

Vasiljevil, Nr. $199^{\mathrm{b}}$

oder:

Alaj se bittar sagleda,

Alaj se viknu, previknu, ...

Kuba 1906, S. $361, N r .36$

In beiden Fällen wird das präfixlose Grundverb noch einmal in prafigierter Porm gesetzt, womit keine Bedeutungsverschiedenheit erreicht werden 8011 (und wird), sondern lediglich eine Vereindringlichure des Ausgesagten (Freie Ubersetzung des

1) Pollok, S. 92 
ersten Beispiels: der Liebste verspricht und versichert es...). Eine iterative Wiederholung wäre diesem 2 weck in ähnlicher Weise gerecht geworden wie die paronomastische.

2. Der semantische Unterschied kann gröBer sein, kann eine gewisse Nuancierung bringen:

Brojila in Mijatova majka,

Brojila in 1 prebrojila in .... 1)

Zovko I, Nr. 73

oder:

Grjehota je djevojku ljubiti,

obljubiti pa je ostaviti,...

Dizdar I, Nr. 149

Bei "zählen" und "überzählen" (= noch einmal nachzählen) in Beispiel eins, sowie bei "küssen" und "abkuissen" in Beispiel zwei handelt es sich zwar um gewisse semantische Nuancierungen, jedoch um ein und dieselbe Handlung.

Oder, ein drittes Beisplel, das wegen seines Inhalts und seines Wortmaterials typisch für die Sevdalinka ist:

Mujo pade, a ljuba dopade:

"Moj Hujaga, moje Zarko sunce,....

Dizdar I, Nr. 303

3. Der semantische Unterschied kann so stark sein, dab sich ein neuer Inhalt im lexikalischen Sinne ergibt:

Jedan pjeva a drugi otpjeva:

"Koja gora od koje najljepsa -...

Ristit, Nr. 32

oder:

A ja istem da mi ga prodadu,

Nit ga dadu, niti ga prodadu...

Kuba 1909, S. 588, Nr. 743

1) Dieses Beispiel und viele andere zeigen deutlich, daB der paronomastischen ifiederholung des Grundverbs sehr häufig eine anaphorische desselben vorausgeht. 
Hier stehen sich als Doubletten singen - (singend) antworten (Beispiel eins), sowie (schenkend) geben - verkaufen (Beispiel zwei) gegenüber.

Die Bedeutung der annominatio für die Liedimprovisation resultiert in vielen Fällen nicht nur aus der setzung dieser Pigur allein, sondern häufig aus der sich anbietenden Verbindung mit anderen Figuren. War es in dem Zovko-Zitat ${ }^{1)}$ die Anapher, so ist es in dem zuletzt zitierten Kuba-Beispiel die Epipher.

DaB die annominatio nicht nur innerhalb eines Verses realisiert wird, zeigte schon das Dizdar I-Beispiel auf S. 60, Nr.149. Als weitere Belege mögen folgende dienen:

Lov lovio Celebija Jovo,

Ulovio lijepu djevojku,...

Bos. vila 1895, S. 315

oder:

Kad mu majka uz besiku pjeva,

Ovako mu majka pripijeva:...

$$
\text { Dizdar I, Nr. } 254
$$

In dem Beispiel:

Soko leti preko grada,

Soko leti i preleti; ...

$$
\text { i.ifrkovit, irr. } 132
$$

handelt es sich um eine stärkere semantische Erweiterung (fliegen - überfliegen). Diese wäre jeaoch insofern überflüssig, als sie in dem vorhergehenden Vers schon enthalten ist. Damit kommt dem zweiten Vers wesentlich formale (improvisatorische) Bedeutung zu.

Eine weitere annominatio per adiectionem ist die besondere Art der Adjektivkomparation mit der Partikel "pre-" im Sudslavischen, die auch in der Sevdalinka zuweiler anzutreffen ist:

1) Siehe S. 60 und S. 60 , Anm. 1. 
"toja sejo, mila i premila,

Kada budes u Yeher Sarajvo, ...1)

Bugarinovit, S. 44 f.

oder, eine ähnliche annominatio, die ebenfalls eine Verstärkung, Bekräftigung beinhaltet:

"Jest mi Cemu, stara majko,

Jest mi cemu $i$ pricemu....

$$
\text { Dizdar I, Nr. } 12
$$

Keinen etymologischen Zusanmenhang wie in den bisher behandelten Beispielen zeigt die annominatio, die die Worte "sam" (1.P8.SB.Präs. zu bíti = seín) und "sáma" (fem. zu såm $=$ allein) nebeneinanderstell $\left.t^{2}\right)$ :

Dođi, dragi, vełeras sam sáma.

"Kad si sama, ja di ti je mama?"

$$
\begin{aligned}
& \text { R.a., inv. br. } 11467 \\
& \text { (vom 20.10. 1957) }
\end{aligned}
$$

Ein ähnliches Beispiel findet sich bei Kuba:

Dodji, diko, dovece sam sama,

Kaico si sama, a gdje ti je mama?

Kuba 1909, S. 589, Nr. 749

\section{b. Annominatio per immutationem}

bei dieser annominatio handelt es sich - wie bei der zuvor untersuchten - zumeist um ein Spiel mit der Etymologie. ilir haben es hier mit der annominatio zu tun, "bei der einzelne lautliche Bestandteile des Wortkörpers durch andere ersetzt

1) Das Bubstantivische Epitheton "לeher Saraj(e)vo" weist dieses Lied sofort als Sevdalinka aus. Vgl. dazu I,14, zum Epitheton.

2) Vgl. dazu auch Follok, S. 94. 
erscheinen. ${ }^{1)}$

Sunce zade a mjesec $\underline{\text { izade }},{ }^{2)}$

Rahman pała u Saraj'vo sad̄e,

Dizdar I, Nr. 224

oder:

Moja Eerko, roda ga odnila,

Loja majko, meni ga donila.

Kuba 1908, S. 412, Nr. 561

Beispiel eins (mit für die Sevdalinka typischem Schauplatz und Person), in dem diese Pigur innerhalb einer Verszeile realisiert ist, und Beispiel zwei, in dem dies in zwei zeilen geschieht, zeigen deutlich, daB diese annominatio - semantisch gesehen - häufig ein Antitheton beinhaltet (untergehen aufgehen; wegtragen - herbeitragen). In beiden Pällen wird bei gleichbleibendem Simplex jeweils das Präfix durch ein anderes ersetzt (etymologische annominatio). Es handelt sich also um ein Spiel mit etymologisch verwandten Wörtern, wobel ein weitgehender semantischer Unterschied bzw. geradezu ein Gegensatz erreicht wird.

Bei einem Nebeneinander von Substantiven in paronomastischer Porm handelt es sich meist um n'yortbildungaparonomasi en ${ }^{3)}$ :

"Sto 11 te mi robce 1 robinja,

"Kad ja nemam sebi gospodara;

Petranovit, Nr. 166

oder:

"Ili volis spenzu nebrojenu?

"Il' cer, draga, roba 11 ' robinju?" - ...

Hak II, Nr. 16

1) Pollok, S. 95 .

2) Graphisch betrachtet handelt es sich auch hier um eine annominatio per adiectionem vel detractionem.

3) Pollok, S. 95. 
Beide Beispiele zeigen die annominatio: rob - robinja, nur daB das erste Wort im ersten Beispiel als Deminutiv (robce) erscheint. Es 18t nicht zuletzt der weitgehende Gleichklang der Worte, der dem Sänger bei der Improvisation entgegenkommt.

N1cht nur Verben und Substantive, sondern auch anaere Wortarten werden in dieser Welse nebeneinandergestellt:

Zlatan mu je jagluk poznavala,

Da je Jovi druga draga dala....

Bugarinovit, S. 39 .

Die Alliteration der in paronomastischer Weise verbundenen Worte wird hier noch durch eine weitere (dala) ergänzt.

Als letzte Gruppe der annominatio per immutationem sollen die preudoetymologischen Wortspiele Erwähnung finden, die "... als Calembourg (Kalauer) den lautlichen Gleichklang bzw. Anklang zweier verschiedener Törter bzw. Gruppen ausnutzen." 1) Diese Gruppe 18t in den Iledern äuBerst produkt1r:

Vir njega sjedi, ter mu besjedi:

Ko ce tI jahat trog dobra konja?

$$
\text { Kuba 1907, S. 630, Nr. } 304
$$

Melst beruht das pseudoetymologische Wortapiel auf einem Spiel mit Namen, was folgendes lied zeigt, das auch heute noch gern geaungen wird:

Bo8a Mara Bosnu pregazila,

Bosnu pregazila,...

$$
\text { Dizdar I, Nr. } 25
$$

oder, bel gleichzeitiger Verwendung einer reduplicatio:

Smilf Smiljana 81 tno smilje brala, Smilfe brala, kroz goru hodila;...

Milanovit III, S. 34 f.

1) Kayser, W., Das sprachliche Kunstwerk, 10. Aufl., Bern-München 1964, S. 110. 
oder, ebenfalls in dreifacher Form:

Nek se smije smilje i bosilje,

Ko nevjerno momce na djevojce....

Dizdar I, Nr. 287

oder:

Neven vene da uvene,

Niene vele da ožene: ...

Nil rkovit, Nr. 3

Hier ist die annominatio per immutationem verbunden mit einer annominatio per adiectionem vel detractionem.

Es folgen noch zwei Beispiele, deren ersteres sich insbesondere durch seine Lokalisierung (Gradacac), sowie durch Verwendung zahlreicher Turzismen als Sevdalinka zu erkennen gibt:

U Gradarcu gradu bielome,

Gradila se biela dzamija....

Dizdar I, Nr. 295

und, verbunden mit einer figura etymologica:

Kad morija morom morijase,

Pomorila i staro i mlado, ...

diilanovit III, S. 118

Oft bedient sich der Sänger dieser Wortspiele auch zur Intensivierung einer emotionalen Aussage:

Bejturane $^{1)}$, Bog t' ubio grane!

Troje grane, po mom srdcu rane....2)

Dizdar I, Nr. 19

1) Skaljit, A., a.a.0., S. 133: "bejturān (begturān) m (ar.) biljka Artemisia annua L.".

2) Dieses Beispiel findet sich wegen des Spieles mit dem Pflanzennamen "bejturan" ausschlieBlich in der Sevdalinka. iieitere Beispiele zu pseudoetymologischen Wortspielen im suidslavischen Liebeslied, vgl. Pollok, S. 97, Goetz, L.K., Volkslied und Volksleben der Kroaten und Serben, Bd. 1, Die Liebe, Slavica, 3d. 12, Heidelberg 1936, S. 152 f., Prodanovic, J.M., Kletva u nałoj narodnoj poeziji, ilaśa narodna poezija (uredio: H.V. Kneževik), Subotica 1928 und Zima, L., a.a.0., S. $286 \mathrm{ff}$. 
Neben Verwuinschungen und Plüchen ${ }^{1)}$, die in den Liebesliedern nicht selten sind ${ }^{2}$, werden durch diese Figur auch wïnsche verstärkt zum Ausdruck gebracht:

Donesi mu u njedrima hlada,

Miloduha, da se milujemo,

Kalopera, da se ne karamo, ...

Hak II, Nr. 18

oder, in einer längeren koordinjerenden Häufung:

Da ti dadem cr'jeta mirisnoga:

Miloduha, da se milujemo,

Karanfila, da se ne karamo,

A ruzice, da se ne ruzimo,

A zambakka, da se zaglédamo.

Davidovit, Nir. $78^{3)}$

Der annominatio kommt, da sie meist innerhalb nur einer verszeile realisiert wird, im allgemeinen eine geringere improvisatorische Bedeutung $2 u$. Sie hat jedoch äuBerst intensive Wirkung. DaB sie im letzten Beispiel dariber hinaus improvisatorische Bedeutung für die Gestaltung eines längeren liedabschnittes gewinnt, liegt weniger an der annominatio als solcher, als vielmehr in ihrem wiederholten Auftreten innernalb jer Figur der koordinferenden Häufung. ${ }^{4}$ )

Eigennamen und geographische Bezelchnungen im pseudoetymologischen Wortspiel verraten oft die Provenienz eines Liedes. ${ }^{5)}$

1) Zu den Plüchen in Volksliedern vgl. den erwähnten Aufsatz von J.M. Prodanovit (8. S. 65, Anm. 2).

2) Vgl. dazu auch Goetz, L.K., a.a.0., Bd.1, S. 1521. Im Hinblick auf die Hochzeitsgeschenke sagt Goetz auf S. 153: "Ganz vereinzelt ist es, daB diese Geschenke ke1ne böse Bedeutung haben.".

5) Ein ähnliches Beispiel siehe auch Petranovit, B., Obicaji srpskog naroda u Bosni, Glasnik srpskog uCenog drustva, $\mathrm{Knj}$. XI, Sv. XXVIII staroga reda, Beograd 1870, S. 203.

4) Vgl. dazu I, 12, zur koordinterenden Häufung.

5) Vgl. dazu zahlreiche Zitate auf S. 64 und S. 65, sowie im folgenden. 
Jedoch darf man dabei nicht voreilig Schlüsse ziehen, da die Lieder wandern und die Namen geändert werden können. i)

Abschließend seien zwei Beispiele gegeben, in denen das pseudoetymologische Mortspiel das Liebeslied deutlich als Sevdalinka ausweist:

"Da te mogu Ufatiti, Pato!

"B'jelo bih ti lice poljubio,...

Vuk V (1898), Nr. 308

Das Hortspiel bedient sich hier der bosnisch-hercegovinischen Dialektform des Verbes "ubvatiti" ("ufatiti") und der in der Sevdalinka häufig anzutreffenden Kurzform des femininen muslimischen Eigennamens "Patima" ("Pata") ("Patima... stur. Patime, Fatma, Zensko ime, ime kteri Wuhamedan ${ }^{2)}$ ).

Und :

Sa prozora ${ }^{3)}$ begu govorila:

"Bjèzi beze, ako Boga mades, ...

$$
\text { Bugarinovit, s. } 33 \text { f. }
$$

Hier wird das Hortspiel mit "bjezi" und dem ähnlich lautenden türkischen Titel "beg" (im Vokativ: beže) durchgeführt.

1) Die Namensänderung kann unbewuBt in nichtmuslimischem Milieu oder bewuBt durch Aufzeichner nichtmuslimischer Herkunft vorgenommen worden sein. Sie begegnet gar nicht 80 selten und oftmals in so naiver Weise, daB sich die ausgewechselten Namen innerhalb des sonst unverändert gebliebenen Wortschatzes der Sevdalinka als Fremdkörper ausnehmen.

Vgl. dazu viele Lieder in Petranovit, Davidovit, den Zeit-" schriften "Bosanska vila", "Gajret" u.a.

2) Škaljit, A., a.a.0., S. 277 .

3) Dies ist übrigens einer der wenigen Fälle, in denen die Sevdalinka die serbokroatische Bezeichnung "prozor" fir "Penster" der ublicheren muslimischen ("pendžer") vorzieht. 


\section{Polyptoton}

"Lockerung in der Flexionsform: polyptoton (...): Die Lockerung der Flexionsform in der wiederholung dient der $v a r$ a $t i o$ : aus dem Gegensatz zwischen der Gleichheit des Wortes und der Verschiedenheit der syntaktischen Punktion wird eine lebendige Wirkung erreicht. ${ }^{1}$ )

Das Polyptoton kommt in der Sevdalinka nicht minder häufig vor als die annominatio und hat wie diese nur eine geringere improvisatorische Bedeutung, da sie meist innerhalb einer oder zweier Verszeilen realisiert wird.

Das Polyptoton findet sich in aller Dichtung ${ }^{2)}$; stellt es in der Kunstdichtung vielfach einen bewubten, versteckten Kunstgriff dar, der vom Leser erst herausgefunden werden muB, so dient es in der Sevdalinka, wie in der gesamten mündichen Volksdichtung, in erster linie der Erleichterung der Improvisation. Der Sänger sucht nicht lange nach einem Synonym oder anderen (z.B. pronominalem) Ersatz, sondern verwendet das sich inm anbietende selbe wort, nur in anderer Plexionsform, sofort noch einmal.

Gewöhnlich tritt das Polyptoton im Iied zusanmen mit anderen Klangfiguren ${ }^{3)}$ auf, am meisten, wie die lintersuchung des Materials ergab. mit der Halbversanapher. Die Wiederholung des Polyptotons mit anderen Wortwiederholungsfiguren kommt jedoch mehr dem Ornatus dieser Lieder zugute, worauf hier nicht weiter eingegangen werden soll.

Häufig findet sich das Polyptoton als Wiederholung des Nomens im Dativ, besonders im Dativ der Anrede:

Katmer sije karanfil divojka, Katmer sije, katmeru besidi: ...

$$
\text { Biser } 1913 / 14 \text {, S. } 283
$$

1) Lausberg $\$ 640$.

2) Vgl. dazu auch Kayser, i., a.a.0., S. 110.

3) Vgl. dazu auch Pollok, S. $100 \mathrm{ff.,}$ sowie Kayser, i., a.a.U., S. 110 f. 
oder:

Je Cam Zele Tuzlanke djevojke,

Je Xam Zele, jeXmu govorile: ...

Dvorovit, S. 24

In beiden Beispielen ist das Polyptoton mit Ganzversanapher und Halbversanapher kombiniert.

Ebenfalls Dativ, aber nicht Dativ der Anrede:

Bajram ide, Bajramu se nadam.

Sta bih dragom bajramluka dala? ...1)

Dizdar I, Nr. 15

Es folgen noch drei Beispiele, die das Substantiv in anderen Flexionsformen wiederholen:

Nom.P1. - Gen./Akk.Sg.:

Svi dilberi! mog dilbera nema!

Al' boluje ali ałikuje? ...

Vuk V (1898), Nr. 288

Nom.Sg. - Gen.Sg.:

Sitan kamen do kamena,

Rosna trava do koljena, ...2)

Rubit XXV, Nr. 6

Direkt, d.h. iterativ aufeinanderfolgend im

Akk.Sg. - Gen.Sg.:

No mi rasti vrhom u visine,

Da se popnem na vrh vrha troga,...

Bos. vila 1887, S. 317

1) Vgl. dazu dasselbe Beispiel in Novi behar 1941/42, S. 42.

2) Der Kunstgriff, eine größere Anzahl von Personen oder Gegenständen in polyptotischer Umschreibung mit "do" (hier: Stein a $n$ Stein) auszudrücken, ist sehr beliebt und findet sich dementsprechend häufig. Ein weiteres Beispiel mag dazu noch ange führt werden:

Sve se b'jeli tador do Xadora,

Sve se vije bajrak do bajraka $\frac{\text {.... }}{\text { Dizdar I, }} 130$ 
Die bisher gegebenen Beispiele zeigten das Polyptoton innerhalb einer Verszeile. In den folgenden wird es in verschiedenen Verszeilen realisiert:

Gen./Akk.Sg. - Vok.Sg.:

Majka Muja po kahvama trazi:

"Sine ujo, Ziv ne bio majci! ...

Vasiljevit, Nr. 68

Gen.Sg. - Lok.Sg.:

"Jesi li sade iz Bosne?

Kakvi je adet u Bosni? ...

Vuk V (1898), Nr. 545

Polgendes Lied bedient sich in seinen drei Einleitungsversen eines dreifachen Polyptotons, jeweils vom selben Wortstamm gebildet:

Draga dragom na ruci zaspala,

Dragi dragu alkatmerom budi:

"Ustaj, draga, draza od otiju, ...1)

Dizdar I, Nr. 57

oder:

Bul djevojka pod dulom zaspala,

끈 se kruni pa djerevojku budi.

Devojka je dulu govorila:

"A moj dule, ne kruni se na me, ...

Milanovit I, Nr. $91^{2}$ )

Hier findet sich das Polyptoton in vier aufeinanderfolgenden Versen (1. zweimal im Nom.Sg. (einmal davon als substantivisches Epitheton; vgl. dazu I, 14), einmal im Instr.Sg., einmal im Dat.Sg. und einmal im Vok.Sg.; 2. zweimal im Nom.Sg. und einmal im Akk.Sg.). Dieses Beispiel darf als besonders charakteristisch für die Sevdalinka gelten, einmal wegen der Ver-

1) 2u dem Polyptoton "draga - draza" siehe weiter unten.

2) Unterschiedliche Schreibweise ein und desselben Wortes (djevojka - devojka) innerhalb eines (!) Liedes findet sich in den Nilanovit-Sammlungen des öfteren.

Vgl. auch die Vorbemerkung zu Teil III. 
wendung von "dul" als substantivisches Epitheton, zum anderen aber auch, weil es uns an einen typischen Schauplatz der Sevdalinka (den Garten, Rosengarten) versetzt.

Neben Substantiven werden auch andere Hortarten in polyptotisch abgewandelter Form wiederholt.

a. Adjektive:

Innerhalb einer Verszeile:

Nom.Sg.m. - Nom.Sg.f.:

U Sarajeva pod Babila ${ }^{1)}$ dvoru -

Zelen Cador 1 zelena trava ...

Bo8. vila 1894, S. 107

Innerhalb zweier Verszeilen:

Gen.Sg.m. - Gen.Sg.f.:

Brez careva oitnoga fermana,

Brez pałine sitne bujruntije, ...

Bos. vila 1895, S. 300

oder:

Nom.Sg.m. - Gen.Sg.1.:

Na glavi mu bijel kalpak,

Od b'jele svile, ...

Kuba 1908, S. 120, Mr. 379

Bellebt ist auch die Adjektivoteigerung in polyptotischer Porm:

"T1 81 ljepsa 1 od dul-ruzice,

"T1 81 bjelja 1 od bjelog snjega, ...

Rist1l, Nr. 13

oder:

Sama ajedi hitar vezak veze

Hitro veze, hitrije izveza...

Zovko II, 2, Nr. 12

1) Der Hame "Babil" 18t eine Ableitung von der aus dem Fersi8 chen uber das Türkische ins Serbokroatische gelangten Bezelchnung fur "otac" ("babo" = "Vater").

VGl. dazu Skalj16, A., a.a.0., S. 109. 
oder iterativ aufeinanderfolgend:

"I da krijem, sakriti ne mogu,

"Jer si dragi drazi od otiju!"

$$
\text { Ristik, Nr. } 3
$$

Diese Form des Polyptotons wird in einem bestimmten iiedkreis gern als Endglied eines längeren Vergleichs verwandt:

"Sire je nebo od mora sinjega,

Brze oti od konja viteza,

Drazi dragi od brata jedina."

$$
\text { Dizdar I, Nr. } 240^{1)}
$$

b. Substantiv und zugehöriges Adjektiv werden gleichzeitig polyptotisch wiederholt:

Akk.Sg. - Vok.Sg.:

Asanaga vjernu ljubu kara:

nvjerna ljubo, sam te bog ubio...

Vasiljevit, Nr. 381

oder:

Akk.Sg. - Nom.Sg.:

Kupicu ti zutu tunju, da jedes.

Sto ke meni zuta tunja, da jedem.

Da ja zutim k'o $i$ tunja za tobcm.

Kuba 1907, S. 631, Nr. 312

In diesem Falle erscheint das Polyototon in $z w e i$ Versen. Das letzte Beispiel dieser Gruppe enthält neben den Wortspiel "Zuta tunja - da ja zutim" Eleichzeitig die Sonderform des Polyptotons "jedeł - jedem", die zu der nächsten Gruppe überführt:

1) Vgl. dazu auch Behar 1905/06, S. 314; 1908/09, s. 13 und öfter. 
c. Das Polyptoton in Form von verschiedenen Verbalendungen:

Innerhalb e i $n$ e $r$ Verszeile (plus annominatio per adiectionem vel detractionem):

Snijeg pade, drumi zapadose,

Dragi dragoj doti ne mogase, ...

Ristit, Nr. 23

Innerhalb $z$ w e $i$ e $r$ Verszeilen (plus iteratio und reduplicatio):

"Bolujes. Mujo, bolujes?"

"Bolujem, draga, a sto ku?" ...

Kuba 1906, s. 361 , Nr. 34

d. Auch ein Verb, das als Gerundium wiederholt wird, stellt insofern ein Polyptoton dar:

Dvie druge vjerno drugovale,

Drugujuti bostan posadile: ...

$$
\text { Dizdar I, Nr. } 63
$$

oder:

Tri putnika putem putovase,

Putujuci sretoße djevojku ....

$$
\text { Kuba 1909, S. 127, Nr. } 424
$$

Wie aus den Beispielen hervorgeht, tritt diese Form des Polyptotons zumeist als reduplicatio auf, d.h. an versende und Versanfang.

Einen gröBeren Raum als zwei Zeilen überspannt das Polyptoton kaum. Deshalb nat es nur - wie oben erwähnt - eine geringere improvisatorische Bedeutung.

Das letzte Beispiel enthielt gleichzeitig eine figura etymologica (putem putovase), die im folgenden Abschnitt behandelt werden soll. 
"Die in der Neuzeit figura etymologica genannte und in der Antike der derivatio (...) zugerechnete (...) Stammiederholung (...) dient der Intensivierung der semantischen Kraft $(\ldots): \ldots n^{1)}$

Obwohl die figura etymologica oft als Sonderform der annominatio behandelt wird ${ }^{2}$, soll sie in dieser Arbeit gesondert untersucht werden, weil sie, was ihre Prequenz in den untersuchten liedern betrifft, eine der wichtigsten Figuren ist. In manchen Fällen wird diese Figur so stereotyp gehandhabt, daB sie Pormelcharakter annimmt. Dieser wird noch dadurch unterstrichen, dab die figura etymologica vom Sänger gern am Liedanfang verwendet wird. Dabei stellt folgende eine der für die Sevdalinka typischsten Einleitungsformeln dar:

Vezak vezla Turalita Pata,

Na krilu joj gjergjef od merdzana, ...

$$
\text { Kurt, Nr. } 62
$$

Findet sich diese figura etymologica auch in den Liebesliedern anderer Gegenden Jugoslaviene, so erfreut sie sich doch in der Sevdalinka besonderer Beliebtheit, was insofern verständlich wird, als es eine der Hauptbeschätigungen des muslimischen Mädchens war, hinter dem Stickrahmen am Fenster zu sitzen und dabei zu singen. So wird gerade der Stickrahmen

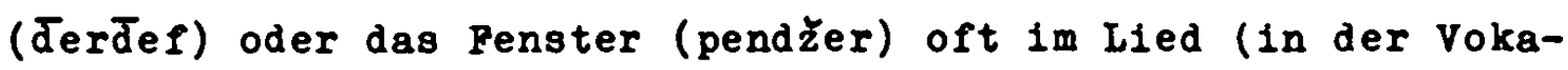
tivform) angerufen, da sie einige der wenigen Dinge darstellen, mit denen ein unverheiratetes muslimisches Mädchen nkommunizieren" konnte. Daher trifft man im bosnischen liebeslied nicht selten auf solche oder ähnliche liedexpositionen, wovon

1) Lausberg, H., Elemente der literarischen Rhetorik, 2. Aufl., München 1963, \$281.

2) Kayser, T., a.a.0., S. 110: "Unter Paronoma $\mathrm{s} i \mathrm{e}$ (annominatio) versteht man das Vorkommen gleichklingender Wörter. Dazu gehören etwa die Pälle des "inneren" objektes (to live a life, einen Gang gehen, ....)." 
noch eine bier angeführt sei:

Vezak rezla Adem-Kada, mlada nevjesta,

Na Cardaku, na visoku džamli pendžeru...

Dizdar I, Nr. 309

Hier wird dariber hinaus noch der "Cardak", der obere Teil des muslimischen Hauses, erwähnt, was wiederum sofort auf ein Lied städischer Herkunft hindeutet. ')

Eine weitere für die Sevdalinka charakteristische figura etymologica am Liedeingang ist folgende:

Bol boluje lijepa Pahira

Pod orahom 1 pod jorgovanom; ...

Orahovac, S. 111

Wie der annominatio und dem Polyptoton kommt der figura etymologica nur eine geringere improvisatorische Bedeutung zu. 2)

Die verschiedensten Wortarten können in dieser Pigur nebeneinandergestellt werden. Im folgenden sollen dazu nur einige Beispiele gegeben werden, die für die Sevdalinka besonders typisch sind und teilweise nur in diesem lied vorkommen. ${ }^{3)}$

Am häufigsten ist der Fall, bel dem Substantiv und Verb in Form einer figura etymologica verbunden sind:

1) Vgl, dazu auch Goetz, L.K., a.a.0., Bd. 2, S. 202 oder Pollok, S. 231, wo es heiBt: "Durch die Details der materiellen Kultur ( (ardak, dicke Matratzen u.ä.) welst sich das Beispiel im übrigen als ein Lied levantinischstädtischer Provenienz aus, ...".

Auf solche Worte, Güter der materiellen Kultur bezelchnend, trifft man in der Sevdalinka als einem Stadtlied sehr häufig. Im Laufe der Arbeit wird noch öfter darauf hinzureisen sein. Vgl. dazu besonders I, 12, zur koordinierenden Haufung. Zu den Stickarbeiten vgl. auch Goetz, L.K., a.a.0., Bd. 2, S. 133.

2) Pollok führt zwar auf S. 107 f. den Extremfall eines (kajkavischen) Liedes an, das sich ron Anfang bis Ende dieser Pigur bedient; ein solcher Fall aber konnte in dem untersuchten bosnisch-hercegovinischen Liedmaterial nicht konstatiert werden.

3) Weitere Beispiele vgl. Zima, L., a.a.0., S. $283 \mathrm{ff}$. und Pollok, S. 105 ff. 
Soko let1 sridom Sarajeva,

Trazi lada, di te ladovat1, ...

Rubit XXIII, Nr. 48

oder, alo redditio:

Sevdi, dragi, troje sevdisanje,

Ubilo te moje uzdisanje! ...

$$
\text { Dizdar I, Nr. } 240
$$

Oder, als 1teratio:

"Šut1, teri, mukom zamuknula!

Kovilica, je vlainja rodila...

$$
\begin{aligned}
& \text { R.a., inv. br. } 11474 \\
& \text { (vom 22. 10. 1957) }
\end{aligned}
$$

oder, ebenfalle als iteratio und typisch fur die Sevdalinka:

Stono dolje u Earłiju telal telali?

Na kocij1 duzel moma, te se prodava,...

$$
\text { Magarazev1t, S. } 296
$$

oder, als Homonymie:

Ja mioli misli svakojake

Il tu ljubit mladu nevisticu...

Erlangenski rukopis, Nr. 102

oder, glelchzeitig mit einer annominatio por aalectionem vel detractionem und einer annominatio per immutationem verbunden:

Ne Zin $_{\text {ind }}$, ne mami mi sina,

Gotor' 81 ga mamom pomamiti

I njegor ordce primamiti.

Jurcil, Nar. uz., Kal. 1944, S. 12 á

Daneben werden auch Substantiv und Adjektiv stammilederbolend verbunden:

O I vana cudno cudo kažu,

Malo polja, al' je plemenito...

Tordinac, Nr. 33 
oder:

Joł je slaōa Hałap1ja devojka,

- Moja draga, moja slatka sladijo, ...1)

Vasiljevit, Nr. 196 a

oder:

U Seheru Seherli ahari,

Po njem ఈeta Šehova kaduna, ...2)

Vuk V (1898), Nr. 405

Auch Verb und Adjektiv werden etymologisierend nebeneinandergestellt:

Palilase 3) faljena djevojka

Sit'ne zvizde sneba ${ }^{4}$ sabajat...

Erlangenski rukopis, Nr. 42

oder:

S vecer' sjala sjajna mjesecina,

Obasjala zelenu livadu....

Drorovit, S. 17

oder, dasselbe Beisplel, in dem die stammwederholenden Worte eine redditio bilden:

Sjajna zvizdo, bje si sinot siala?

"Ja sam sjala viłe Sarajeva....

Kurt, Nr. 165)

1) Dasselbe Beispiel vgl. Zovko I, Nr. 76:

"o djevojko, moja slatka sladijo, ..."

2) "šeher" kommt aus dem Pers1schen über das Türkische ins Serbokroatische, bedeutet soviel wie "große Stadt" und wird bevorzugt als substantivisches adjektiv in Verbindung mit Sarajevo gebraucht.

Vgl. dazu I,14, zum kipltheton.

3) = falila se.

4) $=8$ neba.

5) Dasselbe Lied zitiert Grgec auf S. $128 \mathrm{f}$. 
oder:

Biela sam, nabielit' bu se;

Rumena sam, narumenicu se....1)

Dizdar I, Nr. 200

Die etymologiolerende Stammiederholung kommt auch vor in der Verbindung von Adverb und Substantiv:

Dok obutem sebitno od'jelo,

Doku nokas notu u po noti....

Hovi behar 1930/31, S. 204

oder:

Kad ujutro jutro osvanulo,

Podgrifalo Zareno sunce,...2)

$$
\begin{aligned}
& \text { R.a., inv. br. } 10434 \\
& \text { (vom 20. 6. 1960) }
\end{aligned}
$$

Polgende figura etymologica, die Verb und Adverb verbindet, ist besonders als Liedeinleitung beliebt:

¿ija je ono djevojka

Sto rano rani na vodu? ...

$$
\text { Kuhat I, Nr. } 19
$$

Sie findet $81 \mathrm{ch}$ aber auch im Liedinnern:

Za njom Mujo sitno cucukare:

"Jes' 11, Pate, rano uranzla?" ...

$$
\text { Vuk V (1898), Nr. 3973) }
$$

1) Vgl. dazu Pollok, S. 108, Anm. 38: "WeiBe und rote Schminke aind Dinge, die für die atädtisch orientierten lieder, insbesondere der moslimisch-türkischen EinfluBsphäre typisch sind."

2) Diese figura etymologica findet sich sehr häufig. Vgl.auch:

Kad u jutro jutro osvanulo Majka zove hodze 1 hadzije; ...

$$
\text { Novi behar 1934/35, S. } 16
$$

3) Wie sehr diese Pigur formelbaften Charakter hat, wird daraus ersichtlich, daB die figura etymologica "Jesi li rano uranila" als GruBformel verwendet wird. Vuk St. Karadzit sagt dazu: "Sruda po Hercegovacki jem krajevima, kad se sastanu, mjesto da se upitaju, kako si? reku: jesi l' uranio? a kako si ti?" (Vuk V (1898), S. 294, Anm. 36). 
Jeitaus seltener in den liedern 1st der Pall, dab zwei 11gurae etymologicae unittelbar nacheinander gebraucht werden. Sie können in zwei Verszellen reallsiert werden, we das Dizdar-Beispiel auf S. 78 zeigte, oder auch in $\mathrm{e} i \mathrm{n} r$ Zelle:

Zora zori, rosa rosi,

Pustaj me draga, da 1dem." ...

$$
\text { Blagajit, Nr. } 13
$$

in Varianten $z u$ diesem Lied ${ }^{1)}$ wird verschiedentlich die zwelte figura etymologica folgendermaßen geändert:

Zora zori, pietli poju,

Pusti me, draga moja, ...

$$
\text { Dizdar I, Nr. } 331
$$

1) Es handelt $81 \mathrm{ch}$ um die Varianten eines Iledes, in dem der Bursche auf verschiedenste Art sein Mädchen darauf aufmerksam macht, daB es Zeit sei, das er von thr gehe. Dieses aber will ihn noch bel sich halten und seine Einwände meist mit einem "Wortspiel" entkräften. Auf den Einwand, daB das Morgenrot schon leuchte, sagt es: "nije zora, vel je hora", oder auf den Einwand, das der Morgengebetsruf (ezan) schon zu hören se1, antwortet es: "nije ezan, vel murtezan" (männl. Vorname) u.ä.

Vgl. dazu Dizdar I, Nr. 331. 
11. Synonymie

"Die Lockerung der Gleichbeit hinsichtlich des Wortkörperganzen besteht darin, das bei der Wiederholung nicht das gle1che Wort, sondern ein anderes Wort benutzt wird. Damit uberhaupt elne Einreihung des Phänomens in die > Wortwiederholung< erwogen werden kann, mu das als Wiederholung aufgefaBte Wort mit dem ersten Wort in einem Synonymen-Verhältnis stehen: es wird also die gleiche Wortbedeutung, aber mit verschiedenem Wortkörper wiederholt.

Die Wiederbolung der gleichen Wortbedeutung mit verschiedenem Wortkörper kann in allen Wortwiederholungsweisen (...) vorkommen und wird mit dem allgemeinsten Terminus g y $\mathrm{n}$ o $\mathrm{y}-$ m 1 a ... bezeichnet...." ${ }^{1)}$.

Da es elne völlige Bedeutungsgleichbeit von Worten nicht gibt, es sich also nur um bedeutungsähnliche wörter handelt ${ }^{2}$, 1st der Ubergang von einer Synonymie - zumal wenn innerhalb dieser Plgur mehr als zwei Glieder verbunden werden - zu einer koordinierenden Häufung flieBend. 3 )

Auch die Synonymie hat ihre nicht zu unterschätzende Bedeutung für die Improvisation der lieder: der Sänger verschafft sich zeit, indem er dasselbe noch einmal nur mit anderen Worten zum Ausdruck bringt. Je mehr Glleder dabel die Synonymie aufwelst und je gröBer der Umfang dieser wederholten Glieder ist, desto größer 1st auch ibr Wert für die Improvisation.

Der einfachste Pall einer Synonymie liegt vor, wenn zwei Glieder asyndetisch miteinander verbunden werden und so das

1) Lausberg $\$ 649 \%$

2) Vgl. dazu auch Kayser, T., a.a.0., S. 113.

3) Vgl. dazu Lausberg $\$$ 651: "Der semantische Unterschied der Synonyme kann in überbietender Weise auch selbst so gesteigert werden, daB er zur aufzählenden Koordination oder zum (gewollten) Gegensatz oder zur (gewollten) chaotischen Beziehungslosigkeit wird, wodurch sich die Synonymie in andere Piguren auflö日t $(\ldots)$. "

Vgl. dazu auch Lausberg $\$ 666$. 
Ausgesagte intensivieren:

A on ment odgovara

Tuzno zalosno: ...

$$
\text { Blagajic, Nr. } 31
$$

oder:

Da ne pijem rujna vina,

Rujina rumena, ... 1)

Kuba 1906, S. 363, Nr. 49

Häufig bewirkt diese Synonymie gleichzeitig eine stärkere semantische Verschiebung:

Stan' pricekaj, djevojcice,

Moraz moja biti! ...

$$
\text { Dizdar I, Nr. } 120
$$

oder, typisch für die Sevdalinka:

Truhne, vehne srce $u$ menika,

Sad pocela dzigerica b'jela! ...

$$
\text { Milanovit I, Nr. } 101
$$

Ist jedoch die zweigliedrige Synonymie syndetisch verbunden, erscheint die Bedeutung weniger differenziert:

Rada place i lelece:

- Vrati mene moje Cevre, ...

Vasiljevil, Nr. 400

oder:

Je l'ti tuga i nevolja draga?

- Jes mi tuga i nevolja dragi, ...

Kuba 1906, S. 499, Nr. 65

oder:

Samo zlato zbori i govori:

"Ljepłeg beza nema od meleza, ...

Bo8. vila 1895, Nr. 124

1) rujno vino = Rotwein; rumen $,-a,-0=$ rot. $V_{g l}$. aber auch Karadzit, V.St., Srpski rjecnik, istumacen njemackijem i latinskijem rijecima, 4.izd., Beograd 1935: "rujno vino = gelblicher Wein, vinum fulvum." (fulvum = rotgelb). 
oder, ähnlich:

- ¿ujer lno, cujer duso, sta tice vele?

-Tice vele 1 govore da se żenim ja....

Lulozerit IV, S. 412, Nr. 400

Bei einer syndetischen bzw. polysyndetischen Wlederholung oynonymischer Wörter können gleichzeitig ganze Satzabschnitte wiederaufgenommen werden:

"Heg' se topi srce u junaka,

"Kad te ridi $1 \mathrm{kad}$ te pogledi, ...

Ristit, Nr. 13

Hatte die bigher angefubrte Synonymie allein ihres geringen Omfangs wegen nur einen geringeren improvisatoriachen Wert, so kommt der Synonymie, die zwel Verszeilen erfaBt, eine in dieser Bezlehung gröBere Bedeutung zu, die oft noch dadurch erhöht wird, dab die Glieder dieser Synonymie auBerdem anaphorisch oder epiphorisch miteinander verbunden sind. Nicht selten wird dabel die Zusammengehörigkelt beider verse zudem durch ein Isocolon gestiutzt.

Anaphorisch:

Bosa Rosa rosu pragazila, (81c!)

Bosonoga pari dolazila: ...

Kuba 1906, S. 507, Nr. 114

Epiphorisch plus Isocolon:

Puhni, vjetre, pa mi razbi derte!

Puhni, lade, pa mi razbl fade! ...1)

MH VII, Nr. 36

1) Hier liegt jeweils ein Binnenreim vor: "derte" zu "vjetre" und "jade" zu "lade". Obwohl die Synonymie hier in der Wiederholung des muslimischen (persischen) Wortes "derte" durch das serbokroatische "jade" besteht, handelt es sich nicht um eine völilge Bedeutungagleichheit. Vgl.dazu Gesemann (Gezeman G., 0 bosanskdm sevdalinkama, Prosveta, God.XXI, Br.10-11-12, Sarajevo 1937, S.682 1.: "Jugoslovent ou uzeli 1 nekoliko Cuven. sevdalinskih rect 1 12raza iz turskog jezika, na primer "dert" Srak1 Jugosloven zna łta je dert,...ne, dert je nełto drugo, mnogo komplikovanije,... dert je strastan 1 bolan Ijubaval osecaj, 1 u isto vreme nekakav opsti Weltschmerz, - dert je $k$ nisam vise u stanju da trpim bol 1 "zal" zbog ljubav1 pa $8 e$ opijem, pa, evo, bacim ova cału vina na pod lli o zid: "Od de ta bih otrov pio," kaže jedna sevdalinka,dakle otrov, a ne sa vino....". 
Verbindung von Synonymie mit Ganzversanapher und Halbvereanapher:

Vidio sam, Yto vidio n'jesam, a

Gledao sam, rto gledao n'jesam...

Zovko II, 1, Nr. 228

Oft setzen sich die synonymisch wiederholten Glieder aus neglertem, urspringlichem Antitheton zusammen:

"Koja be mi biti od vas ljuba?"

Sve djevojke sute, ne govore, ...

Ristie, Nr. 11

oder, ähnlich 1m Imperativ:

Sut', ne placi, Eeri moja,

Nisi ljudana: ...

$$
\text { Blagajil, Nr. } 30 \text { u.a. }
$$

Die Synonymie kommt auch in Porm einer periphrastischen Wiederholung des ersten Gliedes vor. Diese periphrastische Synonymie beansprucht zu ihrer Realisierung einen gröBeren Raum. Damit steigt auch ihr Wert fur die Improvisation eines Liedes:

Je li zora, je li svako') sunce

Mogu l' doti di sam pomislio,...

$$
\begin{aligned}
& \text { R.a., inv. br. } 11467 \\
& \text { (vom 20. 10. 1957) }
\end{aligned}
$$

oder:

o Bogati, Pato Livankinjo!

Odakle si, Zijega si soja?"

$$
\text { Gajret 1911, S. } 212
$$

Wurde der Gedanke in den letzten beiden Beispielen innerhalb e i e $r$ Verszeile wiederholt, so zeigt das folgende Zitat eine synonymische Wiederholung uber $z$ e $i$ Verse, gestuitzt durch ein Isocolon:

1) = je I' svanulo sunce. 
Plko ne zna, da je Zenska glava,

srako misli, da je muska glava....

$$
\text { Bo8. vila 1892, S. } 73
$$

Des ofteren findet sich in der Sevdalinka folgende periphrastische Synonymie:

o jeleku bez kaftana,

Raspasana, bez pojasa, ...

$$
\text { B08. vila 1906, S. } 315
$$

Im folgenden Beispiel gehen der Synonymie "raspasana, bez pojasa" noch zwei weitere, ähnliche voraus, so daB eine koordinierende Häufung entsteht, die nicht zuletzt wegen ihres starken Parallelismus fur die Improvisation von Bedeutung 18t:

Bosonoga, bes papuca, Gologlava, bes fesika, A raspasa, bes pojasa....

Bart6k/Lord, Nr. 20 


\section{a. Exkurs: Homonymie}

Nur in einem Exkurs soll hier noch auf die homonymische Wiederholung eingegangen werden. Die Homonymie besteht in "einer Wiederholung gleichlautender Wörter von unterschiedlicher Bedeutung. "1)

Meist handelt es sich im Serbokroatischen mehr um eine "graphische" Homonymie, da die in dieser Pigur wiederholten Norte in den meisten Pällen verschiedene Akzente tragen. Akzentverhältnisse spielen hauptsächlich in der gesprochenen Sprache eine Rolle und sind daher bei der Volksdichtung als mündlicher Dichtung nicht auBer acht zu lassen.

Im folgenden einige Beispiele für homongmische wiederholung:

Sinot sam sâm sjedetki mislio, N'jesam drage za godinu vidio,...2)

Zovko II, 4, Nr. 114

Oder eine Homonymie in Form einer redditio:

Oganj gori u zelenoj gdri.

Xo $l$ 'ga lozi, ko $I$ ' se na njem grije? ... 3)

Kuba 1909, S. 305, Nr. 640

Dieses sind gleichzeitig Beispiele für die seltenere Homonymie etymologisch nicht verwandter Wörter.

Etymologisch verwand te Wörter wiederholt dagegen folgende Homonymie:

Šahin pała Šahu ljubu Ijubi,

Ne ljubi je, ko se ljlabe ljabe....

$$
\text { Zovko II, 3, Nr. } 109
$$

1) Pollok, S. 112. Vgl. dazu auch Lausberg \$8 658-659, zur traductio.

2) Dasselbe Beispiel siehe auch Vuk I (1953), Nr. 471.

3) Dieser Vers dient einer ganzen Gruppe von Varianten als Einleitung. Vgl. etwa auch die Lieder Kuba 1910, S. 530, Nr. 929 oder Novi behar 1941/42, S. 69 u.a. 
oder:

Ja misli mîsli svakojake

Il cu ljubit mladu nevisticu....

Erlangenskd rukopis, Nr. 102

oder:

"Moja draga, moja dragē sladijo,

Ko ti je tako slatko ime nadio,...

$$
\text { Saulie, S. } 45 \mathrm{f.}^{1)}
$$

Hier bilden die Homonymie gleichlautendes Substantiv urd ldjektiv, jeweils in der femininen Form.

Heist werden nur zwei Worte homonymisch verbunden und dann in Porm einer geminatio (iteratio). Es findet sich aber auch der Pall, daB die die Homonymie bildenden Worte in zwei aufeinanderfolgenden Verszeilen stehen.

Hier in epiphorischer Porm, (als Homonymie) einen identischen Reim bildend:

Ja joj rekoh 1 dva 1 tri plata:

"Draga moja, ukloni se s plata!"

Ne ste mi se ukloniti s phta.... 2)

$$
\text { Ristit, Nr. } 34
$$

1) Der Vergleich des Geliebten mit "SüBem" oder "Zucker" ( $\nabla$ gl. dazu auch I,14, zum Epitheton) ist fur die Sevdalinka charakteristioch. In dem untersuchten Material beginnt eine ganze Variantengruppe (vgl. dazu III, 32) mit elnem solchen Vergleich: Majka kara Sećer Salihaga:...

2) Diese homonymische Wiederholung findet oich in einem ganzen Variantenkreis. Vgl. dazu II,9, sowle III, 33. 
II. Piguren der Häufung

\section{Koordinterende Häufung}

Eine der wichtigaten Piguren der Häufung ist die koordinterende Häufung: "Die koordinierende Häufung besteht in der Hinzufügung von Satzgliedern, die einem der im Sprechakt gesetzten Satzglieder semantisch und syntaktioch koordiniert sind." 1 )

Die muslimiache Sevdalinka liebt eine uberschwengliche, reiche Beschreibung. Das durfte einer der Grinde sein, weshalb sie sich gern und vielleicht in stärkerem MaBe als die übrige serbokroatische Volksliebeslyrik Reihungen und Aufzählungen von Einzelworten und Gedanken bedient.

Die einzelnen Glieder der koordinierenden Häufung können asyndetisch, syndetisch und polysyndetisch miteinander verbunden werden. Ein kollektiver Oberbegriff braucht nicht gesondert zum Ausdruck gebracht zu werden. Wird er dagegen angefuhrt, so kann er den Gliedern der koordinierenden Häufung voran- oder nachgestellt werden.

Die Intensität der Aussage, die durch Verwendung einer koordinierenden Häufung errelcht wird, wird nicht selten durch den gleichzeitigen Gebrauch anderer Piguren - zumal des IsocoIons - verstärkt.

Bei der Improvisation der lieder kommt der koordinierenden Häufung eine groBe Bedeutung zu. Durch Aufzählungen und Aneinanderreihungen ähnlicher Worte, Begriffe und Gedanken verschaff sich der Sänger Zeit, den weiteren Verlauf des Liedes zu konzipieren.

Bei koordinierenden Häufungen, die sich über einen längeren Liedabschnitt erstrecken, muß unterschieden werden, ob aie konstruktiven Charakters für die Gestal tung des gesamten Liedes sind oder lediglich eine liederweiternde, überschwengliche Aufzählung darstellen. Allgemein darf jedoch gesagt werden, daB der Wert der koordinierenden Häufung für die Improvisation der Lieder stelgt, je gröBer der Raum ist, den diese Pigur einnimmt.

1) Lausberg $\$ 666$. 
Den geringsten improvisatorischen Wert hat die koordinierende Häufung, die zwel Einzelworte syndetisch oder asyndetisch ohne Nennung des Oberbegriffes aneinanderreint:

"Koji ide morem i Dunavom,

"I trguje dibom 1 kadivom."...

$$
\text { Ristil, Nr. } 26
$$

oder:

Bol boluje liepa Hajrija,

Pod orahom 1 pod jorgovanom....1)2)

$$
\text { Dizdar I, Nr. } 23
$$

In dieser koordinierenden Häufung wird jeweils auch die Präposition wiederholt. Dem zweiten Glied (pod jorgovanom) kommt, da es sich um ein Beispiel aus improvisierter Volksdichtung handelt, im wesentlichen versfüllende Bedeutung $z u$, wohingegen es in der Kunstdichtung symbolischen Wert annehmen könnte (zeitlich: Herbst - Prühling, bzw. lokal: uberall).

I Cetiri konja uvezana, Dva su tugja, dva njegova nisu...

$$
\text { Kuba 1907, S. 250, Nr. } 227
$$

Hier lst der Kollektivbegriff (vier Pferde) vorangestellt.

1) Vgl. auch Nov1 behai 1931/32, S. 125.

2) Ein fast gleichlautendes Beispiel murde schon auf S. 75 angefuhrt. Dort murde es aus der Sammlung von S. Orahovac zitiert, der die Mehrzahl der Iieder aus anderen Sammlungen übernommen hat, ohne die jeweiligen Fund stellen genauer anzugeben. Somit ist diese Sammlung für eine wissenschaftliche Arbeit, besonders wenn es in dieser auf die Entstehungszeit der Lieder ankommt, unbrauchbar. Erschwerend kommt noch hinzu, daB Orahovac aus dichterischer Ambition nicht nur kleinere Änderungen vorgenommen hat, sondern durch willkürliche Kontaminationen von verschiedenen Liedern jeweils die seiner Meinung nach "schönste Passung" konstruiert hat. -

Diese Kritik stützt sich auf einen eingehenden Vergleich zwischen der Orahovac'schen Sammlung und dem Ubrigen bosnischhercegovinischen Liedmaterial. Die Verse auf S. 75 konnten deshaib aus Orahovac zitiert werden, weil sie wenig verändert sind und es auf eine temporale Bestimmung dort nicht ankam. 
Die beiden Glieder der koordinierenden Häufung folgen asyndetisch in Form einer Halbversanapher, wobei der Oberbegriff in scherzhafter, scheinbar antithetischer Form aufgegliedert wird (zwei sind fremde, die anderen beiden nicht seine eigenen).

Im nächsten Beispiel wird die koordinierende Häufung ebenfalls innerhalb einer Verszeile realisiert; dem vorangestellten Kollektivbegriff (rod) folgen hier mehr als zwei Glieder, die polysyndetisch angeordnet sind:

"Naj ti prsten, momle, moj te rod ne voli.

Ni otac ni majka, ni brat ni sestrica.

$$
\text { Dizdar I, Nr. } 47
$$

oder, ähnlich:

Iz te case do tri strucka zalievam:

Djule: katmer i albaber 1 ruze.

$$
\text { Blagajic, Nr. } 5
$$

Blumennamen werden auch im folgenden Beispiel koordiniert, hier in Form einer (asyndetischen) Aufzählung. Der kollektive Oberbegriff wird nachgestellt: ${ }^{1}$ )

Miloduha, kalopera, lala,

Bosioka, ruza, karamfila

I ostalog cr'jeta mirisnoga...

Novi behar $1930 / 31$, S. 76

Handelte es sich in den bisher gegebenen Beispielen um Aufzählungen, die einen kleineren Raum in den Liedern einnehmen, so sollen jetzt solche angefüht werden, die sich - polysyndetisch oder asyndetisch - über längere liedabschnitte erstrecken, wodurch sich ihr Wert für die Improvisation beträchtlich erhöht.

Polysyndetisch verbunden ist folgende längere Aufzählung (ohne Setzung des Oberbegriffes):

1) Die Nachstellung des Oberbegriffes findet sich in den Liedern seltener. 
Dok je ment mog fesa na glavt,

Ne bojim se cara ni vezira,

Ni dzemata do carevih vrata,

N1 muftije, koji fetru daje,

N1 kadije, koji rasugjuje.

$$
\text { Kuba 1907, S. 104, Nr. } 129
$$

Häufig findet sich auch der Pall, daB nur das letzte Glied elner Aufzählung oyndetisch, die restlichen dagegen asyndetisch angeordnet sind:

Donos1 joj svakake ponude,

S mora smokve, sa Carłije halve,

Iz Stambola beterove glave,

Zute tunje u medu varene,

Gurabije na suncu pectene,

Baklaveta, na njemu janjeta,

I bureka na burmu savita....

Kuba 1906, S. 359, Nr. 25

Durchgehend aoyndetische Reihung weisen dio Glleder folgender, durch ein Isocolon verstärkter koordinierender Häufung auf:

U mene ou dvori pilitati,

O mene su konji nekovat1,

O mene je cova nerezata,

o mene su dizije bisera."...

Popovit-Rodoljub, Nr. 13

Besondere Beachtung verdient folgendes lied, das noch heute - leicht verändert - oft zu hören 18t:

Vino piju age Sarajlije,

Na Ilidzi pokraj Zeljeznice:

Dva Morita, 1 dva Dżindzafita,

Sa Bistrika do dva Dženetica,

s Cobanije dvie Turhanije,

S Čeirdzika dvie thuzdedzije,

Iz Zabljaka do dva Vatrenjaka,

Sa Kovaca dva Halilbasica, 
A sa Mlina dvie Turnadzije,

Iz Potoklinice do dvie Penjave,

Sa Vratnika dvie Tahmiscije,...

Dizdar I, Nr. 315

Die koordinierende Häufung - nach vorangestelltem Oberbegriff - wird in ähnlicher Form weitere drei Verse hindurch fortgesetzt. Solche Aufzählungen von an Trinkgelagen tellnehmenden Helden sind besonders als Einleitung in den epischen Liedern beliebt. So liegt die Annahme nahe, daB die o.a. Sevdalinka ihr Einleitungsschema aus den Heldenliedern ubernommen hat. 1)

Die koordinierende Häufung hat in der Sevdalinka nicht nur wie in den bisher angefürten Beispielen teilkompositorische Bedeutung, sondern kann der Komposition elnes gesamten liedes zugrunde liegen:

1) Vgl. dazu folgendes Heldenlied aus Petranov1t, B., Srpske narodne pjesme 12 Bosne 1 Hercegovine (Epske pjesme starijeg vremena), B1ograd 1867, unter dem Titel nZenidba Strahinina Bana", S. 233 f1., Nr. 22, das in Sarajevo aufgezeichnet wurde:

Viño pije dranaest rojroda, Hedu njima bane Strahinine Od lijepe Banjske na Krajini, Vino pise, dok se napojise. Da vam svakog po imenu kažem: Prvo brace devet Jugovita, I dva brata dva Vojinovita, Petrasine 1 s njim Vukasine, S njima bjehu tri srpske vojvode, Kosantitu i a njim Obilitu, I Toplica iz sela Toplika, S njima bjehu dva brata rodena, Mila brata do dva Ugresita, Od Pazara Relja Bosnjanine, Od Zagorja Ijutica Bogdane, Od Sibinja Janko od Sibinja, Od Misira Misirlija Mato, Od Soluna vojvoda Bogdane. 0 svacemu oni besjediłe,...

Es handelt $81 \mathrm{ch}$ hier um eine Aufzählung typischer Helden der epischen Dichtung, die fast alle in der leit von "Kosovo" (1389) lebten ( $\mathrm{Vgl}$. dazu Maretit, T., Nała narodna epika, Beograd 1966, S. 141 ff.). 
Da je meni porez porezati,

Po porezu derze izbirati,

Ja bi znala, kog' bi porezala:

Iz Travnika ne bi ni jednoga,

Iz Saraj'va, samo bi jednoga

Iz Gradizke ne bi ni jednoga

Banjeluke, samo bi jednoga,

Iz Lijerna ne bi ni jednoga,

Iz Mostara, samo bi jednoga. 1)2)

Davidovit, Nr. 127

Als besonders bevorzugtes Stilmittel in der Sevdalinka erweist sich die dreigliedrige koordinierende Häufung, die meist in drei aufeinanderfolgenden Versen verwirklicht wird und der Vorliebe der Volksdichtung für die Dreizahl schon rein formal Rechnung trägt.

Dieser Figur, deren Wirkung vielfach noch durch ihre verbindung mit Isocolon und Klimax verstäkt wird, kommt kompositorische Bedeutung in verschiedenem MaBe zu:

a. Die dreigliedrige koordinierende Häufung kann ein wichtiges Zwischenstück bilden, auf das im weiteren Verlauf des liedes formal und inhaltlich zurickgegriffen wird:

- . -

Nju oblaze sva gospoda redom, Al' najvize tri dilbera mlada. Prvi veli: "Boluję li, Hajro?" Drugi veli: "Bolov'o bi $2 a$ te!" Treti veli: "I umro bi' $2 a$ te!" Progovara liepa djevojka: "Niti boluj, nit' umiri za me, Skini fermen, pa lezi uzame."

$$
\text { Dizdar I, Nr. } 23
$$

1) Ein ähnliches Belspiel vgl, auch Kuba 1906, S. 363, Nr. 47.

2) Es sel noch auf das gleichzeitige Auftreten von Epipher, Ganzversanapher, Isocolon, figura etymologica und redupicat10 in diesem lied hingewiesen. 
oder, in strengerer formaler Wiederholung:

Kijd bunara tri djevojke.

J sdna skodi, konja prima,

Diuga skoti, Xizme skida,

Treba sjedi, te besjedi:

"Sto no skoti, konja prima,

"Ono te mi biti kuma;

"Što no skoði, Xizme skida,

"Ono le mi biti seka;

"Što no sjedi, te besjedi,

"Ono te mi ljuba biti." ${ }^{1)}$

Davidorit, Nr. 56

b. Dle dreigliedrige koordinierende Haufung kann der Romposition eines $g$ a $z$ e $n$ Liedes zugrunde liegen, indem dieses ausschlieblich aus dieser figur und der von ihr ausgelösten, ebenfalls dreigliedrigen Entsprechung ${ }^{2)}$ besteht:

Prvi sevdah - rana pod srdałcem,

Drugi sevdah - rana na srdałcu,

Treti sevdah - rana u srdałcu,

Preboljet tu ranu pod srdascem,

A 1 onu ranu na srdašcu,

Ali ne cu rane u srdałcu.

MH VII, Nr. 76

Die zusätzlich auftretende Klimax wird hier durch den Gebrauch verschledener Prapositionen erreicht.

1) Ahnliche Beispiele vgl. Kuhat II, Nr. 715, Vuk V (1898), Nr. 491 u.a.

2) Vgl. dazu Peukert, H., Serbokroatische und makedonische Volkslyrik, Gestaltuntersuchungen, Veröffentlichungen des Institutes für Slawistik, Nr. 24, Berlin 1961, S. $19 \mathrm{ff}$. und öfter, sowie I,15, zum Isocolon. 


\section{Polygyndeton und Asyndeton}

Obwohl das Polysyndeton zu den Piguren der Haufung, 1) das Asyndeton dagegen $z u$ den figurae per detractionem gerechnet wird, 2) sollen sie hier zusammen behandelt werden, da sie trotz ihres (formalen) Gegensatzes eine enge Verwand tschaft zeigen.

Beide Piguren sind insofern von geringerer eigener Bedeutung, als sie nur die Hilfsmittel fur die Realisierung anderer Piguren, Insbesondere der Synonymie und der koordinierenden Häufung darstellen. Deshalb sollen im folgenden nur einige wenige demonstrierende Beispiele gegeben werden.

\section{a. Polysyndeton}

"Das Polysyndeton ist die stetige Setzung einer beiordnenden Konfunktion vor den Gliedern der Synonymie (...) und der koordinierenden Häufung (...) und zwar sowohl in der Kontakt-(Einzelwort-) Synonymie (...) und -Häufung (...) als auch in der (Satz-)Synonymie auf $\Delta$ bstand (...). Die Figur betrifft also sowohl die Verbindung koordinierter Einzelwörter wie koordinierter Kommata und Kola $\left.(\ldots) . n^{3}\right)$

Die Worte oder Satzteile werden bei dieser Koordinierung jeweils neu und stark hervorgehoben.

Durch ein Polysyndeton können einmal nur einzelne Worte verbunden werden (Binzelwort-Polysyndeton):

Iz martrafe tri crijeta zaljeva,

Mavi sumbul $\underline{i}$ alkatmer $\underline{1}$ ruza,...

Kuba 1908, S. 126, Nr. 418

oder:

"Nije blago ni arebro, ni zlato,

Vet je blago, to je srcu drago,...

Bos. vila 1887, S. 122

1) Vgl. dazu Lausberg $\$ \S 686-687$.

2) Vgl. dazu Lausberg $\$ 709$.

3) Lausberg $\S 686$. 
oder:

Kranila djevojka lava $\underline{i}$ lauda $a^{1}$,

Lava $\underline{i}$ labuda $\underline{i}$ siva sokola....

Miloževil IV, Nr. 393

Zum anderen werden durch das Polysyndeton aber auch Satzteile oder ganze Sätze aneinandergerelht. In diesem Pall ist das Polysyndeton mit der Form der Anapher verknüpft:

S tebe mi se vidi Sarajevo,

I sva sela oko Sarajeva,

I kalarma 18pred Tažlihana,...

Kuba 1907, S. 114, Nr. 182

oder:

Kad' ustanem iz meka dušeka,

Al' bijeli pometeni dvori,

I studena roda donesena,

I reterli kava ispetena,

I bijela pogača skuhana....

Bo8. vila 1887, S. 154

oder:

A ribice svekrvice,

A Zabice jetroice,

A 2 mijice zaovice,...

Behar, 1902/03, S. 191

Die in der Pigur des Polysyndetons am häufigsten anzutreffenden Konjunktionen sind die auch in den Beispielen vertretenen "in" und "a".

Wegen des wiederholten Vorkommens dieser Pigur innerhalb der alavischen Antithese finden sich daneben nicht selten die Konjunktionen "ili" und "ali":

Al' je slava, ali svadba?

ilje slava, niti svadba,

Bos. vila 1895, S. 108

1) = labuda. 
Oft werden auch verschiedene Konjunktionen verwendet: B'jele zube, a bijelje ruke, Crne odi 1 crna pertina,...

$$
\text { Ristit, Nr. } 9
$$

Ein Polysyndeton aus verstechnischen Gründen bei gleichzeitiger Verwendung verschiedener Konjunktionen zelgt folgendes Beispiel:

Od Bargije Portina Avdije,

A od riłe Hadzalita Muše,

I od pera Hrgine Šerife,

Od ljepote Pejzagine Side,

od jordama Dženetita Diłe,

I od nama Merhemita Sehme?n" ${ }^{1)}$

$$
\text { Bejtit (Bilten II), S. } 391
$$

Das Polysyndeton trifft man in den Liedern seltener an als das Asyndeton.

\section{b. Asyndeton}

"Das Asyndeton ist das Gegenteil des Polysyndeton $(\ldots .$.$) : es$ besteht also in der Weglassung der Konjunktionen...".2)

Auch in dieser Pigur können sowohl Einzelworte wie Satzteile, aie dann meist eine ganze Verszeile einnehmen, nebeneinandergestellt werden.

Einzelworte koordiniert das Asyndeton in folgenden Beispielen:

Dode, prode, sjede više glave,

Podize joj kumas jorgan 8 glave....

$$
\text { Bos. vila 1905, S. } 216
$$

oder, ähnlich:

1) Vgle auch das Polysyndeton aus verstechnischen Gründen auf S. 91, Anm. 1 .

2) Lausberg $\$ 709$. 
Bez izuna u odaju Najli

Jogje, progje, sjedi više glave....

Behar 1905/06, S. 157

oder:

jjedi dolje milo, drago moje!

11' ne sjedi vet $u$ ducan 'ajde,... 1)

Popovit-Rodoljub, Nr. 73

Dis nächsten Zitate zeigen das Asyndeton, das Satzteile koordiniert, die jeweils eine Verszeile einnehmen:

Sunce sjaje, javor-drvo sahne;

Kł̧a pada, javor-drvo truhne,

Jjetar pułe, oblama mu grane...

MH VII, Nr. 62

oder:

Sto nosi tel-ti papuce,

Sto nosi turli dimije,

Sto nosi kolan vił njiha,

J̌to nosi fesit nad okom,...

Behar 1901/02, S. 92

oder, besonders typisch für die Sevdalinka, da die muslimischen Gebetzzeiten ${ }^{2)}$ genannt werden:

Podne vika a ja iz Travnika,

ICindija - ja Vakufu Donjem,

Aksam geldi, ja Odžaku Gornjem,

'j jaciju - dragoj pod pendzere.

$$
\text { Dizdar I, Nr. } 211
$$

Neven diesen Angaben lassen vor allem die im vorliegenden Lied rerwendeten bosnisch-hercegovinischen stadtenamen, besonders las zu "vika" einen Binnenreim bildende "Travnik" in der

1) Jas Komma des Aufzeichners läßt schließen, daß es sich um zwei substantivierte Adjektive, asyndetisch zugeordnet, randelt, und nicht um Adjektiv plus substantiviertes Adjekt1v.

2) Vgl. dazu auch Goetz, L.K., a.a.0., Bd. 1, s. 82, sowie liangi, A., a.a.0., S. 11. 
eroten Zeile erkennen, daB dieses 21 tat einer Sevdalinka entnommen 1 st.

Weltaus seltener 1st der Fall, daB drel asyndetiach angeordnete Kola zusammen eine elnzige Verszeile umfassen. Abschliebend dafur ein Beispiel mit einer Klimax, die sich gern des Asyndetons bedients

Rosa parte, sunce sjace, feter stopiti,

$A$ nas droje uraniti, rerbe popiti.

Milosetle IV, Nr. 187

\section{c. Verbindung von Polyoyndeton und Asyndeton}

Vielfach erscheint in den Liedern die Verbindung belder Piguren, meist in der Form, daB das letzte Glied elnes Asyndetons syndetioch angeschlossen wird:

Otac, majka, brat 1 sestra

Orjek za mnom tuguju,...

Kuba 1910, S. 520, Nr. 871

Kunstroll verschränkt aind Asyndeton in anaphorischer und Polyayndeton in halbversanaphorischer Stellung in folgenden Zitaten:

Djevojka je corke natinila:

Od ambera 1 od albabera,

Od katmera $\underline{1}$ od tugizaha,...

Nov1 behar $1928 / 29$, S. 75

oder 8

Kad ne mogu kroz sokake prot

Od ducana $\underline{1}$ od Cefenaka,

od coraka 1 od murebaka,

Od divhana 1 od kamerija,

Od momaka 1 od djevojaka:...

Bejtic (Bilten II), S. 391

Eine Verbindung beider Piguren aus rein verstechnischen Gründen zelgte schon das Bejtit-Beispiel auf S. 96. Als we1- 
teres möge folgendes dienen:

Zuluma su dosta pocinili,

Jadnih majak' u crno zavili

I ljubovca u rod opremili;

Puatih kula sa zemljom eravnili."n

Zovko I, Nr. 57 


\section{Epitheton}

Zu den Figuren der Häufung, nämlich der subordinierenden Häufung, kann auch das Epitheton gerechnet werden: "Das me1stbenandelte Phänomen der subordinierenden Häufung ist das Epitheton: das Epitheton ist ein attributiver Zusatz (Adjektiv, substantivische Apposition, periphrastische Apposition) zu einem Substantiv...". 1)

Das Epitheton findet in allen seinen Spielarten in der Sevdalinka außerordentlich häufige Verwendung. Jedoch haben die einzelnen Épitheta-Arten verschiedenen Wert für die Improvisation der Lieder. Allgemein kann aber festgestellt werden, daB a $l$ l e $n$ Gruppen von Epitheta lediglich eine kleinere improvisatorische Bedeutung zukommt. In dieser Hinsicht haben die sogenannten individualisierenden Epitheta am wenigsten Gewicht, da sie sich im Gegensatz zu den nichtindividualisierenden Epitheta ${ }^{2}$ dem Sänger nicht ohne weiteres anbieten, sondern erst von ihm erarbeitet werden muissen.

Ihre eigentliche Punktion liegt im Bereich des Ornatus. 3) Da aber die Ornatusfunktion in vorliegender Arbeit auBer Betracht bleiben soll, beschranke ich mich im folgenden auf drei Beispiele für individualisierende Epitheta:

Udaje se sizota djevojka,

Cak daleko preko vilajeta, ${ }^{1) 4}$ )...

$$
\text { Dvorovit, S. } 19
$$

oder:

Gledala ga Jelena

Ponosita gospoja:...

retranovit, Nr. 275

1) Lausberg $\S 676$.

2) Im folgenden wird die zweckmäbige binteilung der Epitheta von Yollok ubernomen, wie dieser sie in seinem Aufsatz "Bemerkuneen zur Typologie des Epithetons", in: Beiträge zur Sidos teuropa-Forschung, AnläBlich des 1 . Internationalen Balkanologenkoncresses in sofia, 26 . VIII. - 1. IX.1966, hüinchen 1966, S. ¿̈79-¿84 darêelegt hat.

3) Vel. dazu rollck, S. ili f., sowie Lausberg $\$ 676$.

4) 1) = mnnerkunf des Sammlers: "rokrajine (Bosne)". 
und :

Meksa mi je tvoja desna ruka, NeE' cetiri brusali jastuka." "1)

Milanovit I, Nr. 14

Pür die Improvisation bedeutsamer ist das nichtindividualisierende (oft: typisierende) Epitheton, das in drei Gruppen eingeteilt werden kann. 2)

Nichtindividualisierende Epitheta, bei denen "der Neuigkeitsaussagewert der Adjektive gegenüber den Substantiven gleich Null geworden ist" 3 ), haben wegen des häufigen gemeinsamen Auftretens von Adjektiv und Substantiv "im Laufe der Entwicklung ausgesprochen formelhaften Charakter angenommen". 4)5)

So hat der Sänger von vornherein ein sicheres Gefühl dafür, wieviel Raum (bzw. wieviel Silben) Adjektiv und Substantiv im Vers einnehmen werden.

Diese Gruppe der nichtindividualisierenden Epitheta ist in der gesamten Volksdichtung, und so auch in der Sevdalinka, stark vertreten. Im folgenden werden einige für die Sevdalinka typische Beispiele gegeben:

"Dogji, dragi, u zelenu bašcu,

Ja cu tamo bostan 2aljevati."...6)

$$
\text { Behar 1907/08, S. } 77
$$

1) Diese Verse sind für die Sevdalinka besonders charakteristisch: "brusali" heiBt soviel wie "Seide aus Brusa" (türkische Stadt), mit der auch in Bosnien gehandelt wurde. In Sarajevo erinnert daran der 1551 erbaute Brusa-Bezistan.

2) Pollok, a.a.0., S. 280.

3) Pollok, a.a.0., S. 280.

4) Pollok, a.a.0., S. 280.

5) Vgl.dazu auch Heier, J., Balladen, I., Leipzig 1935, S. 27 : "...reigt sich der münliche Stil in einem starken Vorwiegen des Pormelhaften in Sätzen und Beiwörtern... Alles das diente einerseits dazu, dem Sänger das Improvisieren zu erleichtern,.... Diese Formen des mündlichen Stils... begegnen gleichmäßig auch in der improvisierenden Foesie anderer Länder." - Vgl. daselbst auch S. 29.

b) Als Stadtlied zieht die Sevdalinka häufig die Hendung "zelena basca" der sonst üblicheren "zelena livada" oder "zelena trava" vor. Dennoch sind auch diese nicht selten in der Sevdalinka zu finden: 
Neben den Garten ("baß̨̌") splelt besonders das Penster ("pendzer") als Schauplatz des sogenannten "ałikovanje" (= Plirten) ${ }^{1)}$ in den Liedern eine grobe Rolle.

Bs taucht meist nit einem der zwel ublichen nichtindividua118ierenden Beiwörter auf:

Samo moja dilber draga

Ha demirli pendzeru.... Dizdar I, Nr. 111

oder:

Portsetzung ron S. 101, Anm. 6:

Volia $a$ madim na zelenoj travi,

Veg $8 a$ starim na mehku duseku.

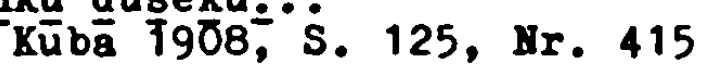

Vgl. dazu auch Gajret 1929, S. 172 und ofter.

1) Vgl. dazu Hangi, A., a.a.0., S. $169 \mathrm{ff}$.

Bei dieser der musilimischen Jugend einzig gestatteten

Form des Plirtes (asirovanje) gebrauchte sie inre eigene Sprache ( $V_{g l}$. dazu auch Mikovit, P. Alfiklijake doskodice 8a gjulpendzera, Sarajevo 1913, S. III). Man "unterhielt" sich meist in zwei- bis Sechszeilern, die oft gereimt sind:

On: Tanka 81 u pasu, K'o pł̌enica u klasu.

Ona: A ti vitak u otruku -

Xeo strina u kuku.

Mirkovit, P., a.a.0., S. 33 u.ä.

Vgl. dazu auch Hang1, A., a.a.0., S. 64 f.:

"Die moslimischen Prauen und Mädchen verhüllen ihr Antlitz, weil die Religion es so verlangt. Besonders die Prauen muissen darauf achten, dass ein fremder Mann ihr Angesicht nicht sehe. Deshalb sind auch die Häuser der Moslims mit hohen Mauern oder Bretterzäunen (tarabe, W.E.) umgeben und die Fenster der Prauenabtellung (Harem, W.E.) mit dichten Gittern versehen. Diese sind aus Holzstäben (mußembak) oder aus Eisenstäben (demir).... Die Prauen und Mädchen können hinter denselben die Vorgange auf der Strasse beobachten, ohne selbst gesehen zu werden." 
Kad se jangin 12 mejhane pomoll,

Pred njim draga dzamli pendzer otvor1,... 1)

Kuba 1907, S. 411, Nr. 283

Ebenfalls typisch fur die Sevdalinka, daneben aber auch fur die Heldenepik, und von dieser vielleicht ubernommen, ist folgende Belwortverbindung:

Probetala po trom bijelu dvoru,

Dror vidjela 1 begenisala,...

Hov1 behar 1929/30, S. 238

Ein weiteres der Sevdalinka we der epischen Volksdichtung gemeinsames Epitheton 1st "tanana robinjan'), fur das die Sevdalinka daneben noch die Variante aus Possesiradjektiv ("pa(ins") plus Substantiv herausgebildet hats

tanana:

Gje tes ljubit tananu robinju.

Mene daju - robinju udaju.

$$
\text { Kurt, Nr. } 70
$$

oder:

Dok zavika tanana robinja:

"Ao zlato, zalosna t1 majka,...

Bugarinovie, S. $24 f$.

pasina:

Za njom Gete beze Mehmed-beze,

Pa govor1 parinol robini1:...

Bugarinovi6, S. $21 \mathrm{f}$.

1) Obwohl hier die zwe1 Möglichke1ten des "eisernen Pensters" (d.h. des vergitterten) und des "Glasfensters" ("dzaml1 pendzer" bzw. die Varlante: "artall pendxer")

(Divojka ga okom zapalila,

Crntm okom kroz srtali pendzer...

Blagaj16, Nr. 7)

zur Auswahl stehen, sind diese Bpltheta nicht zu den indivdualisierenden zu rechnen, da das Substantiv "pendzer" stets mit einem dieser beiden Adjertiva schablonenartig auftritt. Beide Verbindungen oind fur die Sevdalinka äuBerst charakteristisch und haben in ihr gleich formelhaften Charakter.

2) Zu "robinj1ce" (Sklavinnen), Vgl. Milakovit, J., Sužanj, pabirci po narodnoj poezij1, Sarajevo 1915, S. 16:

"Obican im epitet: tanane." 
oder:

Utekla je parina robinja

I uzela dva tovara blaga.... 1)2)

Jugoton EPY 3637 B

Um ein für die Sevdalinka charakteristisches Epitheton dieser Gruppe handelt es sich auch im folgenden:

Ni rakije, skoro prepicane,

Veg geterli-kahru iz fildzana!"

Kurt, Nr. 26

Hier kommt die Leidenschaft des Muslim fur den Kaffee ${ }^{3)}$ und seine gleichzeitige Ablehnung von Alkohol zum Ausdruck. ")

Weitere Epitheta dieser Gruppe, die vorzugsweise in der Sevdalinka anzutreffen sind, sind folgende:

U bekrije nigde nifta nema,

Do 11 jedna sedefli tambura,...5)

Humo, ReX 1 slika, S. 36

und :

1) Mit diesen Epitheta-Varianten verhalt es sich ebenso wie

mit denen zu "pendzer". Vgl. dazu S. 103, Anm. 1.

2) $\mathrm{DaB}$ Geschehnisse um Sklaven und Gefangene besonders in muslims.scher Volksdichtung anzutreffen sind, konstatiert auch Milakovit, J., a.a.0., S. 56: "Nema sumje, da je 8to obi ‘aj a sto fabula o zarobljivanju i zasužnjivanju dosla $k$ nama sa istoka, sto nam najbolje kazuju pjesme muslimanske $i$ undurske, u kojima ima toga elementa mnogo viłe, nego li u drugim pjesmama."

3) Vgl. dazu Hangi, A., a.a.0., s. $80 \mathrm{ff.}$

4) In jüngeren Liedern wird auch oft der AlkoholgenuB besungen. Vgl. dazu z.B. Dizdar I, Nr. 1: "Bez rakije nema zivovanja" und öfter.

b) "Tambura" (auch: "̧argija") ist die Bezeichnung für das Saiteninstrument, auf dem Sevdalinke begleitet werden. Deshalb findet sich dieses Substantiv mit seinem stehenden Beiwort "sedefli" (perlmuttergeschmückt) so haufig in diesem Lied. Es wird 2.B. in Lied 30 (III, 30) und seinen Varianten gebraucht. 
U ruci joj oklagija,

A u drugoj zlatan ibrik... 1)

Odobašit, s. $6 \mathrm{ff}$.

Das stehende Epitheton zu "hurija" ist "dženetska". Die "dženetska hurija" ist in muslimischen Liedern das, was in nichtmuslimischen die "vila" $18 \mathrm{t}^{2)}$; sie findet sich dementsprechend ausschlieblich in der Sevdalinka:

II' si melet (Engel), il' dženetska hurija,

II' te majka nasred raja rodila,...

Hak I, Nr. 57

Diesen Versen folgt im übrigen eine längere Aufzählung (sechs Verse) in Porm einer koordinterenden Häufung (plus Ganzversanapher), die sich für das muslimische lied als so charakteristisch erwiesen hatte. ${ }^{3)}$

Die bisherigen Beispiele zu dieser Gruppe der nichtindividualisierenden Epitheta stellten entweder ausschlieblich typische Pälle für die Sevdalinka oder im gewissen Sinne Sonderfälle dar. Selbstverständlich macht aber dieses lied daneben von den in der sonstigen Volksdichtung üblichen Epitheta wie "bjelo lice" (z.B. Dizdar I, Nr. 199), "vita jela" (z.B. Davidovit, Nr. 111) usw. ausgiebig Gebrauch:

Vjerna njemu odgovara ljuba: ${ }^{4}$ )

"Kad me pitaš, pravo da ti kažem!...

$$
\text { Hak II, Nr. } 55
$$

1) Der "ibrik", ein kupfernes Wassergefäß, spielt im religiösen Kult des Islams eine bevorzugte Rolle (Vgl. dazu Goetz, I.K., a.a.0., Bd. 2, S. 211). Nicht verwunderlich ist es daher, daB ihm das Adjektiv "zlatan, - na, -no = golden" als stehendes Epitheton zuteil wurde.

2) Vgl. dazu Goetz, L.K., a.a.0., Bd. 2, S. 113: "Der slavischen Nymphe, der Vila, entspricht im moslimischen Lied die Huri."

3) Vgl. dazu I, 12, zur koordinierenden Häufung, besonders S. 87.

4) Trotz der verhältnismäBig freien Wortstellung des Serbokroatischen dürten hier die weit auseinandergestellten Glieder der epithetischen Verbindung ein Hyperbaton darstellen. 
Die zweite Gruppe Innerhalb der nichtindividualialerenden Ep1theta bilden die, bei denen das Adjektiv ausschlieblich dem Ornatus dient, ohne eigentlichen Formelcharakter anzunehmen. ${ }^{1)}$ Hierzu and etwa folgende Beisplele zu rechnen:

Zarko sunce pokupl kalove, Da ne kalja gospodu svatove,...

Petranovic, Nr. 74

oder:

I ovako majci govorio:

nulla majko, 121gj1 pred dvore!...

Zovko I, S. 43 f.

Wie aber die individualisierenden Epitheta bei wiederholung des zugehörigen Substantives innerhalb eines Liedes als nichtIndividualisierende Epitheta stets mitwlederholt, also wie formelhafte Epitheta behandelt werden, so können auch die Epitheta mit reiner ornatusfunktion bel eben solcher wiederholung für das Ifed Pormelcharakter annehmen.

DaB auch urspringlich nichtformelhafte Ept theta innerhalb e $1 \mathrm{n}$ e 8 Liedes wle formelhafte Epltheta gehandhabt werden können, unterstreicht den Wert des Epithetons allgemein für die Improvisation des Volksliedes.

Die formelhaften Epitheta, denen bei der Improvisation die größte Bedeutung zukommt, werden auf diese We1se kunstlich vermehrt.

Als dritte Gruppe der nichtindividualisierenden Epitheta sollen hier die pleonsstischen verbindungen (tautologische Epitheta) genannt werden. ${ }^{2)}$ Hinsichtlich der Improvisation gilt für ole das gleiche wie für die zuvor behandelten Typen. Im folgenden werden daher nur einige Beispiele gegeben:

Mladi momc1 da ljub' udovice, Stari starci lijepe djevojke?" Vuk I (1953), Nr. 436

oder:

1) Vgl. Pollok, a.8.0., S. 281.

2) Vgl. Pollok, a.8.0., S. 281. 
"no djevojko, lijepa ljepoto!

Da vidimo, tko $j^{\prime}$ od koga ljepri!...

Andrit II, Nr. 64

oder:

Poigralo kolo

Po ravnoj ravnini, ... 1)

Kuba 1909, S. 593, Nr. 774

oder:

Pod njim sjedi vran gavran,

Otud ide car sultan,...

Kuba 1910, S. 520, Nr. 866

Das zusammengesetzte und das doppelte Epitheton haben, dank ihres größeren Umfangs, auch eine gröBere improvisatorische Bedeutung. Da sie aber in der Sevdalinka seltener vorkomen als die Einwort-Epitheta, sollen jeweils nur einige wenige Beispiele angefuihrt werden:

a. zusammengesetztes Epitheton:

De da igjemo na studen vodicu

Na rodi bjelogrla Pata."...2)

Behar 1909/10, S. 61 f.

oder:

Hoja draga, moja slatka sladijo,3)

Sto me małe 1 l-vezenom Catki fom?! ...4)

Biser $1913 / 14$, S. 173

1) Ein ähnliches Beispiel findet sich in Bos.vila 1903, S. 137, Nr. 10:

Ne Cudim se rilu pri planini,

Ni jelenu na ravnoj ravnini,...

2) In diesem lied kommt die "weiBkehlige Fata" in 40 Zeilen sechsmal vor, was die oben genannte These stützt, daB das individualisierende Epithet on (und hier handelt es sich um ein solches) innerhalb e i $\mathrm{e} s$ Liedes $2 u$ einem formelhaften, nichtindividualisierenden Epitheton werden kann.

3) "slatka sladijo" ist ein weiteres Beispiel für das tautologische Epitheton.

4) Vgl. auch Bos. vila 1886, S. 317. 
oder: *

Poletio siv-zelen sokole

Preko Bosne na Hercegovinu, ... 1)

$$
\text { Bos. vila 1891, S. } 218
$$

Oder:

Njemu veli crnooka

Ijepa djevojka:...

Kuba 1910, S. 531, Nr. 939

Dieses letzte Zitat enthält sowohl ein zusammengesetztes Epltheton (crnooka) als auch ein doppeltes (crnooka - Ijepa), fur das im folgenden noch weitere Beispiele gegeben werden.

b. doppeltes Epitheton:

Sve ljepih mladih momaka,

Još ljepsih mladih djevojak'....

Kuba 1910, S. 522, Nr. 883

oder:

U potoku sitna kisa rosila,

Na djevojci b'jela tanka kosulja....

$$
\text { Milöevic IV, Nr. } 379
$$

oder:

J zoru je svaka voda

Bistra studena,...

Kuba 1908, S. 552, Nr. 621

Das doppelte Epitheton, das sehr oft dem Substantiv nachgestellt wird, tritt in folgendem Lied (und seinen Varianten) in fast regelmäBlger Folge auf:

Izvor-voda izvirala, bistra studena,

Zaljevala struk bosiljka, zimi zelena.

Cuvala ga dilber Mejra, b'jela, rumena.

otud ide star na konju, stara delija:...2)

$$
\text { Dizdar I, Nr. } 93
$$

1) Dasselbe Beispiel findet sich des öfteren; vgl. etwa auch $\mathrm{Ku}$ 1909,. S.886,Nr.730 oder Dizdar I,Nr.159,Nr.256,Nr.257 und ö ter.

2) Vgl. etwa auch Kuba 1908,S.403, Nr.506, ein Iied mit 24 Versen, in denen "bistra-studena" sechsmal und "b'jela-rumena" achtmal wederholt werden. Vgl. dazu auch III,21. 
In den 31 Versen dieses Liedes erscheint das doppelte Epitheton "bistra-studena" siebenmal und das doppelte Epitheton "b'jela-rumena" achtmal, was wiederum ein Beleg dafür ist, daB das Epitheton innerhalb e i n e s Liedes leicht zur formelhaften Wendung werden kann.

Besonders erwähnt werden muB die für die Sevdalinka typische und ausschlieBlich hier anzutreffende Form des doppelten Epithetons "alem kamen dragi". Hier befindet sich das Substantiv in Zwischenstellung zwischen einem substantivischen Epitheton ${ }^{1)}$ und einem adjektivischen Epitheton:

Po dimijam izvezene guje,

U ustim im alem kamen dragi,...

$$
\text { Kurt, Nr. } 84
$$

Diese zwei Verse sind Teile einer sich uber mehr als 60 Verse hinziehenden koordinterenden Häufung, die die Sevdalinka mit vorliebe verwendet. 2 )

Auffallend beim zusammengesetzten und doppelten Epitheton ist das Uberwiegen von Parbadjektiva.

Sehr beliebt sind in der Sevdalinka auch substantivische Epitheta. Was die Differenziertheit dieses Epithetons betrifft, scheint die bosniech-hercegovinische Liebeslyrik reicher als die übrige serbokroatische zu sein, die sich in den meisten Pällen darauf beschränkt, zu einem Personen- oder Ortsnamen ein entsprechendes Substantiv in Epitheta-Funktion zu setzen.

Sehr häufig werden durch das substantivische Epitheton Koseworte ausgedrickt, bei welchen sich gerade das muslimische lied als besonders erfinderisch erweist. 3$)^{9}$

1) Siehe dazu weiter unten.

2) Vgl. dazu I, 12, zur koordinierenden Häufung.

3) Vgl. dazu auch Goetz, I.K., Koseworte, Scherz- und Schimpfworte für die Liebenden im Volkslied der Kroaten und Serben, Zeitschrift für Volkskunde, Neue Folge, Bd. 3 (41), Berlin 1932, S. 213-241.

$\mathrm{DaB}$ os sich bei diesen Epithetarealisierungen gleichzeitig sehr häufig um metaphorische Redeweise handelt, soll nur am Rande vermerkt werden. Vgl. dazu speziell Pollok, K.-H., Zum Gebrauch der Metapher in den balkanslawischen lyrischen Volksliedern, Slawistische Studien zum V. Internationalen Slawistenkongre $B$ in Sofia 1963, Opera Slavica 4, Göttingen 1963, S. 175-206. 
Polgende Beispiele dürfen als für die Sevdalinka typiach gelten:

Knj1gu piłe Stambolija Salko

Te je balje reher Sarajeru....

Vuk V (1898), Nr. 394

Das adjertivierte Substantiv "reher" ist in der Verbindung mit "Sarajevo" ein stehendes, formelhaftes Epitheton geworden." ) Oder:

Sve miello, na jedno smislio:

On poljubi sumbul-udoricu!...2)

$$
\text { Dizdar I, Nr. } 145
$$

Da die muslimischen Mädchen nach dem Gebot der 1slamischen Religion ihr Leben bis gur Verhelratung abgeschlossen von der Omwelt verbringen muBten, wandten sich die jungen Burschen häufig den Witwen zu, die in den Liedern der Mädchen eine wht1ge Rolle spielen und verständlicherweise nicht gerade sehr liebevoll gezeichnet werden.

oder:

Bul-djerojka ${ }^{3)}$ pod dulom zaspala,

Bul se kruni, te djevojku bud1....

Vuk I (1953), Nr. 392

oder:

Moze li biti dilber-djevojka

Dilber-djevojka bez mlada momka?" 4 )

$$
\text { WH VII, Nr. } 9
$$

1) Vgl. dazu auch S. 77, Anm. 2.

2) Vgl. etwa auch Behar 1907/08, S. 158 f. u.a. und das 21 tat aus Milozevit II, S. 15: "Takar nacin u pjevanju razvijao se u naroditom ambijentu "gdje je uzdrzanost 12vjesnih narih pjesama zamijenjena objercu p 0 s 10 o 1 \& $\mathrm{n} 1 \mathrm{~h}$ sarajerskih $u$ b u $l$ u d 0 v 1 c a 1 betara 12 Hovog hana." (Das 2itat ubernahm lilosevic ohne es als solches zu kennzeichnen aus: Corovit, V1., Bosna 1 Hercegovina, SKZ, Beograd 1925, S. 103).

3) Vgl. dazu Skalj1t, A., a.a.0., S. 154: "dul... Cesto se ova rijec stavija u nar. pjesmi u znacenju epiteta pred Zenska imena 111 imenice Zenskog roda."

4) Nach Skaljit, A., a.a.0., S. 217 kann "dilber" (pers.) als Substantiv (z dragan, ljubljenik u.a.) und als Adjektiv (= lijep, krasan) gebraucht werden. - Der Bindestrich 1m oben 
ode::

"Sid, Pazila, mladost1 ti troje,

Natodi ml b18er suze ovoje!"

$$
\text { D1zdar I, Nr. } 1
$$

Ode::

"OJ Boga mi secer Jovo 1z Bosne,

nul smo skoro 12 te Bosne ponosne.... 1)

$$
\text { Grdil-Bjelokosie, Nr. } 11
$$

Jas per1phrastische Epltheton, das bevorzugt in der Anrede vervendet wird, 2) soll die Untersuchung des Epithetons in der Sevialinka abschlieBen.

Is tritt otets als Apposition zur Kennzeichmung der angesprochenen Person oder Sache auf. Die so erwelterte Anrede nimnt in den meisten Fällen elnen ganzen Vers ein:

Obrvice, morgke pljavice.

Valjaju joj Sama 1 Haira;...

$$
\text { Kurt, Nr. } 84^{3) 4} \text { ) }
$$

Portsetzung von S. 110, Anm. 4:

gegebenen Z1tat läBt erkennen, daB der Aufzelchner das Wort "dilber" hier als substantiviertes Adjektiv aufgefabt hat.

1) Auch dieses substantivische Epitheton (Beter plus Eigenname) lot typisch fur die Sevdalinka. Zu dem serbischen Eigennamen "Jovo" in dieser Wortverbindung vgl. S. 21, Anm. 1. Als stehendes Ep1theton zu "Bosna" findet man in demselben Z1tat (wle des ofteren in den bosnisch-hercegovinischen Iiedern) das häufig - we auch oben - einen Schlagrelm bildende "ponosna" (stolz).

2) Vgl. dazu Pollok, S. 125.

3) Der Vergleich der Augenbrauen mit Blutegeln, "pijavice" ("morgke" als stehendes Epitheton), findet oich in der sudslavischen Volksdichtung allgemein. Charakteristioch fur die Sevdalinka im besonderen ist im angefuhrten lied die in der folgenden Zeile enthaltene und in weiteren Versen mehrfach abgewandelte Hyperbel, in der der Nert Jeweils elnes Körpertelles des Mädchens nit dem ganzer Städte und Länder der orientalischen Welt (1m 2itat: Damaskus und Agypten) gleichgesetzt wird.

4) Interessant 1st in diesem Zusammenhang der Vergleich der Mädchenaugenbrauen it dem Buchstaben elif ( $l$ ), dem ersten des arabischen Alphabets, in folgendem Belspiel: 
Oder:

Trebevilu, Flsoka planino,

S tebe mi se vidi Sarajevo,... 1)

Dizdar I, Nr. 285

oder:

Onda ment rell zlato moje:

"OJ, junace, jedna adzamijo!...

Dizdar I, Nr. 11

Die Diskrepanz in der Bedeutung dieser periphrastischen Epithe ton-Verbindung (Junak = Held und adzamlja = Unerfahrener) hat hier, wie so oft in den Ilebesliedern, scherzhaft-spöttischen Charakter.

Abschliebend sel noch einmal besonders darauf hingewiesen, daB aich die Sevdalinka gerade in der Wahl des Epithetons vielfach von den ubrigen serbokroatischen Ilebesliedern unterscheidet, da sle slch gern der úber das Turkische ins Serbokroatische gelangten Worte bedient.

Portsetzung von S. 111, Anm. 4:

Ne b'jell se 1 ne bakami se,

Ne navlaci na elif obrva,...

$\mathrm{MH} X \mathrm{Xr}, 69$

Neben diesem substantivischen Epltheton gehören auch die belden Verben in der ersten Zeile (bjelitil se und bakami-

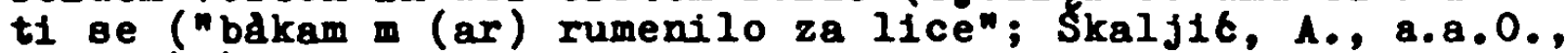
S. 115) ) zum typischen Vokabular der Sevdalinka.

1) Weltere Beispiele dazu rgl. etwa Sajnovit XX, S. 152, Nr. 2, Ristil, Nr. 24 und daselbst Nr. 42 u.a. 
B. Pigurae per ordinem

\section{Isocolon}

"Das Isocolon oder Parison oder die Parisosis besteht in der koordinierten Nebeneinanderstellung zweier oder mehrerer Kola (...) oder Kommata (...), wobei meist die Kola (oder Kommata) jeweils gleiche Satzabfolge zeigen (...)......

Das Isocolon ist eine der wichtigsten, wenn nicht uberhaupt die wichtigste aller sprachlichen Piguren in der Sevdalinka we in der südslavischen Volksdichtung allgemein. In dem untersuchten bosnisch-hercegovinischen Liedmaterial tritt es auffallend häufig auf. So fanden sich unter 50 wahllos herausgegriffenen Liedern nur zwei, die kein Isocolon enthielten.

Einer der wesentlichen Gründe für das zahlreiche Auftreten von Isocola ist darin zu suchen, $d a b$ sich die serbokroatische Volkslyrik des syllabischen Verses bedient. Dabei ist weiterhin von Bedeutung, daB es sich um einen Silbengruppenvers handelt, in dem fast jede Verszeile inhaltich und syntaktisch in sich abgeschlossen 18t. Das veranlast den Sänger leicht, die Verse parallel zu bauen. Man spricht in diesem Pall auch von psychologischen Parallelismen. 2)

Auch die Neigung vereinzelter Lieder und ihrer Varianten zu formelhaften Wiederholungen, z.B. In Form der slavischen Antithese, auf die weiter unten eingegangen werden wird, leistet dem Gebrauch des Isocolons Vorschub.

Durch die parallele Gestaltung von Versen oder ggf. Halbver-

1) Lausberg $\S 719$.

2) Das Isocolon, das in der Sevdalinka schon häufig anzutreffen ist, scheint in den epischen Iiedern noch zahlreicher zu sein. Das liegt vielleicht daran, daB diese durch die ständig gleiche Silbenzahl in a 1 e $n$ Liedern (nämlich 10), wenn man von der ausgestorbenen "bugarstica" absieht, formal bel weitem mehr gefestigt, stabiler und gleichförmiger sind als die lyrischen Lieder, die in ihrer Silbenzahl zwischen 5 und 14 Silben schwanken ( $\mathrm{g} l$. dazu Karadzit, V.St., 0 srpskoj narodnoj poeziji, Beograd 1964, S. 108 ff.). So stöbt man in den epischen liedern auch viel öfter als in den lyrischen auf sog. Isocolaketten. 
sen mit Hilfe von Isocola ${ }^{1}$ ) erlefchtert sich der Sänger die Improvisation ungemein. Die gleichmäBige Wiederholung der syntaktischen Struktur eines Verses bestimmt nicht selten den Bau längerer Iiedabschnitte, ja ganzer Iieder.

Am häufigsten findet sich in den Liedern das zweigliedrige Isocolon:

Jarko sunce da visoko tisi ${ }^{2}$ )

Hoja draga da daleko tisi2)...

Erlangenski rukop1s, Air. 199

oder:

Sarajevo dugo i ziroko,

bioje drasce dugo i visoko,...

$$
\begin{aligned}
& \text { R.a., Inv. br. 8101/III-4 } \\
& \text { (vom 9. 10. 1957) }
\end{aligned}
$$

oder:

Bila lica lspod trepavica,

Bila grla ispod ogrlica....

Rubit IV, S. 289

Dieses zweigliedrige Isocolon wird besonders gern am Liedanfang oder am Liedende als effektvoller LiedabschluB in Form einer Sentenz verwendet:

a. Liedanfang:

Duni mi, duni, hlā̄ane,

Dodi mi, dodi, dragane....

Dizdar I, Nr. 61

oder:

o Xardace, moje ljetovanje!

o pendzeru, moje pogledanje!...

Petranovit, Nr. 103

oder:

1) Auf leichte Abweichungen von der Parallelität oder Chiasmen, die gelegentlich vorkommen, soll bier nicht weiter eingegangen werden.

2) = ti si. 
Crati, ruzo, nemoj opadati!

Boluj, Ahmo, nemoj umirati,...

$$
\text { Andrit II, Nr. } 68
$$

oder, mit weitgehender Vokalharmonie:

Bosno moja, moje zivovanje,

Aj§o moja, moje milovanje,...

$$
\text { Dizdar I, Nr. } 26
$$

b. LiedschluB:

Širi ruke, da se zagrlimo,

Susi usne, da se poljubimo!"

$$
\text { Bejtil (Bilten II), S. } 398
$$

oder:

Pomorila i staro i mlado,

Rastavila i milo i drago!

Dizdar II, S. 109

oder:

Bez rakije nema živovanja,

Bez Fazile nema milovanja! 1)2)

$$
\text { Dizdar I, Nr. } 1
$$

1) Die Dizdar I-Sammlung ist überhaupt reich an Liedern mit Bentenzartiger Verwendung von Isocola am Liedende. Vgl. etwa auch folgendes Isocolon, das in seiner Wirkung durch gleichzeitiges Auftreten von Ganzversanapher, Halbversanapher und Binnenreim besonders unterstrichen wird:

Stet teš muža, venut teł ko ruža,

Stet tes djece, venut tes ko cr'jete."

Dizdar I, Nr. 44

Weitere Beispiele dazu vgl. Dizdar I, Nr. 38, Nr. 181 u.a.

2) $\mathrm{DaB}$ es gerade bei Verwendung von Isocola häufig zu Bildungen von Homoeoteleuton (Gleichklang der Ausgänge der jeweils letzten gischer Endreim) und von Homoeoptoton (Entsprechung der Flexionsformen meist am SchluB der Teile des Isocolons; vgl. dazu Lausberg $\$ 729$ ) (etwa in dem Bejtit-Beispiel: agrlimo - poljubimo) kommt, soll hier nur am Rande vermerkt werden. Vgl. auch die Vokalharmonie im letzten beispiel:

$e, a, i, e, e, a, i, 0, a, a$,

$e, a, i, e, e, a, i, o, a, a$.

Auch sie ist eine Folge des parallelen Baus und trägt weitgehend zu der Ornatusfunktion dieser Figur bei. 
Nicht selten begegnet das zweigliedrige Isocolon auch in der direkten Rede in der Art, daB der erste Teil des Isocolons die Prage, der zweite die Antwort enthält:

"o, devojko, boll li te na me?"

"Vita jelo, ne boli me na te,...

$$
\text { Boв. vila 1911, S. } 27
$$

Von gröBerem Wert für die Improvisation der Lieder ist das dreigliedrige Isocolon. Es tritt, da die Dreizahl in der Volksdichtung elne bevorzugte Rolle spielt, relativ oft auf. Da ein auf der Dreizahl beruhendes Isocolon vielfach auslösenden Charakter hat, ${ }^{1)}$ d.h. Im Iied in ähnlicher Form wieder aufgenommen wird, kommt ihm bei der Gestaltung der lieder häufig teilkompositorische Bedeutung $2 u$.

Der Schmuckcharakter dieses Isocolons wird nicht selten durch seine gleichzeitige Verbindung mit einer Klimax unterstrichen:

Ranfli safun poskupio,

Bistra voda zamracila,

Zarko sunce potamnilo."...

Die auslösende Wirkung dieses Isocolons findet ihre Bestätigung in der anschließenden Wiederaufnahme durch ein ebenfalls dreigliedriges Isocolon mit zusätzlicher Klimax, womit das Lied effektroll abgeschlossen wird:

Ranfli safun - tvoje ruke

Bistra voda - troje suze,

Zarko sunce - troje lisce." $\left.{ }^{2}\right)$

$$
\text { Blagajit, Nr. } 2
$$

oder, ebenfalls ein dreigliedriges Isocolon mit auslösender Wirkung, das sich in einer ganzen Variantengruppe findet ${ }^{3)}$ :

1) Vgl. dazu auch S. 92 und S. 92, Anm.2, zur koordinierenden Häufung.

2) Vgl. dasselbe Iied in leicht veränderter Porm in Behar 1908/09, S. 159, Petranovit, Nr. 150 und öfter.

3) Später werden die drei Pragen entweder verneinend oder bejahend oder verneinend $u n d$ bejahend wiederum in Form von Isocola beantwortet, so daB das ganze Lied zum gröBten Teil aus vier dreigliedrigen Isocola besteht (Vgl. dazu III,21). 
Fieli se tekelija,

Edelise รeftelija,

Ljubilise andelija' ${ }^{1)}$...

Erlangenski rukopis, Nr. 171

oder:

"Nase majke vi nas ne plačite,

Nǎ̧e seke vi nas ne zalite,

Naצe drage vi nas ne Cekajte,...

Hadzijahit, Nar. uz., Kal 1936,

Ein dreigliedriges Isocolon, dessen einzelne Glieder schon äuBerlich durch Numerale eingeleitet werden, zeigt folgendes Beispiel:

Jedna knije noge do koljena,

Druga zlati krila do ramena,

Treta niže krunu od bisera....

Behar 1909/10, S. 44

Neben dem dreigliedrigen Isocolon, das auslösende Punktion hat, findet sich nicht selten ein solches, das - meist weder mit Klimax - das Lied in wirkungsvoller Weise abschlieBt:

I na ruke belenzuke

I na glava almas granu

I na relo zlatno pero.

Novi behar $1934 / 35$, S. 378

oder:

Nehemed mi bijel zambak u čałi,

$\triangle$ Alija mavi zumbul u bašči

Mujo mi je zlatan džerdzer uz jastuk.

Kuba 1910, S. 523, Nr. 888

oder:

1) = Pije li se; Jede li se; Ljubi li se; Andelija. 
Ak' uzkara, izbiti te ne te,

Ak' izbije, izterat te ne te,

Ak' izcera, bjezi mome dvoru! 1 )

Jurcit, Nar. uz., Kal. 1944, S. 122

Während das zweigliedrige Isocolon formal und inhaltich meist In sich abgeschlossen ist, weist das dreigliedrige oft über sich hinaus, einmal wenn es auslösenden Charakter hat, zum anderen wenn es ohne zwingende Begrüdung der Dreizahl innerhalb einer Aufzählung erscheint (Vgl. dazu das Hadzijahit-Beispiel auf S. 117.). In seiner Preude am detaillierten Aufzählen und beschreiben geht der Sänger leicht über den Rahmen eines dreigliedrigen Isocolons hinaus; es entstehen dann sogenannte Isocolaketten, die meist mit der Pigur der koordinierenden Häufung zusammentreffen und eine noch gröBere kompositorische Funktion erlangen als die bisher behandelten Isocola. Durch die wiederholte parallele Aneinarderreihung von Kola und Kommata erleichtert sich der Sänger weitgehendst das Improvisieren:

Sto opada, ono pustenica,

Sto no vene, ono udovica,

Sto se crati, ono nevjestica,

Sto no gondze, ono devojcica....

Fopovit-Rodoljub, Nr. 67

Auch eine solche Isocolakette dient oft als etfektvoller Liedabschluß:

1) Das Isocolon ist hier mit einer Halbversgradatio verbunden. Die Abweichung vom parallelen Bau im letzten Halbvers erhöht nur noch den erstrebten Effekt.

In diesem Lied läBt sich ein Hedchen schon vor seiner Verheiratung mit einem burschen ein, was bei den Kuslimen relativ selten vorkam (Vgl. dazu S. 102, Anm. 1).

Der Kommentar des Aufzeichners zu diesem lied führt nur die Ausnahme zu dieser Regel an: "Ali nije uviek tako, da djevojka uspije otuvati Cast, jer ima slucajeva, da se rade previjanac kao diujo bazrdan,..."

(Jurlit, V., Muslimanska narodna lirika, Narodna uzdanica, Kalendar 1944, S. 122.). 
I Banja Luka bez kadiluka,

I seher Tramik bez pałaluka, 1)

I Sarajevo bez gaziluka,

A ja djevojka bez ałikluka?n

$$
\text { Dizdar I, Nr. } 52
$$

Eine noch umfangreichere Isocolakette mit Klimax, die ein Iied abschliebt, zeigt folgendes Beispiel:

Na sred mora najdublje dubljine,

Nia sred neba najviłe visine,

Na sred polja najłire కirine,

dia Kosovu najviße bojiłte,

Hercegovci najbolji junaci,

Sarajevke najbolje djevojke! ${ }^{2}$ )

Dizdar I, Nr. 241

Solche Isocolaketten können für ein ganzes Iied gestaltungsbestimmend werden. Im folgenden Beispiel schliebt sich drei Einleitungsversen eine füfgliedrige Isocolakette (Frage) an, die nach zwei 2 wischenversen in einer weiteren füfgliedrigen Isocolakette (Antwort) ihre das Lied abschlieBende Entsprechung findet:

$$
\begin{aligned}
& \text { Ima I' Sto కire od mora? }
\end{aligned}
$$

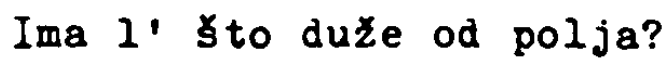

$$
\begin{aligned}
& \text { Ima } l^{\prime} \text { ' } \\
& \text { Ima I' Sto slade od meda? } \\
& \text { Ima } I^{\prime} \text { to draze od brata? } \\
& \text { Sire je nebo od mora. } \\
& \text { Duže je more od polja. } \\
& \text { Brže su oxi od konja. }
\end{aligned}
$$

1) In diesem Lied ist das Substantiv "Travnik" aus verstechnischen Gründen mit dem substantivischen Epitheton "Seher" gekoppelt, das ansonsten das stehende Epitheton zu "Sarajevon ist ( $V_{\text {gl }}$. dazu S. 110.).

2) Beachte auch die tautologischen Epitheta (Vgl. dazu S. 106 f.). 
Sladi je ̧̌ter od meda.

Drazi je dragi od brata!"

$$
\text { Dizdar II, Nr. } 103
$$

Das verschränkte Isocolon kommt meist in direkter Rede vor 1n Form des reinen oder fingierten Dialoges.

Reiner Dialog:

"Mehmed-beže, sta \&e dušek biti?

"Nuro, duso, troje bjelo lice!

"Mehmed-beze, fta le jastuk biti?

"Nuro, duš, troja desna ruka!"

"Mehmed-beze, zta ce jorgan biti?

"Nuro, duso, troji zlatni skuti!

Bos. vila 1898, S. 28

Erster, dritter und funfter Vers sowie zweiter, vierter und sechster Vers bilden hier jeweils ein dreigliedriges Isocolon. Pingierter Dialog:

Kakve su joj obrvice,

Valjaju joj Viß̌grada;

Kakve su joj treparice,

Valjaju joj Carigrada;

Kakve su joj b'jele ruke,

Valjaju joj Banje Luke; ${ }^{2}$

Kakve su joj ruse kose,

Valjaju joj c'jele Bosne ${ }^{2)}$

$$
\text { Dizdar I, Nr. } 134
$$

Eine in der Sevdalinka sehr beliebte Art, die Schönheit eines Mädchens zu preisen, besteht darin, deren Wert (vielfach, wie in diesem Beispiel, spezifiziert) dem ganzer Städte und Län-

1) Das Motiv, daB die Liebenden beim Schlafen einander die Arme unterlegen, findet sich sehr oft in der bosnischen Sevdalinka. Vgl. zu diesem Brauch auch Goetz, I.K., a.a.0., Bd. 1, S. 90 fl.

2) Abgesehen von anderen Kriterien können, wie in diesem Bei8 piel, auch Reim (ruke - Luke) bzw. Assonanz (kose - Bosne) Hinmeise auf die Frovenienz eines Liedes geben. Vgl. dazu auch S. 66 f. und S. 67 , Anm. 1 zum pseudoetymologischen Wortspiel. 
der gleichzusetzen. 1)

Aber nicht nur in direkter, auch in indirekter Rede ist das verschränkte Isocolon anzutreffen:

Gledala sam, kada sudje pere:

Sudje pere, lonca ne opere. -

Gledala sam, kada sobu mete,

Sobu mete, budzak ne izmete....

Novi behar $1927 / 28$, S. 251

In diesem Beisniel ist das Isocolon wirkungsvoll mit einer reduplicatio und einer annominatio verbunden. oder:

Ne placite oxi Carne,

jinot ste je gledale,

Vesel'te se medne usne,

Sinot ste je ljubile!...

$$
\text { Dizdar I, Nr. } 67
$$

Das Isocolon in Vers eins und drei ist hier gelockert einmal durch den Gebrauch der verneinten Verbform (Vers eins) gegenuber der bejahten (Vers drei) am Versanfang, zum anderen durch die Verwendung des Chiasmus "ołi Carne - medne usne" am Versende.

Bei einer Untersuchung des Isocolons verdient besondere Beachtung die sogenannte slavische Antithese, die sich fast immer der Form des Isocolons bedient. Je nach Umfang kann die slavische Antithese teilkompositorische oder seltener gesamtkompositorische Punktion baben. Improvisatorischer Fert kommt ihr in jedem Falle zu. Im folgenden werden zwei Beispiele für die slavische Antithese mit teilkompositorischer Bedeutung gegeben.

Am Liedanfang:

oj isoravo, sto si zamucena?

Ili pasie vojsku vodi,

Il' carevit konja poji?

Niti pašit vojsku vodi,

1) Vgl. dazu auch Goetz, L.K., a.a.0., Bd. 2, S. 23 f., 78 f., 91, sowie Teil I dieser Arbeit, S. 111, Anm. 3 . 
Nit' carevit konja poji,

Vet plivaju dvi Moravke,... 1)

Nilosevit IV, Nr. 429

In Iledinnern:

"Yto ne spavas, tursko momxe mlado!

"Ali ti je na du̧eku tvrdo?

"Ili ti je nisko na jastuku?

"Ili ti je pod jorganom zima?"

Progovara tursko momle mlado:

"Nije meni na duצeku tvrdo,

"Nije meni na jastuku nizko,

"Niti mi je pod jorganom zima,

"Vet ja volim ljubiti djevojku,

"liego Ajku udovicu mladu." 2)

Petranovit, Nr. 250

Palle, in denen ein ganzes lied einzig auf der slavischen Antithese aufgebaut ist, bilden im bosnisch-hercegorinischen Liedmaterial keine Ausnahme. Nachfolgend dazu zwei Beispiele:

Sta se sjaji na sred Sarajeva?

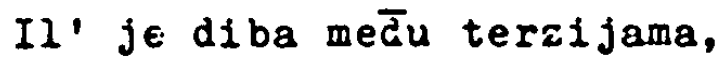

Ili cała me du bekrijama,

Ili svila medu veziljama,

Ili zlato me $\bar{d}$ kujundzijama? -

Nije diba medu terzijama,

Nije గała medu bekrijama,

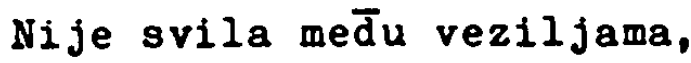

1) Diese slavische Antithese leitet die Lieder einer ganzen Variantengruppe ein. Vgl. dazu II,10, sowie II, 34 .

2) Die einzige Umstellung in der Hortfolge innerialb dieses Isocolons (nisko na jastuku - ra jastuku nizks) muB hier als Hyperbaton angesehen werden, als ein Hype:baton, das in der Prosasprache wegen der freien wortsteliung des Serbokroatischen keines werre. So kann eine Pigur (Isocolon) die andere (byperbaton) erhellen. 
Nije zlato me $\bar{d}$ kujundzijama,

vete sna'a me $\bar{d} u$ deverima.

Bos. vila 1908, S. 472

und :

Sta se sjaji na sred Sarajeva:

Il' je alem, il' je dragi kamen?

II' je diba medu terzijama?

Il' je cura medu djeverima?

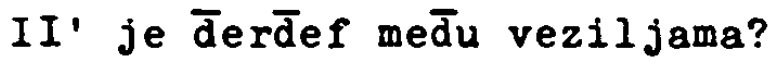

Il' je vila, ili ljuta guja?

II' je Caకa med̄u bekrijama?

Nit' je alem, nit' je dragi kamen,

Nit' je diba me $\overline{d u}$ terzijama,

Nit' je cura me $\overline{d u}$ djeverima,

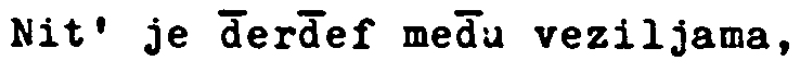

Nit' je vila, niti ljuta guja,

Vet je Łała medu bekrijama!

vino piju cetiri jarana!

Dizdar I, Nr. 272

Wie aus den Beispielen hervorgeht, kann die slavische Antithese eine mehr oder weniger umfangreiche Aufzählung in sich aufnehmen und so die Wirkung intensivieren.

Auch die verkirzte slavische Antithese wird meist in Form eines (nunmehr $z$ weigliedrigen) Isocolons realisiert:

Rodila loza dva grozda,

Hranila majka dvi kterki, 1)

In diesem Lied schliebt sich gleich noch ein weiteres zweigiliedriges Isocolon (ohne Antithese) an:

Jednoj je ime Anica,

Drugoj je ime karica....

Grgec, S. XIV

1) Vgl. dazu Grgec, P., Hrvatske narodne pjesme, Zagreb 1943, S. ALV: "Kadkada se takva poredba (gemeint ist die slavische Antithese, ii.E.) skratuje na taj natin, da se izostavija niekanje, a ostaje samo prvi i treti dio,...". 
Lieder, die sich von Anfang bis Ende der Figur des Isocolons bedienen, bilden in dem untersuchten Liedmaterial keine Ausnahme. Zur Illustration mag ein kürzeres Lied dienen, das aus zwei zweigliedrigen Isocola besteht, denen sich ein dreigliedriges, liedabschlieBendes anschlieBt. Im letzten Isocolon ist gleichzeitig eine dreifache iteratio enthalten:

Visoka jela do neba,

Siroka lista do zemlje.

I pod njom draci boluje,

Vire njeg' ljuba zaluje:

"Boluješ, dragi, bolujes?" -

"Bolujem, duङo, bolujem.

"Žaluješ, ljubo, Zalujes?n" -

Marjanovit, S. 200

AbschlieBend sollen noch einige Sonderformen dieser Figur aufgezeigt werden:

Bisweilen treten in den Liedern Isocola verschiedener Silbenzahl auf, meist in der Art, daB ein Vers (zwe1) Halbversisocola und der folgende ein Ganzversisocolon umfaBt. Diese Isocola sind vorwiegend in Liedern anzutreffen, deren Verse verschiedene Silbenzahl aufweisen, wobei der Hechsel von Acht- und Füf-Silber am häufigster zu sein scheint:

Sunce gledam, suze ronim, Srcem uzdiłem.....1)

Kuba 1908, S. 406, Nir. 522

oder:

Oči Carne, kose vrane,

Usta malena....

Dizdar I, Nr. 86

Diese besondere Form des Isocolons erscteint nicht selten in

1) $\mathrm{DaB}$ es sich um eine Verbindung von Halbvers- und Ganzversisocolon hardelt, wira erst deutlich, wenn man auch die lielodie berücksichtigt. In diesem Beispiel könnte auch ein 13-Silber vorliegen. Daß dies nicht der Pall ist, zeigt Kuba, der sich in erster Linie mit der lielodie beschaftigt und dessen Sammiung das Zitat entnommen ist. 
der elavischen Antithese, wobei dann (innerhalb der Frage) der eine Vers in Halbversisocola unterteilt ist und der folgende ein (erwitertes) Ganzversisocolon aufweist:

Il' je sunce, il' je mjesec,

Il' su sjajne zvjezdice....

Dizdar I, Nr. 276

Handelt es sich bei der Erweiterung zum Ganzversisocolon hier um eiren Grenzfall, so ist das Isocolon, in dem ein syntaktisches Glied (meist ist es das Verb) bei der weiteren Realisierung dieser Pigur weggelassen wird, als reines Isocolon anzusehen:

Akłam mrałe, moj prvi rōace,

A jacijo, moja posestrimo,

A zorice, moja dusmanice,...

Vasiljevit, Nr. $58 \mathrm{~b}$

Reine Halbversisocola kommen im Vergleich zu Ganzversisocola weitaus seltener vor:

A djevojce zalovito,

Jedno iste, oba daje....

Kuba 1908, S. 548, Nr. 594

oder, leicht abgewandelt:

Ne pij piva, ne pußi duvana,

lie asikuj, ne vezi sevdaha....

Bugarinovit, S. 54 (Nr. X)

oder, mit reduplicatio und Zäsurreim im ersten Halbversisocolon:

A ja jadan, a ja gladan,

A ja gladan, a ja Zedan,...

Dizdar I, Nr. 4

Des öfteren finden sich Halbversisocola innerhalb der slavischen Antithese:

"Al' po bogu? al' po rodu?

"hl' po babu? al' po majci?

.... Petrarovit, Nr. 125 
oder, wenn ein zunächst genannter Oberbegriff in den folgenden Versen spezifiziert wird:

Ja imadoh devet prstenova;

Dva su mavi a dva su almazi,

Dva su bjela, dva su od bisera,

A deveti od suroga zlata...

\section{Mirkovit, Nr. 68}

Eine Sonderform des Isocolons bzw. eine Ubergangsstufe zwischen halbvers- und Ganzversisocola ergibt sich oft dann, wenn mehr oder weniger umfangreiche Satzgefüge parallel gestaltet sind. In solchen Fällen tritt die Zäsur so stark in érscheinung, dak man das Ganzversisocolon auch als jeweils zwei durch die Zäsur getrennte Halbvereloocola auffassen kann.

Verbunden mit einem Antitheton:

Ko te ote, ne ponosi mu se;

Ko te nete, ne nameti mu se;...

Hiskovit, Nr. 121

Oft entsteht diese Form des Isocolons dadurch, daB es mit einer similitudo ${ }^{1)}$ verbunden wird, wobei die Glieder der similitudo entweder einen Ganzvers oder jewsils einen Halbvers umfassen:

Crati ruxo, nemoj opadati, (Bildebene)

Boluj draei, nemoj umrijeti;... (Ernstebene)

Bos. vila 1903, S. 288

oder, verstärkt durch Binnenreime:

Zora rudi, majka cerku budi.

Zora svita, majka kerku pita:...

Popovit-Rodoljub, Nr. 120

Ein solcher Sonderfall des Isocolons liegt auch dann vor, wenn in zwei aufeinanderfolgenden Versen zwei parallel gestalteten Aussagen jeweils eine epithetische Anrede vorangestellt ist. Im folgenden Beispiel wird das erste Glied der epitheti-

1) Vgl. dazu auch Pollok, S. 148. 
schen Veridindung in jeder Zeile halbversanaphorisch wieder aufgenommen:

Mili boze - mili ti bijasmo,

Dragi bože - dragi ti bijasmo....

Uirkovit, Nr. 204

Durch den parallelen Bau der Kola und Kommata innerhalb eines Isocolons treten in vielen Fällen automatisch auch andere Figuren auf wie Anapher, Epipher, complexio, reduplicatio, gradatio, Antitheton, Klimax, koordinierende Häufung usw., wobei die Parallelitüt der Gestaltung (Isocolon) auch im einzelnen besonders deutlich wird. Gleichzeitig gewinnen die mit dem Isocolon verbundenen Piguren inrerseits in inrer Wirkung an Farbe und Intensitit. 
TEIL II

\section{Vorbemerkungen}

In Teil II dieser Arbeit soll die Sevdalinka an Hand von Varianten untersucht werden, wobei besonders die sprachlichen Piguren dieses Liedes und deren chronologische Entwicklung betrachtet werden sollen. Als Materialgrundlage dienten 37 Grundlieder mit weit mehr als 500 varianten. ") Für diesen Variantenvergleich wurden nicht nur originäre Sevdalinke herangezogen, sondern auch - wenngleich in weit geringerem NaBe - Liebeslieder, die zwar in Bosnien und der Hercegovina gesungen werden, jedoch genetisch gesenen nicht als reine Sevdalinke anzusprechen sind. Da die Sevdalinka als Stadtlied jederzeit fremden Einfluissen gegenüber offen war, sind von ihr eine große Anzarl lieder anderer Gegenden Jugoslaviens aufgenommen und verarbeitet worden. Die Entscheidung daruber, ob es sich bei einem lied um eine Sevdalinka handelt oder nicht, muB sich stuitzen auf eine Untersuchung sowohl der sprachlichen wie der musikalischen Gestaltung. Es kommt nämlich vor, daß eine dem Text nach genuine Sevdalinka nach einer ihr fremden Volksliedweise wie eine Nichtsevdalinka gesungen wird oder umgekehrt, daB ein Liebeslied aus efrem anderen Bereich Iugoslaviens übernommen und melodisch wie eine Seviailinia ausgefürt wird. ${ }^{2)}$

Vor der 37 Grundliedern wurden 12 besonders typische, die bereits einen repräsentativen Querschnitt ergeben, einer eingehenderen Untersuchung unterzogen.

1) Eiz Verzeichnis cier Grundlieder mit den dazugehörigen Varienten steilt Tetl III dar.

2) Vgl. dazu etwa Milošvit, V., Sevdalinka, Banja Luka 1964, S. 30: "A.1 ?esma kao tekst može da bude ljubavna, dakle, sevdalinka jastirem smislu te rijeti pa da se ipak ne pjeva sevialijski i da ne bude sevdalinka kao melodija."

Oder, Nilozevit, V., a.a.0., S. 32: "Sevdalinka moze da bude svaka pjesma ljubavnog sadržaja; sve zavisi od toga kako se ona izvodi, ali pored toga sevdainka ima svoje muzicke karakteristike po kojima je ona nedvojbeno bas sevdalinka $i$ nista drugo." 
Im allgemeinen wurden nur solche Sammlungen herangezogen, deren Lieder der Herausgeber selbst aufgezelchnet hat oder hat aufzeichnen lassen.

Viele Lieder bzw. Varianten, die von den Aufzelchnern als fragmentarisch, zersungen oder schwach angesehen murden, ernielten aus eben diesen ästhetischen Gründen keinen Eingang in die betreffenden Sammlungen ") und sind somit für immer verloren. Dies ist insofern zu bedauern, als gerade solche schwächeren Lieder Aufschlüsse geben können über die Veränderungen Im Gebrauch der sprachlichen Piguren in bezug auf Improvisat1ons- und Tradierungstechnik.

Unter einem besonderen Punkt murden Kunstlieder, die im Laufe der Zeit zu Sevdalinke geworden sind, behandelt. An dieser Stelle wird auch auf einige andere fremde Einflusse auf dieses lied aufmerksam gemacht werden. ${ }^{2)}$

1) Vgl. dazu etwa das aus dem Jahre 1868 stammende Vorwort von Ristif zu dessen Sammlung, die 1873 erschien, wo es u.a. heiBt, daB Varianten, Pragmente und schwächere Lieder nicht mit in die Sammlung aufgenommen worden seien.

2) Zur chronologischen Einordnung der Lieder vgl. Tell III, Vorbemerkung. 
1. Ajde, draga, da asikujemo ${ }^{1)}$

"Hodi, draga, da ałikujemo!"

- Kako cemo kada ne umimo! -

"Kako bemo sjedi samo ovdje,

Sjedi ovdje, pa namiguj na me,

A ja bu se samo smijat' na te,

Ti ker zlato onda poti za me."

Zovko II, 3, Nr. 23 (1893)

Als Exposition dienen diesem kurzen liedchen die in allen Varianten im wesentlichen stets gleichen Einleitungsverse in direkter Rede ${ }^{2)}$ :

Hodi (ajde), draga (du̧o), da ałikujemo!

Kako cemo kada ne umimo (kad ne umijemo).

Von den zehn Varianten zu diesem Lied fällt lediglich das bel Zovko II, 3, Nr. 115 (1893) aufgezelchnete etwas aus dem Schema, indem es in der ersten 2 eile statt des Imperativsatzes einen (höflicheren) Fragesatz vorzleht:

Hotemo li ałikovat', dragi!

Kako temo, kad allzkin ${ }^{3)}$ n'jesmo!

"In Bosnten und der Hercegovina faljen zwei Haupttypen von Frauenliedern auf, die knappen, expressiv-emotionalen liedchen... und die in der Regel etwas längeren Lieder, die mehr oder weniger gesprächig irgendeine Kleinigkeit erzählen (priCalice)."4) Diese Sevdalinka zählt zweifellos zu den "knappen, expressiv-emotionalen Liedchen". Es ist durchaus möglich und wahrscheinlich, daß sie sich aus dem Brauch des "asikovanje" entwickelt hat, einer besonderen Art der Liebesbegegnung, die

1) Vgl. Teil III, Lied 1.

2) Uber den dialogischen Aufbau von Liedern vgl. Pollok, S. $199 \mathrm{ff}$.

3) aliskin $=$ vjest.

4) Peukert, H., a.a.0., S. 209. 
sich meist an Peiertagen, vor allem am Freitag ${ }^{1}$, dem muslimischen Feiertag, am Hoftor oder Fenster des Mädchens abspielte, und sich oft wochen- und monatelang hinzog. 2) Die Kürze des Iiedes, die Dialogform, die leichte Ironie und die feste Fugung der beiden Einleitungsverse sprechen dafür ${ }^{3)}$, ferner der (morphologische) Endreim der ersten beiden Zeilen "ašikujemo - umijemon, denn, so sagt Zovko: "Koliko sam mogao doznati, kod asikovaha je vrlo znatna stvar s $r$ o $k$ : jedno drugome mora po moguenosti odgovarati u sroku, te se cesto hihovi razgovori nizu kao stihovi." 4 )

Wie in unserem Lied haben auch beim "asikovanje" Rede und Gegenrede meist nur den Umfang von zwei Zeilen, etwa:

On: Dobar vece (jutro), srce drago!

Ona: Dao Bog dobro, moje drago! 5)6)

Von den zehn Varianten dieses Liedes aus dem Zeitraum von 1893-1964 sprengt lediglich WH VII, Nr. 1837) mit seinen 17 Versen den sonst üblichen Rahmen dieses Liedes. Der Omfang der

1) Vgl. dazu Hangi, A., a.a.0., S. 176 und Goetz, I.K., a.a.0., Bd. 1, S. 81, wo es heiBt: "Der beste Liebestag in der ganzen Woche ist der Sonntag, in muslimanischen Iiedern der Preitag,...".

2) Vgl. dazu Hangi, A., a.a.0., S. $173 \mathrm{f}$.

3) Zum Brauch des "asikovanje" vgl. auch S. 25 und S. 102 dieser Arbeit, Hangi, A., a.a.0., S. 169 ff., Mirkovit, P., Ałiklijske doskotice sa gjul-pendzera, Sarajevo 1913 und Zovko, I., Ałikovahe u Herceg-Bosni, ZbNŽ, Knj. 12, Zagreb 1907, S. 156 ff.

4) Zovko, I., a.a.0., S. 156.

5) Zovko, I., a.a.0., S. 157.

6) Etwas uberspitzt leitet Kuba das Entstehen der Sevdalinka ausschließlich aus dem "ałikovanje" ab: "Da nije ałikovanja, ne bi nikle ni one bezbrojne pesme koje izražavaju દežnju zaljubljenih srca. To su poznate sevdalinke." (Kuba, L., 0 bosansko-hercegovackim pesmama, in: Sarajevo, Almanat, Pregled, uredili: Dr. J. Krł̌l i J. Kušan, Sarajevo 1928, S. 23.)

7) Das Lied in IAH VII übernahm Mlat, $\mathrm{Kr}$. in seine Sammlung, Nr. 3. 
übrigen Liedvarianten schwankt zwischen drei und acht versen. Die ersten vier zeilen in MH VII sind mit denen der anderen Varianten identisch. Dann jedoch schlieBt das lied, breit erzählend, noch 13 Verse an.

Die Verse:

Sjedi ovdje, pa namiguj na me,

A ja bu se samo smijat' na te,...

kommen in derselben oder in ahnlicher Form, meist als:

Sjed' preda me, pa namiguj na me.

A ja cu se nasmijati na te!

sechsmal vor. Dreimal fehlen sie gänzlich, und einmal erfahren sie eine interessante Variation:

Stan' preda me prihvati se za me,

A ja tu se nasloniti na te.

Milorevit IV, Nr. 222

Hier sind lediglich die Worte "sjed"n, "namiguj" und "nasmijati" ersetzt worden durch gleiche Wortarten:

"stan"", "prihvati" und "nasloniti".

Das syntaktische Gerüst blieb also auch in dieser Variante erhalten.

Sieht man von R.a., inv. br. 8577 (1958), das mit seinen drei Versen nur ein Pragment darstellt, und VII, Nr. 183, das in stark erweiterter Form vorliegt, ab, so bleiben in den übrigen Varianten die vier besprochenen Verse ubrig, zwischen die sich in der Mehrzahl der Fälle noch folgender 2 wischenvers einschiebt :

Ja tu te be naučiti, dušo

In dieser Porm liegt das Lied dreimal vor (Milanovit, Hak, Dizdar). R.a., inv. br. 9162 (1962) verzichtet auf den Zwischenvers; in Bos. vils 1897, S. 139 fehlt er ebenfalls, erscheint aber in abgewandelter Form am Liedschluß. Zovko II, 3. Nr. 23 ersetzt den $\mathrm{Zwischenvers} \mathrm{durch} \mathrm{einen} \mathrm{anderen} \mathrm{(8.0.,}$ S. 130) und fügt noch einen sechsten, abschließenden Vers hinzu. 

$-133-$
Zusammenfassend kann zu dieser Sevdalinka gesagt werden,
a sie sich von ihrer ersten (1893) bis zur letzten Variante
1964) kaum verändert, dab sie lediglich Erweiterungen und Ve
uurzungen durch jeweils ganze Verse erfahren hat.
Die füf Grundverse gind durch Endreim und schwache Isocola
Halbversisocola) in sich gestutzt, so dab sie sich in allen
arianten leichter in gleicher Form erhalten konnten. $-133-$
Zusammenfassend kann zu dieser Sevdalinka gesagt werden,
daB sie sich von ihrer ersten ( 1893 ) bis zur letzten Variante
(1964) kaum verändert, daB sie lediglich Erweiterungen und Ver
kúrzungen durch jeweils ganze Verse erfahren hat.
Die füf Grundverse aind durch Endreim und schwache Isocola
(Halbversisocola) in sich gestutzt, so daB sie sich in allen
Varianten leichter in gleicher Porm erhalten konnten.

$-133-$
Zusammenfassend kann zu dieser Sevdalinka gesagt werden,
daB sie sich von ihrer ersten ( 1893 ) bis zur letzten Variante
(1964) kaum verändert, daB aie lediglich Erweiterungen und Ver-
kúrzungen durch jeweils ganze Verse erfahren hat.
Die füf Grundverse aind durch Endreim und schwache Isocola
(Halbversisocola) in sich gestutzt, so daB sie sich in allen
Varianten leichter in gleicher Porm erhalten konnten. - $133-$
Zusammenfassend kann zu dieser Sevdalinka gesagt werden,
daB sie sich von ihrer ersten (1893) bis zur letzten Variante
(1964) kaum verändert, daB gie lediglich Erweiterungen und ve
kürzungen durch jeweils ganze Verse erfahren hat.
Die füf Grundverse sind durch Endreim und schwache Isocola
(Halbversisocola) in sich gestützt, so dab sie sich in allen
Varianten leichter in gleicher Form erhalten konnten. - $133-$
Zusammenfassend kann zu dieser Sevdalinka gesagt werden,
B sie sich von ihrer ersten (1893) bis zur letzten Variante
1964) kaum verändert, dab sie lediglich Erweiterungen und ver-
Die funf Grundverse gind durch Endreim und schwache Isocola
Halbversisocola) in sich gestutzt, so dab sie sich in allen
Varianten leichter in gleicher Form erhalten konnten. - $133-$
Zusammenfassend kann zu dieser Sevdalinka gesagt werden,
daB sie sich von ihrer ersten (1893) bis zur letzten Variante
(1964) kaum verändert, daB sie lediglich Erweiterungen und ve
kürzungen durch jeweils ganze Verse erfahren hat.
Die füf Grundverse gind durch Endreim und schwache Isocola
(Halbversisocola) in sich gestutzt, so dab sie sich in allen
Varianten leichter in gleicher Form erhalten konnten. - $133-$
Zusammenfassend kann zu dieser Sevdalinka gesagt werden,
daB sie sich von ihrer ersten (1893) bis zur letzten Variante
(1964) kaum verändert, daB sie lediglich Erweiterungen und ve
kürzungen durch jeweils ganze Verse erfahren hat.
Die füf Grundverse gind durch Endreim und schwache Isocola
(Halbversisocola) in sich gestutzt, so dab sie sich in allen
Varianten leichter in gleicher Form erhalten konnten. 
2. Svi dilberi, samo moga nema $\left.{ }^{1}\right)$

Svi dilberi, samo moga nema!

Da li mi je Cut1, jal' vidjeti,

Il' boluje, ili asikuje!

Volim cuti i da mi boluje

Neg' da $s$ drugom dragom asikuje:

Bolujuti ikad ce mi doti,

Asikujut nikad nidor'jeka.

Vuk I, Nr. 359

Auch von diesem lied, das von einem eifersüchtigen tädchen singt (oder gesungen wird ${ }^{2}$ )), das dem Liebsten eher Krankheit als eine andere Geliebte wüscht ${ }^{3)}$, liegen zehn Varianten vor.

Fir sein relativ hohes Alter spricht nicht nur der Inhalt des Textes, sondern auch die Melodie, die sich der archaischen Pentatonik bedient. Bezüglich der Pentatonik sagt Maric: "U bosansko-hercegovalkom tonskom blagu koje je nekad zivilo i do nas se ocuvalo formirano u tonske sisteme $i$ tonske vrste $i$ koje $i$ danas zivi skrenut cu paznju $P$ e n $t$ a $t \circ n s k \circ j$ ljestvici."4) Als Beispiel führt Marit eben dieses Lied an 5 und sagt dazu: "Osim navedenih primjera ima joł u Kubinoj zbirci mnogo

1) Vgl. Teil III, Lied 3.

2) Die Sevdalinke werden, wie leicht aus dem jeweiligen Inhalt zu ersehen ist, nicht nur von Mädchen gesungen, sondern auch von Burschen. Dieses Nebeneinander von Mädchen- und Burschenliedern ist charakteristisch für die Sevdalinka und kann bis in die neueste 2 eit verfolgt werden. Als guinstig erweist sich daher die Einteilung der Liebeslieder von Nikola Andrit in Band 7 der Matica Hrvatska (MH VII) (das Liedgut dieses Bandes setzt sich vorwiegend aus bosnisch-hercegovinischen Liedern, Sevdalinke, zusammen) in "djevojacke" und "momakke". v. Milosevit (Sevdalinka, Banja Luka 1964, S. 7) spricht in diesem Falle auch von "haremsko" und "begovsko pjevanje".

3) Vgl, dazu auch Goetz, L.K., a.a.0., Bd. 1, S. 130.

4) Niarić, B., Pentatonika u bosansko-hercegovackoj puckoj muzici, Zagreb 1938, S. 3.

5) Marit, B., a.a.0., S. 8. 
pjesama koje u pojedinim djelovima imaju pentatonične značajke." 1)
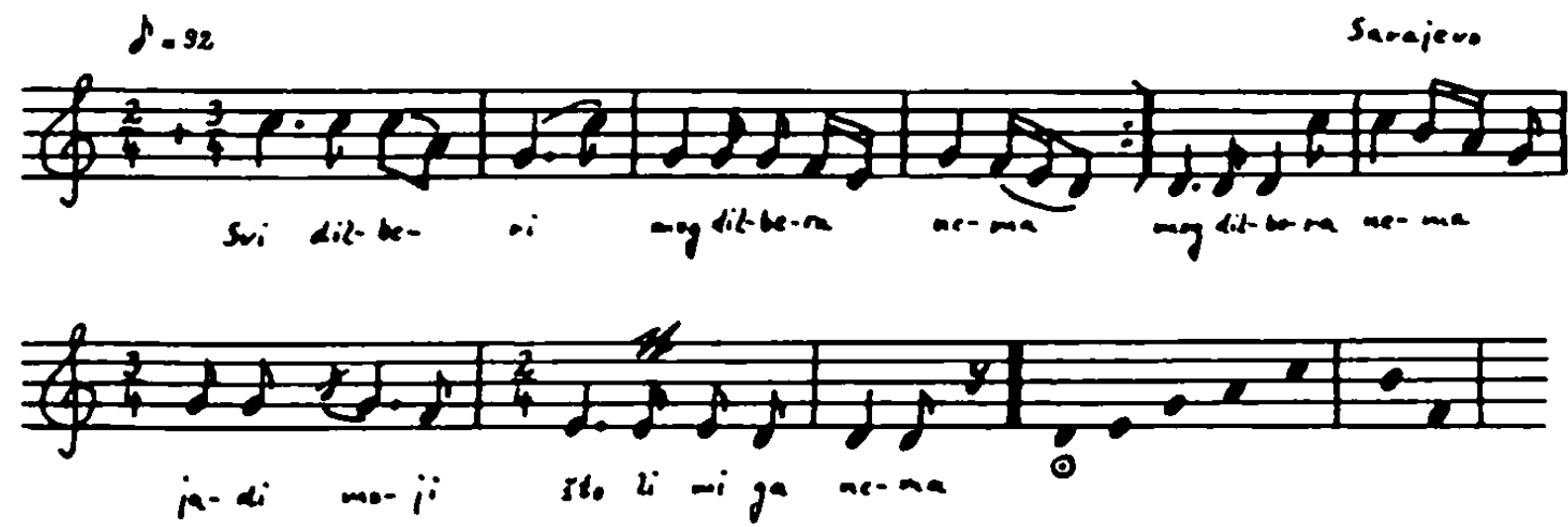

Aus diesem Notenbeispiel wird gleichzeitig die repetitio "Svi dilberi, mog dilbera nema" ersichtlich, die in der bloben Textaufzeichnung nicht erscheint. Bei Milołevit IV, Nr. 379 ist zu diesem selben lied eine andere Melodiefassung angegeben, in der ebenfalls der ganze Vers (Ganzversrepetitio) wiederholt wird. ${ }^{2)}$

Lediglich in der Variante Zovko II, 4, Nr. 239 wird die repetitio auch ohne Notenbild ersichtlich:

Svi dilberi moja mila majko,

Svi dilberi mog dilbera nema.

Da es sich jeweils um eine Ganzversrepetitio handelt, haben wir es gleichzeitig mit einer Anapher und teilweise (Marit, Miloß̌vi() mit einer Epipher zu tun.

Von den zehn Varianten sondern sich nur zwei in weiterem Maße von den übrigen ab. Es handelt sich um das Lied Vuk II, Nr. 68, das, ähnlich wie bei dem unter Punkt 1 untersuchten Lied die MH VII-Variante, in erweiterter Form vorliegt, und um das Dizdar II-Lied, S. 13, das dem Anfangsvers "Svi dilberi samo

1) Maric, B., a.a.0., S. 8.

2) Nicht selten treten $z u$ einem Grundlied neben textliche aucu melodische Varianten. $\mathrm{Vgl}_{\mathrm{g}}$. dazu auch Sarajlit, S., Sevdalinke, Narodna uzdanica, Kalendar 1943, S. 125: "Na primjer: "Igrali se vrani konji", "Kad ja podem na Bendbašn" ili "Je $l$ ' ti žao što se rastajemo?" $i$ t.d. pjevaju se u 2-3-kajde različito." - ileitere solcher Beispiele ergibt ein Vergleich der bedeutenderen kelodiesammlungen (Kuhă̌, Kuba, Killoševic u.a.). 
moga nema" noch ein Naturbild als kurze Exposition vorausschickt. Es 18t typisch und charakteristisch, daB dieses Naturbild als Einleltung ("Bulbul mi poje, zora mi rudi, a moga dragog nema") nur in einer Variante erscheint. Im allgemeinen macht der Sänger der Sevdalinka in nur geringem MaBe von einer solchen Exposition Gebrauch, die $81 \mathrm{ch}$ in den Liebesliedern anderer Gegenden Jugoslaviens gröBerer Bellebtheit erfreut. Die Sevdalinka zieht es vor, sofort in medias res zu gehen. 1 )

Alle Varianten stellen in Form einer Halbversanapher die Prage: "il' boluje, ili asikuje", die in zwel Varianten (Vuk II, Dizdar II) noch um ein bzw. mehrere Glieder erweitert ist.

Wărend wiederum das Dizdar II-Lied als einziges in Porm einer slavischen Antithese weitergefuhrt wird (je dreimal "ili" und "niti") und positiv mit dem Erscheinen des gellebten Burschen endet, fahren alle übrigen Varianten mit den Versen:

Volim Cuti (voljela bih) 1 da mi boluje,

Neg' da 8 drugom dragom arikuje

fort und lassen so das Iied inhaltlich gewissermaBen offen.

Die karge Bugarinovic-Variante endet mit diesen Versen; Vuk II schildert dagegen breit die Hilfelelstungen, zu denen das Madchen im Palle einer Krankheit des Burschen bereit wäre. Alle übrigen Lieder - bis auf die erwähnte Dizdar II-Variante lassen lediglich noch 2 wei erklärende Verse in form elnes schwachen Isocolons folgen, in denen das Mädchen begründend sagt:

Bolujuti 1 kad te mi dots.

Ałikujut nikad ni do v'jeka.

Die oben erwähnten Verse in der strengen Form einer Halbversanapher und die abschließenden, aurch ein (Halbvers-) Iso-

1) Vgl. dazu, die serbischen Liebeslieder betreffend, Burovit, D.P., Studije o srpakoj narodnoj lirici, Skoplje 1921,s. 24: "U srpskoj narodnoj liricl nema pesama, u kojima bi se, 1sključivo crtale slike prirode. Narodna poetika je spojila proletnji 1 ljubavni motiv u jednu pesmu, jer narodni pesnik oseta potrebu u slivanju svoje ličnosti s velikim $i$ divnim u prirodi. Ali se on zaustavija pred Earobnon slikom prirode u osetajnom razmigljanju, pesnika savladuje eroti $x_{n}$ osetaj. I slika prirode sluzi u pesmi samo kao prvi akord za izraz neźnoga ljubavnoga osetanja." 
colon mit jeweils verseinleitenden kontrastierenden Gerundia gestutzten, erweisen sich in den Varianten als die beständigsten.

In vier Varianten, also fast 50\%, wird der Einleitungsvers: jvi dilberi, mog dilbera nema durch einen weiteren, eine Epipher bildenden, erweitert: idil Boze, sto li mi ga nema?

Deatlich tritt hiermit in diesem lied und seinen Varianten die Finktion der sprachlichen Piguren nicht nur als Improvisations-, sondern auch als Tradierungserleichterung zutage, denn gerad: die Verse, die durch Piguren reich gestutzt sind, werden an seltensten im Laufe der Tradierung aufgegeben. 
3. Ne Cudim se mraku ni oblaku')

A. Ne cudim se mraku ni oblaku,

N1 Vrbasu, to se cesto muti,

Vet svom dragom, to se na me ljuti,

Sto sam drugog otim pogledala.

Ako sam ga orim pogledala,

Ja ga nisam $\operatorname{srcom}^{2}$ sevdisala,

Seviliala ni begenisala,

OXi voda, svukuda gledaju,

Medna usta sa svakim govore.

Kuba 1908, S. 549, Nr. 6013)

B. Ne Cudim se prosu pri planini,

Ni Varcaru, sto je u dolini,

Ni Jezeru, sto je na vodici,

A ni Jajcu, sto $j^{\prime} u$ tisnom klancu,

Ni Vrbasu, sto se resto muti,

Vet svom dragom, to se cesto ljuti.

Al ako se ja na njeg razljutim,

Sva nas Bosna pomiriti ne te,

Ni sva Bosna ni Hercegovina,

Ni bijelo Livno do Travnika,

vece opet nasa medra usta,

Medna usta $i$ zecerli riti!

MH VII, Nr. 51

Die Varianten zu dieser Sevdalinka teilen sich in zwei Hauptgruppen ( $v g l$, oben $A$. und B.). Das lied ist in BosnienHercegovina sehr beliebt, wofür äuBerlich schon die große

1) Vgl. Teil III, Lied 6.

2) Hohl: srcem.

3) Obwohl die Sammlungen mit Melodieangaben (Kuhac, Kuba, Miloß̌evit u.a.) ihr Hauptaugenmerk gewöhnlich vor allem auf das Notenbild richten und weniger auf eine vollständige filedergabe des Textes, so stellt hier jedoch der Text Kubas eine brauchbare Variante zu diesem Lied dar. 
Zahl, 22, der aufgefundenen Varianten spricht. Zu diesen gesellen sich noch neun selbständig gewordene Pragmente und zahlreiche Wiederabdrucke des Liedes in populären Sammlungen. Dichterisch verarbeitete dieses Lied Osman Bikil, dessen Gedichte im ubrigen des ofteren als Sevdalinke aufgefaBt und als solche gesungen werden ${ }^{1)}$ :

Moj se dragi naljutio na me, Hefta $j$ ' dana hic ne haje $2 a$ me, Niti da mi na kapiju dode, Nit nałijem sokakom da prode! Da je za to ne bih jadna bila, - Hic mu, vallah, nisam ucinila! Samo sto sam drugog pogledala, Pogledala, selam odazvala! Ako sam ga okom pogledala, Ni jesam ga srcem sevdisala. Ako sam mu selam odazvala, Nijesam ga dragijem nazvala. Jedno srce jednog samo ljubi; Aman dragi, ne ljuti se viłe, Moja dusa $2 a$ te samo dise! Aman do $\bar{d} i, i$ sokakom pro $\bar{d} i$, Ne muci me, ne teraj inada, Srce te mi presvisnut od jada! ${ }^{2)}$

Die Popularität dieser Sevdalinka erklärt sich u.a. aus der Verwendung des beliebten Zornmotivs, dessen Bedeutung im Liebesvolkslied daraus hervorgeht, daß "unter dem verschiedenartigsten Kummer, den der Bursche manchmal schildert, der dritte und größte ist, "daß sich meine Liebste gegen mich erzürnte" "3)4)

1) Vgl.dazu auch Braun, M., Die Anfänge der Europäisierung in der Literatur der moslimischen Slaven in Bosnien und Herzegowina, S. 124 ff.

2) Bikit, O., Ałiklije, Mostar 1903, S. 24.

3) Goetz, L.K., a.a.0., Bd. 1, S. 124.

4) Vgl.dazu auch die Varianten zu diesem Lied in III,6 und die oben angefürte Variante 
oder umgekehrt, vom Mädchen aus gesehen, wie im vorliegenden Text, daß sich der Liebste gegen sie erzürnt. Es ist eben dieses Lotiv, das sich in verschiedenen fragmentarischen Passungen verselbständigt hat. Neben dem Zovko II-Lied (2, Nr. 111) 1Bt eines der schönsten Pragmente, das zu einem selbständigen Ifed wurde, bei Dizdar (I, Nr. 259) zu finden. Es hat die fur die Sevdalinka charakteristische anaphorische Einleitung eines jeden Verses mit der Interjektion "hajn"

Haj, srdo moja, ne srdi se na me!

Haj, jer ako se ja nasrdim na te,

Haj, sva nas Bosna pomiriti nete,

Haj, ni sva Bosna ni Hercegovina,

Haj, ni sva sela oko Sarajeva,

Haj, samo mogu troja medna usta.

In Gedichten der sog. "gradanska lirika" aus dem 18. Jahrhundert tritt dieses Pragment verschiedentlich als $\mathrm{Zwischen-}$ stück auf. 2 )

Aus den letzten Versen der 0.a. Variante A. haben sich wiederum selbständige Ifeder entwickelt, z.B. In Bos. vila 1895 , S. 28 und Popovit-Rodoljub, Nr. 72:

Draga moja ne namiguj na me,

oxi moje ne gledaju na te,

Srce moje $i$ ne haje $z a$ te.

Na oxima kapidzije nema

Na ustima jasidzije nema,

oci, roda svakoga gledaju!

Popovit-Rodoljub, Nr. 72

Um nicht alle Varianten einzeln behandeln zu müssen, trotzdem aber die Wichtigkeit und Beständigkeit der sprachlichen Piguren darlegen zu können, mag zu diesem Lied und seinen 22 Varianten eine Statistik folgen: es bedienen sich des durch den Binnen-

1) Vgl. dazu S. 23.

2) Vgl dazu: Srpska gradanska poezija XVIII 1 s połetka XIX stoleta, I $i$ II, Priredio B. Marinkovit, Beograd 1966, Bd. II, Nr. 439. Das Lied 1st übernommen aus der "Pesmarica Avrama bilietican, 1778-1781, Nr. 34.). 
reim "mraku - oblaku" eindrucksvollen Einlei tungsverses:

Ne Cudim se mraku ni oblaku

14 Lieder

Ne cudim se Pruscu ( $s i p u=$ einmal) pri planini

4 Lieder

Ne Cudim se suncu ni mjesecu

1 Lied

Ne Cudim se mrkonji oblaku

1 Lied

Der Vers fehlt gänzlich in

2 Liedern

22 Lieder

Eine asyndetische koordinterende Häufung, gestützt durch strenge Isocola und oft durch Endreim gebunden, etwa nach dem Schema der oben zitierten B.-Variante, schliebt sich in sieben Liedern dem jeweiligen Einleitungsvers an. Die úbrigen 15 verzichten gänzlich auf diese Erweiterung.

Es folgt in den Varianten entweder sofort oder nach der koordinierenden Häufung (siebenmal) das durch Endreim (muti Ijuti) und schwaches Isocolon zusammengehaltene Verspar:

Ni Vrbasu (Neretvi), sto se cesto muti,

Već svom dragom, sto se na me (Cesto = zweimal) ljuti in 18 Varianten.

Ls ist durch die koordinierende Häufung auseinandergerissen

in 2 Varianten. Es fehlt

in 2 Varianten. 22 Varianten.

Ein Lied (Davidovit) endet bereits mit dem Vers:

Vet mom dragom, sto se na me ljuti.

Die weitgehend parallelen und durch repetitio, Epipher, Isocolon und Alliteration (srcem sevdieala) gestuitzten verse:

Sto sam drugog oxim pogledala.

Ako sam ga oxim pogledala,

Ja ga nisam srcem sevdisala...

treten in der Mehrzahl der Varianten auf:

$14 \mathrm{mal}$

Die ubrigen Varianten fahren wie Variante B. fort: $7 \mathrm{mal}$

21 Lieder.

In den meisten der 14 A.-Varianten schliebt sich eine (in 
der Sevdalinka beliebte) reduplicatio an:

Ja ga n'jesam srcem sevdisala,

Sevdisala, ni begenisala.

Diese Pigur findet sich achtmal. Ihr folgt in der Mehrzahl der Lieder ein sentenzartiger SchluB, der in einigen Varianten noch breiter ausgebaut ist we etwa in der o.a. Variante $A$.

$\mathrm{Z}$ wei Lieder entleihen ihren SchluB Teilen anderer Sevdalinke:

1. Kuba 1908, Nr. 473:

Sevdisala, ni begenisala.

Jesam il ti govorila dragi,

Ne asikuj, ne vezi sevdaha,

od sevdaha gorjeg jada nejma,

A zalosti od asikovanja.

Na zalost te 1 komsija doti

A za jade niko $i$ ne znade, Poßlje boga 1 sevdaha moga. ${ }^{1)}$

2. Rubit IV, S. 290:

Sevdisala ni begenisla.2)

Mili Boze 1 u mene jada!

Sto je gore, da je kalemova,

Sto je vode, da je murecefa,

Sto je momak, da su sve tatibi -

Ne bi moji' jada ispisali. 3)4)

Auch die Untersuchung dieser Sevdalinka und ihrer Varianten macht ersichtlich, daB den sprachlichen Figuren bei der Tradierung der lieder eine besondere Funktion zukommt. Schon jetzt darf gesagt werden, $a a B$ Isocolon, Anapher und Epipher, redupli-

1) Zu diesem SchluB vgl. Lied 7 in II, 13b und III, 7.

2) Wohl: begenisala.

3) Das lied wurde hier wortgetreu mit orthographischen und grammatischen Fehlern übernommen.

4) Zu diesem SchluB vgl. Lied 27 in II, $13 f$ und III, 26. 
catio und Epiploke sowie koordinierende Häufung, repetitio und Reim dabei eine gröBere Rolle spielen als etwa iteratio, Epitheton, Polyptoton, figura etymologica oder annominatio, die mehr für die Improvisation der Lieder von Wichtigkeit sind.

Auffallend 1st ferner, daß der Mehrzahl der Varianten ganze Verse oder Versabschnitte gemeinsam sind, innerhalb derer seitener Worte ausgetauscht werden. Geschieht dieses jedoch, so handelt es sich meist um Eigennamen oder geographische Bezeichnungen (z.B. Im vorliegenden Lied Vrbas - Neretva), was oftmals Rúckschlüsse auf den Entstehungs- bzw. Aufzelchnungsort des Liedes zuläßt.

Unterschiede ergeben sich also hauptsächlich aus dem Fehlen oder Hinzutreten ganzer Verse, aus dem fruh- (ggf. vor-)zeitigen AbschluB von Liedern (Fragmente, deren Ursache nicht selten fragmentarische Aufzeichnungen sind) oder aus der Erweiterung eines liedes durch Verschmelzung mit einem anderen (siehe Rubit IV, S. 290 und Kuba 1908, S. 261, Nr. 473.).

So kommt allen in Tell I behandelten Figuren eine mehr oder weniger wichtige Aufgabe teils fur die Improvisation, teils für die Tradierung $z u$. Es ist nicht nur so, wie Banovit meint, daß der Sänger nach Reimen und Alliterationen "jage" und in ihnen "genießend schwelgen"). Gewi B spielen auch ästhetische Gründe und Freude am Gleichklang eine Rolle, jedoch darf man die Ursache für Reim und Alliteration im fied nicht ausschlieblich hier suchen. Beide Erscheinungen sind eher im Gefolge solcher Piguren wie etwa endreimförderndes Isocolon, figura etymologica, Yolyptoton, pseudoetymologisches Wortspiel, reduplicatio

1) Banovic, S., Tri priloga za proutavanje hrvatske narodne i umjetne poezije, JAZU, Zagreb 1952, S. 205: "Narodno uho ne samo sto uziva u sroku pjesama, nego ono vrlo dobro razabira aliteracije loveli iste suglasnike ne samo, kad su oni na pocetku susljednih rijedi, nego kad su i u njima."

Als Beisplele füht Banovic eine Alliteration im Polyptoton, verbunden mit einer figura etymologica an: Grlo grlu grlovala und einen Endreim im endreimfördernden Isocolon:

Nek se svila u oblake vije, Nek se zlato u topove zbije. 
und annominatio zu suchen, u.zw. "aliteracijan") als Polge von figura etymologica und Polyptoton, "srokn" als Polge des endreimfördernden Isocolons, "leoninski srokn"1) als Polge von reduplicatio und annominatio.

Wie fest die hier behandelten Figuren ins Bemustsein des Volkes eingegangen sind, mag abschliebend noch folgendes demonstrieren: die Zovko II-Sammlung lag in Sarajevo nur in einer Maschinenabschrift vor. Bel der Zovko II-Variante (1, Nr. 201) zu oben untersuchtem Lied unterlief dem Abschreiber eln bezeichnender Pehler, der nach der Korrektur noch zu erkennen war. In der Aufzählung in Porm der koordinierenden Häufung heiBt es in dem Zovko-Lied:

N1 Vakufu, sto je u ravnini,

Ni vrtlima, to su pri brdima.

Das "pri brdima" findet sich unter allen Varianten nur ein einziges Mal; statt dessen wird an dieser Stelle das endreimbildende "pri planint" verwendet. Das tat auch der Abschreiber, ehe er diesen Ausdruck bel der Korrektur durch den weniger geläufigen ersetzte.

1) Diese Begriffe finden sich bei Banovit, S., a.a.0., auf den Seiten 201, 205, 207. Banovit legte anscheinend $2 u$ sehr MaBstäbe der Kunstdichtung an Werke der Volksdichtung an. 
4. Sto se ono Travnik zamaglio ${ }^{1)}$

Sto se ono Travnik zamaglio?

Da li gori? Da l' ga kuga mori?

Niti gori, nit ga kuga mori,

Bevojka ga okom zapalila,

Carnim okom kroz srcali pendzer!

Zapalila dva nova dutana,

I u njima dva mlada betara,

I kaldrmu kud Abiba sece,

I mescemu, de kadija sudi!

Bos. vila 1889, S. 20

Welche Wirkung der Text dieser schönen Sevdalinka auch auBerhalb seines eigentlichen Lebenskreises ausstrahlt, mag folgende

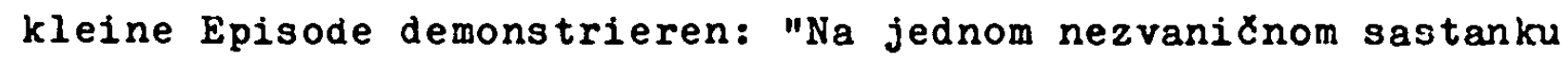
clanova PEN kluba u Stokholmu, u natjecanju ko ke citirati ljepకe stihove pobijedio je pjesnik Jovan DuXit. On nije recitovao svoje pjesme. To su bili oni poznati stihovi:

A sto mi se Travnik zamaglio?

Ili gori il ga kuga mori?

Niti gori nit ga kuga mori,

Djevojka ga okom zapalila!

Crnim okom kroz srtali pendzer."2)

Es liegen insgesamt 15 Varianten vor. In allen Liedern findet sich am Anfang, gestütt durch Anapher, Isocolon und den wirksamen Binnenreim "gori - mori", eine slavische Antithese.

13 der Varianten setzen unmittelbar mit dieser Figur ein, während 2 wei von ihnen noch drei Verse vorausschicken, die aus einem anderen Lied ubernommen sind:

Dv'je planine vrh Travnika grada -

Bukovica, spram nje vilenica.

1) Vgl. T'eil III, Lied 7.

2) Dizdar, H., Gdje je ona Cudnovata djevojka koja se je suncem povezala a mjesecom opasala?, Zivot, jarajevo, juri 1960, God. IX, Br. 6, S. 455. 
Vilenica Bukovicu pita:

"A sto mi se Travnik...

$$
\text { Dizdar II, S. } 8^{1)}
$$

Im Hinblick auf diese Sevdalinka erklärt Bejtit: "Taj motiv, u kojem grad pali djevojka okom, netko je kasnije sastavio 8 djelovima pjesme o pozaru Travnika 1903, pa je nastala opavka smjesa ${ }^{2}$ :...". Es folgt das Dizdar-Iied (siehe Teil III,7), und Bejtic fährt fort: "U stvari, ta pjesma o djevojci i njenom zarenju Travnika nema nikakve veze s onom o pozaru Travnika 19031 mnogo je od nje starija." 3)

Anstelle der geographischen Bezeichnung "Travnik" erscheinen je einmal "Mostar" (Zovko II, 2, Nr. 38) und "Sarajevo" (Jastrebov, S. 380 f.).

Viermal ist die slavische Antithese um jeweils einen Vers:

II' pucaju na gradu topovi bzw.

II' ga Janja odim' zapalila (Vuk I, Nr. 659)

und einmal um zwei Verse:

II' pucaju na gradu topovi,

Il' se Lą̌va u br'jegove Ijulja? (Zovko II, 1, Nr. 200) erweitert.

In elf Varianten schlieBen sich die durch lockere reduplicatio (epithetisch erweitert durch "crni") gefestigten und durch nichtindividualisierendes Epitheton ${ }^{4}$ ) besonders eindringlichen Verse an:

1) Heben dem Dizdar-Lied verwendet noch das von H. Humo aufgezeichnete diese Exposition.

2) Hohl: ovakva pjesma.

3) Bejtit, A., Prilozi proutavanju nasih narodnih pjesama, Bilten instituta a proucavanje folklora, Sarajevo 1953 , Sv. 2, S. 405 .

4) Vgl. S. $101 \mathrm{f}$. 
Djevojka ga okom zapalila,

Crnim okom kroz sreali pendžer. ${ }^{1)}$

2 wei Varianten enden mit diesen Versen (Humo, Blagajit).

Zwei weitere beschließen das Lied mit dem zusätzlichen Vers: Gledajuti, kud joj dragi seta. (Davidovit) bzw.:

Gledajuti dragog iz mehane. (Andrit II).

Alle übrigen Varianten (elf) lassen eine mehr oder weniger umfangreiche koordinierende täufung folgen, die in sich jeweils syndetisch oder polysyndetisch gebunden ist.

In fünf der restlichen elf Varianten $(=45 \not)$ erscheint die reduplicatio:

Izgorjese dva nova dutana,

Dva dutana 1 nova mejhana.

Das im zweiten Glied der reduplicatio aufgegebene Epitheton "nova"2) wird noch im selben Vers in anderer Verbindung wieder aufgenommen (nova mejhana).

Während das lied in sechs der letztgenannten Varianten mit der koordinierenden Häufung endet, wird es in den fünf übrigen in jeweils verschiedener Form (und Inhalt) noch weitergefürt, bei den Liedern Behar, Rubit und Jastrebov zweifelsohne durch Kontaminationen mit anderen Liedern. Bei Jastrebov geht es in einem Hochzeitsbrauchtumslied auf: "Vojdja $v$ komnatu "pochodarki" sadjatsja, a domasnija kladut na stojašcij posredi komnaty stol médpoe sirokoe bljudo. Na èto bljudo podocharki kladut svoi podarki nevestè. Pri ètom poězzane sostavljajut "kolo", prichvatyvajut $v$ kolo i zenicha, ctoby im poljubovalis' test'

1) Dieser Vers dient wiederum als Beleg für die Bedeutung des Fensters als wichtigem Schauplatz in der Sevdalinka. Vgl. dazu auch Goetz, L.K., a.a.0., Ba. 2, S. 200: niler sehnt sich die Jungfrau nach ihrem Liebsten,... Hier bahnt sich oft das Liebesverhältnis an." Vgl. zum "asikovanje" am Penster auch S. 102 und öfter.

2) "novi dutan" ist ein weiteres Beispiel für ein nichtindividualisierendes Epitheton, das für die Sevdalinka charakteristisch ist. Vgl, auch $\mathrm{S} .101 \mathrm{ff}$. 
1 teక̌ða 1 , tarcuja, pojut slędujusłija chorovodnyja pesni:...n ${ }^{1}$ ).

Diesen Ausfuhrungen Jastrebovs folgt der Liedtext, in dem als einzigem die liedeinleitende siavische Antithese in Dialogform durchgefuihrt ist.

Der Vergleich auch dieser Sevdalinka mit ihren Varianten macht deutlich, welch wichtige Funktion die sprachlichen Piguren bei der Tradierung der Lieder haben. Hier waren es besonders die slavische Antithese (plus Anapher, Isocolon und Reim), die reduplicatio, das Epitheton und die (polysyndetisch verbundene) koordinierende Häufung. Die sprachlichen Figuren erweisen sich als die Komponenten eines liedes, die am getreuesten uberliefert werden und also am wenigsten veränderungen unterworfen sind. Sie finden sich in nahezu gleicher Weise in den ältesten wie in den jüngsten Varianten. Lediglich der Schlub der Lieder scheint für gröBere Veränderungen anfälliger zu sein. Denn gerade am Ende (seltener am Anfang) lassen sich leicht Teile aus anderen Liedern anknüpfen. Dies geschieht oft auf so geschickte Art, daB die sich ergebenden Kontaminationen ein in sich geschlossenes neues lied darstellen.

1) Jastrebov, I.S., Obyči i pěsni tureckin Serbov, S.-Peterburg 1886, S. $379 \mathrm{f}$. 
5. Djevojka vice s brda visoka ${ }^{1)}$

Djevojka vice s brda visoka

I doziva sultan-Selima:

"Sultan-Selime, car gospodine,

lioze li biti riba bez vode,

Riba bez vode, ptica bez gore,

Seher Saraj'vo bez agaluka,

A Banja Luka bez kadiluka,

A seher Travnik bez pałaluka,

A Seher Foca bez begovluka,

I ja djevojka bez asikluka?"

Bejtit (Bilten II), S. 400

Diese Sevdalinka liegt in neun Varianten vor, wozu noch eine unvollständige Textfassung zu einer Kelodieaufzeichnung (Milosevit IV, Nr. 170) kommt. Das Lied entstand zwischen 1789 und 1807, zur Zeit der Herrschaft des Sultan Selim III. 2)

Trugen zur getreuen Tradierung der bisher untersuchten lieder wesentlich Piguren wie Isocolon, slavische Antithese und koordinierende Häufung bei, so ubernimmt diese Punktion im vorliegenden Lied (wie schon teilweise in Lied 4) die reduplicatio.

Drei der neun Varianten beginnen mit einer diese figur enthaltenden Exposition: Hir VII, Odobasit und Dizdar:

1) Vgl. Teil III, Lied 8.

2) Vgl. Bejtit, A., Frilozi proutavanju nasih narodnih pjesama, Bilten instituta za proucavanje folklora, Sarajevo 1953, Sv. 2, S. 400 f. Zur Entstehung dieses Liedes sagt Bejtit auf S. 401: "...da je $2 a$ vladavine sultana, opjevanog u toj pjesmi, izasla naredba o zabrani kretanja u gradu poslije mraka, sto su, dakako, zahti jevale neke izvanredne prilike. ia je naredba omela neke notne poslove, ali je isto tako pogodila, veli ta predaja, djevojke $i$ momke u njihovom asikovanju, koje se obilno obavljalo po noti uz musepke $i$ pendzere. hegodovarje protiv te naredbe i samih prilika, $u$ kojima je ona izdana, pojavilo se u djevojackom srcu, $i$ ona ga je na uvijen nadin iskazala u ojesmi $i$ uputila protest ne muteselimu, niti bosanskom veziru, nego caru u Stambol.... lieposredan povod mogla joj je doista biti zabrana notnog kretanja, ali u spomenutim ratnim godinama i nestałica momaka." 
Djerojka vice s visoka brda

$S$ visoka brda iz tanka grla:...

Die Odobasit-Variante notiert dazu noch die melodiebedingten, für die Sevdalinka typischen Interjektionen "dzanum" und "aman":

Djerojka vice s visokog brda,

S visokog brda, dzanum, aman,

Iz tanka grla.

Vier weitere Varianten (Bruerovit, Kuba 1906, Kuba 1907 und Bejtit) begnügen sich mit dem einfachen Einleitungsvers:

Djevojka vile s visoka brda (s brda visoka (golema)).

In ebenfalls vier dieser sieben Varianten folgt wiederum eine reduplicatio:

I doziva sultan-Selima:

"Sultan-Selime, car gospodine...

Als zusätzliche, die getreue Tradierung fördernde Figuren dieser Verse erweisen sich das Polyptoton (Selima - Selime) uná das nachgestellte doppelte substantivische Epitheton (cargospodine).

Einmal (Kuba 1906) heiBt es in leichter Abwelchung:

Care Lazare, po Bogu brate,...

und zweimal (Bruerovit und MH VII) erscheint nur der zweite Vers.

In allen Varianten schliebt sich dann der Monolog des Mädchens an, der den Kern des Liedes darstellt.

Das Zovko-Lied, Nr. 8, setzt unmittelbar mit diesem Monolog ein; es handelt sich also auch hier um den schon öfter konstatierten ausfall ganzer Verse.

Die neunte, letzte Variante endich (R.a., inv.br. 11014) - überhaupt ein schwächeres Lied - gebraucht den zersungenen Einlei tungsvers:

Tanahna grla sultan Selime.

Der honolog beginnt in sieben (!) Varianten wieder mit einer reduplicatio, 
viermal:

Može li biti riba bez vode,

Riba bez rode, ptica bez gore?

zweimal, umgestellt:

Moze 11 biti ptica bez gore,

Ptica bez gore, riba bez vode?

und einmal:

dioze li biti Tramik-kasaba

Travnik-kasaba bez pasaluka...

Die aus den anderen Liedern zitierten reduplicationes erscheinen hier später (s.u. uH VII).

Diese Verse zeichnen sich ferner durch einen strengen parallelen Bau aus.

Nur zweimal (Bruerovis und $R_{.} a_{\bullet}$ ) fehlen diese die reduplicatio enthaltenden Verse.

In allen Varianten folgt eine mehr oder weniger umfangreiche koordinierende Häufung ${ }^{1)}$, die strenge Isocola, Anaphern, ausgeprägte Endreime und teilweise weitergefuhrte reduplicationes aufweist. Sie ist in den meisten Fällen ganz oder - verstechnisch bedingt - teilweise durch die Konjunktionen 1 oder a oder 1 und a polysyndetisch gebunden ( $V_{g l}$. dazu das oben angefürte Bejtit-Beispiel). Mit dieser Reichhaltigkeit an den parallelen Bau der Verse betonenden sprachlichen Figuren geht oft eine weitgehende Vokalharmonie in den betreffenden Versen einher.

Füf der neun Varianten (55\%) lassen in der durch die koordinierende Häufung bewirkten Aufzählung eine deutliche Klimax erkennen und enden das Lied mit dem Vers:

I (a) ja djevojka bez ałikluka?n

Die Odobałic-Variante bricht mitten in der Aufzählung ab und darf als pragment angesehen werden.

1) Es handelt sich dabei wiederum un das Heglassen bzw. Hinzufügen ganzer Verse. 
Das Lied R.a., inv. br. 11014 hält mitten in der Aufzählung ein, endet aber noch nicht, sondern fährt von da an in von den übrigen Varianten abweichender Weise fort.

Kuba 1907 verzichtet ganz auf die reduplicatio, ersetzt diese aber gewissermaßen (in der Aufzählung) durch eine ausgeprägte Ganzversanapherkette (fünfmal in acht Versen). Das lied endet mit dem die Aufzählung abschlieBenden Vers:

Tica brez gore a ja brez draga?

Das wohl formal strengste lied dieser Variantengruppe ist das kunstroll auf die Figur der reduplicatio aufgebaute $\mathrm{MH}$ VII-Lied. Es mag hier vollständig wiedergegeben sein:

Djevojka vice s visoka brda

S visoka brda iz tanka grla:

"Sultan Selime, car-gospodine!

Moze li biti Travnik-kasaba

Tramik-kasaba bez pasaluka

I Banjaluka bez agaluka?

Hoze li biti ptica bez gore, Ptica bez gore, riba bez vode?

boze li biti dilber-djevojka

Dilber-djevojka bez mlada momka?"

iGH VII, Nr. 9

Wie in den bisher behandelten Liedern haben auch in diesem die geschichtlichen Umwälzungen - politisch für die muslimische Bevölkerung Jugoslaviens nicht immer ohne schwerwiegende Folgen ${ }^{1)}$ - keinen Niederschlag gefunden: die älteste Fassung dieses Liedes (Bruerovit, um 1790) ist in den neueren Varianten getreu bewahrt. $z u$ bemerken ist dabei allerdings, dab die in dem Variantenvergleich besonders häufig festgestellte reduplicatio bei Bruerovic noch nicht erscheint. Das von ing aufgezeichnete lied stützt sich formal auf die auch in den jüngeren Varian-

1) ilan denke nur an die österreichische Okkupation (1878), an die Zerschlagung des muslimischen Feudaladels (1919), aber auch an die einschneidenden Veränderuñ్n nach dem zweiten Keltkrieg. 
ten vorhandene Pigur der koordinierenden Häufung, die durch strenge Isocola und stark ausgeprägte Endreime in sich gefestigt ist: die reduplicatio der jüngeren Varianten entwickelt sich aus eben dieser Figur, indem sie jewells den zweiten Halbvers eines Gliedes der koordinierenden Häufung am Versanfang wiederholt. Das Irgebnis ist, daB in den jüngeren Varianten die koordinierende Häufung um einige Glieder erweitert ist. Der jüngsten vollständigen Variante (s.0. das Bejtit-Lied, 1953) soll hier noch die älteste gegenübergestellt werden:

Divojka vice s visoka brda:

"Sultan Selime, car gospodine, More li biti riba bez vode, A Banja Luka bez molaluka, Seher Saraevo bez agaluka, A ja divojka bez asikluka?"1)

1) Zitiert aus "Narodne pesme u zapisima XV-XVIII veka", ausgewählt von M. Pantit, Beograd 1964, S. 251. 
6. Posetala ljepotica Fata ${ }^{1)}$

Posetala ljepotica Fata,

o carøiju, niz carøiju sama.

Ona trazi Muju bazrdana

I Mujina tri nova dutana,

Nā̄e kuju na tretem ducanu:

-Daj mi, Mujo, jednu oku zlata.

- oj boga mi ljepotice Fato,

Ja ne mjerim u subotu zlato,

Jerbo mi se terezija mami,

Neg' unidi u novu magazu,

Ozmi zlata koliko ti treba.

Prevari se ljepotica Fata,

Pa ulazi u novu magazu,

Za njom Mujo zatvorio vrata

I obljubi Fati bijelo lice.

inlosevit IV, Nr. 342

Von den zwölf Varianten dieses liedes verwenden zehn den Einleitungovers:

Poretala ljepotica Pata,...,

wobei im einzelrez Pall ledsglich der Eigenname und gelagentlich noch das dazugehörige (oft substantivische) Epitheton individuell verändert erscheinen. Nur das Bugarinovic-lied (U Sarajua tri nova dutana) und der Text der Schallplatte Jugoton EPY 3637 B haben eine andere Exposition, der Schallplattentext insofern, als er dem oben zitierten Vers noch folgende Zeilen vorausschickt:

Iijepi li su Mostarski dutani, Jos su ljepsł mladi bazerdant, Joళ su ljepకi mladi bazerđani,

A najljepsi bazerdan Mustafa.

Haj, posetala Suljagina Fata,

Haj, posetala do Mostara grada;...

1) Vgl. Teil III, Lied 10. 
Interessant an dieser Liedeinleitung ist, daß sie sich schon in der Erlanger Handschrift befindet, allerdings als Introduction $z u$ einem anderen Lied ${ }^{1)}$ und ohne die Ganzversrepetitio "jos su ljepsi mladi bazerdant". 2)

Die zwölf Varianten weisen eine Durchschnittslänge von 27 Versen auf. Das lied gehört zu den "pricalicen, d.h. "längeren Liedern, die mehr oder weniger gesprächig irgendeine Kleintgkeit erzählen". 3) Es schildert, wie ein Mädchen, meist ist es Fata (<Fatima), das bei einem Burschen, meist ist es Mujo (<Mustafa), Gold kaufen will, von ihm in seinen Laden gelockt und auf drei Liebesnächte mit ihm dort eingeschlossen wird. 4)

Auch die Varianten dieser Sevdalinka bestätigen, daB Verse, die durch sprachliche Figuren formal gestützt sind, von der

1) Gesemann, G., Erlangenski rukopis starih srpskohrvatskih narodnih pesama, Zbornik za istoriju, jezik i knjizevnost srpskog narodna, Prvo odeljenje, Knj.XII, Sr. Karlovci 1925, Nr. 193.

2) Solche repetitiones (wie auch Interjektionen, s.o. etwa den zweimaligen, anaphorischen "haj"-Vorschlag) registrieren Sammlungen, die sich auf den Text beschränken, in der Mehrzahl der Fälle nicht. Vgl. dazu auch S. 32.

3) Peukert, H., a.8.0., S. 209. Vgl, auch S. 130 f. dieser Arbeit. - Der Terminus "episch-lyrische" Lieder, wie ihn Ijuba Simit für diese Art Lieder verwendet (Vgl. Simit, Lj., Prilog klasifikaciji narodne poezije, Posebni otisak Glasnika Zemaljskog muzeja, Etnologija, Sarajevo 1963, S. 145-152), scheint weniger glücklich gewählt, da er zwei exakt voneinander $z u$ trennende Liedgattungen, zumindest im Terminus, zu verbinden trachtet. - Vgl. zu dieser Problematik auch Schmaus, A., Gattung und Stil in der Volksdichtung, Rad kongresa folklorista Jugoslavije u Varazdinu 1957, Zagreb 1959, S. 169-173, sowie Braun, w., Zum Problem der serbokroatischen Volksballade, Slawistische Studien zum V. Internationalen Slawistenkongre B in Sofia 1963, Opera Slavica 4, Göttingen 1963, S. 151-174.

4) Deutlich tritt in diesem Lied der EinfluB orientalischer Bazarkultur auf die Sevdalinka in Erscheinung. Vgl. dazu auch Goetz, I.K., a.a.0., Bd. 2, S. 141: "Der Marktplatz ( Carsija), wo die Läden der Kaufleute und Gewerbetreibenden sind, wird oft erwähnt.... Der "junge Kaufmann", wie er gern näher bezeichnet wird, tritt im lied oft als liebhaber auf." 
ersten aufgezeichneten Fassung (hier: Vuk II, 1866 ${ }^{1}$ ), bis hin zu den jügsten (hier: R.a., inv. br. 7021, 1957 und lillosevic IV, Nr. 342, 1964) getreuer tradiert werden als solche, in denen eine derartige strukturelle Pestigung nicht vorhanden ist. Abweichungen ergeten sich im wesentlichen nur aus der Auswechslung einzelner Worte (meist Eigennamen) und aus dem Weglassen bzw. Hinzufügen syntaktisch einheitlicher Versabschnitte oder ganzer Verse.

Die durch iteratio gefestigten und durch Assonanz am Versende gebundenen und so an Ausdruck gewinnenden Verse:

U Carłiju, niz Carßiju sama

(Od ducana do ducana sama)

Ona trazi kuju bazrd̄ana...

finden sich in fün Varianten. Sie fehlen ebenfalls in füf Varianten. In zwel Varianten schlieBt sich der die Assonanz (sama - bazrđ̄ana) als reinen Reim weiterführende Vers:

I Mujina (1 njegova) dva (tri!) nova dutana

an, der das in der Sevdalinka zum stehenden Epitheton zu nduCan" (Laden ${ }^{2)}$ ) gewordene Adjektiv "nov, -a,-on enthält.

In der Mehrzahl der Varianten folgt dann der Dialog zwischen Mädchen und Burschen in durch Endreim gebundenen Versen, u. zw. dreimal mit der Reimbildung Pato (Vok. zu Pata) - zlato ${ }^{3)}$ :

"Daj mi, Mujo, jednu oku zlata.

- Oj Boga mi ljepotice Pato,

Ja ne mjerim u subotu (nedjelju) zlato,...,

1) Die Lieder stammen von Vuk VrČevit, wie Vuk St. Karadzic selbst im Vorwort zu dieser Sammlung schreibt. Vgl. dazu auch: Milakovie, J., Bibliografija hrvatske $i$ srpske narodne pjesme, Grada, I., Sarajevo 1908, S. 83.

2) Das aus dem Arabischen stammende Wort "ducan" (Laden) ist Besitz der gesamten serbokroatischen Sprache geworden, da sie für "Laden" keinen eigenen entsprechenden Terminus hat. Was die Volkslieder betrifft, so erscheint dieser Begriff je doch uberwiegend in der Sevdalinka als einem eben weitgehend urbanistischen Lied, in dem der EinfluB orientalischer Bazarkultur evident wird (Vgl. dazu auch S. 155, Anm. 4).

3) Wohl wegen der Eignung zur Reimbildung zu "zlato" wird in den Varianten der Eigenname "Pata" am häufigsten verwendet. 
und zweimal mit der Reimbildung zlata - vrata:

"Daj mi, Jovo (!), jednu litru zlata,

"Da usuCem buCmu oko vrata?"

Petranovit, Nr. 290

Nur einmal ist die den Reim bzw. die polyptotische Epipher trennende Zeile:

Al' govori Ivo (!) pelivane:...

Zovko II, 1, Nr. 79

zwischen diese Verse geschoben.

Als GoldmaB wird in den liedern genannt:

7 mal das Iiter $(=1 / 4 \text { Oka })^{1)}$

2 mal die Oka $(=1,28 \mathrm{~kg})^{1)}$

$1 \mathrm{mal}$ die tura $\left.(=\text { ein Bünde } 1)^{2}\right)$

1 mal die unca (= eine Unze)

1 mal wird eine unbestimmte Menge verlangt

$12 \mathrm{mal}$ Daj mi, aga, za derdefa zlata...

Bugarinovit, S. 36 f.

Nicht nur der Vorliebe des Volksliedes für Archaismen, sondern insbesondere "den konservativen Neigungen der bosnischen Moslims ist es auch zuzuschreiben, daB sie bis zum heutigen Tage im Verkehr unter sich noch die metrischen Masse und Gewichte nicht anwenden, sondern die oka...."3).

Die in den einzelnen Varianten unterschiedlich gestalteten Verse, die von der List des Burschen sprechen, werden durch den Vers:

Ijubio je tri bijela dana

fortgesetzt bzw. zu Ende gefürt.

wit der für das Volkslied typischen Dreizahl und dem zum stehenden Epitheton gewordenen Adjektiv "bjel" zu "dan" hat er fast den Charakter einer Schablone angenommen: er erscheint

1) Hangi, A., a.a.0., S. 9.

2) Karadzit, v.St., Srpski rjęnik, a.a.0., S. 780.

3) Hangi, A., a.a.0., S. 9. 
in den zwölf Varianten fünfmal.

In je einer weiteren Variante heiBt es ähnlich:

Tu su bili tri bijela dana (Gajret)

und:

Pa je ljubi $i$ dva $i$ tri puta (Davidovic).

Dieses Lied, das von einem überlisteten Mädchen singt, ist - im Gegensatz zu anderen Sevdalinke - verhältnismäBig arm an 8 prachlichen Figuren; es ist im einzelnen weniger stark festgelegt. Den Sängern stehen somit auch weniger Gedächtnisstuitzen zu Gebote, bzw. sie haben bei der Ausgestaltung des liedes mehr Freiheit zur individuellen Improvisation: so ergibt ein Vergleich der Varianten, daß die Lieder eben dort am häufigsten voneinander abweichen, wo die Verse in geringerem Maße von sprachlichen Figuren getragen sind. Auf eine kurze Pormel gebracht: je weniger sprachliche Piguren, desto unterschiedlicher die Varianten. 


\section{U Mostaru Geter mejtef kazu'}

O Mostaru recer mejtef kazu,

U njem' uxi trista djevojaka.

Hodza im je Omer efendija,

Kalfa im je lijepa Umihana.

Znas 11, kalfo, 8ta citabi kazu?

Prvi kaž da se hodza zeni,

Drugi kaže: nemoj sa daleka,

Treti veli kalfu iz mejtefa.

Kad to Cula lijepa Umihana,

Sve titabe $2 a$ vrata bacila,

Seler mejtef odmah ostavila,

Da se dragom ne bi zamjerila.

$$
\text { Gajret 1929, S. } 155 .
$$

Nahezu alle neun zu diesem Lied aufgefundenen Varianten - nämlich sieben - beginnen mit den Versen:

U Mostaru secer mejtef kazu,

U njem' udi trista (trides't) djevojaka.

Das der Sevdalinka elgentümliche substantivische Epitheton "̧eker mejtef" wird lediglich zweimal durch das adjektivische Epitheton "cudan mejtef" (Davidovit, Orahovac) ersetzt. Bei Davidovit findet sich ferner eine abweichende Lokalisierung des Liedes:

Preko Drine Cudan mejtef kazu.

Drei Varianten zelchnen nach dem ersten Vers auch noch einen - tellweise recht umfangreichen - Refrain auf, der nach jedem einzelnen Vers in gleicher Gestalt wiederholt wird:

1. Burma je jer. 0 ti Ale moj,

Blizu mene stoj, dobro me se boj.

milosevit IV, Nr. 374 (a)

1) Vgl. Teil III, Lied 11. 
2. Sitani, bahani de, ah moj, Dragi hoj, budi, budi moj.

Ako dadne bog, pa ti budes moj,

Blizu mene stoj.

Milosevit IV, Nr. 374 (b)

3. Cim beri bana, kim sana,

Sela masiri, selva burdum

Vezir ja - vezir ja. 1)2)

Davidovit, Nr. 236

Die Zahl der viädchen in dieser türkischen (Religions-) Schu$1 e^{3)}$ wird mit dreiBig (Dreizahl!), fünfmal jedoch hyperbolisch mit 300 angegeben. ${ }^{4)}$ Bei Milorevic IV, Nr. 374 (a) wird in diesem Zusammenhang noch folgender Vers, mit dem vorausgehenden ein schwaches Isocolon bildend, syndetisch angeschlossen:

I Eeterest mladih udovica...5)

Achtmal folgen den oben ange fuhrten Einleitungsversen die

1) Dieses Lied, vor allem aber der Refrain seiner Varianten, macht im Inhaltlichen wie Sprachlichen den orientalischen EinfluB auf die Sevdalinka besonders deutlich.

2) Auf Wiederholungsfiguren wie iteratio und repetitio (budi, budi moj; Vezir ja - vezir ja) im Lied oder im zugehörigen Refrain wird gelegentlich auch in Sammlungen ohne Melodileangaben hingewiesen, so in der Petranovit-Sammlung, etwa:

Gjevojka rani ran-bosiok sadi

$0 j$ dilbere, moj dilbere $\operatorname{dog} j i$ mi dodji? $x /$

Petranovit, Nr. 138

Es folgt die Erklärung:

$x /=$ Ovako se pripjevaju uza svaku vrstu do drugoga pripjeva, pak onda onako.

3) Die Religionsschule ist hier nur Schauplatz des Liedes. Vgl. dazu auch Pollok, S. 102, Anm. 31: "Noch seltener als in den übrigen Liedern ist ein religiöser Hintergrund in moslimischen Liedern zu finden. Religiöse liomente sind hier meist auf AuBerlichkeiten der Liedgestaltung beschrankt,...".

4) Solche Hyperbeln sind recht häufig. Vgl. etwa auch das nächste Lied $(I I, 8)$. In Anbetracht solcher und vieler ähnlicher Erscheinungen könnte man entsprechend dem Begriff der "epischen Naivität" den der "lyrischen Naivität" pragen.

5) Zur Bedeutung der Witwen in der Sevdalinka vgl. auch S. 110 . 
durch strenges Isocolon parallelisierten Verse:

Hodza im je Omer efendija,

Kalfa im je hierusa devojka ${ }^{1)}$,

bei Davidovic lediglich in der Reihenfolge vertauscht.

Nur die neunte Variante (Milosevic IV, Nr. 374 (a)) bildet insofern eine Ausnahme, als sie den zweiten vers ganz ausläBt.

Wie schon des öfteren konstatiert wurde, werden in den Varianten hauptsächlich Personennamen oder geographische Bezeichnungen ausgewechselt. Der Sänger scheint sie mehr oder weniger aus seiner eigenen engsten Umgebung zu wählen. Biographische Angaben über den Sänger, die in den Sammlungen meistens fehlen, könnten hier näheren AufschluB geben. In den beiden oben zitierten Versen, deren Form durch die Namensänderung im wesentlichen unberubrt bleibt, begegnen folgende Eigennamen:

a. für den hodża:

Omer efendija $-5 \mathrm{mal}$

Sacir efendija - $1 \mathrm{mal}$

Uso efendija $-1 \mathrm{mal}$

Seter Salihaga - $1 \mathrm{mal}^{2)}$

mladi efendija - $1 \mathrm{mal}$

9 mal

b. für das Mädchen:

Herusa devojka - $1 \mathrm{mal}$

lijepa Emina - $2 \mathrm{mal}$

lijepa Umihana - $2 \mathrm{mal}$

dilber Umihana - $1 \mathrm{mal}$

Hajra materina - $1 \mathrm{mal}$

Ajkuna djevojka - $1 \mathrm{mal}$

fehlt

$-\frac{1 \mathrm{mal}}{9 \mathrm{mal}}$

1) Zu der Beziehung hodža - kalfa sagt Hangi, A., a.a.0.,S. 153: "Allzugrosse juhe macht sich der Hodza in der Schule mit den Kindern gerade nicht. Er lässt sich von seinem "Gesellen" vertreten. So heissen nämlich im Volke jene älteren Schüler, welche den jügeren als ientoren zugeteilt werden."

2) Vgl. bezüglich dieses Namens die Varianten des Liedes 32 (III, 32). 
Diese Namensbezeichnungen bilden - zusammen mit dem häufig wechselnaen substantivischen bzw. adjektivischen Epitheton Innerhalb des Isocolons hin und wieder einen Chissmus.

In drei Varianten fährt das Lied fort mit dem in den ubrigen fehlenden Vers:

Pred njome su tri (!) titaba bila,

der eine dreifache koordinierende lüufung auslöst.

Andere Varianten schließen den Imperativsatz:

Kazuj hodza sta kitabi kažu

an, dem dann ebenfalls die dreifache koordinierende Häufung folgt.

Unterschiedlich $2 u$ den übrigen setzen nur drei Varianten (Davidovit, Biser, Milosevit IV, Nr. 374 (a)) das Iled fort, wovon das Davidovit-Iied eine Kontamination mit Lied 37 (II, 12, sowie III, 37) darstellt:

Ćitab kaže ne luduj djevojko.

Udakes se 1 pokajaber se,

Ne tes steti carstra djevojastra

Ni fesita, na Bosni pasita.

Abgesehen von den zuletzt genannten drei Varianten folgt in funf der restlichen sechs díe lcoordinierende Häufung:

Jedan (prvi) veli (kaze) da se hodza zeni!

Drugl veli: nemoj izdaleka!

Tret1 veli: kalfu iz mejtefa!n

In der Vuk-Variante lautet der zweite Vers abweichend:

Drugi vell: hoke, ako Bog da.

Das sechste Lied (Hilosevit IV, Nr. 374 (b)) verzichtet auf die Dreiteilung und endet mit den mehr zusamienfassenden Versen:

Kazuj hodza zta k1tavi kazu:

- Kitab veli da se hodza zeni, 
Da uzima Hajru materinu. ${ }^{1) 2 \text { ) }}$

Die Klimax in den drei Versen, die deutliche Betonung der Dreizahl und die Parallelismen im jeweils ersten Halbvers 3 ) haben viel dazu beigetragen, daB sich diese Verse in der Mehrzahl der Varianten (füf) in gleicher Form erhalten haben.

Während die Vuk-Variante mit diesen Versen endet und somit den Ausgang offenläßt, schließen die ubrigen vier lieder entweder (einmal) noch zwei Verse, um die positive oder (dreimal) noch vier Verse an, um die negative Reaktion des llädchens auf die Auslegung der heiligen Bücher durch den hodza zu schildern.

Es ist das Dizdar-Lied (I, Nr. 301), das in zwei Versen (in Dialogform), die durch eine Anapher verbunden sind, die positive Lösung bringt:

"Hotes li me, liepa Emina?"

"Hotu, hodza, prevarit te netu!"

Die drei Varianten Gajret, Orahovac (Islamski glas) und Dizdar II, die das Lied negativ enden lassen, unterscheiden

1) Vgl. dazu Goetz, I.K., a.a.0., Bd. 2, S. 148:

"Der muslimanische $G$ e me i n d e i e h r e r, der hodza, kann heiraten."

2) Ein wie hier deutlich ausgedrückter Heiratswunsch findet sich in den bosnischen Liedern seltener. Vgl. dazu Pollok, S. 175 f., Anm. 38: "Im westlichen Bereich (z.B. Bosnien und Serbien) steht demgegenüber (d.h. den bulgarischen und makedonischen Liedern, W.E.) die voreheliche, sich allein auf die Preuden der jeweiligen Gegenwart konzentrierende und nicht in die Zukunft weisende tiebe $1 \mathrm{~m}$ Vordergrund des Liedgeschehens. Die $z$ wischen den unverheirateten jungen Leuten herrschende Liebesfreude und ihr Liebeskummer sind hier die zentralen, immer wieder anzutreffenden Themen. In bosnischen Liedern erscheinen diese gegenseitigen Liebesbezeugungen insbesondere in der für jene Gebiete spezifischen Porm des geschickt gehandhabten Plirtes (ałikovanje, sevdalisanje)."

3) Ansonsten findet sich bei Versen, die unter Betonung der Dreizahl jeweils mit jedan (prvi), drugi, treli beginnen, Yarallelismus nicht nur im ersten, sondern häufig auch im zweiten Halbvers, z.B.:

Jedan dukat piva pijes,

Drugi dukat svircu dajes,

Treki dukat curi dajes!...

$$
\text { Dizdar I, Nr. } 4
$$


sich in der äuBeren Fassung der jeweils vier letzten verse beträchtlich voneinander. Typischerweise verwenden sie sprachliche Piguren fast gar nicht. 
8. Nostanice, rodo plemenita ${ }^{1)}$

Na Ophodi prema Bakijama

Moba Zanje age Pazlagita:

Sto momaka, trista djevojaka

I pedeset djece rodonora

I pred njima Pata Pazlagica.

Sama Zanje, sama snoplje veže,

Sama pjeva, sama pripijeva:

"Ah, Mostanice, vodo plemenita:

Usput ti je, selam tes mi dragom:

II' nek dōe, il' nek me se prode.

Nek ne kosi trave pokraj Save,

Pokosite moje kose plave.

Nek ne pije bunar vode hladne,

Popite mi moje oci vrane."

Bejtic (Bilten II), S. 387

Diese Sevdalinka liegt in acht Varianten vor, wovon $81 \mathrm{ch}$ 2wei relativ stark vom Grundlied unterscheiden (Zovko II, 2, Nr. 39 und Zovko II, 1, Nr. 40). Eine Melodieangabe zu diesem Lied, aber ohne weiteren Text, liegt bel Milołevit IV, Nr. 23 vor. Pür die nähere Untersuchung sollen deshalb nur sechs Varianten, die man im eigentlichen Sinne des Wortes als solche bezeichnen kann, herangezogen werden.

Das Lied ist sehr bekannt und gern gesungen. ${ }^{2)}$ Nicht zuletzt seiner groBen Bellebtheit verdankt es wohl auch die Dra-

1) Vgl. Teil III, lied 13.

2) Bejtit, A., Prilozi proucavanju nasih narodnih pjesama, Bilten instituta $2 a$ proucavanje folklora, Sarajevo, Sv. 2, Sarajevo 1953, S. 387: "Pjesma Na Ophodi prema Bakijama, poznata jos pod nazivom Mostanice, vodo plemenita, spada u najpopularnije sevaalinke Sarajeva 1 Citave srednje Bosne." 
matisierung durch Rasim Pilipovit. ${ }^{1)}$

Wie berelts mehrfach erwähnt, ist die Sevdalinka als urbanistisches lied nicht selten die individuelle schöpfung eines bekannten Autors. 2) Nichtsdestoweniger ist sie auch in diesem $\mathrm{Pal}-$ le als Volks- und nicht als Kunstlied anzusehen, da sich auch hier der (zwar bekannte) Schöpfer den Gesetzen der Volksdichtung unterwirf, was im Punkte der Improvisation weiter unten erläutert werden wird. 3 )

Die vorliegende Sevdalinka ist erstmals von Ćamila oder Ćanka Pazlagi( ${ }^{4}$ gesungen worden, deren Name später im lied selbst und dann gelegentlich auch verändert als DŽehva, Fata u.a. erscheint. Zur Geschichte des Liedes sei kurz folgendes gesagt: es entstand um 1883 zur Zeit der großen Pest in Sarajevo, die wahrscheinlich 8.000 Menschen hingerafft hat. Damals ubersiedelte der Aga Pazlagit, mit seiner Familie vor der Pest flüchtend, nach Ophoda, nordöstlich von Sarajevo, an die Mostanica, wo seine Besitztümer lagen. Zur Erntezeit sang seine Tochter Camila (nach Bejtit) oder Dzevahiva (nach Dizdar) dieses Lied, in welchem sie ihrer Sehnsucht nach dem Liebsten Ausdruck gab, von dem sie durch die Pest getrennt worden war ${ }^{5)}$ : sie trägt der Moßtanica Grüße an

1) Filipovic, R., Dvije komedije, Mala dramska biblioteka, Sv.8, Zagreb 1951. Bei der zweiten Komödie handelt es sich um eine Dramatisierung der populären Sevdalinka "Otkakn je Banjaluka. postala". Zur Geschichte der letzteren vgl. auch Kulenovit, N., Postanak nałe najljepłe sevdalinke, Vreme, Beograd 1,2, 3,4 maj 1937, God. 17, Br. 5494, S. 21, wo u.a. dieses Lied recht subjektiv als die schönste Sevdalinka hingestellt wird.

2) Aus diesem Grunde u.a. scheint die Zahl der Varianten zu dieser Art Sevdalinka relativ gering zu sein.

$V_{g l}$. auch Dizdar, H., Hostanice, vodo plemenita, usput ti je, selam tes mi dragom, Jugoslovenska posta 1938, Br. 2717 , S.9: "Za razliku od mnogih sevdalinki, koje je, kako znamo, ispjevao sam narod, narołito nałe djevojke, u ceznji, boli, nevolji $i$ radosti, za koje se tadno ne zna kad su $i$ gdje postale, "Moscanica" je vezana uz dogadaje i lica koja su postajala."

3) Zu den Kunstliedern vgl. II, 14.

4) Zur Geschichte der Pamilie Pazlagit, insbesondere von Camila Pazlagit vgl. Bejtit, A., a.a.0., S. 387 ff.

5) Zu diesen Angaben vgl. Bejtic, A., a.a.0., S. 387 ff. und Dizdar, H., a.a.0., S. 9 . 
ihren Iiebsten auf, der jetzt an der Sava weilt. Wenn im allgemeinen die geographischen Angaben in den Iiedern selten der Wirklichkeit entsprechen ${ }^{1)}$, so fällt in dieser Sevdalinka gerade deren Ubereinstimmung mit den tatsächlichen Gegebenheiten auf: die Moßtanica mündet vor Sarajevo in die Miljacka, diese in die Bosna und letztere wiederum in die Sava.

Die Varianten dieses Liedes lassen sich zunächst in zwel Hauptgruppen unterscheiden: die elne Gruppe, die ältere, bewahrt das Iied in seiner ursprünglichen Form als reinen Monolog des Hàdchens; die andere, jügere ${ }^{2)}$, schickt diesem eine Exposition etwa gleichen Umfangs voraus (Bejtit, Dizdar).

In der Exposition unterscheiden sich die varianten nur geringfügig. Den beiden Einleitungsversen

Na Ophodi $($,$) prema Bakijama ($,

Mobu (moba) Zanje aga (age) Fazlagicu (Pazlagita)

folgen drei asyndetisch und syndetisch verbundene verse mit koordinierender Häufung:

Sto momaka, trista djevojaka

I Ceteres' (pedeset) djece vodonosa

I pred (medu) njima Pata (Džehva) Pazlagita...

Die nächsten beiden Verse sind ebenfalls stark durch sprachliche Figuren gestiutz:

Sama Zanje, sama snoplje veze,

Sama pjeva, sama pripijeva:...

Ganzvers- und Halbversanapher, koordinierende Häufung und annominatio per adiectionem lassen die Verse an Wirkung gewinnen und dürten auch dazu beigetragen haben, daß diese in nahezu gleicher Porm in allen Varianten vorkommen, die sich der Ex-

1) Vgl. dazu Bordevit, T.R., Beleske o nałoj narodnoj poeziji, Beograd 1939, Kapitel XXxv, S. 168-172, unter der Uberschrift: "Yeznanje geografije u nasim narodnim pesmama.".

2) Aus der Entstehungsgeschichte dieses Liedes (8.0. S. 166) sowie aus dem Inhalt der Exposition selbst geht hervor, daß die Einleitung nachträglich hinzugefügt worden ist. Vgl. auch III, 13, zur Chronologie. 
position bedienen. Die Verse als solche sind weder neu noch selten: sie sind ziemlich häufig in Ernteliedern anzutreffen, aus welchen sie wahrscheinlich auch ubernommen sind. 1)

Der Monolog, das eigentliche Lied, beginnt in allen acht Varianten mit dem zwei Verse umfassenden Imperativastz, der den im Vokativ verwandten FluBnamen der ersten Zeile durch ein effekt. volles periphrastisches Epitheton betont:

Mortanice, vodo plemenita,

Usput ti je, selam tes mi dragom.

Die beiden sich von den übrigen Varianten in stärkerem ilaBe unterscheidenden Ifeder (beide von Zovko aufgezeichnet) ersetzen den Namen "Mostanica" durch andere PluBnamen. In Zovko II, 1. Nr. 40 erscheint "Lasvo vodo" und in Zovko II, 2, Nr. 39 "Vrbas vodo". Das ist eine Eigentümlichkeit der Sevdalinka, auf die schon verschiedentlich hingewiesen wurde.

In zwei anderen Varianten (Bejtic, Dizdar) erhält der erste Vers den für die Sevdalinka charakteristischen aj-Vorschlag.

Wiederum zwei Iieder (Zovko II, 1, Nr. 40 und Orahovac) bringen den zweiten Halbvers der zweiten Zeile mit dem tirkischen Grußwort "selam tes m1 dragom" in rein slavischer Form: "pozdravi mi dragogn.

Allen Varianten gemeinsam ist dann wieder der folgende, durch Halbversanapher und annominatio per immutationem geprägte Vers:

II' nek dode, 11' nek me se prode...,

der in der Orahovac-Variante allerdings erst nach Einschub zweier weiterer Verse erscheint.

Nach diesem Vers führen die beiden Zovko-Varianten das Lied als Kontamination mit jeweils einem anderen fort.

In Zovko II, 2, Nr. 39 schließen sich z.B. die Kernverse des Iiedes 26 (III,26) mit dem bekannten Vergleich

Sto je nebo da je list hartije... an. ${ }^{2)}$

1) Vgl. dazu die Erntelieder der Petranovit-Sammlung, Nr. 49, Nr. 50 u.a., die eben diese Verse aufweisen.

2) Vgl. dazu II, $13 f$ und III,26. 
Die sechs restlichen Varianten fuhren das lied in einheitlicher Porm weiter:

Nek' ne kosi trave oko (pokraj) Save

Pokosite moje kose plave.

Nek ne pije Save (bunar) vode hladne, Popite mi moje oci vrane. 1)

Diese in fünf Pällen das Lied abschlieBenden Verse erscheinen im einzelnen nur wenig verändert. Großen Anteil an ihrer getreuen Tradierung durften wieder die sprachlichen Piguren haben, die diesen Liedabschnitt zusammenhalten und festigen: streng eingehaltenes verschränktes Isocolon, Ganzversanapher (nek) sowie Binnenreim (trave - Save), Endreim (Save - plave) und Assonanz (hladne - vrane).

Von den sechs Varianten verzichtet lediglich das OrahovacIied auf die ersten beiden Verse. Im Davidovit-lied sind die vier Verse umgestellt. Es handelt sich hier um eine im ganzen schwächere Variante: statt "Save vode hladne" gebraucht sie z.B. das beziehungslose "sode vode hladne" (Sodawasser!). Für die Augen verwendet sie abweichend das Epitheton "plave" (als Endreim zu "Save"), für die Haare das seltenere Epitheton "ruse".

Das bei Odobasic aufgezeichnete Lied geht insofern eigene Hege, als es den Endreim aufgibt und durch eine Epipher auf Abstand ersetzt: kose vrane - oti vrane.

Die in den letzten Versen auftretenden Unterschiede sind also, wie leicht zu ersehen ist, nur geringfügig: das das Versgefuge bestimmende Isocolon ist in allen Varianten gleich streng durchgefürt.

Allein das Lied in Novi behar geht úber die zuletzt behandelten (End-)Verse hinaus, indem es den oben angefuhrten, allen Varianten gemeinsamen Vers:

II' nek' dode, ili me se prode

1) Zu dem Bild vom "Austrinken der Augen" vgl. Goetz, L.K., a.a.0., Bd. 1, S. 99 f. 
an dieser Stelle wieder aufnimmt und inm noch drei weitere, aus einem anderen lied ubernommene ${ }^{1)}$, mit einer dreigliedrigen koordinterenden Häufung folgen läBt.

Wieder bestätigt ein Vergleich der Varianten das Ergebnis der bisherigen Untersuchungen: die Verse elnes Liedes, die in stärkerem Maße von sprachlichen Figuren gehalten sind, werden von der Mehrzahl der Varianten grundsätzlich unverändert iubernommen.

1) Vgl, dazu III,28. 


\section{Dockan podoh iz novoga hana ${ }^{1)}$}

Dockan podoh iz novoga hana, Koja draga iz vruta hamama, Sretosmo se u Citma sokaku. Ja joj rekoh $i$ dva $i$ tri puta:

"Draga moja, ukloni se s puta!" ve ste mi se ukloniti s puta. Ja je uzeh po svilenu pasu, $\mathrm{Pa}$ je bacih u zelenu travu; Zape meni kopca od tozluka Za draginu kitu od terluka, Ja se sagoh koptu odpinjati, Zape meni svilena podveza A za drage svilena pojasa. Ja se sagoh $i$ nju odmrsiti, Zapece mi lanci od sahata Za dragine pavte od bisera, Ja se sagoh lance otpinjati, Zape meni zlateno prstenje $Z$ a dragine sitne ogrlice, Sve odapeh, a prsten ne mogoh, Osta prsten na draginoj ruci, Te se hvali da je isprosena! Je da Bog da muke dotekala: o dvoru mi tri sina rodila.

$$
\text { Ristic, Nr. } 34
$$

24 diesem Lied lassen sich nicht weniger als 21 Varianten anführen. Wegen ihrer großen $Z$ ahl und ihrem zumeist beträchtlichen Umfang sollen sie hier weniger im einzelnen als vielmehr in einer kurzen Uberschau behandelt werden.

Der Schauplatz des Liedes ist wie so oft in der Sevdalinka die Straße bzw. die Gasse $(s o k a k)^{2}$. Hädchen und Bursche tref-

1) Vgl. Teil III, Lied 33.

2) VGl. dazu auch Goetz, L.K., a.a.0., Bd. 2, S. 203 ff. 
fen dort zu später Stunde zusammen (d 0 c $k$ a $n$ pōoh), das Mädchen meist auf dem Heimweg vom Badehaus (hamam ${ }^{1)}$ ), der Bursche in der Mehrzahl der Varianten aus einer "kafana" bzw. "mehana" kommend. Nicht selten (fünfmal) wird auch genauer lokalisiert: Sinot kasno pod̄oh 12 M $\mathrm{r}$ i \& a Hana..., wobei es sich um den beruhmten lioric han in der Altstadt Sarajevos handelt, der sich noch heute in der Straße Saraci befindet.

Bei der Exposition zu diesem Lied unterscheiden sich die einzelnen Varianten vor allem darin, inwleweit sie die in der ältesten Fassung (Erlangenski rukopis) vorhandene ausfuhrliche Einleitung für ihre Liedgestaltung übernehmen, d.h. wann sie jeweils einsetzen. Es lassen sich dabei drei Haupttypen herausstellen, die zunächst nur inhaltlich zu fassen sind.

Beginn des Liedes mit

a. Si tuierung:

Lajka Muju po kafane' trazi,

Po kafane 1 po mehanama,...

suilozevit IV, Nr. 291

b. Dialog (liutter - Sohn):

"Liujko sinko, §to te pała zvase?"

"Da ti kažem, sto me pasa zvase:...

Bo8. Jila 1903, S. 137

c. Hionolog (des Sohnes):

Dockan pođoh 12 novoga hana,

Noja draga iz vruta hamama,...

Ristic, Nr. 34

bzw., noch später einsetzend:

Sretoh dragu u usku sokaku...

Vuk II, Nr. 127

1) Vgl. dazu Hangi, A., a.a.0., S. 62: "Baden und Waschen des Körpers ist den Mosilms religiöses Gebot. In allen größeren orten Bosniens und der Hercegovina gibt es darum öf fentliche Badeanstalten, die gleich dem Baderaume im Hause "Hamam" (Warmbad) heissen. Im Volksliede wird der Bäder öfter Erwähnung getan." 
In der ältesten Passung (Erlangenski rukopis) ist ein ausgesprochener Mangel an sprachlichen Piguren festzustellen; den Sängern standen also in bezug auf die formale Gestaltung des Liedes keine Gedächtnisstützen zur Verfugung. Diese Tatsache erklärt sowohl die unterschiedliche Ausgangsposition der einzelnen Varianten, als auch die ihrerseits ebenfalls zu bemerkende Armut an sprachlichen Piguren, welche wiederum die im ganzen uneinheitliche Ausführung des ersten liedabschnittes verständlich macht.

In den Varianten dieses Liedes etwa auftretende Isocola, koordinierende Häufungen oder reduplicationes und ähnliche Piguren sind weniger als littel zur genauen Tradierung als vielmehr als Improvisationshilfen aufufassen.

Die Vila-Variante (Bos, vila 1903, S. 137), die wie 0.a. mit einem Dialog einsetzt, kann als typisches Beispiel dafür gelten, daB sich in Verspaaren, die Rede und Gegenrede aufnehmen, vielfach Piguren wie Isocolon, Anapher und Epipher ganz von selbst ergeben, dann nämlich, wenn die Gegenrede einen Teil der Rede wiederholt, also nicht nur inhaltilch, sondern auch formal auf diese eingeht. So werden oft ganze lieder stufenweise fortgeführt. ${ }^{1)}$

Weitgehende Ubereinstimmung aller Varianten ist erst mit dem Einsetzen folgender Verse zu konstatieren:

Ja joj rekoh $i$ dva $i$ tri puta:

Moja draga (draga moja) skloni mi se s puta...2)

Diese durch den äuBerst effektvollen homonymischen Reim zu-

1) Ähnlich und noch zahlreicher sind Lieder, in denen Rede und Gegenrede jeweils für sich eine (verschränkte) Isocolaket te darstellen. Ein solches Lied führt Pollok auf S. 208, Anm.79 an.

2) Zu der Aufforderung des Burschen an das Wädchen, ihm Platz zu machen, vgl. Goetz, L.K., a.a.0., Bd. 2, S. 203 ff.: "Vielfach we $i$ c h $t$ das Weib vor dem lann bei der Begegnung a $4 \mathrm{~s}$, was in ihrer dienenden stellung gegenüber den lann begrüdet 1st... Ist das Hädchen eigensinnig, so weicht es eben nicht aus;...". Oder, Hangi, $\Lambda_{.}, a_{.0 .0 .}$ S. 203: Weil der Moslim seine Prau in aller Porm kauft, wird er ihr unumschränkter Herr und Gebieter, dem sie in allem gehorsam und untertänig sein muss." 
sammengehaltenen Zeilen erscheinen in nicht weniger als $13 \mathrm{Va-}$ rianten. Sie finden sich sowohl in der ältesten Variante (Erlangenski rukopis) als auch in der jüngsten (Milosevil IV).

In vier Varianten (Mirkovit, Popovit-Rodoljub, MH VII und Jugoton EPY 3117 A) fehlen sie dagegen ganz.

Die Zovko-Variante (II, 1, Nr. 38) verzichtet ebenfalls auf diese Verse. Dieses Lied kann aber in der weiteren Untersuchung auBer Betracht bleiben, da es sich nach seinen sechs, den der übrigen Varianten ähnlichen Einleitungsversen relativ unabhängig weiterentwickelt.

Lediglich in drei Varianten werden die sonst stets gleichen Verse vom Sänger abgewandelt:

1. Bos. vila 1903, S. 137:

Tri put vikah lijepoj devojci:

"nukloni se lijepa devojko;nn...

2. Kuba 1907, S. 251, Nr. 235:

Pa joj rekoh: draga, ukloni se s puta, Il' se ukloni, draga, il' lišce zakloni... (annominatio per immutationem).

3. Dizdar I, Nr. 53:

Pa joj rekoh: "Draga, ukl on' mi se s put.a, Ili se ukloni, il' liłce zakloni! "... 1)

Die nachfolgenden Verse umfassen in allen Varianten eine mehr

1) Allem Anschein nach übernahm Dizdar dieses Lied aus der Sammlung von Kuba. Dafür sprechen neben der weitgehenden Ubereinstimmung beider lieder im allgemeinen noch gewisse nur ihnen gemeinsame Züge: 80 etwa der Einschub des Vokativs "draga" nach der Zäsur in fast allen Versen und die repetitio "ne plac, ne plac, draga" im letzten Vers. Eine allerdings nur an der Dizdar-Variante festzustellende $\mathrm{Be}-$ sonderheit ist das wechselnde Epitheton zu dem zweimal auftretenden Substantiv "sokak" (u t'jesnu sokaku; na Ceknu sokaku). Dies ist insofern bemerkenswert, als ein einmal einem Substantiv beigegebenes Adjektiv bei Wiederholung des Substantives innerhalb e $i \mathrm{n}$ e 8 Ifedes gewöhnlich als stehendes (nichtindividualisierendes) Epithet on wieder dazugesetzt wird. Vgl. dazu auch S. 106. 
oder weniger umfangrelche asyndet1sche koordinierende Häufung mit streng ineinander verschränkten Isocola:

Zapełe ml kop̌e od cakłı ra

Za Umine mor-mavi dimije.

Ja se sageh, da kopce otpucim,

Zapese mi bazl od sahata

Za Umine ogre od derdana.

A ja pođoh, da bage odapnem,

Smjesase se brc1 1 soluf1,...

Gajret 1913. S. 75

Auffallend lst hier zur Bezelchnung von Kleldungs- und Schmuckstücken der ausschliebliche Gebrauch von Worten orienta11 schen Ursprungs. 1 )

1) Vgl. dazu auch Corovit, VI., Bosna i Hercegovina, SKZ, BeoGrad 1925, S. 103 f.: "Posle, muslimanskd elemenat je unosen 1 iz njthovih verskih obicaja... Ili iz njihovih drustrenth narlka...1li prema 12vesnim dintocima njthove materijalne kulture:...". Es folgt das 0.a. Zitat nach Gajret 1913,s. 75, allerdings ohne Quellennachwels.

In diesem Lled und selnen Varianten finden sich im wesentlichen folgende Ausdrucke: sahat (ar., Uhr), bag (türk., (Uhr-)band), solul (pers., Locke), derdan (pers., Kette), mor-dimije (turk., violett, griech., lange weite Hose der turkischen Prauen\}, caksire (tük., Beinkleider), tozluci (turk., Strümpe), terluke (türk., Pantoffeln der Prauen), pafte (pers., verzierte Knópfe, melst aus Silber, an der Prauenkleidung), perizan (pers., silberner Kopfschmuck der Prauen), Ciftijane (pers.-tük., Prauenhosen), sindzir (pers., Kette), decerma (tuirk., Brustleibchen), diza bisera (türk., Perlenrelhe, -kette) u.v.a.

Zur Vorliebe der muslimischen Prauen und lädchen fur reichen Schmuck, vgl, auch Hang1, A., a.a.0., S. $140 \mathrm{ff}$, wo es u.a. he1Bt: "Im Volke erzählt man noch heute von der überaus re1chen, mit Gold und Silber gestickten Prauentracht,.... Die moslimischen Prauen schmücken sich selbst und auch ihre kle1nen weiblichen KInder sehr gern... Wieviel Schmuck Prauen oder Mädchen an sich tragen, beschretben die Haremslieder."

Die Mehrzahl der bisher vorliegenden Untersuchungen oder Betrachtungen zum bosnischen lyrischen lied beschränkt olch auf den sicherlich wichtigen Nachweis des häufigen Vorkonmens von Turzismen. Vgl. dazu Bajraktarevit, P.. Pregrét narodnih pesama iz Bosanskog Skoplja, SAN, Posobna Izdanja, Knj. CCCXXXV, Etnografaki Inst1tut, Knj. 11, Beograd 1960, S. 2 f.: "...tako naprimer, ne samo u muslimanskim pesmama 
Die Varianten Narodna uzdanica 1935, Dizdar II und Milosevit IV, Nr. 290 enden bereits nach der koordinierenden Häufung. In den ubrigen Liedern bilden den AbschluB in der Regel zwei bis drei im einzelnen Palle zum Teil verschieden gestaltete Verse. Pünf Liedern gemeinsam ist der durch Halbversisocola und Halbversanapher geprägte Vers:

Tu padosmo 1 tu osvanusmo.

Portsetzung von S. 175, Anm. 1:

nego i u onima iz istornih krajeva nalazimo vise muslimanskih ("turskih") imena, verskih uzvika (u Kurta Cesto: "Rabbum Allah!" 1 orijentalnih rexi, a na Zapadu (...) vise hriscansko-katolickih elemenata..., ali u samim motivima teśko da ima znatnije razlike izmedu njih."

Dies reicht aber zu einer Charakteristik nicht aus. So wies Goetz auf die spezifische Motivik dieser Lifeder hin. Vgl. dazu Goetz, L.K., a.a.0., Bd. 1, S. 6: " $N$ e b e $n$ den Iledern des

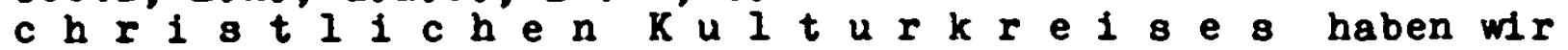
die des $1 \mathrm{~s} l \mathrm{a} \mathrm{m} 1 \mathrm{~s} \mathrm{ch}$ e $\mathrm{n}$, zumal in Bosnien und Herzegowina. Hier zeigt sich die Trennung, das Auseinandergehen der südslavischen Stammesgenossen in verschiedene Lager nicht nur direkt auf dem religiösen Gebiete des Glaubens und Kultes, sondern in stärkerem MaBe auf dem der ganzen westlichen Kultur und Lebensgestaltung,.... Es tritt uns das entgegen nicht nur in der Sprache, im Wortschatz der moslimischen Lieder, die reich durchzogen sind von türkischen Ausdrücken. Die ganze Auffassung des Liebesverhältnisses, die ganze Gestaltung der Beziehungen zwischen Mann und Prau in der. Ehe ist in den moslimischen tiebesliedern (sevdahlinke) und Balladen vielfach eine andere als in den Gesängen der christlichen Kroaten und Serben. Eine höhere äuBere Kultur des türkischen Herrenvolkes gegenüber der der christlichen Untertanen, der sogenannten "Rajan, kommt zum Vorschein in der durchweg reicheren, prunkvolleren, auch weichlicheren, sensualistischen Schilderung der handelnden Personen der Iieder, ihrer Tracht und ihres Schmuckes, ihres Auftretens und Lebens."

Und Pollok machte auf die Besonderheiten im Ornatus aufmerksam. Vgl. dazu S. 221: "Eine solche Reichhaltigkeit an schmuickenden Piguren, die mitunter schon fast ins Dekadente abgleitet, ist für die lyrische Volksdichtung moslimischer Gegenden, vor allem der Städte, charakteristisch."

Eine umfassende Darstellung dieses liedtypus steht jedoch bislang noch aus. Vgl. dazu Peukert, H., a.a.O., S. 205: "Zweifellos wichtig wäre eine genaue Analyse des bosnischen Liebesliedes, dessen Eigengestalt in Porm der $S$ e $v a$ l $i \mathrm{n} k$ zwar anerkannt, aber nicht nachgewiesen wird." 
Drei Varianten enden in annähernd gleicher Porm:

1. Poljubih je 1 dra 1 tri puta,

Da ko broji, staße viłe biti;...

$$
\text { Vuk II, Nr. 127 } 7^{1)}
$$

2. Poljubih je 1 dva 1 tri puta...

Da ko broja ne bi prebrojio!

Popovit-Rodoljub, Nr. 100

3. "Nijesam joj nista uxinio,

"Vet to sam je tri put poljubio."

Kałikovit I, Nr. $88^{2)}$

Die Variante Bos. vila 1901, S. 206 hat ihre Endverse einem anderen Lied entliehen ${ }^{3)}$ :

Dusek nam je trava detelina,

Jastuk nam je ruka preko ruke,

Jorgan nam je sjajna mjesecina.

Bei zum Teil beträchtlichen Schwankungen in der Gestaltung von Exposition und LiedschluB, die jeweils einen deutlichen Mangel an sprachlichen Figuren erkennen lassen, zeichnen sick die Varianten dieses liedes durch relative Stabilität des Mittelteiles aus, der durch verschränkte Isocola innerhalb der koordinierenden Häufung besonders gefestigt wird.

Abschließend sei noch darauf hingewiesen, dab es sich bei dem zu den jüngsten Varianten zählenden Schall plattentext (Jugoton EPY 3117 A) wahrscheinlich um eine Kontamination mit dem Gedicht "Emina" von A. Šantił handelt. ${ }^{4)}$

1) In diesem Lied folgen jedoch noch drei weitere verse.

2) Zur Formelhaftigkeit der Verse mit dem Motiv des drei(bzw. mehr-)maligen Küssens vgl. Goetz, I.K., a.a.0., Bd. 1, S. 106.

3) VgI. dazu III,22.

4) Vgl. dazu II, 14. 
10. Sto Morava mutno te飞e ${ }^{1)}$

Sto se ono more muti:

II' carevit konja poji

Il pašina vojska ide?

-Nit' carevit konja poji

Nit' pasina rojaka ide,

vet su ono utonule

Dvi morkinje, dvi sestrice:

Beg-Emina 1 Fatima;

Beg-Emina utonula

A Patima isplivala.

Beg-Emina govorila:

"oj Fatima, sestro mila,

Nemoj kazat' miloj majci

Da sam mlada utonula,

Vet da sam se ja udala

Priko mora za carita.

of virovi - diverovi,

of Zabice - svekrvice,

I ribice - zaovice,

Sinje more - dragke moje.

Nov1 behar $1939 / 40$, S. 346

Von diesem Lied konnten 18 Varianten gefunden werden, wovon allein 15 mit der slavischen Antithese beginnen:

of Moravo, sto si zamukena?

(Što se ono more (dreimal) (Sava (zweimal)) mut1?)

Ill pasit vojsku vodi,

Il' carevit konja poji?

Niti parit rojsku rodi,

Nit' carevil konja poji,

Vet plivaju dvi Moravke,...2)

1) Vgl. Tell III, Lied 34.

2) Vgl zu dieser slavischen Antithese am Liedeingang S. $121 \mathrm{f}$. 
Ihr schliebt sich ein weiterer erläuternder Vers (seltener zwei) an, der mit zu dieser Pigur gerechnet werden muB:

(Dvi Moravke, dvi sestrice)

Beg Emina 1 Patima....

Eine der Varianten (Prodanovit, Nr. 271) erweitert die slavische Antithese um ein zusätzliches Glied:

Da l' devojke platno bele...

Zwei der drei von den übrigen abweichenden lieder (PopovitRodoljub und Mokranjac) gebrauchen die slavische Antithese in verkurzter Form ${ }^{1}$ ):

Sto Horava mutno texe?

Kupale se dvije seke-,...,

während das letzte Lied (Behar 1900/01, S. 304) ganz auf sie verzichtet und mit dem Vers beginnt:

Dvije seke zaronile....

In der Kurt-Variante lautet der erste Vers abweichend:

Kakva huka iz daleka?...

Dann aber wird das lied in der oben zitierten Porm fortgesetzt.

Die bei Mokranjac zur Melodie angegebene Textvariante weist eine dreifache melodiebedingte Ganzversrepetitio auf:
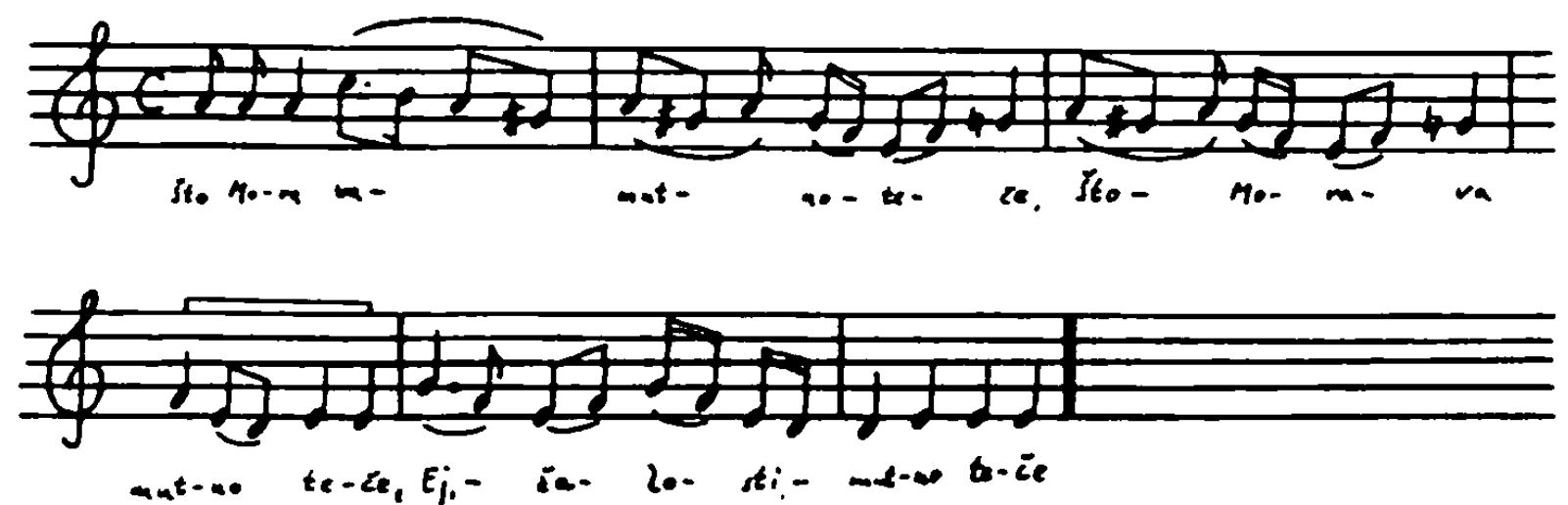

$$
\text { Mokraniac, Nr. } 908
$$

1) Vgl. dazu S. 123. 
Der großen Wirkung der slavischen Antithese ${ }^{1)}$, dieser durch strenge Isocola, Ganzversanaphern und die Epipher auf Abstand in sich gefestigten Figur, die die Tradierung erheblich erleichtert, ist es vor allem $z u$ verdanken, daB sich diese Ledeinleitung in der Mehrzahl der Varianten (ca. 83\%) in gleicher Form findet. Abweichungen betreffen auch hier wiederum nur die geographischen Bezeichnungen (Morava, Sava, more) sowie die weiblichen Vornamen (Emina, Fatima, Alivera, Todora u.v.a.).

Nach dieser Einleitung folgt in den meisten Varianten $(16=$ ca. 88 \%!) ein dreigliedriges Isocolon mit jeweils gleicher verbalform am Versende (Homoeoptoton):

Beg-Emina utonula,

A Fatima isplivala.

Beg-Emina govorila:...

In sechs dieser 16 Varianten heiBt es im letzten Vers leicht abweichend, jedoch nicht das Isocolon zerstörend:

Mrtva glava govorila (viermal)

Mrtva Toda govorila (einmal)

urtva Mara govorila (einmal).

Eine Variante (Novi behar 1939/40, S. 345 f.) begnügt sich mit einem zweigliedrigen Isocolon.

Die Mokranjac-Variante (Nr. 90 b) wiederum erweitert diesen Liedabsclunitt (mit Einfügung einer dritten Persor):

Banjale su tri devojke.

Prva bełe esmer-Gina,

Druga bese dilber-Sinda,

Treta bere crna Suta.

Gina se je zantjala,

Sind̄a si je preplivala,

Suta se je udavila....

Sie setzt zunächst ein dreigliedriges Isocolon, dessen jeweils mit "prva", "druga", "treka" eingeleitete Verse ein weiteres dreigliedriges Isocolon auslösen.

1) Nicht zuletzt wird durch solche Retardierungen die Spannung beim Hörer erhöht. Vgl. dazu auch Follok, S. 39 f. 
Nach den in 16 Varianten annähernd gleichen Versen (zwei, sokranjac und Kuba 1906 verzichten ganz auf sie):

Beg Emina, sestro moja, (nachgestelltes substantivisches Ti ne kazuj nałoj majci Epitheton)

Da sam mlada utonula,

Vet da sam se ja udala (schwaches Isocolon plus Homoeopto(Preko mora za Omera) ${ }^{1) 2)}$ ton)

folgt in allen ( 1 ) Varianten eine mehr oder weniger lange, streng eingehaltene Isocolakette, mit der das lied seinen Abschlub findet. Als dem Isocolon übergeordnete Pigur hat in diesen Versen die (Vergleiche ausdrückende) koordinierende Häufung zu gelten, deren einzelne Glieder zumeist in einer Klimax angeordnet sind.

Iediglich MH $V$ fügt dann noch einen zusätzlichen SchluB hin$z u$, der aus Lied 13 ubernommen worden ist $^{3}$ ):

Mandalina, seko moja!

Pozdravi mi majku moju;

Nek ne pije Save rode;

Popit te mi crne oxi.

Mandalina, seko moja!

Pozdravi mi brata moga,

Nek ne hvata sitnih riba;

Uhvatit te ruke moje.

In diesem lied und seinen Varianten sind es vornehmlich die slavische Antithese, das Isocolon (Isocolaketten) und die koordinierende Häufung, zu denen sich sekundär Anapher, Epipher u.a. gesellen, die die in der Mehrzahl der Varianten getreue Uberlieferung garantierten.

1) Vgl. dazu Milakovil, J., Majka u našoj narodnoj pjesmi, Sarajevo 1896, S. 109: "Sin ili kterka na umoru talje obi kno poruku svojoj materi; no da je ne razalosti, kusa prikriti svoju gorku sudbinu i slikovitom i njeznom pripovijedanju, iz kojega proviruje sva ta tuzna zgoda."

2) Zum kotiv des Sterbens als eines Sichvermählens, das in den Liedern vereinzelt anzutreffen ist, vgl, auch Goetz, I.K., a.a.0., Bd. 1, S. $161 \mathrm{f}$.

3) Vgl. dazu II,8 sowie III,13. 
11. Telal vice od jutra do mrake(1)

Telal vice od jutra do mraka:

"KO $J^{\prime}$ u koga notas na konaku,

Nek ne Ide rano $8 a$ konaka,

Utekla je pasina robinja

I odniela dva tovara blaga

I ukrala sahat iz njedara

I odvela ata iz ahara

I povela Muju haznadara."

Susreli je pasind kavazi.

"Kuda bjezis pasina robinjo?

Sto ce tebi dva tovara blaga,

Sto ukrade sahat iz njedara,

Zasto vodis ata iz ahara,

Kuda vodis kuju haznadara?"

"Blago nosim, da putem ne prosim,

Sahat nosim, da gdje ne zakasnim,

Ata vodim, da pjerke ne hodim,

Haznadara - da ne spavam sama."

$$
\text { Dizdar I, Nr. } 279
$$

Diese Sevdalinka, die noch heute oft zu hören ist, liegt in elf Varlanten vor. Dazu konuten nuch zwei jieder gefunden werden (Cubelit, S. $151^{2}$ ) und Blagajit, Nr. 47), die sich nur der drei Einleitungsverse des $0 . a$. Liedes bedienen, dann aber anders fortfahren. Sie können daher in der folgenden Untersuchung auBer Betracht bleiben.

Die vier Einleitungsverse dieser Sevdalinka finden sich in allen Varianten. Veränderungen treten nur im zweiten Halbvers der ersten zeile auf, u.zw. helBt es in vier Varianten:

1) Vgl. Teil III, Lied 36.

2) Cubelit übernahm sein hied aus der Sammlung von N. Tordinac. 
Telal vice od jutra do podne.')

Und drel Varianten ersetzen diesen Halbvers durch wederum einen anderen, lokalisierenden:

Telal vice po Hercegovini. 2)

Die Rubit-Variante fügt zwischen Zeile eins und zwei noch folgenden Vers eln:

U bijelu gradu Carigradu,

um das lied auf ihre Weise zu lokalisieren.

Der Text zur Schallplatte Jugoton EPY 3637 B wiederholt den ersten und dritten Vers je zweimal; es handelt sich dabei wieder um Ganzvers repetitiones.

Zusammengehalten werden die Verse zwel und drei durch die po-

1) Das "grt "telal" ist relativ schwer übersetzbar. Vgl. dazu auch Skaljit, A., Telal, Bilten instituta za prouCavanje folklora u Sarajevu, Sv.1, Sarajevo 1951, S. 100: "Jer, lako je telal javnl objavijivac, glasnik, dobosar, 1zvikivad, staretinar, posrednik - nijedan od onih izraza ne bi bio pravi sinonim rijeci telal."

Der "telal" spielte in friherer Ze1t eine wichtige Rolle sowohl als Verküner allgemeiner Nachrichten gls auch 8 peziell als Ausrufer im Handelsgewerbe. Vgl. dazu Skalj16, $\mathrm{A}_{\text {., }}$ a.a.0. S. 102: "Telal je u trgovin1 Igrao znałajnu ulogu. B1o je odlican trgovacki posrednik 1 majstor $2 a$ vrłenje reklame $u$ prodajama, a isto tako dobar 1zvikivac i hvaldzija robe kod skupnih prodaja na privatnim drazbama. "Podaj na telala pa ce ono nat1 ovoj kimet!" "Dat1 na telala". "prodat1 na telalu" znacilo je prodati nesto posredstrom telala." Vgl. dazu auch folgende Verse aus Lied 30 (III, 30):

Obadva bi na telala dala

Pa bekriji tamburu skovala.

H. Humo, ReX 1 slika, S. 36

Der "telal" blleb auch nach dem Aufkommen von Zeitungen und anderen Publikationsmitteln wegen des weitverbreiteten inal phabetentums noch lange unentbehrlich.

2) Skaljic sagt in seinem Aufsatz (Skaljic, A., a.a.0., S. 100), daß der "telal", der ja über elne kräftige stimme verfügen muBte, nicht selten bis zu zwel $\mathrm{km}$ weit zu hören war. Wenn also in drel Varianten der erste Vers lautet:

Telal vice po Hercegovini,

so handelt es sich zwar auch hier um eine der im Volkslied allgemein beliebten Hyperbola, aber diesmal mit durchaus realem Hintergrund. 
lyptotische Epipher konaku - konaka, die Verse eins und drei in vier Varianten durch den Kreuzreim mraka - konaka.

Diesen Einleitungsversen folgt in allen Varianten eine polysyndetische koordinierende Häufung, deren durchschnittlich vier Glieder jeweils einen Vers umfassen:

I odniela dva tovara blaga

I ukrala sahat iz njedara

I odvela ata 12 ahara

I povela kuju haznadara ${ }^{1}$ )...

Sie aind parallel gebaut, so daB sie eine Isocolakette bilden, die teilweise durch Ganzversanapher oder Endreim betont wird.

Dre1 Varianten (Blagajit, Nr. 34, BH VI und Odobasit) fügen zwischen die ersten beiden Glieder der koordinierenden Häufung einen durch reduplicatio dem vorhergehenden zugeordneten vers ein:

I odniela po pašina blaga, Po pasina, pola tehajina...

$$
\text { Blagajić, Nr. } 34
$$

Eine Variante (Davidovit) endet bereits mit dieser koordinierenden Häufung und stellt somit ein Pragment dar.

In acht der übrigen zehn Varianten schließen sich zwei bis drei formal unterschiedliche Ubergangsverse an, in denen das Einfangen der Sklavin geschildert wird. In drei Varianten (Rubit, $4 H$ VI und MH VII) sind diese Verse durch eine Ganzversanapher zusammengehalten:

Uhvatiße pasinu robinju,

Uhvatiłe, paßi dovedołe....

Charakteristischerweise sind dies die einzigen Varianten, die die gleichen überleitenden Verse aufweisen. ${ }^{2)}$ Diese beiden, durck

1) Der "haznadar" (Schatz-, Zahlmeister des Sultans) ist in den muslimischen Iiedern sehr beliebt. Vgl. dazu auch Goetz, L.Y a.a.0., Bd.2, 3. 167 .

2) $2 u$ bemerken wäre nur, daB die Variante MH VI nicht das schon im vierten Einleitungsvers verwand te substantivische $\mathbf{E}$ ithe- 
Ganzversanapher verinuipften Verse erscheinen ebenfalls in der Nametak-Variante, hier aber nicht als Uberleitungs-, sondern - bei etwas verändertem Liedaufbau - als AbschluBverse.

In sieben von zehn Varianten wird sodann die obige, mit Isocola verbundene koordinierende Häufung in Prageform wieder aufgenommen. Sie zeichnet sich in der überwiegenden Zahl der Fälle durch jeweils gleiche Reihenfolge und gleiche Anzahl der Glieder aus. Abweichungen in der Folge dieser Glieder durfen als unbeabsichtigt angesehen werden.

Die in Frageform wieder aufgenommene koordinierende Häufung löst ihrerseits eine nochmalige Reprise dieser Figur aus, die die Beantwortung der vorhergehenden darstellt und das lied abschliebt. Reihenfolge und Anzahl der Glieder dieser letzten koordinierenden Häufung, die wiederum mit strengen Isocola verbunden ist, entsprechen dabei jeweils der Reihenfolge und Anzahl der Glieder der vorletzten.

Drei Varianten weichen von diesem Aufbauschema ab. a. So werden im Kuba-Lied die Glieder der letzten beiden koordinierenden Häufungen ineinander verschachtełt. Die Isocola innerhalb einer koordinierenden Häufung werden so $2 u$ verschränkten Isocola.

b. Die Varianten bei Odobasic und Nametak verzichten ganz auf die koordinierende Häufung in Frageform und lassen der ersten koordinierenden Häufung unmittelbar die dritte folgen.

Die Varianten zu diesem lied bestehen also hauptsächlich aus vier Einleitungsversen und drei groBen, sich gegenseitig auslösenden koordinierenden Häufungen in der wiederholten Aufnahme durch jeweils einen anderen sprecher.

Die dreimalige Anwendung dieser umfangreichen Wiederholungsfigur und ihre Festigung durch weitere sprachliche Figuren wie Isocola, Polysyndeton, Ganzversanapher und Endreim, die die Pa-

Fortsetzung von S. 184, Anm. 2:

ton "pašina robinja" wiederholt, sondern das (im allgemeinen übliche) Epitheton "tanahna" zu "robinjan setzt. Vgl. dazu S. 103. 
rallelität der einzelnen Glieder betonen, garantieren, wie die Varianten beweisen, eine ziemlich getreue Tradierung des Liedes.

Derartig großangelegte Wiederholungen, auch Fügungsparallelis. men genannt, sind in der Sevdalinka nicht selten. Dabel sel noch auf folgendes lied verwiesen: ${ }^{1}$ )

Hadzijina Fata, izadi na vrata,

Pa pokazi ruse kose, da in mrsim ja.

Sta bi bolji bio, kad bi in mrsio!

U trgovca crn 1 bribim, jesi I' vidio?

Jos su crnje moje kose, more $\bar{d} 1 d i j o$ !

Hadzijina Pata, Lad̄i na vrata,

Pa pokazi medna usta, da in ljubim ja.

Sto bi bolji bio, kad bi in ljubio?

U kafant sladak serbet, jesi l'vidio?

Jos su slada moja usta, more didijo!

Hadzijina Fata, 1zadi na vrata,

I iznesi biele grudi, da in grlim ja!

Sto bi bolfl bio, kad bi in grlio?

U kafezu dra goluba, jesi l' vidio?

Joł su ljepse moje grudi, more didijo! 2)3)

Dizdar I, Nr. 80

1) Weitere auslösende koordinierende Häufungen mlt starken Parallelismen, wobei die Dreizahl oft eine bevorzugte Rolle spielt, siehe Teil III, die Lieder $17,18,21,30,31$, 35 u. a. und $I, 12$, zur koordinierenden Häufung.

2) Dieses Iied scheint territorial weit verbreitet zu sein. Eil Belgier (E. Orsolle) zeichnete ein dieser Sevdalinka ähnliches Lled in der zweiten Hälfte des 19. Jahrhunderts in Per. sien, südlich des Kaspischen Meeres, in einem Gebirgodorf al $V_{g l}$. dazu Skerlit-Corovit, J., Jedna persiska pesma 1 jedna bosanska sevdalinka. Prilozi za knjizevnost, jezik, istoriji 1 folklor, Knj. XVIII, Sv. 1-2, Beograd 1938, S. 580-583. Skerlit-Corovit meint (S. 583) abschlieBend: "A sasvim je verovatno, da je pesma mogla biti prenesena iz Persije u muslimansku sredinu Bosne."

3) Zu der offenheit, mit der Liebesereignisse besonders in den muslimischen Iiedern besungen werden, sagt Goetz, I.K., a.a.0., Bd. 1, S. 16: "Dann aber wird auch die besondere sinnliche Erregung der Liebenden offen besungen. Das ist 
Diese groB angelegten Wiederholungen mit Austausch von nur wenigen Worten erleichtern nicht nur dem Sänger die Improvisation; sie erleichtern auch dem Hörer das Mitsingen, indem sie inn die weitere Gestaltung des Textes vorausahnen lassen. ") Im selben Zuge fördern derartig weiträumige wiederholungen auch die Herausbildung von Strophen. ${ }^{2)}$

Fortsetzung von S. 186, Anm. 3:

viel in den moslimischen Liedern der Pall, in der für diese Gesänge so charakteristischen Art die Schönheit und Uppigkeit der äuBeren Erscheinung der Person in den Vordergrund stellen und die in ihrer weichlichen Lebensauffassung die Einwirkung dieser Pracht des Körpers und seiner Tracht auf die Erregung der Sinne glühend schildern."

Die Unbefangenheit der Sevdalinka in Liebesdingen zeigt auch die wirkungsvoll an den SchluB gesetzte Antwort des b.ädchens im zuletzt behandelten lied: Haznadara - da ne spavam sama.

Vgl. dazu auch das Lied in Dizdar I, Nr. 311.

1) Vgl. dazu auch Pollok, S. 88 f., Anm. 15.

2) H. Dizdar zeichnete sein Lied denn auch in Strophenform auf. Ein Ansatz zu Strophenbildung ist auch schon in dem "Telal"-Lied und seinen Varianten zu erkennen. 
12. Djevojka je malo djevorala ${ }^{1)}$

Djevojka je malo djevovala:

Sedamdeset $i$ sedam godina.

Sedam puta ćabi dolazila,

Sedam put je ćabi govorila:

"Ćabo moja, bi l' se ja udala?"

Sedmi put joj Eaba progovara:

"Hajd' ne huduj liepa djevojko,

Udat tes se i pokajat tes se,

Stet tes muza, venut ter ko ruza,

Stet tes djece, venut tes ko cr'jete."

$$
\text { Dizdar I, Nr. } 44
$$

Von dem letzten lied, das hier ausfuhrlicher behandelt werden soll, liegen 15 Varianten vor. Unberücksichtigt bleiben dürfen davon Milosevic IV, Nr. 147, das mit seinen fün versen lediglich eine Kurzfassung darstellt und Petranovit, Nr. 208, ein breitausgestaltetes Lied, das mehrere verschiedene Motive verarbeitet.

Die übrigen 13 Varianten weisen eine weitgehend übereinstimmende Exposition auf:

Djevojka je malo djevorala:

Sedamdeset $i$ sedam godina.

Sedam puta Ćabi dolazila,...2)3)

wörtlich gebrauchen diese Einleitung sieben der 13 Varianten. Eine Variante (MIH VII) ersetzt lediglich im ersten Vers das Ad-

1) Vgl. Teil III, Lied 37.

2) Dieses ironische Liedchen verspottet das "sitzengebliebene" Wädchen. Vgl. zu diesem Motiv auch Goetz, L.K., a.a.0., Bd. 2, S. 34 f.

3) Die Zahl "sieben" spielt neben der Dreizahl in der Volksdichtung eine groBe Rolle. In diesem Lied kommt ihr in Zusammenhang mit der "Caba", dem muslimischen Heiligtum, noch eine besondere religiöse Bedeutung zu: "Das "Bejt-Ullah" (Haus Gottes), die Kaaba wird siebenmal umkreist." (Hangi, A., a.a.0., S. 36). 
verb "malo" durch "dugo" und verbirgt so die Ironie.

Eine weltere Variante (Kurt) ändert nur im dritten Vers die Zahl "sieben" zur Dreizahl um.

Die restlichen vier Varianten bringen bei gleichem zweiten und dritten Vers lediglich einen jeweils verschiedenen ersten Vers:

Sjedila je sirota djevojka

(Mirkovit)

Osjeroti lijepa djevojka

(Kas̆ikovit) $)^{1)}$

Posid̄ela na gradu đ̄evojka

(Popovit-Rodoljub)

Djevojka dugo bolovala

(Zovko II, 4).

Die figura etymologica (als redditio angeordnet)

in Vers eins

$7 \mathrm{mal}$,

das (schwache) verschränkte Isocolon in den Versen

eins und drei

$13 \mathrm{mal}$,

die Ganzversanapher in den Versen zwei und drei

$12 \mathrm{mal}$

haben sicherlich entscheidenden Anteil an der weitgehenden Ubereinstimmung dieses Liedabschnittes in allen Varianten.

Der zweite Liedabschnitt, der das Gespräch des Mädchens mit der "Kaaba" gestaltet, wird formal wie inhaltlich in den einzelnen Varianten recht verschieden durchgefuhrt. Lediglich der durch Halbversisocolon und morphologischen Binnenreim geprägte vers:

Udates se i pokajaces se

ist sieben Varianten gemeinsam, viermal in der Verbindung mit dem folgenden Vers:

Spominjaces (pozalices) carstro djevojacko,

welche Versverbindung sich auch in dem eingangs erwähnten, nur bedingt als Variante anzusehenden Lied Fetranovit, Nr. 208 findet.

Die am häufigsten in den verschiedenen Schlußfassungen der

1) Das im Volkslied allgemein beliebte Epitheton "lijepa djevojkan, das hier in funf Varianten vorkommt, unterstreicht in seiner Anwendung auf eine 77-jährige die Ironie dieses Liedchens.

Daneben finden sich als individualisierende Epitheta "hadzija" (zweimal), "zakletna" (einmal) und "sirota" (einmal). 
einzelnen Varianten verwand te Figur 1st die koordinierende Häufung, vielfach verbunden mit dem Isocolon wie etwa:

Bog joj dade! dilber Begovila

I devera Omer Begovita,

Starog svata od Bosne vezira,

Svekrvicu - Ali-på̆inicu.

$$
\text { Popovit-Rodoljub }
$$

oder:

"Udat' Ces se, lijepa đevojko,

"Dok suh javor rodi jabukama,

"Ravno polje drobnijem biserom." ${ }^{1)}$

$$
\text { Gajret } 1913
$$

Formal am strengsten gehalten ist der LiedschluB in der im ganzen sehr sorgsam durchkomponierten Variante Lizdar I, Nr. 44:

Stet cę̆ muža, venut tę ko ruza,

Stet ter djece, venut teß ko cr'jete."

1) Vgl. zu diesem LiedschluB auch Pollok, S. 187. 
13. Bemerkungen zu einigen der übrigen untersuchten lieder und ihren Varianten

Von den in Teil III aufgeführten 37 Grundliedern und ihren Varianten wurden in Teil II bisher zwölf einer eingehenderen Untersuchung in bezug auf Improvisations- und Tradierungstechnik unterzogen. Da ein Vergleich der ubrigen 25 lieder mit ihren Varianten im wesentlichen dieselben Ergebnisse brachte, soll im folgenden nur noch auf einige ganz besonders erwähnenswert erscheinende 2 üge hingewiesen werden. Es sind das hauptsächlich Merkmale, die entweder in den anderen Liedern noch nicht in Erscheinung traten oder solche, die hier besonders markant hervortreten und deshalb noch einmal hervorgehoben $z u$ werden verdienen. Auf die zahlreichen Ubereinstimmungen und Gemeinsamkeiten in der Handhabung der sprachlichen Figuren dieser Lieder mit den zuvor behandelten soll dagegen an dieser Stelle nicht mehr eingegangen werden.

a. Karanfile, crijete moje ${ }^{1)}$

DaB Varianten zu Sevdalinke bis in die jünste zeit hinein entstehen und dabel politische pärbung annehmen können, mag folgende Variante zu diesem lied demonstrieren:

Meslidane, lipo ime,

Da je ment troje sime,

Ja bih znala, gdi bih cvala! ${ }^{2}$ )

Bilu gradu na bedemu

I Jadranu na kamenu.

Partizane zakitila,

Jer je borba pobidila!

A najuize druga Tita!

Nek se cuje birom svita,

1) Vgl. Teil III, Lied 2.

2) Zu dem Wunsch des Mädchens, sich in eine Blume (meist Nelke) oder Quelle zu verwandeln, den beiden Hauptmotiven dieses Liedes, vgl. Goetz, L.K., a.a.0., Bd. 1, S. $25 \mathrm{ff}$. 
Da je Tito heroj pravi, Zato njega narod slavi.

$$
\text { Cubelit, S. } 336
$$

Das Lied, zu dem sich diese Variante entwickelte, ist nicht ausschlieblich auf bosnisch-hercegovinisches Territorium beschränkt. Es scheint vielmehr in fast allen Gegenden Jugoslaviens bekannt und beliebt zu sein.

Beide von Nokranjac mit Notenbild aufgezeichneten Varianten weisen je zwei Ganzversrepetitiones auf. Als Beispiel sei ein Lied, das Mokranjac selbst als "gradska pesma" bezeichnet, wiedergegeben:

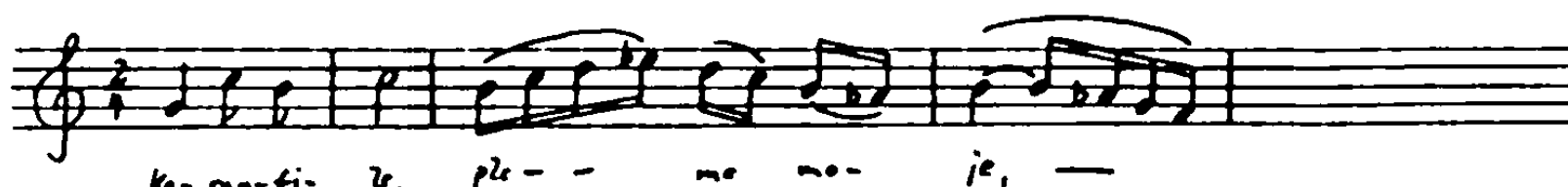
ka-narfi- is, ple- - me no- ie, -
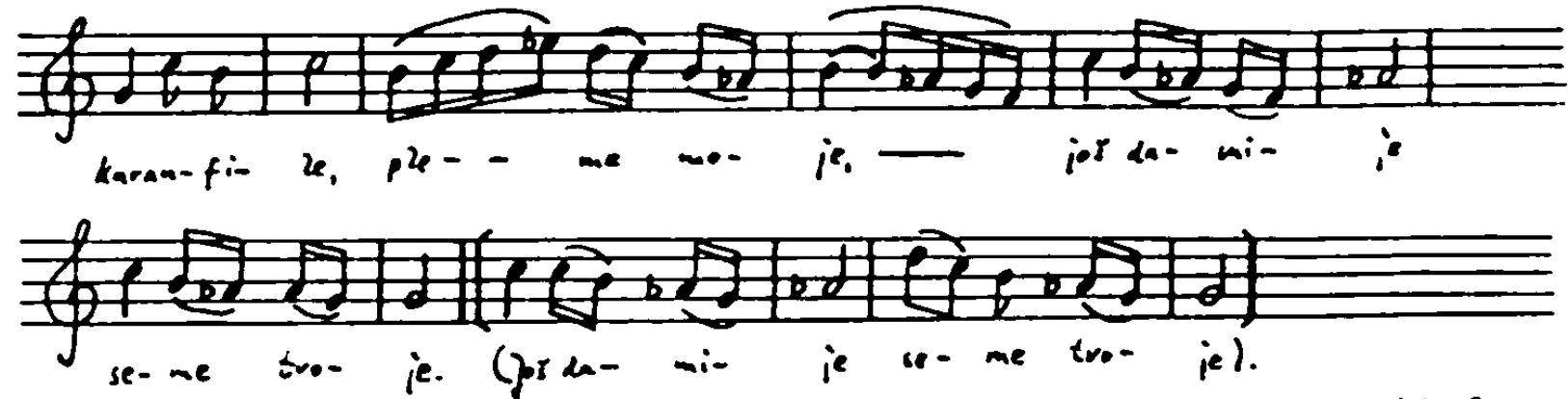

Mokranjac, No. 81

In der Sevdalinka mit ihren oft sehr gedehnten blelodien stellt schon die einfache Hortwiederholung (iteratio) eine improvisatorische Erleichterung dar, insofern sie dem Sänger zeit zur Besinnung auf die Fortfuihrung des Liedtextes schafft, um wieviel mehr erst die umfangreichere Ganzversrepetitio.

Neben der geminatio (hier als Ganzversrepetitio) soielen andere, innerhalb dieser Figur mitwiederholte figuren keine besondere Rolle mehr für Improvisation und Tradierung, da sie ganz automatisch im Rahmen der geminatio wieder auftreten.

An der getreuen Tradierung des Liedes sind in vorliegendem Fall die Reime wesentlich beteiligt, auf die auch Peukert schon hinwies ${ }^{1)}$, so die Binnenreime:

1) Vgl. dazu Peukert, H., a.a.0., S. 96 f. und S. 103. 
svlati - oblaci (annominatio per immutationem),

znala - crala (ggf. izvirala)

und die Endreime, die teilweise vom Isocolon hervorgerufen

werden:

mirisati - uzdisati,

moje - troje.

b. Od sevdaha goreg jada nema ${ }^{1}$ )

Der Kern dieses Liedes lautet:

"Ne asikuj, ne vezi sevdaha!

Od sevdaha goreg jada nema,

Ni Zalosti od asikovanja.

Na Zalost te 1 kombija doti,

Al' za jade nitko $i$ ne znade,

Osim Boga 1 sevdaha (srdałca) moga! $n^{2}$ )

Dieser Liedkern, der sich in gleicher Gestalt in fast allen Varianten findet, wird auch gern von anderen Liedern aufgenommen, wodurch Kontaminationen entstehen. ${ }^{3)}$

Die bestimmende Figur dieser Verse, die koordinierende Häufung, wird in jüngeren Varianten unter dem Einflub der "kafanska pjesma" (Kaffeehauslied) oft noch um einige Glieder erweitert, etwa:

Ne pij piva, ne pusi duvana,

Ne asikuj, ne veži sevdaha...

Es sind hauptsächlich Ganzvers- und Halbversisocolon und Ganzvers- und Halbversanapher, die mit dieser koordinierenden Häufung verbunden sind.

1) Vgl. Teil III, Lied 4.

2) Zum "ałikovanje" vgl. S. 102.

3) Vgl. dazu besonders einige Varianten des Liedes III,5: "Vjetar puße, alkatmerom niłe". 
c. Vjetar puße, alkatmerom ni $\mathrm{e}^{1)}$

Einige Varianten dieses Liedes (Magarałevit, Dizdar I, Grgec, Andric II) sind es, die das oben zitierte Teilstuick des Liedes 4 (III,4) oft sehr geschickt in oich aufnehmen.

Wichtig für die Improvisation und rradierung ist in diesem Iled einmal mehr die koordinierende Häufung wit einer auslösenden Dreizahl. In strenger Parallelität der Verse wird aufgezählt, was jeweils in einem von drel Amuletten geschrieben steht. 2 )

d. Kakva ti je u Alage ljuba 3)

Einige Varianten dieses Liedes nehmen das Zornmotiv:

Jer ako se ja nasrdim na te,

Sva nas Bosna pomiriti nete...,

das ansonsten ein wichtiger Bestandteil des Liedes III, 6 ist ${ }^{4}$ ), in sich auf.

Im Gegensatz $z u$ anderen Liedern und deren Varianten, in denen vielfach gerade die Eigennamen wechseln, erscheint in den Varianten dieses Liedes der Name Alaga durchgehend. 5)

1) VBl. Teil III, Lied 5.

2) Zu den Amuletten (amajlije), wozu auch der Koran selbst zählt, vgl. Đord̄evit, T.R., Belełke o nałoj narodnoj poezij1, Beograd 1939, Kapitel XXVII, S. 129-132. Uber die weite Verbreitung und Benutzung solcher glückzwingenden, aber auch apotropäischen Mittel, vgl. Hangi, A. a.a.0., S. 107 .

3) Vgl. Tell III, Lied 9.

4) Vgl. dazu II, 3 sowie III, 6.

5) Hierbei muB es sich nicht unbedingt zugleich um einen Titel handeln, denn "auch die ärmste prau spricht anderen Prauen gegenüber von ihrem Mann nur von ihrem Aga oder Beg denn er ist ja tatsächlich ihr Gebieter".

(Hang1, A., a.a.0., S. 238). 
e. Kujundzija, tako ti zanata ${ }^{1)}$

Zu diesem Lied existiert eine sehr interessante Variante, in die der Dichter A. Santic Eingang fand, dessen eigene Gedichte zum Teil als Sevdalinke aufgefaBt und gesungen werden ${ }^{2)}$ :

Kujundzija, tako ti zanata!

Sakuj meni junaka od zlata

Na priliku Santila Alekse, Stojli stasa Radulovic Mile, Crna oka DuCileva Jove, Dikli brka Bołkovita Riste.

$$
\text { Corovit, S. 116 } 3 \text { ) }
$$

Die ubrigen Varianten dieses kurzen Liedchens zeichnen sich durch die im wesentlichen stets gleichen Reime (zanata - zlata) und die Epipher auf Abstand (tako ti zanata) aus, die zur getreuen Tradierung des liedes beigetragen haben.

\section{f. Dva su crjeta u bostanu rasla $a^{4)}$}

Dieses lied verdankt seine verhältnismäßig gleiche Tradierung in allen Varianten besonders dem Gebrauch von koordinierender Häufung und Isocolon. Dies zeigt sich vor allem am Kermstück dieses Liedes, das sich schon in der Erlanger Handschrift findet:

"Sto je nebo, da je list hartije,

Sto je gora, da su kalemovi,

Sto je more, da je crn muretef,

Pa da pisem tri godine dana,

1) Vgl. Teil III, Lied 14.

2) Vgl. dazu II, 14 .

3) Dazu sagt Corovit, vl., Bosna i Hercegovina, SKZ, Beograd 1925, S. 116: "Srediste pokreta bio je Aleksa Santit, lep "kao slika", druževan, dobar pevac, raspoložen Łaldzi ja. On je predmet ljubavi mnogih devojaka, zajedno sa celim drustrom opevan u jednoj zenskoj pesmi:... (Es folgt das oben zitierte Lied.)."

4) Vgl. Teil III, Lied 26. 
Ne bih mojih izpisala jada!"

Dizdar I, Nr. $62^{1)}$

g. Dva se draga na livadi ljube ${ }^{2)}$

Die Varianten zu diesem Ified erhalten ihre feste Form durch eine umfangreiche Isocolakette mit durchgehender gradatio, die eine zweite Isocolakette mit gleicher Anzahl und Reihenfolge der einzelnen Glieder auslöst. Nicht selten finden sich lieder, die $z u \quad 7 / 8$ aus dieser Figur bestehen. In der zweiten, ausgelösten Isocolakette, die häufig eine Klimax aufweist, steht das Verb meist am Versende, was zur Blldung einer umfangreichen Homoeoptoton-Reihe fürt. ${ }^{3}$ )

1) Dieser hyperbolische Vergleich findet sich in den Literaturen vieler Völker, z.B. im Talmud und im Koran_(sura 31, Vers 26 und sura 18 , Vers 109). Vgl. dazu Đordevit, T.R., Belezke o nałoj narodnoj poeziji, Beograd 1939, Kapitel XXXVII, S. $176 \mathrm{ff}$. Auf S. 180 heiBt es: "Njegovo (d.i. Rajnhold Keler, d.i. Reinhold Köhler, W.E.) je pak mißijenje u tome da ovaj hiperboli "treba traziti poreklo kod Jevreja, $i$, dokle god se ne nade kakav stariji podatak, treba smatrati rabi Johanana kao njezinog tvorca." Dalje, on misli, da ju je $K$ o $r$ a $n$ pozajmio iz $T$ a $I m u-$ d a ,...".

Innerhaib der jugoslavischen Volksdichtung ist diese Hyperbel am häufigsten im bosnischem städtischen Liebeslied anzutreffen, in dem Papier, Tinte usw. als typische Requisiten erscheinen ( $\mathrm{Vgl}$. dazu Pollok, S. 212, Anm. 83.).

2) Vgl. Teil III, Lied 27.

3) In einigen Varianten dieses Liedes werden religiöse Momente eingeflochten, so wenn in dem Kuhat II-Lied (Nr. 729) die beiden Liebenden mit Jesus und Maria verglichen werden, oder wenn das Prodanovic-Lied (Nr. 110; im übrigen von Saulic übernommen) eingeleitet wird durch den aus religiösen Liedern übernommenen Vers:

Bože mio, na svemu ti hrala, Ijubilo se mombe i devojka,... 
14. Die Sevdalinka und das Kunstlied

Die Sevdalinka als ein ausgesprochen urbanistisches Lied unterliegt in sehr starkem Maße fremden Einflüssen. ${ }^{1)}$ Einer der wichtigsten neben vielen anderen ${ }^{2)}$ ist der von seiten des Kunstliedes, zu dem die Sevdalinka vielfälige Beziehungen hat, die

1) Unverständlich sind daher Auffassungen wie: "One (d.i. sevdalinke, W.E.) ne trpe u svojoj kuti nikoga, ko nije clan njihove porodice,..." (Orahovac, S., Nała sevdalinka $i$ njeni tipovi, slobodna rijet $1932, \mathrm{Br} .38$, S. 9).

2) Hingewiesen sei an dieser Stelle auf den Einfluß österreichischer Lebensart, dem dieses Lied im Zeitraum von 18781918 unterlag. Im Rahmen dieser Arbeit soll jedoch nicht näher darauf eingegangen werden, da sich dieser EinfluB nur in geringeren Veränderungen in Lexik und Inhalt (Tendenz zum Spottlied) bemerkbar macht, wobei die formale Gestaltung der Lieder weitgehend unberührt bleibt. Hier seien nur zwei kürzere Liedabschnitte aus der an diesbezüglichen Beispielen reichen Sammlung von Dvorovic (= Hofbauer) zitiert:

Tebe gleda njemacka parada. Lene gleda sarajska gospoda. Otic ce ti njemacka parada, Ostat te mi po Bosni gospoda!"

und : Dvorovit, S. 13

Sarajevska Cuprija

Hej, Jarena ko kutija!

Po njoj sece oberster,

Saren zelen ko guster,

" $0 j$ soldati, soldati,

Kako vam je u Bosni?"

Dvorovit, S. 23

Gelegentlich wird auch auf bogumilischen EinfluB auf die Sevdalinka aufmerksam gemacht: "Izmi jeßana je u njoj (d.i. sevdalinka, H.E.) slovenska boletivost $i$ melanholija sa dahom bogumilske Bosne i mraxnim nesvhatljivim tajnama Azije." (Dizdar, H., Izvor sevdalinka, Gajret 1938, Sv.14, S. 247).

Nachhaltiger wirken die Volkslieder anderer Gegenden Jugoslaviens auf das bosnisch-hercegovinische liebeslied, welches denn auch aus Motivik, Lexik und Ornatus verschiedene Elemente von ihnen übernahm und sie seinen eigenen Gesetzen entsprechend verarbeitete und assimilierte. Vgl. dazu nur einige Varianten in Teil III zu den Liedern $22,24,25$ u.a. 
sich hier wie dort als Wechselbeziehungen gestalten. ${ }^{1)}$ Die Aufnahme von Kunstliedern in den Kreis der Sevdalinke scheint verständlich vor allem bei solchen, die durch bewuBte und oft recht geschickte Imitation des Volksliedstiles entstanden sind. Zu ihnen gehört zunächst das Gedicht der Umihana Cudovina (Cujdina) 2), der ältesten bosnischen Dichterin. "Sarajlije igju na rojsku protiv Srbije (1813)", dessen erste Strophe hier zur Illustration angefuhrt werden soll:

Evo danas sedam godin dana,

Kako cvili bosanska fukara:

Niti ima pase, ni vezira,

Dok ne dogje pasa Ali-pasa.

A Cim dogje pała Ali-pała

On popisa svu butum Krajinu,

Svu Krajinu i Hercegovinu,

Najotragu mlade Sarajlije,

Sarajlije mlade jenicare

I pred njima gazi Memi 8 -agu. 3)

Mit dem Volkslied gemeinsam ist diesem Gedicht u.a. der ausgiebige Gebrauch von in dieser Arbeit untersuchten sprachlichen Piguren wie Isocolon, koordinierende Häufung, reduplicatio, Anapher, Epipher und iteratio. 4)

1) Vgl. dazu Wellek, R. und Warren, Au., Theorie der Iiteratur, Berlin 1963, S. 39: "...und bis auf den heutigen Tag befinden sich mündliche und schriftliche Dichtung in ständiger Hechselbeziehung."

2) In II,8 murde ebenfalls ein Lied mit bekanntem Schöpfer untersucht. Handelte es sich dort jedoch um ein echtes Volkslied (vgl. S. 165 ff.), so liegt hier ein Kunstlied vor, dessen Autor sich lediglich an den Volksliedstil anlehnt und diesen imitiert.

3) Vollständig abgedruckt in türkischer und serbgkroatischer Sprache in: Kemura, Scheich Seiffudin Ef. und Corovit, Vl., Serbokroatische Dichtungen bosnischer Hoslims aus dem XVII., XVIII. und XIX. Jahrhundert, Sarajevo 1912, S. 52 ff.

4) Vgl. auch die für die Sevdalinka besonders charakterigtische iteratio: pasa Ali-pasa.

Vgl. dazu S. 21 . 
Durch seine formale wie inhaltliche Nähe zum Volkslied ist es zu erklären, daB Motive und ganze Passagen dieses Gedichtes von der bekannten Sevdalinka "Perman dode iz Stambola, bujruntija iz Sarajevan 1) übernommen worden sind. 2)

Besondere Beachtung verdienen in diesem Zusammenhang drel Gedichte von Aleksa Santit, die heute in mehr oder weniger stark veränderter Porm als Sevdalinke aufgefaBt und gesungen werden. Es handelt sich um die Gedichte "Eminan"3), "Ko pokida pod grlom derdane" 4) und "Azra". Letzteres ist besonders bemerkenswert deshalb, weil es eine dichterische Nachübersetzung des gleichnamigen Gedichtes von Heinrich Heine darstellt. Vergleichshalber seien hier Original-, Ubersetzungs- und Sevdalinkatext nebeneinandergestellt, da sie von nicht geringem philologischen Interesse sein durften:

A. Heine:

Der Asra

Täglich ging die wunderschöne Sultanstochter auf und nieder Um die Abendzeit am Springbrunn, Ho die weiBen Wasser plätschern.

1) Vgl. dazu Kurt, S. $104 \mathrm{ff}$. und Blagajit, S. $21 \mathrm{f}$.

2) Vgl. dazu Hadzijahit, M., Pjesme Umihane Cudovine 1 narodna poezija, Narodna uzdanica, Kalendar, Sarajevo 1936, S. 88-94.

3) Vgl. dazu Santic, A., Pjesme, Mostar 1908, S. 76 und die Schallplattentexte Jugoton EPY 3196 A (Unter dem Plattentitel "Emina" steht hier bezeichnenderweise: "Narodna pjesma iz Hercegovine (RijeXI Aleksa Santic 1 Sevda Katica)" und Jugoton EPY 3117 A sowie die bel Odobaril, S. 45 aufgezeichnete Variante.

4) Vgl. dazu Milołevic, M.N., Nała narodna poezija, Beograd 1930, S. 36: "Ima ih koje nisu narodne, kojima se zna pisac, all je narod pesmu oteo od pisca, preradio je $i$ udesio $2 a$ sebe, izmenio je toliko, da $i$ sam piģac ne bi mogao poznati svoj rodeni rad. Jedna od takvih je Santiceva pesma: "Ko pokida pod grlom derdane"... Kao sto rekoh, ta Santiceva pesma nije viłe njegova, vect narodna.", sowie Dukit, T., Polklor u Santicevoj poezi $j i$, Rad IX-Og kongresa saveza folklorista Jugoslavije u Mostaru i Trebinju 1962, Sarajevo 1963 , S. 137-140. 
Täglich stand der junge Sklave

Um die Abendzeit am Springbrunn,

Wo die weiBen Wasser plätschern;

Täglich ward er bleich und bleicher.

Eines Abends trat die Fürstin Auf inn zu mit raschen Worten:

Deinen Namen will ich wissen, Deine Heimat, deine Sippschaft!

Und der Sklave sprach: ich heiBe

Mohamet, ich bin aus Jemen,

Und mein Stamm sind jene Asra,

Welche sterben, wenn sie lieben. ")

B. Santic

Azra

Svakog dana o veceri

Sultanova kterka lepa

Slazila je na Sedrvan,

Gde srebrna voda pljusti.

Svako vece rob je mladi

Staj'o pokraj కedrvana,

Gde srebrna voda pljußti,

I sve bivo ble $\bar{d} i$, ble $\bar{d} i$.

Jedno vece kneginjica

Pristupi mu, zborit ode:

"Hotu da znam troje ime,

Troj zavitaj i poreklo!"

1) Heine, H., Sämtliche Werke, hg. von Frof, Dr.Elster, E., in 7 Bänden, Leipzig und 将e o.J. (1890), Bd. 1, S. 357 f. Vgl. auch die kritischen Anmerkungen zu diesem Gedicht in Bd. 7, S. 624 f. 
A rob rece: "Muhamed se

Zovem, rod̄en u Jemenu;

A moje je pleme Azra,

Sto umire kada ljubi." 1 )

C. Sevdalinkatext

Azra

Kraj tanana Sadrvana,

Gdje zubori voda Ziva,

Svakog dana setala se

Sultanova kterka mila.

Svakog dana jedno robce

Stajalo kraj badrvana.

Kako vr'jeme prolazilo,

Robce bljede, bljede bilo.

Jednog dana pitala ga

Sultanova keerka draga:

"Kazuj, robe, odakle 81 ,

Iz plemena kojega si?"

"Ja se zovem el tuhamed

Iz plemena starih Azra,

Sto za ljubav zivot gube

I umiru kada ljube." 2 )

Das Gedicht "Der Asra" von $H$. Heine ist des öfteren in die serbokroatische Sprache ubersetzt worden. Der sevdalinkatext

1) Santic, A., Iz Hajneove lirike, Hostar 1923, S. 138.

2) Text der schallplatte Jugoton EPY 3514 A, gesungen von H. Polovina. Die lielodie dieses Liedes hat ebenfalls einen berühten Schöpfer: in einem Album des jugoslavischen 0 pernsängers Zarko Savic befand sich eine Vertonung dieses Gedichtes von Anton Rubinstein, an deren Echtheit kein $\mathrm{Zweifel}$ bestehen soll. Diese ingabe verdanke ich derrn Dr. VI. idilosevit, Banja Luka, mündlich. 
hat sich dabel mehr an die äuBerst gelungene Ubertragung von Dragutin J. Ill $t^{1)}$ als an die von A. Santit angelehnt. Es sel dazu nur die erste Strophe der Ubersetzung von Ilit angefuhrt, in der lediglich das individualisierende Epitheton "divna" durch das der Volksdichtung näherstehende "mila" ersetzt worden ist:

\section{Kraj tanana Zedrvana, Gde zubori voda ziva, Setala se svakog dana Sultanova teri dima. ${ }^{2}$ )}

Eine enge Verbindung mit der Sevdalinka gingen auch verschiedene Gedichte anderer bekannter Dichter ein. So lassen sich zu dem Gedicht "Abasah" von Jovan Ilit bereits drei - im wesentlichen ubereinstimmende - Volksliedvarianten anfuhren ${ }^{3)}$, von denel im folgenden eine dem Originaltext gegenübergestellt werden sol:

\section{A. Il16}

\section{Abasah}

Na pr'jestolu kalif sjedi, Harun-al-Rałid, Do njeg' sjedi mlad vezire, Dzafer Barmeldd.

"A cu li me, mlad vezire, "Znał li tko sam ja?" "Ti 81 kalif, sunce jarko, "Sto nad ov'jetom sja!" -

1) Vgl. dazu Lauer, R., Heine in Serbien, Ph1l.Diss., Prankfurt/Main, Meisenheim am Glan 1961, S. 154: "... eine Ubersetzung des "Asra" (...) von Dragutín llik, die zu den besten Ubersetzungen der serbischen literatur überhaupt gebört."

2) Lauer, R., a.a.0., S. 154 (nach Il1t, D., Pesme, Beograd 18

3) Es handelt sich um die Lieder Zovko II, 1, Nr. 151, Bart6k/ Lord, Nr. 42 (b) und Jugoton EPY 3514 B. 
"Kazi pravo, mlad vezire,

"Amana ti trog!

"Tko ti dade zlatne kljuce,

"Od harema mog?" -

"Dala mi in seja troja,

"I poljupca dva,

"A do zore kolko bjere,

"Ne znam Bogme ja!" -

"A znader li, mlad vezire,

"Ne znao te jad,

"Da ce dzelat glavu troju

"Ukinuti sad?" -

"Sv'jetla kruno od Azije,

"Da l'jepo ti ajar!

"Hoj kalife, gospodaru,

"Da malo t1 znar!

"A da znades, moj kalife, " Sto ja znadem sam,

"Po Bagdada ti bi dao

"I Misir i Sam!

"A da znades, moj kalife,

"Gdje ja notas bi,

"Sto zivota da imades,

"Halalio b' ti!

"O Abasah, ružo rajoka!

"I'jep je miris troj!

"slada mi je dusa troja,

"Nego zivot moj!"

To izrece mlad vezire,

Ode bez glasa, 
Urtva glava progovara:

"Zbogom .... Abasah!" ${ }^{1)}$

\section{B. Sevdalinkatext}

Na prestolu sultan sjedi, Abdulah Džemil,

A do njega mlad vezire, Abdul Alidah.

"O Boga ti, mlad vezire, amana ti tvog,

Ko ti dade zlatne kljuce od harema mog?"

"Dala mi je troja aeja, i poljubca dva,

A do zore sto bijase, ni sam ne znam ja!"

"Suti, more, mlad vezire, nasao te jad,

Jer ke dそelat tvoju glavu odrizati sad."

"Joł da znadeß, moj sultane, sta no notas bi,

Trista glava da imadem, halal bijeli!"

To izusti mlad vezire, osta bez glasa.

Mrtva glava-i progovara: "Z Bogom, Abasa!"

"Oj, Abaso, duso rajska, mil mi miris tvoj,

Milija mi duša tvoja, neg sav zivot moj!" 2)

Im Gegensatz zu dem Gedicht der Umihana Cudovina (s. S. 198 f.) hat das von Jovan Ilit nur äuBerst wenig der in dieser Arbeit untersuchten und für die Sevdalinka typischen sprachlichen Piguren aufzuweisen. Das spiegelt sich auch in den Varianten wider. Die 0.a. Volksliedvariante unterscheidet sich vom Kunstlied hauptsächlich durch Austausch von Eigennamen und Titel ${ }^{3)}$, durch Weglassen dreier Strophen (der 2., 6. und 7.) und durch Umstellung der beiden letzten Strophen. In diesem Beispiel ist also die Grundstruktur des Kunstgedichtes in den Volkslied-

1) Ilit, J., Pesme, SKZ, Beograd 1894, S. 34 f. - Vgl. ferner zur Einstellung von J. Ilit zur Sevdalinka: Skaric, vl., Booanski muslimani i narodna poezija, Jugoslovenska njiva, God.V, Br. 45, Zagreb 1921, S. 712 f. und den mit "S.A.J." unterzeichneten Artikel in Bosanska vila 1889, S. 7-8 und S. 20-22: "Sevdalije bosanske (slika iz knjizevnosti)".

2) Bart6k/Lord, Nir. 42 (b).

3) J. Ilit verwendete in seinem Gedicht bekarnte historische Persönlichkeiten der arabischen Helt, wie z.B. den abbasidischen Kalif Harun al-Raschid (786-809). 
varianten weitgehendst erhalten.

Eine freiere Behandlung der dichterischen Vorlage bei gleichzeitiger enger Anlehnung an den Text zeigt folgende, bisher einzige Volksliedvariante zu dem Gedicht "Djevojka i golubica" von Safet Beg Basagit:
A. Bałagit
Djevojka i Golubica

Golubice, sivoga ti perja!

Ne zoblji mi sa grla biserja;

To je dragi meni dao lani,

Kad se zakle da me uzet kani.

Nakar do sad ne odrzo rieci,

Ovaj biser meni jade liecti.

Golubice, sivoga ti perja!

Ne zoblji mi sa grla biserja; -

Ijubavna je uspomena sveta,

Ja je ne dam za obadva svieta.

Od dragosti nosim je vis grudi,

Kako tilsum od opakih ljudi.

Golubice, sivoga ti perja!

Ne zoblji mi sa grla biserja; -

Ne ljubi mi neljubljeno lice,

Ne kvari mi rujne jagodice!

Kada mladu povedu me svati,

Dragom cu in za uzdarje dati. 1)

B. Sevdalinkatext

Aj golubice, sivoga ti perja, Aman sivoga ti perja, Aj ne trgaj mi sa grla bisera!

1) Bašagic-Reď̌epałic, Safet Beg (Mirza Safet), Odabrane pjesme, Sarajevo 1944, S. 41 f. 
Aj ovaj biser kupio mi dragi,

Aman kupio mi dragi,

Kupi lant, jer me zentt' kani.

Aj ako dragi ne odrzi riedi,

Aman ne održi rieci,

Aj ovaj biser nek' mi rane lieci. 1)

Von den drei Strophen des Originalgedichtes ubernahm die Sevdalinka nur die erste und gestaltete sie in ihrem Sinne um unter Verwendung eben der sprachlichen Figuren, die sich für sie als typisch erwiesen hatten: zunächst erhält jeder einzelne Vers einen der charakteristischen interjektiven Vorschläge aj bzw. aman. ${ }^{2)}$ Des weiteren werden die Zeilen eins, drei, fünf der eroten Strophe des Originalgedichtes jeweils in Form einer Ganzversrepetitio wiederholt. ${ }^{3)}$ Auf diese Weise bildet das Volkslied seinerseits Strophen heraus ${ }^{4)}$ : aus der ersten Strophe des dreistrophlgen Gedichtes von Bałagil entstand so mit Hilfe der sprachlichen Figuren eine Sevdalinka von ebenfalls drei Strophen.

Das Verhältnis von Kunstlied und Sevdalinka stellt sich also abschließend folgendermaßen dar:

1. Das Kunstlied verzichtet weitgehend auf sprachliche Piguren. Das Volkslied überniont das Kunstlied ebenfalls unter Verzicht dieser Piguren. ${ }^{5)}$

Beispiele: Santit, Ilit.

1) Dizdar, I, Nr. 76.

2) Vgl. dazu S. 23 f.

3) Vgl. dazu I, 1b.

4) Der Aufzeichner (H. Dizdar) gab diese Sevdalinka auch in Strophenform wieder.

5) Das mag mit der Grund dafür sein, daB sich im Gegensatz zu den originären Sevdalinke zu den aus Kunstliedern entstandenen weit wenlger Varianten nachweisen lassen. Der Volksliedsänger kann nicht auf die sprachlichen Figuren zurúckgreifen, die ihm bei der Improvisation und Tradierung so nutzlich, wenn nicht gar erforderlich sind. So konnten für das Gedicht "Abasah" von J. Ilic lediglich drei Varianten gefunden werden (Zovko II, 1, Nr. 151, Bart6k/Lord, Nr. 42 (b) 
2. Das Kunstlied verzichtet weitgehend auf sprachliche Piguren. Das Volkslied ubernimmt das Kunstlied unter Verwendung von sprachlichen Figuren.

Beispiel: Bałagit.

3. Das Kunstlied verwendet sprachliche Figuren in bewubter Anlehnung an den Volksliedstil.

Das Volkslied übernimmt das Kunstlied mit seinen sprachlichen Piguren.

Beispiel: Ćudovina. 1)

Diese Gegenüberstellung will das Verhältnis von Kunstlied und Sevdalinka klären nur im Hinblick auf die dieser Arbeit zugrunde liegende Themenstellung. Es versteht $81 \mathrm{ch}$, daB sie einer allgemeinen Betrachtung der Wechselbeziehungen beider nicht gerecht werden kann. Eine solche hätte die verschiedensten Aspekte dieses Problems zu berücksichtigen, was aber eine gesonderte Untersuchung erforderte.

Fortsetzung von S. 206, Anm. 5:

und Jugoton EPY 3514 B. Fü die Gedichte von A. Šantic bzw. D. Ilic fanden si ch ebenfalls nur wenige volksliedvarianten, U.zw. fur "Azra" - eine (Jugoton EPY 3514 A), fur "Ko pokida pod grlom derdane" - eine (vgl, dazu Milołevic, M.N., a.a.0., S. 36) und für "Emina" - drei (Odobasic, S. 45, Jugoton EPY 3117 A und Jugoton EPY 3196 A).

Zu dem Verhältnis von Kunstlied und Volksliedvarianten vgl. auch Braun, M., Das Volkslied als philologisches Problem, Welt der Slaven, Jg. 3, Wiesbaden 1958, S. 5 f.

1) Zu dieser Gruppe gehören auch Gedichte von Bikit und Zmaj. Vgl. dazu das Gedicht "Moj se dragi naljutio na me", in: Bikit, 0.A., Asiklije, jostar 1903, S. 24 und die Sévialinka in Teil II, 3: "Ne Čudim se mraku ni oblaku". Und vgl. dazu Bordevit, T.R., Beleske o nasoj narodnoj poeziji, Beograd 1939, Kapitel XXXVIII, S. 181 f.: "Jedna Zmajeva pesma u narodu" und die Sevdalinka bei Popovit-Rodoljub, Nir. 120. 
15. $\underline{\operatorname{SchluB}}$

Das bosnisch-hercegovinische städtische Liebeslied, die Sevdalinka, bedient sich in starkem MaBe der in Teil I behandelten Piguren. In dieser Hinsicht unterscheidet es sich nicht von dem bereits untersuchten ubrigen Volksliedmaterial des balkanslavischen Raumes. Der - nicht selten bekannte - Schöpfer dieses Liedes, der seinen Text aus dem Augenblick des Vortrags heraus gestaltet, gebraucht die sprachlichen Figuren nicht zuletzt zur Erleichterung der Improvisation. ${ }^{1)}$ Einige dieser Figuren haben diesbezüglich einen geringeren Wert: geminatio, redditio, annominatio, Polyptoton, figura etymologica und Epitheton. Sie erleichtern dem Sänger die Improvisation in der Regel nur innerhalb einer einzigen Verszeile. Durch Wiederholung von Worten oder Wortgruppen in gleicher oder abgewandelter Form bleibt dem Sänger das Suchen nach einem entsprechenden synonymischen oder pronominalen Ersatz erspart. Einige der 0.a. Figuren erweisen sich dabei als speziell für die Sevdalinka charakteristisch, wodurch sich dieses lied von der ubrigen lyrischen Volksdichtung des balkanslavischen Raumes einerseits und von der epischen Volksdichtung dieses Gebietes andererseits abhebt. So bedient sich die Sevdalinka z.B. mit Vorliebe der iteratio oder repetitio mit interjektiver Vorschlag. etwa:

Ah moj beze, dobri beže

$$
\text { Nije meni dodijalo... (iteratio) }
$$

oder:

San zaspala, aj san zaspala

Dilber Ajła u basci... (repetitio).

Ein weiteres Charakteristikum der Sevdalinka, wodurch sie sich von den ubrigen liebesliedern des balkanslavischen Raumes unterscheidet, ist die iterative Wiederholung von Titeln und Rängen:

1) Darliber hinaus haben diese Figuren eine wichtige Ornatusfunktion. Ihr Schmuckcharakter wurde in dieser Arbeit jedoch weitgehend auBer acht gelassen, da er bereits von anderer seite ausfuhrlich untersucht worden ist.

Vgl. dazu Pollok, a.a.0. 
Tut prolazi hodza Omer-hodża,

Govorio hodza Omer-hodza:...

Nennung des Ranges zieht in der Sevdalinka in den meisten Fällen automatisch Erwähnung des Namens seines Trägers und nochmalige Setzung des Ranges nach sich.

Auch im Gebrauch der annominatio, insbesondere des pseudoetymologischen Tortspieles, hat dieses Lied seine eigenen Pormen herauggebildet. Typische Wortspiele mit Orts- und Eigennamen lassen vielfach die Provenienz eines Iiedes erkennen:

U Gradascu gradu bielome

Gradila se biela dzamija... (Lokalisierung) oder:

"Da te mogu ufatiti, Fato!

"Bjelo bih ti lice poljubio.... (Eigenname).

Ahnlich verhäl es sich mit der Verwendung bestimmter Epitheta: fur das in der epischen Volksdichtung gebräuchliche Epitheton "tanana" zu "robinja" hat die Sevdalinka daneben noch die variante aus Possessivadjektiv ("pasina") plus Substantiv herauggebildet:

Za njom కete beže_Mehmed-bež $e_{-}^{1)}$

Pa govori pasinoj robinji:...

Gegenüber anderen lyrischen Liedern des serbokroatischen Raumes zeichnet sich die Sevdalinka durch reichliche verwendung von Turzismen gerade in bezug auf das Epitheton aus. Hierher gehören etwa folgende: sedefll tambura, dzenetska hurija u.v.a.

Solche - nur der Sevdalinka eigene - Epitheta finden sich auch unter den zusammengesetzten Epitheta:

Moja draga, moja slatḱka_s ladijo,

"Što me mases al-vezenom Eatkijom?!...

Ais besonders erfinderisch erweist sich das muslimische lied aber in der Bildung von substantivischen Epitheta. Zu dieser Gruppe gehören etwa: Stambolija-Salko, §eher Sarajevo, sumbuludovica, dul-djevojka u.v.a.

1) VGl. zu dieser iteratio s. 208. 
Der einzelne Vers der Sevdalinka stellt in der Regel ein syntaktisch-semantisch wie melodisch abgeschlossenes Ganzes dar, was dem improvisierenden Sänger den Ubergang von Vers zu Vers insofern erschwert, als er jeweils nach einem neuen Einsatz zu suchen hat. Dies wird ihm durch die verwendung von reduplicatio und Epiploke erleichtert, die durch Gebrauch desselben Wortes (oder ggf. derselben Wortgruppe) das Ende eines Verses mit dem Anfang des folgenden binden. Dieser ihrer Eigenschaft verdanken reduplicatio und Epiploke hauptsächlich ihre häufige Verwendung in der Sevdalinka. Hat der Särger einmal ihren Hert für die Improvisation erfahren, gebraucht er sie in seinem lied gern des öfteren, so da $B$ ihnen nicht selten ein liedgestaltender Charakter zukommt. 1)

Geradezu prädestiniert jedoch, über die improvisatorische Funktion hinaus auch eine kompositorische zu erlangen, sind Anapher, Epipher, koordinierende Häufung und Isocolon. 2) Durch ihre Verwendung vermag der Sänger größere Liedabschnitte, ja ganze Lieder zu binden ( $\mathrm{V}_{\mathrm{gl}}$. etwa das auf $\mathrm{S}, 124$ ange führte lied u.ä.)

Darüber hinaus kann er vor allem durch den Gebrauch der koordinierenden Häufung seiner Freude am Aufzählen von Kleidungs-, Schmuck- und Luxusgegenständen Ausdruck verleihen. Diese Freude an detaillierten Darstellungen und umfangreichen Beschreibungen scheint auf orientalischen EinfluB zurückzugehen. ${ }^{3)}$ Da die koordinierende Häufung diesem Bedürfnis des Sängers in besonderer Weise entgegenkommt, findet sie sich in der Sevdalinka im Vergleich mit der übrigen südslavischen lyrischen Volksdichtung auffallend häufig. Auf Beispiele, die oft eine beträchtliche länge erreichen, soll an dieser Stelle verzichtet werden ( $V_{g l}$. etwa das Lied Kurt, Nr. 84 u.a.).

Die in der Sevdalinka beliebten Aufzählungen sind vielfach

1) Vgl. dazu etwa die Beispiele auf S. 35 f. (reduplicatio) und S. 39 f. (Epiploke).

2) Polysyndeton und Asyndeton sind im wesentlichen Hilfsmittel zur Realisierung anderer Piguren, vornehmlich der Synonymie und der koordinierenden Häufung.

3) Vgl. dazu S. $87 \mathrm{ff}$. und S. $174 \mathrm{f}$. 
mit ausgeprägten Anapherketten verbunden ( $\mathrm{Vgl}$. dazu das Lied Hak I, Nr. 38, wo eine solche sich über zwanzig Verse hinzieht). Wicht selten werden detaillierte Beschreibungen formal auch durch groBangelegte Isocolaketten, oft durch verschränkte Isocola, gefestigt. Fir die Sevdalinka charakteristisch sind $z . B$. durch Isocola gestützte Aufzählungen, in denen die Schönheit eines Mädchens gepriesen wird, etwa in der Art:

Kakve su joj obrvice,

Valjaju joj viłegrada;

Rakve su joj trepavice,

Valjaju joj Carigrada;

Kakve su joj b'jele ruke,

Valjaju joj Banje Iuke;

Kakve su joj ruse kose,

Valjaju joj c'jele Bosne!

Die hier noch einmal kurz angesprochenen, in Teil I im einzelnen durchgeführten Untersuchungen zeigen, daB die Sevdalinka gerade im Gebrauch der sprachlichen Figuren neben vielen Gemeinsamkeiten mit der ubrigen südslavischen Volksdichtung (und improvisierter Dichtung allgemein) eine ganze Reihe typischer Beoonderheiten aufuweisen hat.

Vergleiche der unterschiedlichsten Lieder ergaben, daB sich die sprachlichen Piguren über alle Zeiten in der Sevdalinka erhalten haben, von der Erlanger Handschrift bis zu Milołevic IV.

Das gilt auch für die Lieder, deren Autor (Erstsänger) nachgewiesen werden kann, wie etwa für das in II, 8 behandelte Lied "Mołcanice, vodo plemenita", die aber nichtsdestoweniger als genuine Sevdalinke anzusprechen sind ( $V_{g l}$. dazu S. 166 f.).

Eine Ausnahme hierzu bilden lediglich aus Kunstliedern entstandene Sevdalinke (II,14) mit stets bekanntem Autor, die in ihrer Mehrzahl auf diese Piguren verzichten.

Auf Grund des Variantenvergleiches im zweiten Teil dieser Arbeit zeigte sich indirekt und ergänzend zu Teil I die Beständigkeit der sprachlichen Piguren in der Sevdalinka bis in die jüngste Zeit. Als weiteres Resultat des zweiten Teiles ergab sich, daß die Figuren über ihre improvisatorische und kompositorische 
Punktion hinaus auch einen entscheidenden Anteil bei der Uberlieferung der Lieder haben. In ihrer die Einprägsamkeit erleichternden Eigenschaft und Wirkung dienen sie dem Sänger als Gedächtnisstützen. Es erwies sich, daB Lieder oder Liedpassagen, die durch eben diese Piguren in sich gestützt sind, über gröBere Zeiträume in ünlicher Porm, oft sogar wörtlich tradiert werden: die Varianten zu den einzelnen Grundliedern weichen in solchen Fällen nicht allzusehr voneinander ab.

Besonders zu erwähnen sind in diesem Zusammenhang Piguren wie Isocolon, Anapher, Epipher, reduplicatio, Epiploke und koordinierende Häufung, d.h. die Piguren, die - wie aus Teil I schon ersichtlich - uber inre improvisatorische Punktion hinaus auch eine kompositorische erlangen können.

Das Lied II,6 ("Pošetala ljepotica Pata") brachte - mit umgekehrten Vorzeichen - dasselbe Ergebnis: die Varianten zu diesem Grundlied unterscheiden sich teilweise recht beträchtlich. Typischerweise ist dieses lied sehr sparsam im Gebrauch von sprachlicken Figuren.

Abweichungen bei der Tradierung ergeben sich einmal durch das Weglassen ganzer Verse, die also - und mit ihnen die Piguren an sich nicht verändert werden, des weiteren durch Kontamination eines liedes mit anderen. Für solche größeren Veränderungen zeigt sich insbesondere der liedschluB anfällig, da sich an dieser Stelle leicht Motive aus anderen Liedern anschließen lassen. ${ }^{1)}$ So entleihen 2.B. zwei Varianten des Liedes II,3 ("Ne Cudim se mraku ni oblaku") ihren SchluB jeweils einem anderen lied, die Kuba-Variante (1908, Nr. 473) dem Lied III,7 und die Rubit-Variante (IV, S. 290) dem Lied III,26. Daneben kommt es aber auch vor, daß einige lieder vorzeitig enden, wobei es sich manchmal einfach um Pragmente handelt, so z.B. bei der Variante R.a., inv. br. 8577 (1958) zu dem Grundlied II, 1 ("liajde, draga, da ašikujemo") u.a.

1) Vgl. dazu Grgec, P., Hrvatske narodne pjesme, Zagreb 1943 , S. XaII: "I u lirici postoje stalni motivi, koji se obraduju s razlicitim ugodajima $i$ u razlicitim stihovima $i$ s razlicitim imenima osoba, mjesta $i$ vremena. Ako se dva motiva ujedine skupa tako, da se opaza njihovo drojstro, time nastaje kontaminacija ili poriełanost, koja obicno (aber nicht Irmer, H.E.) oslabljuje pjesnitku snagu pjesme." 
Anderungen unterworfen sind bei der Tradierung des weiteren besonders Personennamen und geographische Bezeichnungen, die der Sänger mehr oder weniger aus seiner näheren Umgebung zu wählen scheint. So erscheinen 2.B. in II,7 ("U Mostaru Seter mejtef kažu") und seinen neun Varianten fünf verschiedene maskuline und sechs feminine Vornamen, in II, 10 ("Sto Morava mutno tecen) und seinen 18 Varianten drei verschiedene Plubbezeichnungen und für die zwei Schwestern 19 verschiedene Eigennamen. Nur in einem einzigen Lied (II,13d: "Kakva ti je u Alage Ijuba") wird ein und derselbe Personenname (Alaga) in allen Varianten beibehalten.

Wenn solche und ähnliche Abweichungen bei der Untersuchung der Lieder auch nicht unterbewertet werden oder gar unberuicksichtigt bleiben dürfen, so ändern sie doch grundsätzlich nichts an der Tatsache, daB die sprachlichen Figuren in der Sevdalinka eine wichtige Punktion bei der Improvisation, Komposition und Tradierung dieses Liedes haben. 
Te1I III

\section{Vorbemerkungen}

Der folgende Anhang (Teil III) stellt ein Verzeichnis der 37 Grundlieder mit den dazu aufgefundenen Varianten dar. Als Beispiel murde jeweils ein Lied, das die untersuchten sprachlichen Piguren in besonders charakteristischer Weise verwendet, vollständig zitiert und der betreffenden Variantengruppe vorangestellt. Dabel wurde eine wiederholung der bereits in Tell II (1-12) vollständig angegebenen Lieder vermieden.

Die Varianten wurden in der Reihenfolge thres Erscheinungsdatums aufgeführt, wobel das Datum der Erstausgabe berücksichtigt wurde. Zwel Sammlungen (Milanovit und Odobasit) enthalten keine Angaben über ihr Erscheinungsjahr. Zu beiden fanden $81 \mathrm{ch}$ jedoch diesbezügliche Hinweise an anderer Stelle: so erschien nach Pollok die Milanovit-Sammlung $1924^{1)}$ und nach Morpurgo die Odobałit-Sammlung 1933.2)

Schwierigkeiten bei der chronologischen Einordnung der Lieder ergaben sich bei Sammlungen, die bereits veröffentlichte Lieder zum Hiederabaruck bringen und

a. Uiberhaupt keinen Quellennachweis fuhren (etwa $\mathrm{Hak}^{3}$ ) ) oder

b. die Fundstelle äuBerst ungenau bzw. falsch und irreführend angeben (etwa Cubelic ${ }^{4}$ ).

1) Vgl. dazu Pollok, S. 259.

2) Vgl. dazu Morpurgo, V., I fratelli Ibro e Paso Moric nell'intuizione popolare delia ballata bosniaca, Bari 1962, S. 14, Ansis. 31.

3) Vgl, dazu auch Corovit, V1., Srpske narodne pjesme, Bibliografski pregled zbirki, Srpski knjizerni glasnik, 16.11.1911, S. 756: "Mihajlo Milanovit izdao je u Sarajevu "Muslimanske sevdalinke", koje je skupio neki Abdul Hak. Medutim u tu su zbirku prosto prestampavane neke ranije, 1 to mnogo poznate pjesme.... Osim toga je preko pedeset pjesama (sve od broja 89-142) direktno preneseno 12 Bugarinoviceve zbirke, samo su pravoslavna imena zami jenjena muslimanskim."

4) Vgl. etwa auf S. 384 die Quellenangaben von Cubelit $2 u$ den liedern "Pripjev" (S. 62) oder "Smrt Omera i Merimen (S.237). Daneben nimmt Cubelic orthographische Anderungen vor, ohne 
Jedoch konnte durch sorgfältigen Vergleich der einzelnen Sammlungen die jewellige Quelle ermittelt werden.

Bei den im Verzeichnis in Klammern gesetzten Liedvarianten handelt es sich um solche, die der Herausgeber jeweils aus einer anderen Sammlung ubernommen hat, u.zw. aus der im Verzeichnis unmittelbar zuvor angeführten.

Aus den Erscheinungsdaten der einzelnen Sammlungen und zeitschriften geht hervor, daB die Bemühungen um Aufzeichnung von Volksdichtung, also auch von Sevdalinke, in Bosnien um die Jahrhundertwende besonders intensiv waren. 1 )

Die einzelnen lieder murden so zitiert, wie sie vorgefunden mar den, d.h. in threr jewelligen Orthographie (z.B. in etymologischer Schreibweise, etwa "srdce" u.a. bel Dizdar), mit Druckfehlern (reichhaltig bei Kuba u.a.), in den verschiedenen Dialekten ( $1-$, je- und ekavisch und mit dialektischen Wortneuschöpfungen in IIedern des R.a.) und mit offensichtlichen Pehlern (Milanovit ${ }^{2}$ u.a.).

Eine einzige Veränderung wurde vorgenommen: die Zeilenanfänge wurden grundsätzlich mit groBen Buchstaben wiedergegeben (so auch in Teil I und II).

Vuk kennzeichnete seine Lieder hinsichtlich des Aufzeichnungsortes Sarajevo gelegentlich mit dem Hinweis "sarajevska" oder " $\mathrm{T}^{\mathrm{x}}$, der hier beibehalten murde. 3 )

Portsetzung von S. 214, Anm. 4: sie als solche zu kennzeichnen oder auf sie aufmerksam zu machen. So findet man be1 Cubelit auf S. 123: "udat tu", während es im Original (Petranovit, Nr. 153) "udacun heiBt.

Das Wort "Bog" gibt Cubelie ohne Rücksicht auf die verschiedenen Vorlagen grundsätzlich in Kleinschreibung wieder.

1) Vgl. dazu T.K., Najplodniji period skupljanja narodnih umotvorina u Bosnt, Pregled, Nov.-Dec.1947, S. 834: NNajplodnij1 period u skupljanju narodnih umotvorina u Bosni bio je osamdesetih godina prołlog veka...".

2) Zu Milanovit sagt z.B. Ćorovit, VI., a.a.0., S. 754: "nspske narodne zenske pjesme iz Sarajevan objavio je u Sarajevu trgovac Mihajlo Hilanovic 1893. U zbirci ima ljepsih 1 novijeh pjesama, samo one nijesu uvijek dobro saopstene. Kao sve Saraj lije tako 1 Uilanovic ne 2 na da razlikuje slova $c$ i $i d z$ $i$ d."

3) Die mit " $\mathrm{T}^{x}$ gekennzeichneten Lieder stammen von einer $\mathrm{Zi-}$ geunerin in Sarajevo. Vgl. dazu Karadzit, V.St., 0 srpakoj narodnoj poeziji, Beograd 1964, S. 336 . 
1. Hadje, duso, da asikujemo

"Hajde, duso, da asikujemo!"

"Rako temo kad ne umijemo?"

"Ja cu tebe nauciti, duso!

Sjed' preda me, pa namiguj na me.

A ja cu se nasmijati na te!n

$$
\text { Dizdar I, Nr. } 81
$$

\section{Varianten}

1. Zovko II, 3, Nr. 23

2. Zovko II, 3, Nr. 115

3. Bosanska vila 1897, S. 139

4. Lilanovit I, Nr. 20

(5. Hak II, Nr. 40)

6. SiH VII, Nir. 183

7. Dizdar I, Nr. 81

8. R.a., inv. br. 8577

9. R.a., inv. br. 9162

10. Kiloševic IV, Nr. 222

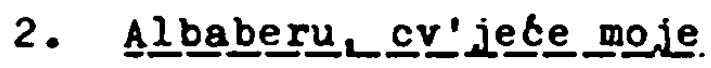

Albaberu, cv'jete moje!

Da je meni sjeme troje,

Ja bi znala de bi crala:

U studenu Taslihanu,

U mog dragog u magazi.

Kad mi dragi knjigu piše,

Nek albaber primirise,

liek mu draga na um padne,

Na um padne, pa uzdane,

jek mom dertu priuvise. ${ }^{1)}$

Bosanska vila 1896, S. 251

1) = da njezinom dertu njegov dert bude nalik. 


\section{Varianten}

1. Vuk I, Nr. 350

2. Petranovit, Nr. 142

3. Petranovit, Nr. 143

4. Petranovit, Nr. 284

5. Kuhad I, Nr. 146

6. Popovit-Rodoljub, Nr. 64

7. Zovko II, 1, Nr. 144

8. Zovko II, $3, \mathrm{Nr} .28$

(9. HH VII, Nr. 26)

10. Bosanska vila 1895, S. 29

11. Mokranjac, Nr. 81

12. Mokranjac, Nr. 82

13. Bosanska vila 1896, S. 251

14. Kurt, Nr. 27

15. Andrit II, Nir. 3

16. Manovit II, Nr. 5

(17. Hak II, Nr. 5)

(18. Prodanovit, Nr. 18)

(19. Cubelit, S. 113)

(20. Dizdar II, S. 67)

21. Rubit XXV, S. 366

22. N VII, Nr. 39

23. MH VII, Nr. 43

24. Dizdar I, Nr. 39

25. Cubelit, S. 336

26. R.a., inv. br. 8643

27. R.a., inv. br. 9133

28. R.a., inv. br. 11717

29. Hilosevit IV, Nr. 118 


\section{Svi dilberi, moga, majko, nejma}

Svi dilberi, moga, majko, nejma.

Nill Boze, sto ll mi ga nejma:

II' boluje, ill asikuje?

Volim cuti 1 da mi boluje,

Neg' da 8 drugom dragom astkuje.

Bolujuti ikad te mi doti,

Asikujut nikad, ni do v'jeka.

$$
\text { Dizdar I, Nr. } 266
$$

\section{Varianten}

1. Vuk I, Nr. 359 (sarajevska)

(2. Andric II, Nr. 105)

(3. Milanovit I, Nr. 9)

(4. Hak II, Nr. 10)

5. Vuk II, Nr. 68

(6. Dizdar II, S. 115 f.)

7. Kuhat I, Nr. 361

8. Zovko II, 2, Nr. 229

9. Zovko II, 4, Nr. 239

10. Bugarinovik, S. 34

(11. Milanovit I, Nr. 74)

(12. Hak II, Nr. 134)

13. Dizdar I, Nr. 266

(14. Dizdar II, S. 110)

15. Dizdar II, S. 13

16. Vasiljevit, Nr. 11

17. Milosevit IV, Nr. 136 


\section{Jesam 11 ti govorila, dragi}

" "Jesam if ti govorila, dragi, Ne ałikuj, ne vezi sevdaha! Od sevdaha goreg jada nema, Ni zalosti od asikovanja! Na zalost te 1 komsija doti, A $2 a$ sevdah niko 1 ne znade, Osim Boga 1 srdašca moga, Ah! srdasca i moga 1 troga!"

Milanovit III, S. 128

\section{Varianten}

1. Davidovit, Nr. 27

2. Blagajic, S. 3

3. Nirkovit, Nr. 26

4. Zovko I, Nr. 78

5. Bugarinovit, S. 54

6. Marunovic, S. $55 \mathrm{f}$.

7. Kuba 1908, S. 256, Nr. 441

8. Kuba 1908, S. 409, Nr. 542

9. Milanovit III, S. 116

10. Milanovit III, S. 128

11. Dizdar I, Nr. 108

12. Mlac, Nr. 23 i)

13. Vasiljevit, Nr. 116

14. Milosevit IV, Nr. 181

15. Milosevit IV, Nr. 182

1) Das Lied ist ubernomen aus der Sammlung: Livadit, V., Bosancice, Crte, pjesme, price 1 pripovjesti iz zivota bosanskoga, Zagreb 1882 . 


\section{Vjetar puše, alkatmerom niše}

Vjetar puše, alkatmerom niłe,

Sad moj dragi amber-du§om diðe,

Dus̆om diðe, a kalemom pise:

"Djevojke su zlatne amajlije;

U jednoj se amajliji pise:

Ko te hote, ne ponosi mu se!

U drugoj se amajliji pise:

Ko te ne te, ne nameti mu se!

od nameta fajde ne imade

Nit' u rodu nit' u trgovanju,

A kamo li u asikovanju.

U tretoj se amajliji pise:

Ne Cin' jada, lijepa djevojko,

Ne $\varkappa_{i n}$ ' jada, ne vezi sevdaha!

Od sevdaha goreg jada nema

Ni zalosti od asikovanja!

Na zalost te $i$ komsija doti,

Al' za jade niko $i$ ne znade

Osim Boga 1 srdał́ca moga."

Grgec, S. XXVI

\section{Varianten}

1. Vuk I, Nr. $498\left(T^{x}\right)$

(2. Burit, S. 69)

3. Vuk II, Nr. 69

4. Mirković, Nr. 121

5. Andrit II, Nr. 1

(6. Grgec, S. XXVI)

(7. Dizdar I, Nr. 319)

(8. Dizdar II, S. 128)

(9. Nagaraß̌evit, S. 260)

10. AIH VII, Nr. 163

11. Narodna uzdanica 1935, S. 136

12. Milosevit IV, Nr. 269 
6. Ne cudim se mraku ni oblaku

Ne cudim se mraku ni oblaku,

Ni Vrbasu, sto se Cesto muti,

Vet mom dragom to se na me ljuti.

Ni jesam mu nista ucinila,

Vet ako sam koga pogledala!

Ako sam ga okom pogledala,

Nijesam ga srdcem sevdisala,

Sevdisala, ni begenisala.

Na oxima nema kapidzije,

Na ustima nema sahibije.

\section{Varianten}

1. Grā̄anska lirika II, Nr. 439

2. Vuk II, Nr. 49

3. Vuk II, Nr. 62

(4. Cubelit, S. 116)

5. Petranovit, Nr. 213

(6. Prodanovit, Nr. 147)

(7. Milanovic I, Nr. 24)

(8. Hak II, Nr. 54)

9. Davidovit, Nr. 128

10. Davidovit, Nr. 129

11. Blagajit, Nr. 32

12. Zovko I, Nr. 59

13. Popovit-Rodoljub, Nr. 30

14. Popović-Rodoljub, Nr. 72

15. Zovko II, 1, Nr. 201

16. Zovko II, 2, Nr. 111

17. Bosanska vila 1895, S. 28

18. Rubit IV, S. 290

19. Kurt, Nr. 33

20. Bosanska vila 1903, S. 137

21. Đikit, S. 24

22. Kuba 1908, S. 261, Nr. 473 
23. Kuba 1908, S. 549, Nr. 601

24. Bosanska vila 1908, S. 220 f.

25. $\mathrm{VII}, \mathrm{Nr} .14$

26. NH VII, Nr. 51

27. MH VII, Nr. 106

28. Gajret 1930, S. 220

29. Narodna uzdanica 1935, S. 135, Nr. VII

30. Narodna uzdanica 1936, S. 148, Nr. VIII

31. Narodna uzdanica 1942, S. 209, Nr. V

32. Dizdar I, Nr. 175

(33. Dizdar II, S. 82 f.)

34. Dizdar I, Nr. 259

(35. Dizdar II, S. 114)

36. R.a., Inv. br. 9330

37. Milosevit IV, Nr. 141

7. Dv'je planine vrh Tramika grada

Dv'je planine vrh Travnika grada -

Bukovica, spram nje Vilenica.

Vilenica Bukovicu pita:

"A sto mi se Tramik zamaglio,

Ili gori, 1l' ga kuga mori?"

"Niti gori, nit' ga kuga mori,

Djevojka ga okom zapalila,

Crnim okcm kroz srcali pendzer!

Izgorjese dva nova ducana,

Dva ducana 1 nova mejhana,

I mestema, gdje kadija sudi!n

Dizdar II, S. 8

Varianten

1. Vuk I, Nr. $659\left(\mathrm{~T}^{\mathrm{x}}\right)$

(2. Andric II, Nr. 88)

3. Davidovit, Nr. 169 
4. Blagajic, Nr. 7

5. Jastrebov, S. 380 f.

6. Bosanska vila 1889, S. 20

7. Zovko II, 1, Nr. 200

8. Zovko II, 2, Nr. 38

9. Behar $1900 / 01$, S. 367

10. Andrit II, Nr. 32

11. Rubit XXIII, Nr. 35

12. Cubelic, S. 114 (aus Frodanovit)

13. ReX 1 slika, S. 37

14. Odobasit, S. 25

15. Bilten II, S. 404

16. Dizdar II, S. 8

8. Jjevojka vice 8 visoka brda

Djevojka vice 8 visoka brda

S visoka brda iz tanka grla:

"Sultan Selime, car-gospodine!

Moze 11 b1t1 Travnik-kasaba

Travnik-kasaba bez pałaluka

I Banjaluka bez agaluka?

Moze 11 biti ptica bez gore,

Ptica bez gore, riba bez vode?

Moze li biti dilber-djevojka

Dilber-djevojka bez mlada momka?"

แH VII, Nr. 9

\section{Varianten}

1. Pantit, S. 251 (aus Bruerovit)

2. Zovko II, 1, Nr. 89

3. Kuba 1906, S. 508, Nr. 119

4. Kuba 1907, S. 243, Nr. 185

5. VII, Nr. 9

6. Odobalic, S. 42

7. Dizdar I, Nr. 52 
(8. Dizdar II, S. 31)

9. Bilten II, S. 400

10. R.a., Inv. br. 11014

11. Hilosevil IV, Nr. 170

9. Lepa t1 je u Al-age ljuba

Lepa ti je u Al-age ljuba!

Te lepote u svoj Bosnt nema,

U suoj Bosnt 1 Ercegovint,

Zalud njojzi sva lepota njena,

Kad Al-aga 1 ne gleda na nju;

Vet on ljubi Omerovo zlato,

Kojeno je u kavezu raslo,

Nit' je vid'lo sunca ni meseca,

Niti znade, na Xem zito rodi,

Na Cem' zito, na cem' rujno vino.

Kuhat II, Nr. 782

\section{Varianten}

1. Vuk I, Nr. $384\left(T^{X}\right)$

(2. Andrit II, Nr. 43)

3. Kuhat II, Nr. 782

4. Bosanska vila 1889, S. 20

5. Hangi, S. 172

6. Kuba 1907, S. 251, Nr. 234

7. Kuba 1907, S. 405, Nr. 245

8. Nillanovit I, Nr. 7

(9. Hak II, Nr. 7)

10. LA VII, Nr. 156

11. Odobazit, S. 54

12. Dizdar I, Nr. 147

13. Dizdar I, Nr. 259

(14. Dizdar II, S. 114)

15. Dizdar II, S. 73

16. Hilosevic IV, Nr. 276 
10. Posetala Najla Dzafer-bega

Poßetala Najla Dzafer-bega

Uz Carłıju, niz carłiju sama.

Ona trazi Muja bazardzana

I njegova dva nova dutana.

Ona nade Muja bazerdzana

I njegova dva nova dutana:

"Daj mi, Mujo, jednu litru zlata."

"Ja ne mjerim u subotu zlato."

otvori joj dva nova dutana:

"Hajde, Najlo, te ti biraj zlato."

Prevari se binula je guja,

Ode Najla sama birat zlata.

Za njom Hujo zatvorio vrata.

Tu ou bili tri bijela dana,

Onda Mujo otvorio vrata:

"Hajde, Najla, karate te majka!"

"Netu, ifujo, Zivota mi troga!

Gdje sam bila tri bijela dana,

Tu cu mlada vijek vjekovati."

Gajret 1930, S. 276

\section{Varianten}

1. Erlangenski rukopis, Nr. 193

2. Vuk II, Nr. 154

3. Petranovit, Nr. 290

4. Davidovit, Nr. 214

5. Zovko II, 1, Nr. 79

6. Bosanska vila 1895, S. 156

7. Bosanska vila 1895, S. 284 f.

8. Bugarinovit, S. $36 \mathrm{f}$.

(9. Hak II, Nr. 94)

10. Milanovit III, S. $41 \mathrm{f}$.

11. Gajret 1930, S. 276

12. R.a., inv. br. 7021

13. Jugoton EPY 3637 B

14. Miloševit IV, Nr. 342 


\section{O Mostaru seber mejtef kazu}

O Mostaru secer mejtef razu,

O njem' uXi trides't devojaka,

Hodza im je Omer efendija,

Kalfa in je Meruła đevojka,

Pred njome ou tri titapa bila.

Veli njemu Lerusa devojka:

"Kazuj, hodza, to titapi kazu?"

Hodza uci, Merusi govori:

"Jedan veli: da se hodza Zent,

"Drugl vell: hoce, ako $\mathrm{Bog} \mathrm{da}$,

"Treti vel1: Merußom devojkom."

Vuk II, Nr. 132

\section{Varianten}

1. Vuk II, Nr. 132

2. Davidovit, Nr. 236

3. Biser 1913, S. 44

4. Gajret 1929, S. 155

5. Islamski glas, br. 13, S. 13

6. Dizdar I, Nr. 301

7. Dizdar II, S. 134

8. Milosevit IV, Nr. 374

9. Wilorevit IV, Nr. 374 (Varlante)

12. Platno b'jele sarajke devojke

Platno b'jele sarajke devojke. Fred njima je Hazla materina. Uzgrunula uz ruke rukave, A uz none zarene dimije, la proima jelek razapela. Gledałe je sa Cardaka majka: nšeri moja, - Hazlo materina! 
Sputti areri ndz ruke rukave,

A niz none sarene dimije,

Spenji jelek na proima,

Jer te naljet' celebija Risto,

Pa ce t.ebe bceri nakarati."

Popovit-Rodoljub, Nr. 86

\section{Variant.en}

1. Mirkovit, Nr. 157

2. Popovit-Rodoljub, Nr. 86

3. Zovko II, 1, Nr. 32

4. Zorko II, 2, Nr. 22

5. Bugarinovit, S. 34

6. Behar 1905/06, S. 221

7. Kuba 1910, S. 529, Nr. 923

8. Mat VI, Nr. 95

9. NH VII, Nr. 158

10. Jugoton EPY 3526 B

11. Milosevit IV, Nr. 220

12. Milosevit IV, Nr. 221

\section{Mostantce, vodo plemenita}

Mostanice, vodo plemenita,

Uz put ti je, selam ter mi dragom,

Nek mi dojde, il nek me se projde!

Nek ne kosi trave pokraj Save,

Pokosite moje kose vrane.

Nek ne pije Save vode bladne,

Popite mi moje oti vrane.

Odobalit, s. 58

\section{Varianten}

1. Dvorovit, S. 72

2. Zovko II, 1, Nr. 40

3. Zovko II, 2, Nr. 39

4. Novi behar $1928 / 29$, S. 75 
5. Slobodna rijed 1932 , br. 38, S. 9

6. Odobafit, S. 58

7. Jugoslovenska posta, br. 2717 (1938), S. 9

8. Bilten II, S. 387

9. Dizdar II, S. $76 \mathrm{f}$.

10. Milosevit IV, Nr. 23

\section{Molila se Ana materina}

Holila se Ana materina

Kujundzij1 u gornjoj Carłiji:

"Kujundzija, tako ti zanata,

Sakuj meni junaka od zlata;

Nemoj plava, tako ti zanata, -

Srednja boja - prilika je moja."

$$
\text { Blagajit, Nr. } 4
$$

\section{Varianten}

1. Vuk I, Nr. 491

2. Petranovit, Nr. 147

3. Davidovit, Nr. 110

4. Tordinac, Nr. 11

5. Jastrebov, S. 189 f.

6. Blagajic, Nr. 4

7. Zovko II, 1, Nr. 96

8. Zovko II, 2, Nr. 158

9. Zovko II, 2, Nr. 211

10. Andrit II, Nr. 10

(11. Milanovi6 I, Nr. 11)

(12. Hak II, Nr. 12)

13. Corovit (Bosna 1 Hercegovina), S. 116

14. MH VII, Nr. 439

15. Nametak, S. 108

16. Milorevit II, Nr. 114 


\section{Procvietala ruza i sevlija}

Procrjetala ruza 1 sevlija Bol boluje lijepa Hajrija -

Pod orahom 1 pod jorgovanom Bol boluje godinicu dana. Zale Hajmu sva gospoda redom Ponajuibe tri dilbera mlada. Prvi veli: "Bolujer li Hajro? Je l' ti muxno bolovati samoj?" Drugi veli: "Bolovo bih za te! Da znam da ceł ozdraviti, Hajro." Tredi veli: "I umro bih $2 a$ te Kad bih znao da bes umrijeti." Progovara lijepa Hajrija:

"Niti boluj, niti umri za me Skidaj fermen, pa lezi uza me, $P a$ mi razbi muke $i$ dermane I Bog znade lakše te mi biti."

Gajret 1931, S. 92

\section{Varianten}

1. Kuba 1908, S. 407, Nr. 529

2. Kuba 1910, S. 520, Nr. 872

3. MH VII, Nr. 38

4. Gajret 1931, S. 92

5. Dizdar I, Nr. 23

6. Dizdar II, S. 17

7. Miloßevit IV, Nr. 296

16. Znas li, duso, kad oi moja bila

Znas li, duso, kad si moja bila, Na mom krilu grozne suze lila, Suze lila, kroz plac govorila: 
"Bog ubio onu svaku drugu Koja drzi vjeru u junaku!

Kao tto je ono vedro nebo, Casom vedro, a casom oblacno, Onaka je vjera u junaka: Dok te ljubis "Ozecu te, duro!" Rad obljubi: "Cekaj do jesent!" Jesen prode 1 zima nastane, $A$ on 8 ' onda 8 drugom razgovara."

Vuk I, Nr. 538

\section{Varianten}

1. Gradanska lirika I, Nr. 194

2. Vuk I, Nr. 538

3. Blagajit, Nr. 3

4. Zovko II, 2, Nr. 54

5. Marunovit, S. 69

6. Dizdar I, Nr. 329

(7. Dizdar II, S. 146)

8. Durit, S. 122

17. Sve ptixica pripjevaze, jęna ne pjeva

Sve ptilice pripjevare, jedna ne pjeva. Pitale je drugarice: "Sto ti ne pjevał?" Prod'te me se, drugarice, kazacu vam ja. Kene mati jednu ima, jednu jeditu,

Pa me dala intijaru, ne cu joj ga ja. Kad ja hocu u rod dajdem meni star ne da. Nejdi hanko, nejdi katko, susreste te mlad. Kad ja hotu dibu obuc, meni star ne da. liemoj hanko, nemoj katko, vidjete te mlad. Kad ja hotu coijet zadjet, meni star ne da. Nemoj hanko, nemoj katko, crijet sam ti ja!

hovi behar 1930/31, S. 285 


\section{Varianten}

1. Blagaj16, Nr. 49

2. Zovko I, Nr. 21

3. Bosanska vila 1892, S. 299

4. Rubie IV, S. 290

5. Behar 1901/02, S. 172

6. Sajnovit XX, S. 155, Nr. 7

7. Milanovil III, S. 80

8. IH VII, Nr. 309

9. Novi behar 1930/31, S. 285

10. Novi behar $1941 / 42$, S. 128

11. Dizdar I, Nr. 264

(12. Dizdar II, S. 110 f.)

13. Bart6k/Iord, Nr. 40

14. Hilorevit IV, Nr. 408

15. Milosevit IV, Nr. 409

18. Kisa 1de, trava raste

Kisa ide, trava raste,

Gora zelent,

Aj, 1 gora se o listom sasta,

A ja nemam $8 \mathrm{kdm}$.

Imam dragog na daleico,

U tuãoj zemlji,

Pa mu mlaca porucujem:

"DodI dragane!"

A on ment odgovara:

"le mogu $t 1$ doc,

Ne mogu ti, draga, doet

Jo8 2 a godinu, 
Pusti puti zatvoreni

od Rumenlije,

Skenderbeg in zatvorio,

Hote da robi,

Toga mori, pasa robi,

Tuga golema! "

Vasiljevit, Nr. 266

\section{Varianten}

1. Erlangenski rukopis, Nr. 148

(2. Gradanska lirika I, Nr. 244)

3. Davidovit, Nr. 39

4. Blagajit, Nr. 51

5. Mirkovit, Nr. 159

6. Zovko I, Nr. 22

7. Zovko II, 4, Nr. 240

8. Behar 1905/06, S. 221

9. Kuba 1908, S. 408, Nr. 539

10. Milanovic I, Nr. 17

(11. Hak II, Nr. 34)

(12. Prodanovit, Nr. 6)

(13. Cubelit, S. 129)

14. Name tak, S. 76

15. Dizdar I, Nir. 201

16. Vasiljevit, Nr. 152

17. Vasiljevit, Nr. 266

18. Vasiljevit, Nr. 326

19. Dizdar II, S. 18

20. R.a., inv. br. 8943

21. R.a., inv. br. 10437

22. Nilosevit IV, Nr. 203 
19. Bulovi se razdulal1, ja $1^{\prime}$ ne berem

Bulort se razdulali, ja 1 ' ne berem. Ja $1 z a \bar{d} e$ u dul bas̆tu da 1 ' uzberem. Iznad mene tica let1, ja je ugleda'. rico moja, sestro moja, vide $l^{\prime}$ dragog mog?

Curo moja, vjero moja, ja ti ga ne znam.

- Poznater ga po odjelu, ako bude moj.

Na njemu su tulbet gate, tur sunoves,

Na njemu je tanka ko8a, Hase Ogrosa, Priko krila rargijica malog Mehmeda, Oko glave ahmedija hodze nasega, Na prea mu sitna puca Vele okjta.

Mlorevit IV, Nr. 415

\section{Varianten}

1. Blagajit, Nr. 9

2. Rub16 IV, S. 291

3. Kuba 1906, S. 505, Nr. 103

4. Kuba 1908, S. 120, Nr. 379

5. Kuba 1908, S. 545, Nr. 574

6. Kuba 1909, S. 600, $\mathrm{Mr} .817$

7. Kuba 1909, S. 601, Nr. 818

8. R.a., inv. br. 8532

9. R.a., Inv. br. 9167

10. R.a., Inv. br. 9138

11. Mlobevit IV, Nr. 415

20. Konf zelenko rognu travu pase

Kong zelenko roenu trave pase,

2a Cas pase, za dva prislurkuje

Gde devojka evoju majku moll:

"Ne daj nene, majko, 28 nedraga!

volin o dragim po gorl odit1, 
Glog zobat1, o lista rodu pit1, Studen kamen pod glavu metati, Neg a nedragim po droru retat1, Secer jest1, u ovil1 sparat1."

Fuk I, Nr. 310

\section{Varianten}

1. Vuk I, Nr. 310

(2. Prodanovit, Nr. 99)

(3. Andri6 II, Nr. 35)

(4. Dizdar I, Nr. 136)

(5. D1zdar II, S. 67)

6. Petranorle, Nr. 181

7. Davidori6, Nr. 141

8. Drorovit, S. 63

9. Popovit-Rodoljub, Ir. 73

10. Zovko II, 2, Nr. 172

(11. MH VII, Nr. 63)

12. Kuba 1908, S. 265, Nr. 497

13. Gajrot 1912, S. 121

14. Gajret 1913, S. 143 f.

15. Cube11t, S. 117

16. Milosevit IV, Nr. 293

\section{Irvir roda 12virala}

Izvir voda 12virala

B1stra otudena,

Irnosila struk bosilja

Zimi zelena,

Cuvala ga divojeica

Bila rumena.

Tud nahodi otar delija

Starac na konju:

"Selam-alejkj, dirojtice, 
Bila rumena,

PIje li se bistra roda,

Bistra studena,

Ijubi li se divojeica

B1la rumena?"

"Alejkj-selam, star delija

Starac na konju,

Ne pije se bistra roda

Bistra studena,

Ne ljubi se divojeica

Bila rumena."

"Hoter 11 me, dirojeice,

Duro 1 srce?"

"Hajd otalen, star delija,

Nisi $2 a$ mene,

Daj ti meni troga sina,

Sto je za mene."

Izvir roda izvirala

Bistra studena,

Iznosila otruk bosilja

2 imi zolena,

Cuvala ga divojeica

Bila rumena.

Tud nahodi mlado momle

Mlado na konju:

"Selam-alejkj, divojtice,

Bila rumena,

Pije li se bistra roda

Bistra studena,

Ljub1 li se divojtica

B1la rumena?"

"Alejkj-Belam, mlado mom

Mlado na konju,

Pije mi se bistra voda

Bistra studena,

Ljubi mi se divojeica 
Bila rumena."

"Dirojeice, duricice,

Hoร 11 za mene?"

"Bome hoku, mlado momke,

Bar si za mene."

Kurt, Nr. 38

\section{Varianten}

1. Erlangenski rukopis, Nr. 171

2. Gradanska lirika I, Nr. 149

3. Gradanska lifika II, Nr. 484

4. Vuk I, Nr. 398

5. Vuk I, Nr. 399

(6. Andrit II, Nr. 239)

7. Kuhat III, Nr. 1071

8. Hirkovit, Nr. 152

9. Rubit IV, S. 289

10. Kurt, Nr. 38

11. Kuba 1908, S. 403, Nr. 506

12. Kuba 1908, S. 550, Nr. 605

13. Kuba 1910, S. 513, Nr. 832

14. Gajret 1913, S. 76

15. WI, Nr. 112

16. MH VI, S. 406

17. Rubit XXIII, S. 242, Nr. 33

18. Dizdar I, Nr. 93

19. Magarazevit, S. 238

20. Hilorevit IV, Nr. 86

22. Raslo drvce bademovo

Raslo drvce bademoro,

Tanko visoko,

Pod njim lezi droje mladi,

Droje Ijubljeni; 
Durek im je rosna trava,

Rosna zelena;

Jastuci im bile ruke,

Jedno drugome;

Pokrovac im vedro nebo,

Sjajnim zolzdama.

Varianten

Rubit XXV, S. 367

1. Vuk I, Nr. 622

2. Petranovit, Nr. 231

3. Zovko I, Nr. 30

4. Bosanska Vila 1890, S. 303

5. Rubi6 IV, S. 290

6. Kurt, Nr. 39

7. Kuba 1907, S. 247, Nr. 212

8. Kuba 1907, S. 250, Nr. 229

9. Kuba 1907, S. 629, Nr. 301

10. Kuba 1908, S. 120, Nr. 383

11. Kuba 1909, S. 586, Nr. 726

12. Kuba 1910, S. 516, Nr. 842

13. Gajret 1912, S. 154

14. Gajret 1913, S. 208

15. Rubit XXIII, S. $241, N r .27$

16. Rubic XXV, S. 367

17. Gajret 1929, S. 172

18. Novi behar $1929 / 30$, S. 67

19. Novi behar $1939 / 40$, S. 321

20. Nov1 behar 1939/40, S. 321 (Variante)

21. Novi behar $1939 / 40$, S. 347

22. Dizdar I, Nr. 206

23. Dizdar I, Nr. 226

24. Bilten II, S. 129, Nr. 69

25. Vasiljevit, Nr. 62

26. Vasiljevit, Nr. 117

27. Vasiljevit, Nr. 117 (Variante)

28. Vasiljevit, Nr. 131

29. Vasiljerit, Nr. 190

30. Vasiljevit, Nr. 215 
31. Vasiljev1t, Nr. 328

32. Mlozerte I, Nr. 138

33. R.a., 1nv. br. 8585

34. Milorevit IV, Nr. 395

\section{Sadim almu nasred Atmejdana}

Sadim almu nasred Atmejdana.

Gledam dragu tri godine dana.

Kad je alma bila za trganja,

Onda draga bjere za ljubljenja.

Duhnu vjetar, salomi joj grane, Dode jaran, odvede mi dragu.

Kene jaran zove u djeverstro.

Luka iti, job gora ne $i b 1$.

Ako ne 1dem, ostah zeljan drage, $k$ ko 1dem, nagledah oe jada.

Sve mislio, na jedno smislio, Da ja odem dragoj u djeveretro.

Proten dajem, na nogu joj stajem, Duvak metem, na uho joj saptem:

Kam' t1 vjera, nevjernice mila!

Do godine udovica bila,

A u drugoj moja sudenica!

$$
\text { Odobarit, S. } 701 .
$$

\section{Varianten}

1. Vuk I, Nr. 521

2. Kurt, Nr. 34 
3. Kuba 1907, S. 108, Nr. 149

4. Rubic XXIV, S. 308, Nr. 1

5. Rubit IXIV, S. 308, Nr. 3

6. ReX 1 olika 1927, S. 35

(7. Dizdar I, Nr. 233)

8. Gajret 1929, S. 155

9. MH vII, Nr. 66

10. Novi behar 1929/30, S. 67

11. Odobarte, s. 701 .

12. Novi behar $1941 / 42$, S. 127

13. Milozevit IV, Nr. 348

24. Zafal1 se zut1 limun na noru

Zafal1 se Eut1 na moru:

"Danas nema nifta ljepse od mene." To zacula zelenika jabuka:

"Mala t' fala, Eut limune na moru, Danas nema nirta ljepre od mene." To zacula nekoðena livada:

"Mala t' Pala, zeleniko jabuko, Danae nema ntsta ljepse od mene." To zacula neźnjevena płenica:

"Mala t' fala, nekorena livado, Danas nema nifta ljepre od mene." To sacula neljubljena djevojka: "Mala t' fala, neźnjevena psentce, Danas nema nista ljepre od mene." To zacuo mad nerenjen junace: "Mala vama ovina fala od mene: Ja cu obrat' Eut1 liman na moru, I otrertu zeleniku jabuku, Pokosilu nekorenu livadu, 
Požnjeti cu nežnjevenu pకenicu,

I poljubit' neljubljenu devojku!n

Dizdar II, S. 141

\section{Varianten}

1. Erlangensk1 rukopis, Nr. 7

2. Gradanska l1rika II, Nr. 454

(3. Ostojit-Corovit, S. 147, Nr. 123)

4. Vuk I, Nr. 619

5. Vuk I, Nr. 620

6. Vuk II, Nr. 218

7. KuhaX II, Nr. 440

8. Bosenska vila 1887, S. 154

9. Kuba 1906, S. 508, Nr. 121

10. Kubs 1907, s. 103, Nr. 122

11. Kuba 1908, S. 256, Nr. 444

12. Kuba 1908, S. 549, Nr. 597

13. NH VII, Nr. 83

14. MII, Nr. 209

15. Bart6k/Lord, Nr. 15

16. Bilten II, S. 129, Nr. 68

17. Dizdar II, S. 141

18. Milozevit I, Nr. 83

19. R.a., Inv. br. 11552

20. Mlorevit IV, Nr. 378

25. Vifala ee vinoloza Vinova

Vijala oe vinoloza vinova

Oko jednog b'jela grada Budina, Vijala se Finoloza Finova. To ne bila vinoloza vinova, Vet to b1lo droje alads' 1 drag ' Stono su se jor od mlada gledall, Jor od mlada, od malena djeteta. Dode rrene da se ont rastaju. 
Na rastanku jedno drugom govor1:

"Hajde, dragi, kroz tu goru zelenu,

Tu ter nati bunar vodu ledenu,

Na bunaru jednu plocu mramora,

Nia toj ploci jednu casu srebrenu,

O toj Cari jedna gruda snijega.

Uemi, dragi, onu grudu snijega

Pa je metni a l'jeve strane kraj srca.

Ako ti se ona gruda rastopi,

Onda place moje srce za tobom."

Bilten II, S. 146, Nr. 138

\section{Varianten}

1. Erlangenski rukopis, Nr. 152

(2. Gradanska lirika I, Nr. 137)

3. Gradanska lirika I, Nr. 160

4. Građanoka lifika I, Nr. 182

5. Vuk I, Nr. 554

6. Vuk I, Nr. 555

(7. Prodanovit, Nr. 8)

8. Mlad, Nr. 40 i)

9. Kuhat I, Nr. 68

10. Kuhat I, Nr. 233

11. Blagajit, Nr. 53

12. Dvorovit, S. 251 .

13. Dvorovit, S. 531 .

14. Popovit-Rodoljub, Nr. 128

15. Kurt, Nr. 85

16. Kuba 1906, S. 499 P., Nr. 68

17. Kuba 1907, S. 108, Nr. 150

18. Kuba 1908, S. 256, Nr. 438

19. Kuba 1909, S. 581, Nr. 690

20. $\mathrm{V}, \mathrm{Nr} .169$

1) Das Lied ist der Sammlung entnommen: Plohl Herdvigov, R.F., Hrratske narodne pjeeme i pripovjetke I-III, Varazdin 1868-1878. 
(21. Indrit II, Nr. 298)

22. Indrit II, Nr. 91

23. Bilten II, S. 146, Nr. 138

24. R.a., inv. br. 11659

25. Milogevit IV, Nr. 386

26. Dva eu crjeta u bostanu rasla

Dva su crjeta u bostanu rasla,

Sumbul plavi 1 zelena kada.

Sumbui plav1 ode na Doljane,

Oota kada u poljand sama

Porucuje sumbulj sa Doljana:

Kako joj je u bostanu samoj?

Odgovara 12 bostana kada:

Sto je nebo da je l18t hartije,

Sto je gore da ou kalemovi,

Sto je more, da je crn mureter,

He bi moga 1opisati jada.

Kuba 1910, S. 521, Nr. 873

\section{Varianten}

1. Erlangenski rukopis, $\mathbb{B r}, 20$

2. Građanska 11rika I, Nr. 185

3. Gradanska lirtka I, Mr. 304

4. Duk I, Nr. 553

(5. Prodanov16, Hr. 1)

(6. Andri6 II, Nr. 106)

(7. Mlanovi6 I, Br. 6)

(8. Hak II, Nr. 6)

(9. Dizdar I, Nr. 62)

(10. Cubelit, S. 126)

11. Petranovit, Hr. 212

12. Petranovit, Hr. 222

13. Kuhac II, Hr. 729 
14. Kurt, Nr. 40

15. Bosanska Vila 1906, S. 270

16. Bosanska vila 1906, S. 315

17. Kuba 1910, S. 521, Mr. 873

18. Saulit, S. 7

19. Andrit II, Nr. 107

20. LH VII, Nr. 103

21. NH VII, Nr. 212

22. Lillogevit IV, Nr. 271

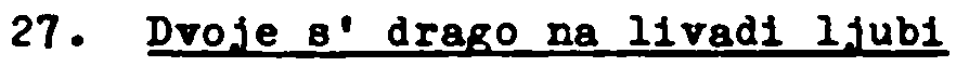

Droje $8^{\prime}$ drago na livadi ljubl

To ne vide niko ni oklena

vet livada na kojoj se ljube.

Livada je ovcam povidela,

Bjele orce cobaninu svome,

Coban kaza u putu putniku,

Putnik kaza na moru brodaru,

Brodar kaza u selu imamu,

Imam kaza deci u mejtefu,

A deca su ocu 1 materi.

Kad to Cula lijepa devojka,

Ljuto kune do Boga se cuje:

"O livado, ne zelentla se!

"Bjele ovce, poklall vas vuci!

"Cobanina objesili Turci!

"A putnika purka udarila!

"A brodara roda odnijela!

"A imama pritiola munara,

"Sru mu decu kuga pomorila!!"

Grōitt-Bjelokosit, Nr. 6

Varianten

1. Pantic, S. 236 (aus: Buro Ferit)

2. Vuk I, Nr. 444 
(3. Andrit II, Nr. 56)

4. Vuk II, Nr. 92

5. Kuhad II, Nr. 729

6. Bosanska vila 1892, S. 251

7. Zovko II, 2, Nr. 66

8. Grdit-Bjelokosit, Nr. 6

9. Rubit IV, S. 289

10. Bosanska Vila 1907, S. 218

11. NI, Nr. 59

12. $\mathrm{VI}, \mathrm{Nr} .60$

13. LifH VI, S. 370

14. Sajnovit $\mathrm{XX}$, S. 152, Nr. 1

15. Bajraktarevit, S. 11 f., Nr. VIII

16. Prodanovit, Nr. 110 (aus: Saulit)

17. Novi behar $1929 / 30$, S. 35

18. Narodna uzdantca 1942, S. 215

19. K.a., Inv. br. 8701

20. Lilozevit IV, Nr. 345

28. Snifeg pade drumi zapadore

Snjjeg pade drumi zapadore, Cuprije se mrazom zamrzore, Drag1 dragoj doti ne mogare, vet po drugon pozdravljałe dragu

Po ticici 1 po lastavici,

Po putniku 1 po namjerniku:

"Pozdraviter milu dragu noju,

Nek mi sprens duse u jabuct, B'jela lizca u al-ospurlij1, Crna oka u zlatnoj kutifi."

Bosanska Fla 1905, S. 216

\section{Varianten}

1. Ristic, Nr. 23

2. Hrkovit, Nr. 122 
3. Kurt, Nr. 73

4. Bosanska vila 1905, S. 216

5. Milanovi6 I, Nr. 21

(6. Hak II, $8 r .42$ )

7. Prodanovit, Nr. 7

8. Saulle, S. 441 .

9. Novi behar 1930/31, S. 204

10. Odobarite, S. 391 .

11. Narodna uzdantca 1935, S. 135, Mr. VII

12. Dizdar I, Nr. 254

(13. Dizdar II, S. 112)

14. Milozevit IV, Mr. 270

29. Nit ja spavam, nit ja drimam

Nit ja spavam, nit ja drimam,

Nit ja sna imam,

Nit ja eparam, nit ja drimam,

Iit ja ona imam.

Imam dragog nadaleko,

2 a njeg 1 ne znam.

Ja mu pirem bilo pismo:

- Dodj1, dragane!

$\Lambda$ on ment otpisuje

TuLno Lelosno:

- Hema mene, draga moja,

2 a tri godine.

Al' ne prodje nt tri dana,

Eto dragana.

I on jaye dobra doru

Demir-jablana,

Pa se rece, pa se rece

Prid moje drore.

onmi nazva dobra vecer 
I pomozt bog;

Ja ce njemu odazivljem:

Dao mi te bog!

Bilten I, S. 47, Br. 31

\section{Varianten}

1. Zuhad I, Vx. 17

2. Blagajic, $\mathrm{Mr}, 30$

3. Blagaj16, Ar. 31

4. Zovko II, 4, Nr. 208

5. Kuba 1907, S. 631, Ir. 313

(6. Dizdar I, Mr. 262)

7. Zuba 1907, S. 633, Nr. 327

8. Nov1 behar $1939 / 40$, S. 349 .

9. Dizdar I, Hr. 178

10. Bilten I, S. 47, $\mathrm{Nr} .31$

11. Bart6k/Lord, Nr. 45

12. Dizdar II, S. 831 .

13. Vasiljevit, Br. 158

14. Mloxerte IV, Ir. 399

30. Asan-agy nu gradu oled jase

Lean-aga na gradu ejedjare,

Vjernu ljubu na krilu drzałe,

Svojoj ljubi tio gororabe:

"Vjerna ljubo, vjera t1 pomogla!

"Sto te pitam, pravo ta mi kafer,

"Kol'ko 61 se puta udavala?

"O koga 11 Fiř blaga bjeře?

"I koj1 te najbolje pazabe?"

Asan-agi ljuba govorase:

"ABan-aga, dragi goepodare!

"Triput sam se dosad udavala,

"Prvi put oam za pałitem bila, 
"Drugi put sam ra dervibem bila,

"Evo tretom za te $18 a n-a g o m ;$

"O pariba mlogo blaga b'jase,

" 11 ' me paril polore pazare;

- U dervira blaga ne bijare,

"Al' me junak dobro milovate,

"Kad e'probud1, u lice me 1jubl,

"Da m1 reku: eto t1 dervira,

"Ja bi tebe muxtuluka dala."

Petranov16, Mr. 152

\section{Varianten}

1. Vuk II, Dr. 142

2. Petranovi6, Nr. 152

3. R1st16, Ir. 41

4. Rub16 IV, S. 288

5. Kuba 1906, S. 362, Nr. 40

6. Kube 1908, S. 124, Nr. 408

7. Hak II, Hr. 55

8. MH VI, Mr. 103

9. Red 1 slika 1927, S. 36

10. Odobar16, S. 21 1.

11. Dizdar I, Mr. 15

12. Dizdar I, Hr. 83

13. Bart6k/Lord, Ir. 27 b

14. Mlobet16 I, Mr. 148

15. Mloxert6 IV, Ir. 347

\section{Al1ber se ljubon gavad10}

Alibeg se ljubom zavadio,

Prov notcu na meku dusaku.

Sverao jof ruke aspurllom:

Od lakata do bjell nokata;

Is nokata crna krvea kapa. 
"Kazuj ljubo ko te je ljubio?"

"Pußt1 beze pravo cu ti kazat':

Dva Pasica tri Dizdarevica,

Dizdarevil za redak dukata

A Paślti za zlatnu feredzu."

On zamanu osjece joj glavu.

Poskakuli glava govorila:

"Volim biti mrtva Dizdaricka

Nego Ziva Alibegovica!"

Mirkovit, Nr. 44

\section{Varianten}

1. Vuk I, Nr. 733

2. Davidovit, Nr. 109

3. Bosanska vila 1886, S. 235 (vgl, auch: Kałı kov:t II, Nr.24)

(4. Andrit II, Nr. 144)

5. Mrkovit, Nr. 44

6. Bosanska vila 1895, S. 28

7. Bosanska vila 1901, S. 246

8. Kurt, Nr. 23

9. Bugarinovie, S. 751 .

(10. Hak II, Nr. 98)

11. Behar 1905/06, S. 251

12. Bosanska F.la 1906, S. 315

13. Kuba 1907, S. 103, Hr. 125

14. Kuba 1907, S. 634, Nr. 336

15. Kuba 1908, S. 266, Nr. 505

16. Behar 1909/10, S. 111

17. Gajret 1913, S. 144

18. ReX i slika 1927, S. 37 I.

(19. Dizdar I, Nr. 7)

20. Gajret 1929, S. 305

21. MH VII, Nr. 470

22. Dizdar I, Nr. 8

23. Vasiljevit, Nr. 147

24. R.a., inv. br. 8734

25. R.a., inv. br. 10434

26. Miloševit IV, Nr. 299 
32. Ma,jka B_Mehom večer večerałe

Majka Mehom vecer vecerałe, Mehemedu tiho govorase:

" $A$ moj Meho, moje dite drago,

"Šta god stece, sve dade divojci!"

'Sta joj dadoh, mila majko moja:

Dvi telije $i$ dvi anterije,

Dvi catkije renka stambolskoga,

Zute mestre zlatom izvezene,

I papuce srebrom poktovane,

Sve joj dadoh, oxiju ne vidih.

Ako bude crnoka divojka,

Jos toliko dat joj hotu, majko,

Dat joj hocu, a uzet je hocu;

Ako bude plavoka divojka,

Sve joj dadoh, a uzet je necu!'

Pa on ide lijepoj divojci,

Pa je njojzi rici glovorio:

"Nu pogledaj, draga duకo moja,

Eno $1 \overline{d u}$ uz polje svatovi,

Eno vode menika divojku!"

Prevari oe, ujede je guja,

I pogleda niz polje zeleno:

Ona plava kako liti trava!

Ostavi je gondze wehemede.

Bajraktarevit, S. 11, Nr. VII

\section{Varianten}

1. Vuk I, Nr. $618\left(\mathrm{~T}^{\mathrm{x}}\right)$

2. Petranovit, Nr. 287

3. Blagajit, Nr. 38

4. Risti6, Nr. 27

5. Dvorovit, S. $54 \mathrm{ff}$.

6. Bosanska vila 1896, S. 292 f.

7. Kurt, Nr. 48

8. Biser 1918, S. 183 
9. Bajraktarevit, S. 11, Nr. VII

10. Milanovit I, Nr. 108

11. MH VII, Nr. 251

12. Nametak, S. $31 \mathrm{ff}$.

13. Bilten II, S. 393

14. Vasiljevit, Nr. 68

15. Milosevit IV, Nr. 452

\section{Sinot podoh iz Morita hana}

"Sinoc pō̄oh iz Morita hana,

"Sretoh Umu 12 vruta hamama.

"Ja joj rekoh 1 dva $i$ tri puta:

"nDilber Umo, ukloni se s puta!"

"Ne scede se ukloniti Uma.

"A ja odoh, da prodem mimo nju.

"Zapeze mi kopre od cakrira

"Za Umine mor-mavi dimije.

"Ja se sageh, da kople otpucim,

"Zape $\zeta e$ mi bazi od sahata

"Za Umine ogre od derdana.

"A ja pō̄oh, da bage odapnem,

"Smjerase se brci 1 solufi.

"B'jeli mi se zubl omakore

"Za gr'osce dilber-Umihane:

"Prosute se ogre od derdana,

"Iz grla joj krvcu otvorio.

"Tu padosmo u zelenu trava,

"Be padosmo, tu 1 osvanusmo!"

$$
\text { Gajret 1913, S. } 75
$$

\section{Varianten}

1. Erlangensid rukopis, Nr. 104

2. Vuk II, Nr. 127

3. Mirkovit, Nr. 25

4. Ristit, Nr. 34 
5. Dvorovit, S. 36 ff.

6. Popovit-Rodoljub, Nr. 100

7. Bosanska vila 1892, S. 360

8. Zovko II, 1, Nr. 38

9. Bosanska vila 1901, S. 206

10. Bosanska vila 1903, S. 137

11. Kuba 1907, S. 251, Nr. 235

12. Gajret 1913, S. 75

13. Kałikovit I, Nr. 88

14. VII, Nr. 425

15. Narodna uzdanica 1935, S. 136, Nr. XIII

16. Novi behar $1941 / 42$, S. 126

17. Dizdar I, Nr. 53

18. Dizdar II, S. 28

19. Jugoton EPY 3117 A

20. Miloševit IV, $\mathrm{Nr}, 290$

21. Milosevit IV, Nr. 291

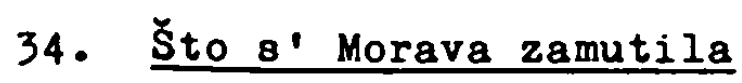

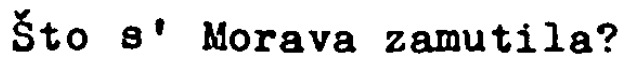

Ili Pasit konja poji,

Il Carevit vojsku vodi?

Niti Parit konja poji,

Nit Carevit vojsku vodi,

Vec plivaju dv'je Moravke,

Dv'je Woravke, obje seke:

Mandalina 1 Kalina.

Mandalina preplivala,

A Kalina utonula.

Mrtva glava progovara:

"Mandalina, seko moja,

Nemoj kazat miloj majci,

Da sam mlada utonula, 
Vet da sam se ja udala:

Sitni p'jesak - jetrvice,

Sitne vrbe - zaovice,

Jablan-drvo - svekar-babo,

A Horava - drago moje."

Andric II, Nr. 188

\section{Varianten}

1. Blagajit, Nr. 45

2. Kurt, Nr. 36

3. Popovit-Rodoljub, Nr. 184

4. Zovko II, 2, Nr. 6

5. Behar 1900/01, S. 304

6. Behar 1902/03, S. 191

7. Mokranjac, Nr. 90 b

8. Kuba 1906, S. 507, Nr. 115

9. Ruba 1907, S. 638, Nr. 359

10. MH V, Nr. 51

11. Andrite II, Nr. 188

12. Prodanovit, Nr. 271

13. Novi behar $1939 / 40$, S. 345

14. Novi behar 1939/40, S. 345 f.

15. Novi behar $1939 / 40$, S. 346

16. Wiloళ้eviદ I, Nr. 122

17. R.a., inv. br. 11255

18. Miloßevic IV, Nr. 429

35. Rasla tunia na ored dzehenema

Rasla tunja na sred dzehenema.

Tuj mi gore tri lipa junaka:

Jednom gore oli 1 obrve;

Drugom gore ruke do lakata;

Trecem gore alsecerli usta!

Kojem gore odt 1 obrve, 
Oni gleda zene pod niţahom. Kojem gore ruke do lakata, Oni bije ostarilu majku. Kojem gore alsecerli usta, Oni ljubi zlato nevincato.

Biser 1913, S. 283

\section{Varianten}

1. Petranovit, Nr. 25

2. Bosanska vila 1887, S. 106

3. Zovko II, 2, Nr. 27

4. Bosanska vila 1895, S. 200

5. Behar $1901 / 02$, S. 350

6. Biser 1913, S. 283

7. Novi behar $1929 / 30$, S. 238

8. Narodna uzdanica 1942, S. 209, Nr. IV

9. Dizdar I, Nr. 289

10. Novi behar 1944, S. 178

11. R.a., inv. br. 11463

12. Mllosevit IV, Nr. 355

36. Telal vite po Hercegovini

Telal vice po Hercegovini:

"Ko f' koga nokas na konaku,

Nek ne ide rano sa konaka:

Utekla je pałina robinja

I odniela po pasina blaga, Po parina, pola cehajina,

I odvela hata 12 podruma

I na njemu vrata od dukata,

I odniela sahat is njedara,

I odvela Muju haznadara,

I odniela Cedo 12 besike."

Sustigli je pasini nirant, 
Pa je mladu naopako vežu,

Pa je vode pari u avate.

Njojzi pała tiho progovara:

"Što odnese pola moga blaga,

Pola moga, pola tehajina?

Sto odvede hata 12 podruma

I na njemu vrata od dukata?"

- Blago nosim, nek imam sto troßit,

Djoga vodim, da se ne umorim,

Sahat nosim, da se ne odosnim,

Muju vodim da sama ne hodim,

Cedo nosim, da se razgovorim.

Blagajit, Nr. 34

\section{Varianten}

1. Davidovit, Nr. 189

2. Blagajit, Nr. 34

3. Blagajit, Nr. 47

4. Kuba 1907, S. $630, \mathrm{Nr} .302$

5. $\mathrm{uH} \mathrm{VI}, \mathrm{Nr}, 57$

6. Rubit XXIII, S. 236, Nr. 10

7. MHI, Nr. 385

8. Odobašit, S. 79

a. Nametak, S. 103 f.

10. Dizdar I, Nr. 279

11. Bart6k/Lord, Nr. $12 \mathrm{c}$

12. Cubelit, S. 151 (aus: Tordinac)

13. Jugoton EPY 3637 B 
37. Đevojka je malo devovala

Đerojka je malo devovala

Sedamdeset 1 sedam godina.

Sedam puta na ćabu hodila,

Cabi kuti 'vako govorila:

"Éabo kuto, hotul' se udati?"

A iz Cabe nesto progovara:

"Udat keł se, lijepa devojko,

"Dok suh javor rodi jabukama,

"Ravno polje drobnijem biserom."

Kad to Cula lijepa devojka,

Ona ode svom' bijelu droru,

Pa nakiti javor jabukama,

Ravno polje drobntjem biserom.

I uda se budala devojka.

Gajret 1913, S. 76

\section{Varianten}

1. Vuk II, Nr. 176

(2. Cubelit, S. 288)

3. Petranovit, Nr. 207

4. Petranovit, Nr. 208

5. Mirkovit, Nr. 163

6. Popovit-Rodoljub, Nr. 109

7. Zovko II, 4, Nr. 175

8. Bosanska vila 1894, S. 367

9. Bosanska vila 1895, S. 28 f.

10. Kurt, Nr. 14

(11. Andrit II, Nr. 152)

12. Gajret 1911, S. 157

13. Gajret 1913, S. 76

14. Kasikovit III, Nr. 23

15. MH VII, Nr. 449

16. Dizdar I, Nr. 44

17. Milosevit IV, Nr. 147 


\section{Iiteraturverzeichnis}

\section{A. Liedersammlungen}

Andrit, N., Izabrane narodne pjesme, II, Zenske, Zagreb 1913. Bajraktarevit, P., Pregrst narodnih pesama iz Bosanskog

Skoplja, SAN, Posebna izdanja, Knj. CCCXXXV, Etnografski inst1tut, Knj. 11, Beograd 1960.

Bartbr, B. and Lord, A.B., Serbo-Croatian Folk Songs, Columbia Oniversity Press, New York 1951.

Bałagib-Redzepałit, Safvet Beg (Mirza Safvet), Odabrane pjesme,

Sarajevo 1944.

Behar, List za pouku 1 zabavu, Sarajevo 1900/01-1910/11.

Biser, List za sirenje prospjete megju muslimanima u Bosni 1

Hercegovini, Mostar 1912, 1913, 1914, 1918.

Blagajit, K., Hrvatske narodne pjesme $i$ pripoviedke iz Bosne, Zagreb 1886.

Bosanska vila, List za zabavu (,) pouku 1 knjizevnost, Sarajevo $1885 / 86-1914$.

Bosiljevac, S., Album bosansko-hercegovałkih pjesama, Naj-

ljepse narodne pjesme iz Herceg-Bosne, Naklada knjižare

L. Hartmana (Stj. Kugli), Zagreb o.J.

Bugarinovit, M., Sarajke, Srpske narodne Zenske pjesme, Mostar 1904.

Cubelit, T., Izbor iz narodne književnosti, Knj. 1-3, Zagreb

1952. [Lyrische Lieder, u.a. auch Sevdalinke in Bd. 1]. Davidovit, S.N., Srpske narodne pjesme iz Bosne (Ženske〉,

Pantevo 1884.

Dizdar, H., Sevdalinke, Izbor iz bosansko-hercegovacke narodne lirike, Sarajevo 1944.

Dizdar, H., Ljubavne narodne pjesme iz Bosne 1 Hercegovine,

Sarajevo 1953.

Dvorovit, Nj. [auch: Hofbauer, D.] Hrvatsko narodno blago,

Zbirka hrvatskih narodnih pjesama 1 pripoviedaka iz Bosne

i Hercegovine, Sv. 1, Senj 1888.

Đikik, O.A., Asiklije, ifostar 1903. 
Burit, V., Narodne Iirske pesme, Novo pokolenje, Beograd 1953. Folklorni arhiv Zemaljskog muzeja u Sarajevu [FAZM], Narodne

pjesme po inventarnim brojevima.

Gajret, Glasilo "Gajreta", drułtra za potpomaganje muslimana na srednjim i visim 8kolama (1910-1921 und 1925-1930 und

1931-1941 mit anderen Untertiteln), Sarajevo 1907-1913, 1921, 1922, 1925-1941.

Gesemann, G., Erlangenski rukopis starih srpskohrvatskih narodnih pesama, Zbornik za istoriju, jezik i knjizevnost srpskog naroda, Prvo odeljenje, Knj. XII, Sr. Karlovci 1925. Grdic-Bjelokosit, L., Smilje 1 bosilje ( Iz naroda u narod, Knj. III), Novi Sad 1898.

Hak, A., Muslimanske sevdalinke iz Bosne $i$ Hercegovine, Sarajevo 1906.

Hak, A., Ałiklije muslimanske sevdahlinke, Momacke 1 djevojaðke pjesme iz Bosne $i$ Hercegovine, Drugo znatno povetano izdanje, Sarajevo 1914.

Heine, H., Sämtliche Werke, hg. von Prof. Dr. Elster, E.,

Bd. 1-7, Leipzig und Wien 0.J. (1890), Bd. 1.

Hrvatske narodne pjesme [ed.], Matica Hrvatska, Knj. 1-10,

Zagreb 1896-1942 [Iyrische Lieder Bd. 5-7 und 10].

Humo, H., Sevdalinke, Ret 1 slika 1927, I, S. 33-38.

Ilit, J., Pesme (SKZ), Beograd 1894.

Karadzit, V.St., Srpske narodne pjesme, Knj. 1-4, Beograd

1953-54 [Lyrische Lieder, u.a. auch Sevdalinke in Bd. 1]. Karadzil, V.St., Srpske narodne pjesme, Knj. 1-9, Biograd 1891-1902 [Lyrische Lieder, u.a. auch Sevdalinke in Bd. 1, 5].

Karadzit, v.St., Srpske narodne pjesme iz Hercegovine (Ženske), BeC 1866 [Die Lieder sind von Vrčevit, V. gesammelt].

Kałikovit, N.T., Narodno blago, Knj. 1-3, Sarajevo 1927. 1928 (Zbirka Nikole T. Kałikovita, Knj. 1.2., Sarajevo 1927, Knj. 3, Sarajevo 1928). 
Kuba, I., Pjesme 1 napjev1 12 Bosne 1 Hercegovine, Glasnik Zemaljskog muzeja u Bosni 1 Hercegovini, Knj. 18, str. 183-208, str. 355-366 1 str. 499-508, Knj. 19, str. 103114, 243-252, 405-414, 629-638, Knj. 20, str. 117-128, 255-266, 403-413, 545-552, Knj. 21, str. 303-312, 581-598, Knj. 22, 8tr. 513-536, Sarajevo 1906, 1907, 1908, 1909, 1910.

Kuhą, P.S., Juzno-slovjenske narodne popievke [Knj. 5: popievke], Knj. 1-5, Zagreb 1878-1941 [Knj. 5 erschien posthum ed. V. B. Sirola und VI. Dukat in der Serie "Zborntk jugoslavenskih puCkth popjevaka" als Knj. 2], [Sevdalinke in Bd. 1-4]. Kurt, $M_{.}-D Z$., Hrvatske narodne Zenske pjesme (Muslimanske〉, Sv. 1, Mostar 1902. Magarabevit, Br., Narodne lirske pjesme, Zagreb 1951. Mamuz16, I., Narodne lirske pesme, Skolska biblloteka 26-27, Beograd 1953.

Marjanofle, I., Hrvatske narodne pjesme sto se pjevaju u gornjoj Hrvatskoj, krajini 1 u turskoj Hrvatskoj, Sv. I, Zagreb 1894 [Zenske pjesme: str. 175-207]. diarunof16, I.J., Narodne pjesme [Po Herceg-Bosnt], Zadar 1906. HIianorlt, M., Sevdalinke, ljubarne asiklije, skupio M. M.-t,

Izdanje 1 naklada knjtzare 1 papirnice Mihatla Milanovila

u Sarajeva, Sarajevo 0.J. [1924].

Mllanovit, M., Nuslimanske sevdalinke, Narodne pjesme iz Bosne

1 Hercegovine, Izdanje knjtzarnice 1 papimice Mihaila

wlanovila, Sarajevo O.J. [1924]. Xilanovi6, M., Srpske narodne Zenske pjesme iz Sarajeva, Sarajevo 1893.

illlołerit, Vl., Bosanske narodne pjesme, Knj. 1.2.3.4., Narodni muzej, Odeljenje za muzickl folklor und Narodni muzej, Odsjek za narodne pjesme 1 igre und Muzej bosanske krajine, Odsjek $2 a$ narodne pjesme 1 Igre, Knj. 1.2.3.4., Banja Luka 1954-1964.

ill rkov1t, P., Srpske narodne pjesme iz Bosne, Pančevo 1886. Mlac, Kr., Ijubavne narodne pesme, Zagreb 1953. 
Mokranjac, St.St., Zapisi narodnih melodija, Huzikoloskd institut, Posebna Izdanja, Knj. 13, Beograd 1966. Nametak, A., Rodoskvrnje, Zbornik za narodni zivot i obicaje južnih Slavena [zbNŽo], Knj. XXXXII, Sv. 1, Zagreb 1939, str. 235-237.

Nametak, A., Muslimanske zenske pjesme, Hrvatsko narodno

blago, Zagreb/Sarajevo 1944.

Narodna uzdanica, Kalendari za godine 1933-1945, Sarajevo

1933-1945.

Narodne pesme u zapisima XV-XVIII veka 〈Antologija), Izbor

1 predgovor von Pantit, M., Beograd 1964.

Novi behar, List za pouku i zabava, Sarajevo 1927/28-1945. Odobałit, S., Velika nova narodna pjesmarica, Zagreb o.J. [1933].

Orahovac, S., Sevdalinke, balade 1 romanse Bosne i Hercegovine, Sarajevo 1968.

Cstojlt, T. i Ćorovit, Vl., Srpska gradanska lirika 18.-og veka, SKA, Beograd-Sremski Karlovci 1926.

Petranovit, B., Srpske narodne pjesme, Knj. 1-3, Sarajevo-

Beograd 1867-1870, Knj. 1, Srpske narodne pjesme iz Bosne (Ženske), Sarajevo 1867, Knj. 2, Srpske narodne pjesme iz Bosne $i$ Hercegovine (Epske pjesme starijeg vremena), Biograd 1867.

Popovit-Rodoljub, li.S., Srpske narodne umotvorine, I, Srpske sevdalinke, Pancevo 1892.

Prodanovit, J.H. Zenske narodne pesme (Antologija), Beograd 1925.

Rihtman, Cv., Ciłak Janja, narodni pjevał sa Kupresa, Bilten instituta za proudavanje folklora u Sarajevu, Sv. I, Sarajevo 1951, etr. 45-63.

Ristit, K.H., Srpske narodne pjesme, pokupljene po Bosni, Biograd 1873.

Rubit, St., Nuit, A., Duvno 〈Župańac〉, [Lirske pjesme], ZbNŽo, Knj. 4, Zagreb 1899, str. 288-291. Rubit, St., Narodne pjesme (Duvno u Bosni), Kolo 1-3, 2 bNŽo, Knj. 23, str. 232-246, Knj. 24, str. 308-315, Knj. 25, str. 363-371, Zagreb 1918, 1919, 1924. 
Simib, Lj., Pjesme jajackog sreza, Bilten instituta za proudavanje folklora, Sarajevo, Sv. 2, str. 103-160, Sarajevo 1953. Simit, Ij., Narodne pesme, Ijubavne, Glasnik Zemaljskog muzeja, NS, Sv. 14, Etnologija, Sarajevo 1959, 8tr. 188-193. Simit, Ij., Narodne pesme, Lirske, Glasnik Zemaljakog muzeja, NS, Sv. 15/16, Etnologija, Sarajevo 1961, str. 294-299. Simit, Ij., Pripovedne 1 lirske pesme, Glasnik Zemaljskog muzeja, NS, Sv. 17, Etnologija, Sarajevo 1962, str. 199-225 [Iiebeslieder S. 211-212].

Simil, Lj., Narodne pesme stanovniłtva jednog dela Bosanske posavine, Glasnik Zemaljskog muzeja, NS, Sv. 20/21, Etnologija, Sarajevo 1966, str. 167-208.

Srpska gradanska poezija XVIII 1 a pocetka XIX stoleta, I 1 II, Priredio Marinkovit, B., Beograd 1966.

Sajnovit, I., Djevojacke pjesme, Kola u Bosni, zbNŽo, Knj. 20, Zagreb 1915, str. 152-156.

Santit, A., Iz Hajneove lirike, Mostar 1923. Santit, A., Pjesme, Mostar 1908. Saulit, N., Srpske narodne pjesme (Iz zbirke narodnih pjesama Novice Sauli(a), Knj. 1, Sv. 2, Beograd 1926. Tordinac, N., Hrvatske narodne pjesme 1 pripoviedke 12 Bosne, Drugo popravljeno izd., Vukovar 1884.

Vasiljevitt, I.j.S., Srpake norodne pjesme (I.z Srpskog Naroda po Bosni), Tuzla 1908.

Vasiljevit, M.A., Narodne melodije iz Sandzaka, Posebna 1zdanja, SAN, Knj. 205, Muzikoloðki institut, Knj. 5, Beograd 1953.

Zovko, I., hercegovke I Bosanke, Sto najradije pjevanih Zenskih pjesama, Sarajevo 1888.

Zovko, I., Zbirka hrvatskih Zenskib pjesama po Bosni 1 Hercegovinf [Diese unveröffentlichte Samlung lot Eigentum der Matica Hrvatska in Zagreb und besteht aus ver Heften mit je 250 Liedern ( $=1000$ Ileder). Die Handschrift stammt aus dem Jahre 1893, und eine Maschinenabschrift existiert im Zemaljald muzej in Sarajevo. Vgl. dazu auch Delorko, 0., Rukopisni zbornik narodnth pjesama Ivana Zovka, Rad IX-Og kongresa savera folklorista Jugoslavije u Mostaru 1 Trebiniu 1962,Sarajevo 1963, str. 119-125]. 
B. Hilfsmittel und Untersuchungen

Ahmedov (Šehit), H., Jedan skromni kulturni radnik, sakupljac narodnog blaga Nuharem Kurtagit, Narodna uzdanica, Kalendar 1938, str. 158-161.

Aličlt, A., Narodna pjesma o Moritima, Novi behar 1941, God. XIV, Br. 5, Sarajevo 1941, str. 155. Andrit, I., Put Alije Berzeleza, Sabrana dela I. Andrita, Knj. 8, 8tr. 9-33, Beograd 1937.

Banovit, St., Tri priloga $2 a$ proulavanje hrvatske narodne 1 umjetne poezije, JAZU, Zagreb 1952.

Bausinger, H., Volkslied und Schlager, Jahrbuch des Osterreichischen Volksliedwerkes, Bḋ. 5, Wien 1956, S. 59-76.

Bejtic, A., Prilozi proucavanju nasih narodnih pjesama, Bilten instituta za proukavanje folklora, Sarajevo, Sv. 2, str. 387-405, Sv. 3, str. 105-123, Sarajevo 1953, 1955. Bibliografija folklorne grade u deset godista Behara 8 indeksom motiva, Bilten instituta za proucavanje solklora, Dopunska izdanja [Knj. 1], Sarajevo 1957.

Bose, F., Volkslied-Schlager-Folklore, Zeitschrift für Volkskunde, Jg. 63, Kohlhammer-Verlag 1967, I, S. 40-49. Braun, M., Das Volkslied als philologisches Problem, Welt der Slaven, Jg. 3, Hi esbaden 1958, S. 1-13. Braun, hi., Zum Problem der serbokroatischen Volksballade, Slawistische Studien zum $V$. Internationalen SlawistenkongreB in Sofia 1963, Opera Slavica 4, Göttingen 1963, S. 151-174.

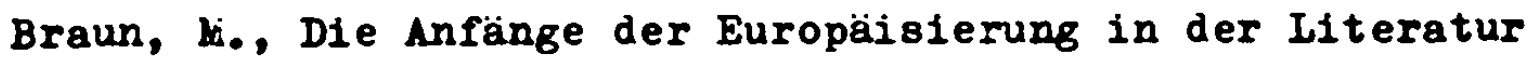
der moslimischen Slaven in Bosnien und Herzegowina, Leipzig 1934.

Cubelit, T., Problematika hrvatskog narodnog pjesnictva, Hrvatska revija, God. XVII, Br. 4, 1944, str. 211-213. Cubelit, T., Kanconijer iz Bosne 1 Hercegovine, Telegram, Zagreb, 29. ozujka 1968, str. 4. Ćemalovit, S.-A., Nacionalizam 1 Muslimani, Srpska Omladina 1913, Br. 6-7, str. 113-117. 
Ćorovit, V1., Bosna 1 Hercegovina, SK2, Beograd 1925. Corovi $6, \mathrm{Vl} .$, Srpske narodne pjesme, Bibliografski pregled zbirkd, Srpaki knjizeval glasnik, 16.11.1911, str. 750-758. Delorko, 0., Rukopisni zbornik narodnih pjesama Ivana Zovka,

Rad IX-Og kongresa saveza folklorista Jugoslavije u Mostaru i Trebinju 1962, Sarajevo 1963, str. 119-125. Dizdar, H., Na tragovima bosanske sevdalinke, Jugoslovenska posta 1938, Br. 2701, str. 7, Br. 2741, str. 10, Br. 2764, str. 9-10, 1939, Br. 3053, str. 9.

Dizdar, H., Moßtanice, vodo plemenita, usput ti je, selam ces mi dragom, Jugoslovenska pozta 1938, Br. 2717, str. 9. Dizdar, H., Kako je postala jedna lijepa sevdalinka, Jugoslovenska posta 1938, Br. 2689, str. 9-10.

Dizdar, H., 0 postanku sevdalinke, in: Tahmiłtit, H., Poezija Sarajeva, Sarajevo 1968, str. 270-271 [Dersel be Aufsatz befindet sich in der Einleitung zu Dizdar, H., Sevdalinke,

Sarajevo 1944, str. 23-24].

Dizdar, H., Izvor sevdalinka, Gajret 1938, Sv. 14, str. 247. Dizdar, y., Gdje je ona cudnovata djevojka koja se je suncem povezala a mjesecom opasala?, Zivot, Sarajevo, juni 1960, God. IX, Br. 6, str. 447-456.

Đordevit, T., Cigani i muzika u Srbiji, Bosanska vila, Sarajevo 1910, God. XXV, str. 75-81.

Đord̄evit, T.R., Belełke o nałoj narodnoj poeziji, Beograd 1939. Đukit, T., Folklor u Santitevoj poeziji, Rad IX-og kongresa 8aveza folklorista Jugoslavije u Mostaru i Trebinju 1962,

Sarajevo 1963, str. 137-140.

Gurovic, D.P., Studije o srpskoj narodnoj liric1, Skoplje 1921. Filipovic, R., Dvije komedije, Mala dramska biblioteka, Sv. 8,

Zagreb 1951 (Otkako je Banjaluka postala, str. 5-55;

Mostanice, vodo plemenita, str. 57-108).

Fischer, H., Volkslied Schlager Evergreen, Volksleben, Bd. 7,

Tübingen 1965.

Gezeman [Gesemann], G., 0 bosanskim sevdalinkama, Prosveta 1937, God. XXI, Br. 10-12, str. 682-687 (Kalendar Sarajevo), Sarajevo 1937. 
Gezeman [Gesemann], G., Prolegomena povodom gramofonskog snimanja bosanske narodne pesme, Prilozi proutavanju narodne poezije, Knj. IV, Sv. 1-2, Beograd 1937, str. 222-240. Gezeman [Gesemann], G., 0 znaðaju narodne pesme za nacionalnu kulturu jugoslovenskog naroda, Prilozi proucavanju narodne poez1je, Knj. IV, Sv. 1-2, Beograd 1937, str. 161-173. Goetz, I.K., Volkslied und Volksleben der Kroaten und Serben, Bd. 1, Die Liebe, Bd. 2, Die Liebenden, Personen und Schauplatz des Iiedes, Slavica, Bd. 12, Heidelberg 1936-1937. Goetz, I.K., Koseworte, Scherz- und Schtmpfworte fur die Liebenden im Volkslied der Kroaten und Serben, Zeitschrift rur Volkskunde, NP, Bd. 3 (41), Berlin 1932, S. 213-241. Grgec, P., Podrietlo hrvatskoga narodnog pjesničtva, Hrvatskd

Narod, Br. 217, 1944, Btr. 5.

Grgec, P., Hrvatske narodne pjesme, Zagreb 1943..

Hadžijahit, M., Najstariji glasovi o muslimanskoj narodnoj

pjesmi u Herceg-Bosnt, Narodna uzdanica, Kalendar, Sarajevo 1934, otr. 118-121.

Hadžijahit, M., Narodni pjevact na dvorovima bosansko-hercegovacke aristokracije, Narodna uzdanica, Kalendar, Sarajevo 1935, str. 73-77.

Hadzijabit, M., Gradja za povijest narodne poezije Muslimana

12 Bosne u XVI, XVII 1 XVIII stoljecu, Sarajevo 1935. Hadzijahit, M., Pjesme Umihane Cudovine 1 narodna poezija, Narodna uzdanica, Kalendar, Sarajevo 1936, str. 88-94. Hakman, St., Propadanje feudalizma u Bosnt 1 Hercegorint 1 narodna pesma, Gajret 1937, Br. 4, Sarajevo 1937, str. 65-66.

Handżl, M., Književnt rad bosansko-hercegovačkih Muslimana, Separat iz glasnika vrhovnog starjesinstva 1slamske vjerske zajednice, Sarajevo 1933.

Hangi, A., Zivot 1 obi $X_{a j 1}$ muslimana u Bosni 1 Hercegovini, Sarajevo 1906 [deutsch: Die Moslims in Bosnien-Hercegorina, Sarajevo 1907].

He1tsch, E., Aphroditehymnos, Aeneas und Homer, Sprachliche Untersuchungen zum Homerproblem, Göttingen 1965. 
Humo, H., Muslimant Bosne i Hercegovine posmatrani kroz sevdalinku, Gajret-Kalendar za 1937 g., Sarajevo, Gl. odbor druß., Gajret 1936, Btr. 177-180.

Humo, H., Mi, Bosna 1 naß izraz u ređi, Gajret-Kalendar za

1940 g., Sarajevo 1939, str. 222-224.

Jastrebov, I.S., Obyčai 1 pěsni tureckich Serbov, S.-Peterburg 1886.

Jelit, St., Vrednost 1 značaj naše narodne poezije, Naša narodna književnost (uredio: Kneževit, M.V.), Subotica 1928.

Jensen, J., Untersuchungen zur Metrik und Rhythmik des serbokroatischen Volksliedes [Phil.Diss., Göttingen 1953, maschinenschriftlich].

Jurlit, V., Huslimanska narodna lirika, Narodna uzdanica, Kalendar, Sarajevo 1944, str. 121-130.

Karadzit, V.St., 0 srpskoj narodnoj poeziji, Beograd 1964. Karadžlt, v.St., Srpsid rjęnik, istumąen njemačkj jem 1

latinskijem rijecima, 4. izd., Beograd 1935.

Katoli $k i$ tjednik, Sarajevo, Nedjelja, 12. siję̌nja 1936,

God. XII (XV), Br. 2, str. 4 [Der Artikel ist mit Dr. Ins. unterzeichnet].

Kayser, H., Das sprachliche Kunstwerk, 10. Aufl., Bern-Hünchen 1964.

Remura, Šejh Sejfudin, Sarajevske džamije $i$ druge javne zgrade turske dobe, XXII., Vekilharčeva ("hadžijska") džamija pod Alifakovcem, GZM 1910, Sarajevo 1910, str. 100-109. Kemura, Scheich Seiffudin Ef. und Ćorovit, Vl., Serbokroatische Dichtungen bosnischer Moslims aus dem XVII., XVIII. und XIX. Jahrhundert, Sarajevo 1912.

Kneževit, N.V., Nă̌a narodna poezija, Književni sever, God. IV, Knj. IV, Sv. 7,8 i 9, Subotica 1928.

Kreševljakovi6, H., Noriti, Novi behar 1938/39, God. XII, Br. 1-4, Sarajevo 1938/39, str. 5-14.

Kreševljakovit, H., Hanovi 1 karavansaraji u Bosni 1 Hercegovini, Naulno društvo NR Bosne i Hercegovine, Djela, Knj. VIII, Odeljenje istorisko-filoloških nauka, Knj. 7, Sarajevo 1957. 
Krnjevit, H., Brata Moriti - Istorija i poezija, in: Tahmiǧčlt,

H., Poezija Sarajeva, Sarajevo 1968, str. 249-263.

Krłi , J., Bosanska sevdalinka, Žena danas 1939, Br. 24,

str. 4-5.

Kršiধ, J., Sarajevo u sevdalinci, in: Tahmiščit, H., Poezija

Sarajeva, Sarajevo 1968, 8tr. 264-269.

K., T., Najplodniji period skupljanja narodnih umotvorina u

Bosni, Pregled, Nov.- Dec. 1947, str. 834-837.

Kuba, I., O bosansko-hercegovačkim pesmama, Sarajevo,

Almanah, Pregled, uredili: Dr. J. Kŗ̌il i J. Kušan, Sarajevo 1928, str. 22-23.

Kuhač, Pr.X., Das türkische Element in der Volksmusik der

Croaten, Serben und Bulgaren, Wien 1899.

Kulenovit, N., Postanak nałe najlepłe sevdalinke, Vreme, Beo-

grad 1,2,3,4 maj 1937, God. 17, Br. 5494, str. 21.

Kurtovit, S., Sevdalinka - naša narodna pjesma (Povodom radio-

eseja Ž. Zdravkovi(a), Glasnik vrhovnog islamskog starješin-

stva u FNRJ, God. IX, Sv. 3-5, Sarajevo 1958, str. 184-187.

Kušan, J., Dva Morila, Sarajevo, Almanah, Fregled, uredili:

Dr. J. Krك̌ic i J. Kušan, Sarajevo 1928, str. 25.

Kušan, J., Dva Morita, dva Pał̌ita, Drama u jednom činu, Sara-

jevo, Gajret 1933, God. XIV, Sarajevo 1933, str. 196-198 1

299-302.

Lauer, R., Heine in Serbien, Die Bedeutung Heinrich Heines für

die Entwicklung der serbischen Literatur 1847-1918 Phil.

Dis8., Prankfurt am Main, Meisenheim an Glan 1961.

Lausberg, H., Handbuch der literarischen Rhetorik, Bd. 1,2,

München 1960.

Lausberg, H., Elemente der Iiterarischen Rhetorik, 2. erw.

Aufl., München 1963.

Maretit, T., Nał̌a narodna epika, Beograd 1966.

Mari6, B., Pentatonika u bosansko-hercegovałkoj pučkoj muzici,

Zagreb 1938 (Prełtampano iz "Svete Cecilije", God. 1938). uledenica, R., Fonografsko snimanje naših pesama u Sarajevu,

Prilozi proučavanju narodne poezije, Knj. IV, Sv. 1-2,

Beograd 1937, str. 272-275. 
Meier, J., Balladen, I., Leipzig 1935.

Milakovit, J., Bibliografija hrvatske 1 srpske narodne pjesme, Grā̄a, I., Sarajevo 1908.

Milakovit, J., Majka u nǎ̧oj narodnoj pjesmi, Sarajevo 1896. Milakovil, J., Sužanj, pabirci po narodnoj poeziji, Sarajevo 1915.

Miloð̌vit, M.N., Naß̌a narodna poezija, Beograd 1930. Milołevit, vl., Sevdalinka, Banja Luka 1964. Mirkovit, P., Ał̌iklijske doskoðice sa gjul-pendžera, Sarajevo 1913.

Morpurgo, V., I fratelli Ibro e Paß̌ Morit nell'intuizione popolare della ballata bosniaca, Bari 1962.

Morpurgo, V., Il dramma umano nei canti popolari musulmani

femminili della Bosnia e dell'Erzegovina, Bari 1959.

Muradbegovit, A., Sevdalinka, pesma feudalne gospode, Politi$\mathrm{ka}, 5.12 .1940, \mathrm{Br} .11677$, Beograd 1940, str. 14.

Nametak, A., Jedna stara mostarska narodna pjesma, Narodno stvaralałtvo 1962, Sv. 2, Beograd 1962, str. 91-92.

Nedeljkovit, D., Problemi etnološke metode 1 naše dană̌nje usmeno narodno stvaralätvo na temu "Smrt Omera 1 Merime", Zbornik za narodni život 1 obiłaje, Knj. 40, JAZU, Zagreb 1962, str. 385-400.

Nedit, Vl., Jugoslovenska narodna lirika, Narodna knj1ževnost, Priredio: Nedit, V1., Beograd 1966, str. 42-54.

Orahovac, S., Narodna sevdalinka i njeni tipov1, Islamski glas 1935, Br. 13, str. 13.

Orahovac, S., Nała sevdalinka i njeni tipovi, Slobodna rijec 1932, Br. 38, str. 9.

Ostojit, I.K., Sevdalinka, Jadranska Fla 1931, Br. 10, str. 145-146.

Pelletier, R., La chanson d'amour a Sarajevo, Besançon 1938. Petranovil, B., Običaji srpakog naroda u Bosnt, Glasnik srpokog uXenog drütva, Kaj. XI, Sv. XXVIII staroga reda, Beograd 1870, str. 176-227, Knj. XII, Sv. XXIX staroga reda, Beograd 1871, str. 237-255, Knj. XXX, Beograd 1871, str. 313361 . 
Peukert, H., Serbokroatische und makedonische Volkslyrik, Gestaltuntersuchungen, Veröffentlichungen des Institutes für Slawistik, Nr. 24, Berlin 1961.

Peukert, H., Die Punktion der Pormel im Volkslied, Poetyka,

Warszawa 1961, S. 525-536.

Pollok, K.-H., Studien zur Poetik und Komposition des balkanslawischen lyrischen Volksliedes, Opera Slavica V, Göttingen 1964.

Pollok, X.-H., Bemerkungen zur Typologie des Epithetons,

Beiträge zur Sudosteuropa-Forschung, AnläBlich des 1. Internationalen Balkanologenkongresses in Sofia, Sonderdruck, München 1966, S. 279-284.

Pollok, K.-H., Zum Gebrauch der Metapher in den balkanslawischen lyrischen Volksliedern, Slawistische Studien zum V. Internationalen Slawistenkongre $B$ in Sofia 1963, Opera Slavica 4, Göttingen 1963, S. 175-206.

Prodanovit, J.M., Kletva u našoj narodnoj poeziji, in: Naša narodna poezija, uredio: Kneževit, M.V., Subotica 1928. Prodanovit, J.M., Nała narodna književmost, Savremenik Srpske knjǐ̌erne zadruge, Kolo 2, knj. 8, Beograd 1932. Radulovit, J., Poslednji Vukovci u Hercegovini, Novi talas romantizma u Hercegovini, Prosveta, God. XXI, Br. 10-11-12, Sarajevo, oktobar, novembar, decembar 1937, str. 701-711. Sarajlit, Š., Sevdalinke, Narodna uzdanica, Kalendar, Sarajevo 1943, str. 123-127.

Schmaus, A., Gattung und Stil in der Volksdichtung, Rad kongresa folklorista Jugoslavije u Varaždinu 1957, Zagreb 1959, Btr. 169-173.

Schneeweis, E., Grundrise des Volksglaubens und Volksbrauchs der Serbokroaten, Celje 1935.

Seemann, E. und Wiora, W., Volkslied, in: Deutsche Philologie im AufriB, hg. v. Stammler, W., Bd. 2, 1954, S. 1-24, Spalte 25.

Serdalije bosanske, Slika iz knjižemosti od S.A.J., Bosanska vila 1889, str. 7-8 1 20-22. 
Simlt, Ij., Prilog klasifikaciji narodne poezije, Glasnik Zemalj8kog muzeja, NS, Sv. 18, Etnologija, Sarajevo 1963, str. 145-152.

Singer, S., Beiträge zur Iiteratur der kroatischen Volkspoesie, Agram 1882.

Skarit, Vl., Bosanski muslimani 1 narodna poezija, Jugoslorenska njiva, God. V, Br. 45, Zagreb 1921, str. 711-713. Skerlit-Ćorovit, J., Jedna persiska pesma $i$ jedna bosanska sevdalinka, Prilozi za knjižemost, jezik, letoriju 1

folklor, Knj. XVIII, Sv. 1-2, Beograd 1938, str. 580-583. Sokolovit, 0.A., Dvije-tri sevdalinke pisane arabicom, Gajret 1937, Br. 4, 8tr. 64.

Sokolovit, 0.A., Pregled štampanih djela Muslimana Bosne $i$ Hercegovine na srpsko-hrvatskom jeziku od 1878-1948, III, Glasnik vrhovnog islamskog starješinstva, Sarajevo 1959, str. 3-14.

Sokolovit, 0. 1 Hadžijahit, M., Prvi pokułaj štampanja radova bosanskih Muslimana, Sarajevo 1963.

Stanit, R.D., Za istinski izvornu narodnu pjesmu, Svijet, Sarajevo, 30. jun 1961, God. IV, Br. 161, str. 3 . Suppan, W., Volkslied, Stuttgart 1966. Škaljit, A., Turcizmi u narodnom govoru 1 narodnoj književnosti Boene 1 Hercegovine, Knj. 1.2., Bilten instituta 29 proučavanje folklora u Sarajevu, Dopunska izdanja, Knj. 2, Sarajevo 1957. Prikazl rečnika: 1. Prilozi za književnost, jezik, 1storiju i folklor, Knj. XXVI, Sv. 3-4, Beograd 1960, str. 334-344 i Knj. XXVII, Sv. 1-2, str. 65-79, Beograd 1961 [Beide Artikel sind von Bajraktarevit, P.] Skaljit, A., Turcizmi u srpskohrvatskom jeziku, Sarajevo 1965. Skaljit, A., Telal, Bilten instituta za proulavanje folklora

u Sarajevu, Sv. I, Sarajevo 1951, str. 99-103. Stur, Ij., O narodnim pesmama 1 pripovedkama slavenskim ( Cežkoga preveo Božkovit, Io.), Novi Sad 1857. Tahmiščl, H., Poezija Sarajeva, Antologija, Sarajevo 1968. Umitevit, D., Sevdalinke u Bosanskoj krajini, Razvitak 1938, God. 4, Br. 12, str. 361-365. 
Umitevit, D., Seoska sevdalinka Bosanske krajine, Razvitak 1938, God. 5, Br. 3, str. 75-79.

Umikevic, D., Muzilka obrada narodne pjesme u Bosanskoj krajini,

Razvitak 1938, God. V, Br. 11, Banja Luka 1938, str. 325-333. Umicevit, D., Na tragovima prołlosti, Kulturne oznake u naక̌oj

sevdalinki, Jugoslovenska połta 1940, Br. 3324, str. 10. Varatanovit, I., Pogibija brake Morita 1 strahovit pokolj

Sarajlija 1756 godine, Jugoslovenska połta, Sarajevo, 31.12.1932, God. IV, Br. 1087, str. 11.

Wellek, R. und Warren, Au., Theorie der literatur, Berlin 1963. Wilpert, G. v., Sachwörterbuch der Literatur, 4. Aufl., Stuttgart 1964.

Z1ma, I., Figure u našem narodnom pjesničtvu s njihovom teorijom, Zagreb 1880.

Zovko, I., Ał̌ikovahe u Herceg-Bosni, Z bNŽo, Knj. 12, Zagreb 1907, str. 156-159. 


\section{Abkurzungsverzeichnis der benutzten Texte}

\section{Allgemein}

\begin{tabular}{|c|c|}
\hline ar. & arabisch \\
\hline BiH & Bosna i Hercegovina \\
\hline br. & broj, brojevi \\
\hline a. & editio, editor \\
\hline PAZY & Polklornl arhiv Zemaljokog muzeja \\
\hline NRJ & Pederativna Narodna Republika Jugoslavija \\
\hline 8 & godina \\
\hline 1. & glasnik \\
\hline god. & godina, godirte \\
\hline inv. br. & inventarni broj \\
\hline$t . d$. & I tako dalje \\
\hline בס & Jugoelovenska Akademija za Umjetnost \\
\hline aj. & knjiga, knjige \\
\hline & Matica Hrvatika \\
\hline & neue Polge \\
\hline $\mathbf{N}$ & Narodna Republika \\
\hline $\mathbf{H}$ & nova serija \\
\hline pers. & persisch \\
\hline AN & Srpska Akademija Nauka \\
\hline KA & Srpska Kraljevska Akademija \\
\hline 22 & Srpska knj1ževna zadruga \\
\hline $\mathbf{r}$. & strana, strane \\
\hline & eveska \\
\hline rk. & türki $8 \mathrm{ch}$ \\
\hline oŇ̌o & Zbornik za narodni život 1 običaje \\
\hline
\end{tabular}




\section{B. Texte}

Andr16 II = Andrit, N., Izabrane narodne pjesme, II, Ženske, Zagreb 1913.

Bajraktarevit = Bajraktarevit, F., Pregrét narodnih pegama iz Bosanskog Skoplja, SAN, Fosebna 1zdanja, Rnj. CCCXXXV,

Etnografski Institut, Knj. 11, Beograd 1960.

Bart6k/Lord = Bart6k, B. and Lord, A.B., Serbo-Croatian Polk

Song8, Columbia University Pres8, New York 1951.

Behar = Behar, Ilot za pouku 1 zabavu, Sarajevo 1900/01 -

$1910 / 11$.

Bejt1C = Bejt1C, A., Prilozi proutavanju nałih narodnih

pjesama, Bilten instituta za proukavanje folklora, Saraje-

vo, Sv. 2, str. 387-405, Sv. 3, str. 105-123, Sarajevo

1953, 1955.

Bilten $(I, I I)=$ Bilten instituta $2 a$ proutavanje folklora $u$

Sarajevu, Sv. 1, 2, Sarajevo 1951, 1953.

Biser = Biser, Ilst za birenje prosvjete megju muslimanima $u$

Bosnd 1 Hercegovint, Mostar 1912, 1913, 1914, 1918.

Blagaj1C = Blagaj1C, $K$., Hrvatske narodne pjesme 1 pripoviedke

12 Bosne, Zagreb 1886.

B08. vila = Bosanska V1la, Ilst za zabavu $($,$) pouku 1$ knjlževnost, Sarajevo 1885/86-1914.

Bruerovit $=$ Narodne pesme u zapisima XV-XVIII veka (Antologija),

Izbor 1 predgovor Pant16, M., Beograd 1964.

Bugarinovit = Bugarinovi6, M., Sarajke, Srpske narodne ženske

pjesme, Mostar 1904.

Cubel1t = Cubel1t, T., Izbor 12 narodne knj1Ženost1, Knj.

1-3, Zagreb 1952 [Iyrische Lieder, u.a. auch Sevdalinke in

Bd. 1].

Corovit (Bosna 1 Hercegovina) = Corovit, VI., Bosna 1 Hercegovina, SRZ, Beograd 1925.

Daridovit = Davidovit, S.N., Srpske narodne pjesme iz Bosne (Zenske), Panðevo 1884.

Dizdar $I=$ Dizdar, H., Sevdalinke, Izbor 12 bosansko-hercegovacke narodne 11rike, Sarajevo 1944. 
Dizdar II = Dizdar, H., Ljubavne narodne pjesme iz Bosne 1 Hercegovine, Sarajevo 1953.

Drorovit = Dvorovit, Nj., Hrvatsko narodno blago, Zbirka hrvatskih narodnih pjesama $i$ pripoviedaka iz Bosne $i$ Hercegovine, Sv. 1, Senj 1888 .

Dikit = Đikit, 0.A., Ał̌klije, Mostar 1903. Burit = Burit, V., Narodne lirske pesme, Novo pokolenje,

Beograd 1953.

Erlangenski rukopis = Gesemann, G., Erlangenski rukopis starih srpskohrvatskih narodnih pesama, Zbornik za istoriju, jezik

1 književnost srpskog naroda, Prvo odeljenje, Knj. XII, Sr. Karlovei 1925.

Gajret = Gajret, Glasilo "Gajreta", društva za potpomaganje muslimana na srednjim $i$ viłim žkolama (1910-1921 und 19251930 und 1931-1941 mit anderen Untertiteln), Sarajevo 1907-1913, 1921, 1922, 1925-1941.

Grad̄anska lirika = Srpska građ̄anska poezija XVIII i s počtka XIX stoleta, I I II, Priredio Marinkovit, B., Beograd 1966. Grāit-Bjelokosit $=$ Grāit-Bjelokosit, L., Smilje $i$ bosilje

(Iz naroda u narod, Knj. III), Novi Sad 1898. Grgec = Grgec, P., Hrvatske narodne pjesme, Zagreb 1943. Hadžijahit, Narodna uzdanica, Kalendar 1936 = Hadžijahit, M.,

Pjesme Umihane Cudovine i narodna poezija, Narodna uzdanica, Kalendar, Sarajevo 1936, str. 88-94.

Hak $I$ = Hak, A., Muslimanske sevdalinke iz Bosne $i$ Hercegovine, Sarajevo 1906.

Hak II = Hak, A., Ał̌iklije muslimanske sevdahlinke, Momačke

$i$ djevojacke pjesme iz Bosne $i$ Hercegovine, Drugo znatno povetano izdanje, Sarajevo 1914.

Hangi = Hangi, A., Zivot $i$ obiCaji muslimana u Bosni 1 Hercegovini, Sarajevo 1906.

Humo, Ret i slika = Humo, H., Sevdalinke, Ret i slika 1927, I, S. 33-38.

Islamski glas = Islamski glas 1935, Br. 13, str. 13. Jastrebov = Jastrebov, I.S., Obyð̌ai 1 pěsni tureckich Serbov, S.-Peterburg 1886. 
Jugoslovenska połta $=$ Jugoslovenska poð̌ta 1938, Br. 2701, str. 7, Br. 2717, str. 9, Br. 2764, str. 9-10, Br. 2689, str. 9-10, 1939, Br. 3053, str. 9.

Jugoton = Texte nach den Schallplatten Jugoton po brojevima EPY.

Jurtit, Nar. uz., Kal. 1944 = Jurtit, v., Muslimanska narodna lirika, Narodna uzdanica, Kalendar, Sarajevo 1944, str. 121-130.

KaSikovit (I, II, III) = Kałikovit, N.T., Narodno blago,

Knj. 1-3, Sarajevo 1927, 1928.

Kuba $(1906,1907,1908,1909,1910)=$ Kuba, L., Pjesme 1 napjevi iz Bosne i Hercegovine, Glasnik Zemaljskog muzeja u Bosni i Hercegovini, Knj. 18, 19, 20, 21, 22, Sarajevo 1906-1910.

KuhaX (I, II, III) = Kuhą, F.Š., Južno-slovjenske narodne popievke, Knj. 1-5, Zagreb 1878-1941. Kurt = Kurt, M.-Dž., Hrvatske narodne Zenske pjesme 〈Huslimanske), Sv. 1, Mostar 1902.

Magarał̌evit = Magarałevit, Br., Narodne lirske pjesme, Zagreb 1951.

Mamuzit = Mamuzit, I., Narodne lirske pesme, Beograd 1953. ilarjanovit = Marjanovit, L., Hrvatske narodne pjesme కto se pjevaju u gornjoj Hrvatskoj, krajini i u turskoj Hrvatskoj, Sv. 1, Zagreb 1894 [Ženske pjesme: str. 175-207]. Marunovit = Marunovit I.J., Narodne pjesme [Po Herceg-Bosni] Zadar 1906.

MH $(V, V I, V I I, X)=$ Hrvatske narodne pjesme [ed.], Matica Hrvatska, Knj. 1-10, Zagreb 1896-1942 [Lyrische Lieder Bd. 5-7 und 10].

Milanovit $I$ = Milanovit, L., Sevdalinke, ljubavne ałiklije, skupio M. M.- $\ell$, Izdanje i naklada knjižare $i$ papirnice Mihaila Milanovita u Sarajevu, Sarajevo o.J. Milanovit II = Milanovit, M., Muslimanske sevdalinke, Narodne pjesme iz Bosne 1 Hercegovine, Izdanje knjižarnice $i$ papirnice Mihaila Milanovica, Sarajevo o.J. 
Milanovit III = Milanovit, M., Srpske narodne Ženske pjesme iz Sarajeva, Sarajevo 1893.

Milołevit (I, II, III, IV) = Milołevit VI., Bosanske narodne pjesme, Knj. 1.2.3.4., Narodni muzej, Odeljenje za muzicki folklor und Narodni muzej, Odsjek za narodne pjesme i igre und Muzej bosanske krajine, Odsjek za narodne pjesme i igre,

Knj. 1.2.3.4., Banja Luka 1954-1964. Hirkovit = Mirkovit, P., Srpske narodne pjesme iz Bosne, Pancevo 1886. Mlac = Mlac, Kr., Ijubavne narodne pesme, Zagreb 1953. Mokranjac = Nokranjac, St.St., Zapisi narodnih melodija, Nuzi-

kolołk1 institut, Posebna izdanja, knj. 13, Beograd 1966. Niorpurgo (I fratelli) = Morpurgo, V., I fratelli Ibro e Pało Moric nell'intuizione popolare della ballata bosniaca, Bari 1962.

Nametak = Nametak, A., Nuslimanske Zenske pjesme, Hrvatsko narodno blago, Zagreb/Sarajevo 1944. Narodna uzdantca = Narodna uzdanica, Kalendari za godine 1933-1945, Sarajevo 1933-1945.

Novi behar = Novi behar, List za pouku i zabavu, Sarajevo $1927 / 28-1945$.

Odobałit = Odobałit, S., Velika nova narodna pjesmarica,

Zagreb o.J.

Orahovac = Orakovac, S., Sevdalinke, balade 1 romanse Bosne

i Hercegovine, Sarajevo 1968.

Orahovac, Islamski glas = Orahovac, S., Narodna sevdalinka 1

njent tipovi, Islamski glas 1935, Br. 13, str. 13. Ostojit-Ćorovit = Ostojit, T. $i$ Ćorovit, vl., Srpska grad̄anska lirika 18.-og veka, SKA, Beograd-Sremski Karlovci 1926. Pantic = Narodne pesme u zapisima XV-XVIII veka 〈Antologija),

Izbor i prejgovor Pantic, M., Beograd 1964.

Petranovit = Petranovit, B., Srpske narodne pjesme, Knj. 1-3,

Sarajevo-Beograd 1867-1870, Knj. 1, Srpske narodne pjesme iz Bosne (Zenske), Sarajevo 1867. Popovit-Rodoljub = Popovit-Rodoljub, M.S., Srpske narodne umotvorine, I, Srpske sevdalinke, Pančevo 1892. Irojarovit = Prodanovit, J.H., そenske narodne pesme, Beograd 1925. 
Fistic = Ristit, K.H., Srpsike narodne pjesme, pokupljene po

Bosni, Biograd 1873.

Rubit 4 = Rubit, St., Nuic, A., Duvno 〈Županac), [Lirske pjesme],

Z bNŽo, Knj. 4, Zagreb 1899, str. 288-291.

Rubit (XXIII, XXIV, XXV) = Rubit, St., Narodne pjesme 〈Duvno u

Bosni〉, Kolo 1-3, ZbNžo, Knj. 23, str. 232-246, Knj. 24,

str. 308-315, Knj. 25, str. 363-371, Zagreb 1918, 1919, 1924. slobodna rijex = Orahovac, S., Nała sevdalinka $i$ njeni tipovi,

Slobodna rijec $1932, \mathrm{Br} .38$, str. 9.

Sajnovit = Sajnovit, I., Djevojačke pjesme, Kola u Bosni,

ZbŇ̌o, Knj. 20, Zagreb 1915, str. 152-156.

Saulit = Saulić, N., Srpske narodne pjesme ( $I_{2}$ zbirke narodnih

pjesama Novice Saulića), Knj. 1, Sv. 2, Beograd 1926.

Tordinac $=$ Tordinac, $N_{.}$, Hrvatske narodne pjesme 1 pripoviedke

iz Bosne, Drugo popravljeno izdanje, Vukovar 1884.

Vasiljevit = Vasiljevit, M.A., Narodne melodije iz Sandzaka,

Posebna izdanja, SAN, Knj. 205, Muzikoloకki institut, Knj.5,

Beograd 1953.

Vuk I (1953) = Karadzit, V.St., Srpske narodne pjesme, Knj. 1-4,

Beograd 1953-1954, Bd. 1, Beograd 1953.

Vuk V (1898) = Karadzit, V.St., Srpske narodne pjesme, Knj. 1-9,

Biograd 1891-1902, Bd. V, Biograd 1898.

Vuk II = Karadžt, V.St., Srpske narodne pjesme $1 z$ Hercegovine (Ženske), Beč 1866 [Die Lieder sind von Vrと̌evit, v., gesammelt].

Zovko $I=$ Zovko, I., Hercegovke 1 Bosanke, Sto najradije

pjevanih Zenskih pjesama, Sarajevo 1888.

\section{Unveröffentlichte Liedsammlungen}

R.a. = Polklorni [Rukopisni] arhiv Zemaljskog muzeja u Sarajeva (FAZN), Narodne pjesme po inventarnim brojevima.

Zovko II = Zovko, I., Zbirka hrvatskih Zenskih pjesama po

Eosni $i$ Eercegovini [Diese Sammlung ron 1000 Liedern $18 t$

Eigentum der Matica Hrvatska in Zagreb]. 